\title{
Geochemistry of Water in Relation to Cardiovascular Disease
}

PANEL ON THE GEOCHEMISTRY OF WATER IN RELATION TO CARDIOVASCULAR DISEASE

Subcommittee on the Geochemical Environment in Relation to Health and Disease U.S. National Committee for Geochemistry

Assembly of Mathematical and Physical Sciences

National Research Council

This report was prepored as an account of work This report was prepared as an account of werk United States nor the United States Department of Enesgy, nor any of their employees, nor any of their

contractors, subcontractors, of their employees, makes

any warsanty, express or implied, or assumes any legal.

liability or responsibility for the accuracy, completeness

or usefulness of any information, apparatus, product or

process disclosed, or represents that its use woutd not

infringe privately owned rights.

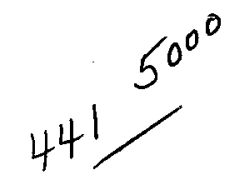

$\sqrt{\text { NATIONAL ACADEMY OF SCIENCES }}$

Washington, D.C. 1979 


\section{DISCLAIMER}

This report was prepared as an account of work sponsored by an agency of the United States Government. Neither the United States Government nor any agency Thereof, nor any of their employees, makes any warranty, express or implied, or assumes any legal liability or responsibility for the accuracy, completeness, or usefulness of any information, apparatus, product, or process disclosed, or represents that its use would not infringe privately owned rights. Reference herein to any specific commercial product, process, or service by trade name, trademark, manufacturer, or otherwise does not necessarily constitute or imply its endorsement, recommendation, or favoring by the United States Government or any agency thereof. The views and opinions of authors expressed herein do not necessarily state or reflect those of the United States Government or any agency thereof. 


\section{DISCLAIMER}

Portions of this document may be illegible in electronic image products. Images are produced from the best available original document. 
NOTICE: The project that is the subject of this report was approved by the Governing Board of the National Research Council, whose members are drawn from the Councils of the National Academy of Sciences, the National Academy of Engineering, and the Institute of Medicine. The members of the Committee responsible for the report were chosen for their special competences and with regard for appropriate balance.

This report has been reviewed by a group other than the authors according to procedures approved by a Report Review Committee consisting of members of the National Academy. of Sciences, the National Academy of Engineering, and the Institute of Medicine.

\section{Library of Congress Cataloging in Publication Data}

U.S. National Committee for Geochemistry. Panel on the Geochemsitry of Water in Relation to Cardiovascular Disease.

Geochemistry of water in relation to cardiovascular disease.

Includes bibliographies and index.

1. Cardiovascular system-Diseases-Etiology:

2. Water-Physiological effect. 3. Water-Composition.

4. Geochemistry. I. Title. [DNLM: 1. Cardiovascular diseases-Etiology. 2. Water-Analysis. WG100.3

P191g]

$\begin{array}{llll}\text { RC699.US26 } & 1979 & 616.1^{\circ} 07^{\circ} 1 & 79-19176\end{array}$

ISBN 0-309-02884-1

Available from

Office of Publications

National Academy of Sciences

2101 Constitution Avenue, N.W., Washington, D.C. 20418

Printed in the United States of America 


\section{PANEL ON THE GEOCHEMISTRY OF WATER IN RELȦTION TO CARDIOVASCULAR DISEASE (POWC)}

ERNEST E. ANGINO, Chairman; University of Kansas, Lawrence

HAROLD H. SANDSTEAD, Vice Chairman; Agricultural Research Service, USDA, Grand Forks, North Dakota

GEORGE W. COMSTOCK, Johns Hopkins School of Hygiene, Hagerstown, Maryland ROBERT G. CORBETT, University of Akron, Akron, Ohio

JACK P. STRONG, Louisiana State University Medical Center, New Orleans

A. WOUTER VOORS, Louisiana State University Medical Center, New Orleans

\section{Liaison Representatives}

GARDNER C. McMILLAN, National Heart, Lung, and Blood Institute, Bethesda, Maryland

A. RICHEY SHARRETT, National Heart, Lung, and Blood Institute, Bethesda, Maryland

Staff Members

WILLIAM L. PETRIE, Executive Secretary

FRED BLOCK, Staff Officer

JUNE R. GALKE, Secretary 


\section{SUBCOMMITTEE ON THE GEOCHEMICAL ENVIRONMENT IN RELATION TO HEALTH AND DISEASE (GERHD)}

IVAN C. SMITH, Co-Chairman; Midwest Research Institute, Kansas City, Missouri LEONARD T. KURLAND, Co-Chairman; Mayo Clinic, Rochester, Minnesota HAROLD J. GLUSKoter, EXXON Production Research Co., Houston, Texas ROLF HARTUNG, University of Michigan, Ann Arbor

DONALD J. HORVATH, West Virginia University, Morgantown LUCILLE S. HURLEY, University of California, Davis EVERetT A. JENNE, U.S. Geological Survey, Menlo Park, California

ALBERT L. PAGE, University of California, Riverside HAROLD G. PETERING, University of Cincinnati, Cincinnati, Ohio GEORGE B. SCHREIBER, Department of National Health and Welfare, Ottawa, Ontario, Canada 


\section{U.S. NATIONAL COMMITTEE FOR GEOCHEMISTRY}

rosemary J. VIDALE, Chairman; Los Alamos Scientific Laboratory, Los Alamos, New Mexico

BRUNO J. GILETTI, Vice Chairman; Brown University, Providence, Rhode Island

EARL W. BAKER, Florida Atlantic University, Boca Raton

ROBERT A. BERNER, Yale University, New Haven, Connecticut

JohN R. CASTAÑo, Shell Development Co., Houston, Texas

LaWrence M. Cathles III, Pennsylvania State University, University Park

HAROLD J. GLUSKOTER, EXXON Production Research Co., Houston, Texas

JAMES J. PAPIKE, State University of New York, Stony Brook

ARThUR W. ROSE, Pennsylvania State University, University Park

E-AN ZEN, U.S. Geological Survey, Reston, Virginia

\section{Ex Officio Member}

George W. WeTherill; President, International Association of Geochemistry and Cosmochemistry; Carnegie Institution of Washington, Washington, D.C. 


\section{Preface}

This report is the first in a series of panel reports prepared under the guidance of the Subcommittee on the Geochemical Environment in Relation to Health and Disease (GERHD) of the U.S. National Committee for Geochemistry.

The Panel on the Geochemistry of Water in Relation to Cardiovascular Disease (POWC), which prepared this report, was formed along with several others as an example of the Subcommittee's new format to replace the large workshops, held at Asilomar, Capon Springs, and Captiva Island. Each of those involved some 50 people in the production of the three-volume Geochemistry and the Environment series:

- Geochemistry and the Environment, Volume I, The Relation of Selected Trace Elements to Health and Disease

- Geochemistry and the Environment, Volume II, The Relation of Other Selected Trace Elements to Health and Disease

- Geochemistry and the Environment, Volume III, Distribution of Trace Elements Related to the Occurrence of Certain Cancers, Cardiovascular Diseases, and Urolithiasis

The use of smaller ad hoc panels to consider specific questions is regarded as a more expeditious way of producing on a timely basis the kind of product that has become a GERHD hallmark—one that consistently attempts to balance both the environmental and the biomedical considerations in everything it prepares. To help maintain this parity, the membership of the panels as well as the Subcommittee itself is appointed with due regard to this consideration-in fact, the Subcommittee has two co-chairmen; currently one is an analytical chemist and the other is an epidemiologist. POWC is chaired by a geochemist, but the vice chairman is a nutritionist-physician; the rest of the membership reflects both scientific persuasions.

Other panel studies currently under way in the new GERHD series are as follows:

- Panel on the Trace Element Geochemistry of Coal Resource Development Related to Health (PECH)

- Panel on Aging and the Geochemical Environment (PAGE)

- Panel on the Geochemical Environment and Urolithiasis (POGU)

$v i i$ 


\section{Acknowledgments}

The report of the Panel on the Geochemistry of Water in Relation to Cardiovascular Disease has been made possible by the welcome support of the U.S. Bureau of Mines and the U.S. Geological Survey under contract S0144074, the National Cancer Institute under contract N01-CP-45616, the U.S. Atomic Energy Commission and the Energy Research and Development Administration (now Department of Energy) through transfer of funds under National Science Foundation contract NSF-C310 task order 206 and ERDA/DOE contract EY76C02 2708 015, and Environmental Protection Agency contract 68032554 , which greatly assisted with the completion of this publication and with the ongoing work of the Subcommittee on the Geochemical Environment in Relation to Health and Disease. The financial support provided by these agencies is gratefully acknowledged.

The Subcommittee and the Panel acknowledge with special appreciation the efforts of the Subcommittee on Epidemiology of the Safe Drinking Water Committee, Assembly of Life Sciences, and the other prepublication reviewers as well as Howard C. Hopps of the University of Missouri at Columbia, C. E. Roberson of the U.S. Geological Survey, and John Marier of the National Research Council of Canada.

George Comstock gratefully acknowledges the assistance of Lena Dlugosz, Stephen S. Hartwick, and Vincent P. Olivieri for translating several of the foreign papers, as well as the assistance of Kathleen E. Trumpower for typing the several versions of his manuscript.

The Subcommittee also wishes to thank the Panel on the Geochemistry of Water in Relation to Cardiovascular Disease for their contribution of time, and all of the various secretaries, typists, and NAS-NRC support units that helped with the timely production of this report. 


\section{Contents}

1 INTRODUCTION, SUMMARY, AND RECOMMENDATIONS

Ernest E. Angino

Introduction and Summary, 1

Recommendations, 2

2 GEOCHEMISTRY OF DRINKING WATER AS AFFECTED BY DISTRIBUTION AND TREATMENT

Ernest E. Angino

Methods of Water Analysis, 3

Hardness, 4

Effects of Treatment on Water, 5

Home Treatment of Water (Water Softeners), 7

Changes Brought about Through Water Distribution, 7

Contamination in Water Supply Systems and Tap Water, 10

Metal Intake, 11

Effects of Storage on Treated Water, 12

Summary, 12

Manuals of Analytical Methods, 12

References, 13

3 GEOLOGY AND WATER CHARACTERISTICS

Robert G. Corbett

Water Types, 14

Construction of a Simple Piper Diagram, 15

The Hydrologic Cycle and Water Quality, 17

Chemical Nature of Precipitation, 18

Rock Types and Relative Solubility, 18 
Controls on Surface Water Chemistry, 18

Surface Water Chemistry and Geologic Terrain, 20

Simple Situations, 20

Complex Situations, 22

Specific Environments, 23

Groundwater Chemistry and Geologic Terrain, 27

Compilations of Data, 27

Information Available on a National Basis, 27

Major Cities, 31

Summary, 37

References, 38

4 SOME INTERACTIONS AMONG ELEMENTS AND BINDING LIGANDS

THAT MAY RELATE TO CARDIOVASCULAR DISEASE

Harold H. Sandstead

Zinc and Other Metals, 39

Cadmium and Other Metals, 40

References, 42

5 Pathogenesis AND Classification OF

CARDIOVASCULAR DISEASES IN RELATION TO

MINERALS IN THE DRINKING WATER -

Jack P. Strong and A. Wouter Voors

Cardiovascular Disease, 45

Hypertension, 45

Stroke, 46

Concluding Remarks, 47

References, 47

6 THE ASSOCIATION OF WATER HARDNESS AND CARDIOVASCULAR

DISEASES: AN EPIDEMIOLOGICAL REVIEW AND CRITIQUE

George W. Comstock

General Statistical and Epidemiological Problems, 49

Experimental Animal Studies, $51^{\circ}$

Water Hardness and Cardiovascular Deaths Within Geographic Areas, 51

National and International, 51

Major Intra-national Divisions (States or Provinces), 54

Counties and Cities, 56

Evaluation of Observed Associations, 57

Consistency, 58

Strength of Association, 59

Dose-Response Effect, 59

Specificity, 59

Experimental Changes, 60

Coincidental Factors Associated with Cardiovascular Risk, 62

Possible Confounding Factors, 63

Biological Plausibility, 64

Conclusion, 64

References, 64 
7 THE ROLE OF CHEMICAL CONSTITUENTS OF DRINKING WATER IN CARDIOVASCULAR DIŚEASE

A. Richey Sharrett

Associations of Elements in Drinking Water with Hardness, 69

Associations of Elements in Drinking Water

with Cardiovascular Diseases, 73

Association of Elements in Drinking Water

with Elements in Human Tissues, 78

References, 80

8 THE ASSOCIATION OF TRACE ELEMENTS AND

CARDIOVASCULAR DISEASES: A SELECTED REVIEW OF

POSITIVE FINDINGS IN THE LITERATURE

A. Wouter Voors

General Statistical, Epidemiological, and Analytical Problems, 82

Method, 83

Choice of Trace Elements, 83

Selection öf Literature, 83

Metal Toxicity and Host Defense, 84

Experimental Animal Studies, 84

Host Defense System Involving Cadmium, 84

Kidney Regulation of Water Excretion on

a Long-Term Basis, 84

Cardiac Conduction Tissue with Emphasis on Cadmium, 85

Lead and Cardiomyopathy, 85

Selenium and Protection Against Cadmium and Other Toxicities, 85

Zinc and Protection Against Cadmium Toxicity, 85

Silicon and the Cardiovascular System, 85

Trace Elements and Cardiovascular Deaths: Epidemiological Studies, 85

Cadmium, 86

Lead, 86

Selenium, 87

Zinc, 87

Silicon, 87

Evaluation of Observed Associations, 87

Summary, 88

References, 88

INDEX 


\section{Introduction, Summary, and Recommendations}

\section{INTRODUCTION AND SUMMARY}

This publication is an attempt to review and document relations between trace and major element chemistry of drinking water and cardiovascular diseases. Several aspects of the problem, related both to the pathway that drinking water takes to man and to its transit through man, are reviewed. These topics range from the effects of the distribution system on water chemistry to the role of the constituents of drinking water in cardiovascular diseases.

Natural waters may be characterized by concentration (total dissolved solids or, for certain purposes, hardness) and by a name based on the dominance of specific cations and anions. No clear relation between natural water and terrain has yet been established with regard to trace elements.

Well-defined chemical changes in water composition occur at all stages in the water distribution system, starting with water treatment itself, and proceeding to storage, distribution, and delivery at the tap. Major changes in water hardness are commonly generated at the water treatment stage, either to increase it (for pipe protection) or to decrease it to make water less damaging to other equipment and also to make it more palatable.

Several steps in the pathogenesis of hypertension, stroke, and cardiovascular disease that could be affected by suspected water factors were explored. Subclassification of cardiovascular disease is important in understanding the possible relationship of water chemistry and cardiovascular disease. If water factors do have an effect on any subcategory of cardiovascular disease, we should determine the precise point at which each causative water factor exerts its effect.

There is little evidence bearing on the question of a substantial contribution from drinking water to human tissue levels of cadmium, chromium, or zinc. Copper and magnesium levels of tissues may be related to drinking water, however, but confirmatory evidence is needed. Lead levels in blood and possibly other tissues are most certainly affected by lead levels in drinking water in areas where these levels are unusually elevated. The possible implications of low dose chronic exposure should be of considerable interest.

There is little evidence that relatively low levels (less than $0.05 \mathrm{mg} / \mathrm{l}$ ) of lead are toxic to the cardiovascular system, except for the causation of cardiomyopathy. The protective action of selenium and zinc applies mainly to cadmium toxicity. The mode of the protective action of silicon, if any, is unclear at present. Some epidemiological associations between the cadmium level or cadmium:zinc ratio in liver, kidney, or spleen and cardiovascular disease have been reported for several studies, but other studies are contradictory. Some epidemiological support exists for the notion of a protective effect by selenium; results for zinc are equivocal.

Harmful action of dissolved elements from pipes and kitchen utensils as carried by water is a possibility.

Interactions within the human system involving calcium and selected trace elements (such as chromium, zinc, cobalt, and molybdenum) might be very important for the cardiovascular system. A detailed study of elemental 
interactions as revealed by animal studies is in order, as these very likely have implications for cardiovascular disease in humans. Some of these relations are discussed in the chapter by $\mathbf{H}$. H. Sandstead.

Extensive review of the epidemiological literature indicates that there may be a water factor associated with cardiovascular disease. Its existence, however, is far from certain. The factor can hardly be softness (or hardness) as such because of its biological implausibility and the numerous exceptions to the negative association of hardness with cardiovascular disease. Its effects, if any, must be very weak in comparison with the effects of known risk factors; an association of even modest strength should surely show up more consistently. Available evidence suggests that the water factor is not mediated solely by blood pressure or serum lipids.

One possible mechanism is that enough magnesium is present in some hard waters to prevent borderline magnesium deficiencies in some persons, thereby reducing their liability to sudden cardiac death as a result of arrhythmia following occurrence of an infarct.

The reported inverse relationship between mortality from cardiovascular diseases and hardness of local drinking water supplies appears to be considerably less distinctive in small regional studies. Furthermore, on the basis of a detailed review of the literature pertaining to this controversial subject, the most meaningful assessment of this relationship is that, clearly, the issue is still equivocal. Additional investigation is definitely warranted.

\section{RECOMMENDATIONS}

One striking conclusion emerges from this detailed study of the geochemistry of water in relation to cardiovascular diseases: The relation is clearly equivocal. It is obvious that additional studies with considerably more scientific rigor are required if the issue of a relation between water hardness and cardiovascular diseases is to be resolved satisfactorily.
More attention should be given to the role that magnesium plays in the water chemistry-food chaincardiovascular diseases relationship. Additional attention should be directed toward the relation between the concentration of individual chemical constituents in water and cardiovascular diseases-rather than considering "lumped" parameters such as hardness.

It is possible that conflicting evidence from various studies confirming or denying the inverse relation between water hardness and cardiovascular diseases is simply a matter of identifying which waters are low or high in sodium. This possibility should be addressed, and more rigorous experimental design tests are needed to assess the impact of the sodium factor.

Confirmatory evidence is needed to assess the important possibility that copper and magnesium levels in human tissues may be related to the element concentration levels in drinking water.

The possible long-term implications of low-dose chronic exposure to selected trace elements in water, as they relate to cardiovascular problems, should be investigated in considerable detail. For example, lead levels in blood, and possibly other tissues, are almost certainly affected by lead levels in drinking water in certain geographical areas or in water systems where these levels are particularly elevated. This need is particularly of concern in areas where corrosive water (e.g., very soft water) and lead plumbing exists. Waterborne lead could conceivably be a factor in cardiovascular disease.

The possibility should be investigated that some soft waters may contain biologic risk factors other than those discussed in this study that may have an effect on cardiovascular diseases.

There is some evidence that silicon, carried in water in the form of silica, may act as a protection against cardiovascular diseases. Further research to assess this possible protective action is needed.

ERNEST E. ANGINO

- Panel Chairman 


\title{
Geochemistry of Drinking Water as Affected by Distribution and Treatment
}

\author{
ERNEST E. ANGINO
}

Considerable interest and concern are currently being expressed about the relation of the environment to health, disease, and mortality. More specifically, the relation between trace and major elements in drinking water and the incidence of arteriosclerosis and hypertensive disease is undefined. The reported inverse relationship between mortality from these diseases and hardness of local drinking water supplies has become one of the most controversial issues in present-day epidemiology. As noted by many reviewers, significant inverse correlations between the hardness of drinking water and local cardiovascular mortality rates have been commonly reported for studies covering large regions. The correlation appears to be considerably less consistent in studies of small regions.

A relatively recent review of the issue (Neri et al., 1974) cites 49 studies from 9 countries relating areal differences in cardiovascular disease to drinking water composition. However, their study finds the data insufficient to discriminate between fundamental hypotheses. Clearly, as Sharrett and Feinleib (1975) have demonstrated,

the question remains open as to whether the bulk or the various trace elements usually found in hard water is protective or whether something in soft water is harmful. The correlations may mean only that water quality is an index of something else, a factor not transmitted through drinking water. Although it has been estimated that the maximum attainable mortality reduction from optimal conditioning of drinking water is at most 15 percent, the absolute number of potentially preventable deaths is large; so recent meetings of investigators have given strong endorsement to continuing research in this area.
As a result of the uncertainty surrounding this issue, the U.S. National Committee for Geochemistry of the National Academy of Sciences through its Subcommittee on the Geochemical Environment in Relation to Health and Disease convened a Panel on Geochemistry of Water in Relation to Cardiovascular Disease. The charge to this Panel was to review and assess the relationship between the presence or absence of certain trace and major components in water and their effect; direct or indirect, on the incidence and effects of cardiovascular disease.

The Panel focused a large portion of its effort on the water hardness-cardiovascular problem. Topics considered include the following: geology and water characteristics; interactions of components in water; effects of treatment on water; pathogenesis of hypertension, stroke, and cardiovascular disease as related to water chemistry; chemical constituents of water to disease; trace element associations; and recommendations.

It is our hope that this report will, to quote another panel report, "foster a better understanding of the whole range of processes and effects involved in the occurrence and movement of critical components through the geochemical environment and through man."

\section{METHODS OF 'WATER ANALYSIS}

Many analytical methods are available for the analysis of individual water constituents (e.g., sodium and calcium). Different methods are sometimes applicable for waters of differing compositions. However, experience has taught those concerned with the chemical analysis of water that 
certain analytical methods are more accurate and reliable than others. This results in the use of different manuals for analyses and endorsements by different groups. Some have much in common. For example, compare Methods for Chemical Analysis of Water and Wastes (U.S. Environmental Protection Agency, 1974) with Annual Book of ASTM Standards, Part 31, "Water" (American Society for Testing and Materials, 1974) and other manuals of analytical methods listed at the end of this chapter.

The recommended or preferred analytical method for a given element variously listed in these manuals is adequate for most purposes; however, those of the ASTM, the Association of Official Analytical Chemists (AOAC), and the American Public Health Association-American Water Works Association-Water Pollution Control Federation have stood the test of time. More importantly, they have also stood the tests of court action. Some problems related to sampling, analysis, and storage are reviewed in Geochemistry and the Environment, Volume III (NRC Subcommittee on the Geochemical Environment in Relation to Health and Disease, 1978).

To review in detail the relative merits of each manual and of one analytical method over another is beyond the scope of this study. For measurement of the hardness parameter, the techniques outlined in each of the manuals are sufficiently reliable to provide usable information.

\section{HARDNESS}

In all of these manuals the definition for hardness is essentially the same. That of Brown et al. (1970) states it best: "The hardness of water is that property attributable to the presence of alkaline earths." Calcium and magnesium are the principal alkaline earth elements present in natural waters. Strontium and barium, which are also alkaline earth elements, are present in very low concentrations in all except the most unusual water systems.

The ions of iron, manganese, and aluminum normally are not present in sufficient concentration in natural waters to affect the test for hardness. The term hardness is used in many ways, each with its own definition. Whenever the term is used, one should be certain which of the several definitions is meant:

- Carbonate hardness is the amount of hardness chemically equivalent to the amount of bicarbonate and carbonate in solution.

- Noncarbonate hardness is the difference between the hardness calculated from the total amount of calcium plus magnesium in solution and the carbonate hardness.

- Total hardness equals calcium plus magnesium hardness.
- "Hardness of water is defined as its content of metallic ions which react with sodium soaps to produce solid soaps and which react with negative ions, when the water is evaporated in boilers, to produce solid boiler scale." (Camp, 1963).

- "Hardness is a characteristic of water generally accepted to represent the total concentration of calcium and magnesium ions." (American Society for Testing and Materials, 1972).

For our purposes the definition of choice is that for socalled total hardness, where the contribution of strontium and barium is usually neglected.

A single criterion for maximum hardness in public water supplies is not possible. Table 1 provides a comparison of various scales of water hardness (Höll, 1972). Water hardness is largely the result of interaction with the geological formations containing the water source or over which the water source flows. Public acceptance of hardness varies from community to community. Consumer sensitivity for water is normally related to the degree of hardness to which a person is accustomed (Clark et al., 1971).

Water is commonly classified with respect to hardness according to the following summary (Table 2), given in terms of the amount of calcium carbonate or its equivalent (Durfor and Becker, 1964).

Most concentration values for calcium and magnesium are given as milligrams per liter $(\mathrm{mg} / \mathrm{l})$ or parts per million (ppm) (these values are essentially the same for fresh waters). To calculate the hardness in terms of $\mathrm{CaCO}_{3}$, one must convert to milliequivalents per liter (meq/1), proceeding as follows: For any water under study, measure the calcium, magnesium, barium, or

TABLE 1 Various Scales of Hardness of Water

\begin{tabular}{|c|c|}
\hline $\begin{array}{l}1 \text { German degree of hardness, } \\
\text { German } \mathrm{dH}^{\circ}\end{array}$ & $\begin{array}{l}=10 \mathrm{mg} \mathrm{CaO} / 1 \\
=7.14 \mathrm{mg} \mathrm{Ca} / \mathrm{l} \\
=17.9 \mathrm{mg} \mathrm{Ca}\left(\mathrm{HCO}_{3}\right)_{2} / 1 \\
=1.25 \mathrm{English} \mathrm{H}^{\circ} \\
=1.79 \text { French } \mathrm{H}^{\circ}\end{array}$ \\
\hline $\begin{array}{l}1 \text { French degree of hardness, } \\
\text { French } \mathrm{H}^{\circ}\end{array}$ & $\begin{array}{l}=10 \mathrm{mg} \mathrm{CaCO} 3 / \mathrm{l} \\
=0.56 \mathrm{German}_{\mathrm{dH}}{ }^{\circ} \\
=0.7 \mathrm{English}^{\circ}\end{array}$ \\
\hline $\begin{array}{l}\text { 1. English degree of hardness, } \\
\text { English } \mathrm{H}^{\circ}\end{array}$ & $\begin{array}{l}=10 \mathrm{mg} \mathrm{CaCO} 30.7 / 1 \\
=0.8 \mathrm{German} \mathrm{dH}^{\circ}\end{array}$ \\
\hline 1 American degree of hardness & $\begin{array}{l}=1 \mathrm{mg} \mathrm{CaCO} / 1 \\
=0.056 \mathrm{German} \mathrm{dH}^{\circ}\end{array}$ \\
\hline $\begin{array}{l}1 \text { international degree of hardness, } \\
\text { mval* }^{*}\end{array}$ & $\begin{array}{l}=1 \text { meq } / 1 \\
=\left(\text { German } \mathrm{dH}^{\circ}\right) / 2.8\end{array}$ \\
\hline
\end{tabular}

* An mval is $1 \mathrm{meq} / \mathrm{l}$ of material concerned and is the proposed international unit of hardness.

SOURCE: Höll (1972). 
TABLE 2 Hardness Classification

\begin{tabular}{ll}
\hline Hardness, $\mathrm{mg} / \mathrm{l}$ as $\mathrm{CaCO}_{3}$ & Classification \\
\hline $0-60$ & Soft \\
$61-120$ & Moderately hard \\
$121-180$ & Hard \\
$>180$ & Very hard \\
\hline
\end{tabular}

SOURCE: Durfor and Becker (1964).

strontium in milligrams per liter, convert to milliequivalents per liter by multiplying each value by a conversion factor that is the reciprocal of the combining weight of the ion, adding the values and multiplying by 50.05 . However, in practice, the barium and strontium concentrations can usually be omitted. Thus

$\mathrm{Ca}$ in $\mathrm{mg} / \mathrm{l}$ (or ppm) $\times 0.04990=\mathrm{Ca}$ in meq $/ 1$

$\mathrm{Mg}$ in $\mathrm{mg} / \mathrm{l}$ (or ppm) $\times 0.08226=\mathrm{Mg}$ in meq $/ 1$

$\mathrm{mg} / 1$ of hardness as $\mathrm{CaCO}_{3}=\Sigma(\mathrm{Ca}+\mathrm{Mg}$ in $\mathrm{meq} / 1) \times 50.05$

Below $60 \mathrm{mg} / \mathrm{l}$ of hardness as $\mathrm{CaCO}_{3}$, the water is called soft; above this value, it would be considered hard in various degrees.

In considering hardness, one also needs to make a distinction between the hardness of the raw (untreated or unfinished) water supply and the hardness of the finished water from the same source as well as from the tap. In most hard water cities the hardness value is lowered considerably by water treatment. Rarely, however, is the hardness lowered below $60 \mathrm{mg} /$.

If the supposed relation between water hardness and cardiovascular functions is to be studied properly, an area taking its water supply from a uniform aquifer would be recommended. For example, the Florida hard water aquifers (Miami Oolite, Biscayne, and Floridian systems) all underlie an area of sufficiently large population to be considered for this purpose. Furthermore, being relatively pure $\mathrm{CaCO}_{3}$ systems, the input of magnesium would be minimal. This circumstance provides a means of studying the effects of calcium separately from those of magnesium. Conversely, a properly selected area where the magnesium content would be high should be sought so that an assessment of the part that magnesium in water might play in the cardiovascular function may be evaluated (Seelig and Heggtveit, 1974). Maps, such as those showing hardness of surface and subsurface waters, may be particularly useful for this purpose (see Geraghty et al., 1973). However, studies comparing health effects resulting from drinking waters of widely differing chemical composition are desperately needed.

When these data are available, they could be coupled with knowledge of the distribution of groundwater aquifers in the United States (Geraghty et al., 1973) for maximum utility. In brief, one might focus attention on areas of hard water with a single water source of uniform composition, keeping in mind the differences between finished and unfinished water.

\section{EFFECTS OF TREATMENT ON WATER}

All water treatment processes, such as chlorination, $\mathrm{pH}$ adjustment, and softening, change the chemical composition of water (Durfor and Becker, 1964). The prevalent sodium, potassium, and chloride ions are not removed in conventional water treatment, but the carbonate, bicarbonate, and sulfate ions are removed by precipitation in some water-softening processes. Obvious changes in water chemistry include a lowering of the calcium and magnesium concentrations to obtain soft water and a raising of the fluoride level for dental prophylaxis. Other changes are, in many ways, less dramatic but of equal significance. The levels of iron and manganese in drinking water are usually monitored and often lowered, for reasons of taste, from those normally present in the raw water. Though affecting iron and manganese, and in some instances copper and zinc, routine water treatment processes (e.g., chlorination) do little or nothing to remove arsenic, barium, cadmium, hexavalent chromium, cyanide, lead, phenols, selenium, and silver from drinking water, even though drinking water standards (maximum permissible concentrations) have been established for many of these contaminants (Table 3). This discussion does not consider bacteriological changes. The concentrations of many other constituents, especially those present in trace amounts (10 ppm or less), are not changed to any significant degree. Some of the major changes that occur in water during lime treatment, limesoda treatment, and cation-exchange processes are shown in Figure 1 (Durfor and Becker, 1964).

Treatment of water with lime $\left[\mathrm{Ca}(\mathrm{OH})_{2}\right]$ (softening) removes what is called carbonate hardness (Clark et al., 1971). Calcium and bicarbonate are removed about equally from water by lime treatment, if the water hardness is primarily caused by calcium. The resulting calcium carbonate precipitation also removes minor amounts of magnesium. If most of the carbonate hardness is caused by magnesium (which is uncommon), additional lime will increase the removal of magnesium, as $\mathrm{Mg}(\mathrm{OH})_{2}$, along with the softening precipitate or sludge. Coprecipitation of iron, manganese, strontium, and other trace metals with the calcium and magnesium 
occurs with lime softening. Removal of calcium and magnesium by precipitation may be accomplished by the addition of soda ash $\left(\mathrm{Na}_{2} \mathrm{CO}_{3}\right)$ by itself. Trace elements present may be removed in these processes but the data are scanty-a point of considerable concern to any reviewer of the relation between trace elements, geochemistry, the environment, and human health.

In brief, softening of water by the addition of soda ash and lime $\left[\mathrm{Ca}(\mathrm{OH})_{2}\right]$-the so-called lime-soda softening process-causes a decrease in the calcium, magnesium, strontium, bicarbonate, and sulfate concentration of the water, but it simultaneously increases the sodium content, a commonly overlooked side result. An increase in sodium content is not beneficial to individuals restricted to a low-salt diet, as is the case for some cardiovascular disorders. In the lime and lime-soda treatment processes, the chloride, nitrate, and fluoride content of the water remains essentially unchanged, as do the concentrations of many trace components such as arsenic and selenium.

During the chlorination process the soluble chloride remains in the system and increases the chlorine content. However, the chlorine reacts with the water, releasing oxygen, which then acts as a disinfecting agent. It also forms hydrochloric acid, which lowers the $\mathrm{pH}$ of the

TABLE 3 Surface Water Criteria and Standards for Public Water Supplies

\begin{tabular}{|c|c|c|}
\hline $\begin{array}{l}\text { Constituent or } \\
\text { Characteristic } \\
\text { Inorganic Chemicals }\end{array}$ & $\begin{array}{l}\text { Permissible } \\
\text { Criteria, } \\
\mathrm{mg} / 1\end{array}$ & $\begin{array}{l}\text { Standards } \\
\text { Effective } \\
\text { June 24, 1977, } \\
\mathrm{mg} / 1\end{array}$ \\
\hline Ammonia (as $\mathrm{N}$ ) & 0.5 & - \\
\hline Arsenic & 0.1 & 0.05 \\
\hline Barium & 1.0 & 1.0 \\
\hline Cadmium & 0.01 & 0.010 \\
\hline Chloride & 250 & - \\
\hline Chromium, hexavalent & 0.05 & 0.05 \\
\hline Copper & 1.0 & - \\
\hline $\begin{array}{l}\text { Fluoride (temperature } \\
\text { dependent) }\end{array}$ & 2.0 & $1.4-2.4$ \\
\hline Iron (filterable) & 0.3 & - \\
\hline Lead (filterable) & 0.05 & 0.05 \\
\hline Manganese (filterable) & 0.05 & - \\
\hline Mercury & - & 0.002 \\
\hline Nitrates (as N) & 10.0 & 10.0 \\
\hline Nitrites (as N) & 1.0 & - \\
\hline $\begin{array}{l}\mathrm{pH} \text { range (temperature } \\
\text { dependent) }\end{array}$ & $6.0-8.5$ & - \\
\hline Selenium & 0.01 & 0.01 \\
\hline Silver & - & 0.05 \\
\hline Sulfate & 250 & - \\
\hline Zinc & 5.0 & - \\
\hline
\end{tabular}

SOURCE: For "Permissible Criteria," U.S. Environmental Protection Agency (1973a); for "Standards Effective June 24, 1977," U.S. Environmental Protection Agency (1976).

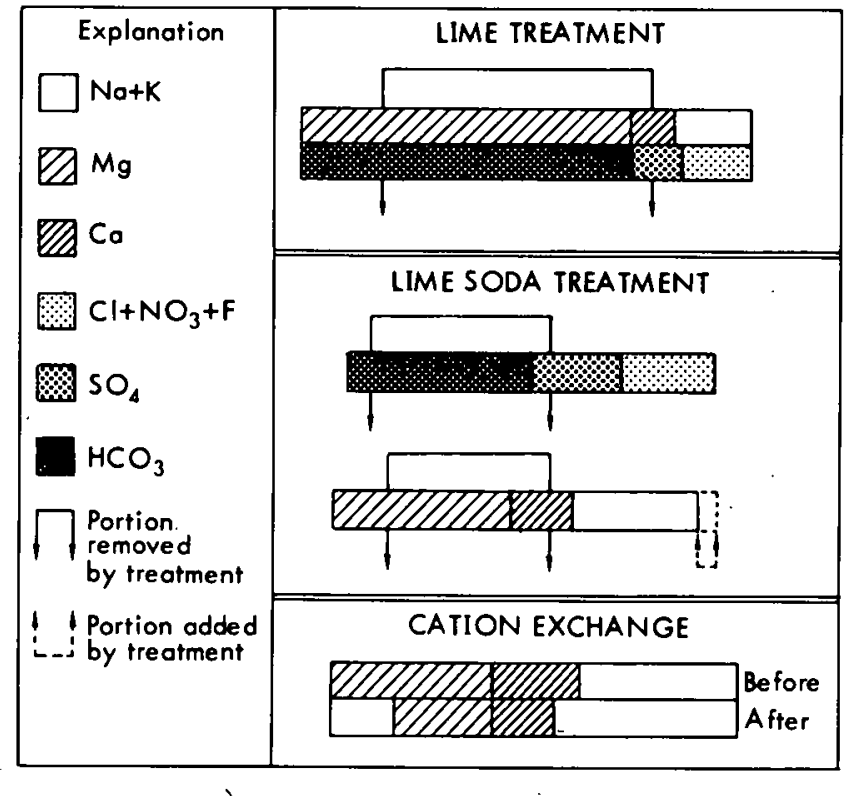

FIGURE 1 Effect of water softening upon the chemical composition of the water being treated. Note that cation exchange softens water by replacing a part of the calcium with non-hardness-causing sodium and also by replacing part of the magnesium with sodium. The bicarbonate, sulfate, and chloride concentrations remain unchanged. During cation softening, the dissolved solids content of the water is usually increased, but the hardness is lowered. Modified from Durfor and Becker (1964, p. $60)$.

water. Therefore the chlorination process is in itself an acidification step, which is usually counteracted to reduce corrosion in the distribution lines by the subsequent addition of lime. This latter step increases the water hardness and strontium content slightly. The use of sodium carbonate will raise the $\mathrm{pH}$ without increasing water hardness.

Acids and alkalies are commonly added to water to adjust the $\mathrm{pH}$ for one purpose or another. Typical acids used to lower the $\mathrm{pH}$ are sulfuric and phosphoric acids. Their use, of course, increases the $\mathrm{SO}_{4}$ and $\mathrm{PO}_{4}$ concentrations, respectively. Alkalies used to raise the $\mathrm{pH}$ are lime and soda ash; the latter leads to a direct increase in the carbonate content of the water. The soda ash also increases the sodium content.

A coagulation process is used to remove turbidity and suspended solids from drinking water. Two commonly used coagulants, aluminum sulfate and iron sulfate, lower the bicarbonate and carbonate concentration in water, by precipitating $\mathrm{Al}_{2}\left(\mathrm{CO}_{3}\right)_{3}$ and $\mathrm{FeCO}_{3}$, and increase the sulfate concentration.

Aluminum sulfate is the standard coagulant used in the water treatment process. Addition of this agent causes a decrease in water alkalinity and a simultaneous increase in carbon dioxide. This increase in $\mathrm{CO}_{2}$ is 
undesirable, as it lowers the $\mathrm{pH}$ of the water, thereby increasing its corrosiveness. Because both aluminum and iron sulfate are acidic in nature, the $\mathrm{pH}$ of the water so treated is reduced. However, it is often readjusted upward by the addition of lime. The $\mathrm{pH}$ of drinking water is commonly raised prior to passing it into the distribution system as a means of reducing corrosion in the distribution lines.

\section{HOME TREATMENT OF WATER (WATER SOFTENERS)}

The use of water softeners in residential and industrial installations has expanded considerably in the last few years. This is a natural response, both for securing soft water for home use and as a reaction to the concern about the environmental pollution of public water supplies.

The materials used in the process of ion exchange are relatively insoluble granular materials that possess the ability to exchange ions. The, type of ion-exchange materials used (such as synthetic resins and gel zeolites) is determined by the type of water treatment required (U.S. Environmental Protection Agency, 1973b).

Cation exchange is the basis of the most widely used water-softening process for residential units. Cation exchange softens water by exchanging some of the calcium and magnesium in the water with non-hardnesscausing sodium. The ion-exchange reactions for softening can be written schematically as follows:

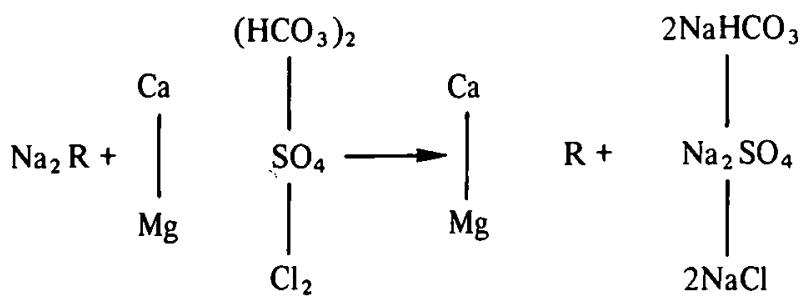

where $R$ represents the exchange resin (Clark et al., 1971). This simplified reaction shows that when water containing calcium and magnesium salts (such as $\mathrm{HCO}_{3}$ and $\mathrm{SO}_{4}$ ) and chloride is passed through an ion exchanger, the calcium and magnesium are adsorbed on the resin, which in turn simultaneously releases sodium ions in exchange. These latter ions then form the soluble sodium compounds indicated. The exchange, as shown in the equation, is on a two-for-one basis for sodium. Two sodium ions are introduced into the solution for each calcium ion removed, and two more sodium ions for each magnesium ion. For those individuals restricted to a lowsodium diet, this process is detrimental, but may be overlooked. Small amounts of lithium are also added to the exchange solution. Water softeners will also remove small amounts of dissolved iron and manganese (Water Supply Subcommittee MWPS-14, 1968).

Throughout the cation-exchange process the concentrations of the bicarbonate, sulfate, chloride, and nitrate remain unchanged. Some trace components may be removed in the cation-exchange process. The affinity of cations for cation exchangers increases primarily with increasing elemental valence and secondarily with atomic number. Because of the higher affinities of the trace metals, they will be harder to regenerate (remove) from the resin. That is, there may be a buildup of trace metals on the resin (G. Klumb, personal communication, 1977). Passing waters through ion exchangers will remove 99.9 percent of all radioactive materials (Bevis, 1960). By cation exchange it is possible to reduce concentrations of calcium and magnesium to values near zero-but this is not desirable, as any water so treated is very corrosive. Subsequent distribution of the water in metal pipes may tend to add trace elements such as lead, zinc, cadmium, and copper to the water.

In practice, the operations of resin-based cation exchangers (home water softeners) are simple and straightforward. They do, however, tend to pass monovalent trace elements and all anionic species, regardless of charge.

Water treatment processes, regardless of whether for public or private sources, change the chemical composition of water. The obvious changes involve the major dissolved components normally present in drinking water, such as calcium, magnesium, and sodium. The greatest change occurs in lowering the concentration of calcium and magnesium in the water-softening step for hard waters.

\section{CHANGES BROUGHT ABOUT THROUGH WATER DISTRIBUTION}

To understand properly the chemical changes that can occur in water in distribution systems, one must understand the problem of corrosion in pipes. Some reliable data on the distribution of $\mathrm{pH}$ values and selected elements in drinking water by type of piping have been provided by Schreiber et al. (unpublished data, 1976) and are presented in Table 4. These data are from selected households from Washington County, Maryland. Households were selected so as to have a balance between homes with different types of piping, and both old and new homes were included. Sample populations for each table are indicated by $N$ values.

In most nonrural areas, water undergoes some treatment before it is consumed, even if it consists of little more than chlorination. Attention paid to natural surface 


\section{GEOCHEMISTRY OF WATER IN RELATION TO CARDIOVASCULAR DISEASE}

TABLE 4a Distribution of $\mathrm{pH}$ Values of Drinking Water by Type of Piping

\begin{tabular}{|c|c|c|c|c|c|c|c|c|c|c|c|c|}
\hline \multirow[b]{3}{*}{ Pipe Type } & \multicolumn{10}{|c|}{ pH Value } & \multirow{2}{*}{\multicolumn{2}{|c|}{ Total }} \\
\hline & \multicolumn{2}{|c|}{$\leqslant 6.9$} & \multicolumn{2}{|c|}{$7.0-7.2$} & \multicolumn{2}{|c|}{$7.3-7.5$} & \multicolumn{2}{|c|}{$7.6-7.8$} & \multicolumn{2}{|c|}{$7.9+$} & & \\
\hline & $N$ & $\begin{array}{l}\text { Per- } \\
\text { cent }\end{array}$ & $N$ & $\begin{array}{l}\text { Per- } \\
\text { cent }\end{array}$ & $N$ & $\begin{array}{l}\text { Per- } \\
\text { cent }\end{array}$ & $N$ & $\begin{array}{l}\text { Per- } \\
\text { cent }\end{array}$ & $N$ & $\begin{array}{l}\text { Per- } \\
\text { cent }\end{array}$ & $N$ & $\begin{array}{l}\text { Percent } \\
\text { of Total }\end{array}$ \\
\hline Copper & 17 & 13.1 & 27 & 20.8 & 48 & 36.9 & 28 & 21.5 & 10 & 7.7 & 130 & 45.8 \\
\hline Galvanized & 10 & 13.5 & 15 & 20.3 & 36 & 48.6 & 10 & 13.5 & 3 & 4.1 & 74 & 26.1 \\
\hline Copper and galvanized & 9 & 16.7 & 10 & 18.5 & 30 & 55.6 & 3 & 5.6 & 2 & 3.7 & 54 & 19.0 \\
\hline $\begin{array}{l}\text { Copper or galvanized } \\
\text { and plastic }\end{array}$ & 5 & 45.5 & 2 & 18.2 & 4 & 36.4 & 0 & & 0 & & 11 & 3.9 \\
\hline Plastic & 2 & 50.0 & 2 & 50.0 & 0 & & 0 & & 0 & & 4 & 1.4 \\
\hline Not applicable & 2 & 20.0 & 3 & 30.0 & 3 & 30.0 & 1 & 10.0 & 1 & 10.0 & 10 & 3.5 \\
\hline Not stated & 0 & & 0 & & 1 & & 0 & & 0 & & 1 & 0.4 \\
\hline TOTAL & 45 & 15.8 & 59 & 20.8 & 122 & 43.0 & 42 & 14.8 & 16 & 5.6 & 284 & 100.0 \\
\hline
\end{tabular}

SOURCE: Schreiber, G. B., G. W. Comstock, and K. J. Helsing (unpublished data, 1976). Arteriosclerotic heart disease mortality and water quality in Washington County, Maryland. Training Center for Public Health Research, Johns Hopkins University, Hagerstown, Md.

TABLE 4b Distribution of Lithium Content of Drinking Water by Type of Piping

\begin{tabular}{|c|c|c|c|c|c|c|c|c|c|c|c|c|c|c|}
\hline \multirow[b]{3}{*}{ Pipe Type } & \multicolumn{12}{|c|}{ Lithium Concentration, ppb } & & \\
\hline & \multicolumn{2}{|c|}{$0.0-0.9$} & \multicolumn{2}{|c|}{$1.0-2.9$} & \multicolumn{2}{|c|}{$3.0-4.9$} & \multicolumn{2}{|c|}{5.0 .9 .9} & \multicolumn{2}{|c|}{$10.0 \cdot 19.9$} & \multicolumn{2}{|c|}{$20.0+$} & \multicolumn{2}{|c|}{ Total } \\
\hline & $N$ & $\begin{array}{l}\text { Per- } \\
\text { cent }\end{array}$ & $N$ & $\begin{array}{l}\text { Per- } \\
\text { cent }\end{array}$ & $N$ & $\begin{array}{l}\text { Per- } \\
\text { cent }\end{array}$ & $N$ & $\begin{array}{l}\text { Per. } \\
\text { cent }\end{array}$ & $N$ & $\begin{array}{l}\text { Per- } \\
\text { cent }\end{array}$ & $N$ & $\begin{array}{l}\text { Per- } \\
\text { cent }\end{array}$ & $N$ & $\begin{array}{l}\text { Percent } \\
\text { of Total }\end{array}$ \\
\hline Copper & 53 & 40.8 & 33 & 25.4 & 26 & 20.0 & 9 & 6.9 & 6 & 4.6 & 3 & 2.3 & 130 & 45.8 \\
\hline Galvanized & 26 & 35.1 & 20 & 27.0 & 20 & 27.0 & 2 & 2.7 & 4 & 5.4 & 2 & 2.7 & 74 & 26.1 \\
\hline Copper and galvanized & 24 & 44.4 & 18 & 33.3 & 6 & 11.1 & 3 & 5.6 & 3 & 5.6 & 0 & & .54 & 19.0 \\
\hline $\begin{array}{l}\text { Copper or galvanized } \\
\text { and plastic }\end{array}$ & 3 & 27.3 & 2 & 18.2 & 0 & & 0 & & 4 & 36.4 & 2 & 18.2 & 11 & 3.9 \\
\hline Plastic & 1 & 25.0 & 0 & & 1 & 25.0 & 1 & 25.0 & 0 & & 1 & 25.0 & 4 & 1.4 \\
\hline Not applicable & 2 & 20.0 & 4 & 40.0 & $i$ & 10.0 & 3 & 30.0 & 0 & & 0 & & 10 & 3.5 \\
\hline No: stated & 0 & & 1 & 100.0 & 0 & & 0 & & 0 & & 0 & & 1 & 0.4 \\
\hline TOTAL & 109 & 38.4 & 78 & 27.5 & 54 & 19.0 & 18 & 6.3 & 17 & 6.0 & 8 & 2.8 & 284 & 100.0 \\
\hline
\end{tabular}

SOURCE: Schreiber et al. (unpublished data, 1976).

TABLE 4c Distribution of Cadmium Content of Drinking Water by Type of Piping

\begin{tabular}{|c|c|c|c|c|c|c|c|c|c|c|c|c|c|c|}
\hline \multirow{3}{*}{ Pipe Type } & \multicolumn{12}{|c|}{ Cadmium Concentration, ppb } & & \\
\hline & \multicolumn{2}{|c|}{0.0 .49} & \multicolumn{2}{|c|}{$0.50-0.74$} & \multicolumn{2}{|c|}{$0.75-0.99$} & \multicolumn{2}{|c|}{$1.00-1.99$} & \multicolumn{2}{|c|}{$2.00-4.99$} & \multicolumn{2}{|c|}{$5.00+$} & \multicolumn{2}{|c|}{ Total } \\
\hline & $N$ & $\begin{array}{l}\text { Per- } \\
\text { cent }\end{array}$ & $N$ & $\begin{array}{l}\text { Per- } \\
\text { cent }\end{array}$ & $N$ & $\begin{array}{l}\text { Per- } \\
\text { cent }\end{array}$ & $N$ & $\begin{array}{l}\text { Per- } \\
\text { cent }\end{array}$ & $N$ & $\begin{array}{l}\text { Per- } \\
\text { cent }\end{array}$ & $N$ & $\begin{array}{l}\text { Per- } \\
\text { cent }\end{array}$ & $N$ & $\begin{array}{l}\text { Percent } \\
\text { of Total }\end{array}$ \\
\hline Copper & 119 & 91.5 & 2 & 1.5 & 3 & 2.3 & 4 & 3.1 & 2 & 1.5 & 0 & & 130 & 45.8 \\
\hline Galvanized & 45 & 60.8 & 8 & 10.8 & 6 & 8.1 & 5 & 6.8 & 9 & 12.2 & 1 & 1.4 & 74 & 26.1 \\
\hline Copper and galvanized & 41 & 75.9 & 5 & 9.3 & 1 & 1.9 & 5 & 9.3 & 2 & 3.7 & 0 & & 54 & 19.0 \\
\hline $\begin{array}{l}\text { Copper or galvanized } \\
\text { and plastic }\end{array}$ & 9 & 81.8 & 1 & 9.1 & 0 & & 0 & & 1 & 9.1 & 0 & & 11 & 3.9 \\
\hline Plastic & 3 & 75.0 & 1 & 25.0 & 0 & & 0 & & 0 & & 0 & & 4 & 1.4 \\
\hline Nol applicable & 7 & 70.0 & 0 & & 1 & 10.0 & 1 & 10.0 & 1 & 10.0 & 0 & & 10 & 3.5 \\
\hline Not stated & 1 & 100.0 & 0 & & 0 & & 0 & & 0 & & 0 & & 1 & 0.4 \\
\hline TOTAL & 225 & 79.2 & 17 & 6.0 & 11 & 3.9 & 15 & 5.3 & 15 & 5.3 & 1 & 0.4 & 284 & 100.0 \\
\hline
\end{tabular}

SOURCE: Schreiber et al. (unpublished data, 1976). 
TABLE 4d Distribution of Lead Content of Drinking Water by Type of Piping

\begin{tabular}{|c|c|c|c|c|c|c|c|c|c|c|c|c|}
\hline \multirow[b]{3}{*}{ Pipe Type } & \multicolumn{10}{|c|}{ Lead Concentration, ppb } & & \\
\hline & \multicolumn{2}{|c|}{$0.0-4.9$} & \multicolumn{2}{|c|}{$5.0-9.9$} & \multicolumn{2}{|c|}{$10.0-19.9$} & \multicolumn{2}{|c|}{$20.0-49.9$} & \multicolumn{2}{|c|}{$50.0+$} & \multicolumn{2}{|c|}{ Total } \\
\hline & $N$ & $\begin{array}{l}\text { Per- } \\
\text { cent }\end{array}$ & $N$ & $\begin{array}{l}\text { Per- } \\
\text { cent }\end{array}$ & $N$ & $\begin{array}{l}\text { Per- } \\
\text { cent }\end{array}$ & $N$ & $\begin{array}{l}\text { Per- } \\
\text { cent }\end{array}$ & $N$ & $\begin{array}{l}\text { Per- } \\
\text { cent }\end{array}$ & $N$ & $\begin{array}{l}\text { Percent } \\
\text { of Total }\end{array}$ \\
\hline Copper & 77 & 59.2 & 33 & 25.4 & 15 & 11.5 & 5 & 3.8 & 0 & & 130 & 45.8 \\
\hline Galvanized & 49 & 66.2 & 15 & 20.3 & 4 & 5.4 & 5 & 6.8 & 1 & 1.4 & 74 & 26.1 \\
\hline Copper and galvanized & 33 & 61.1 & 15 & 27.8 & 2 & 3.7 & 4 & 7.4 & 0 & & 54 & 19.0 \\
\hline $\begin{array}{l}\text { Copper or galvanized } \\
\text { and plastic }\end{array}$ & 7 & 63.6 & 2 & 18.2 & 2 & 18.2 & 0 & & 0 & & 11 & 3.9 \\
\hline Plastic & 3 & 75.0 & 0 & & 1 & 25.0 & 0 & & 0 & & 4 & 1.4 \\
\hline Not applicable & 6 & 60.0 & 1 & 10.0 & 2 & 20.0 & 1 & 10.0 & 0 & & 10 & 3.5 \\
\hline Not stated & 1 & 100.0 & 0 & & 0 & & 0 & & 0 & & 1 & 0.4 \\
\hline TOTAL & 176 & 62.0 & 66 & 23.2 & 26 & 9.2 & 15 & 5.3 & 1 & 0.4 & 284 & 100.0 \\
\hline
\end{tabular}

SOURCE: Schreiber et al. (unpublished data, 1976).

TABLE 4e Distribution of Copper Content of Drinking Water by Type of Piping

\begin{tabular}{|c|c|c|c|c|c|c|c|c|c|c|c|c|c|c|}
\hline \multirow[b]{3}{*}{ Pipe Type } & \multicolumn{12}{|c|}{ Copper Concentration, ppm } & & \\
\hline & \multicolumn{2}{|c|}{$0.00-0.05$} & \multicolumn{2}{|c|}{$0.06 \cdot 0.09$} & \multicolumn{2}{|c|}{$0.10-0.19$} & \multicolumn{2}{|c|}{$0.20-0.49$} & \multicolumn{2}{|c|}{$0.50 \cdot 0.99$} & \multicolumn{2}{|c|}{$1.00+$} & \multicolumn{2}{|l|}{ Tota! } \\
\hline & $N$ & $\begin{array}{l}\text { Per- } \\
\text { cent }\end{array}$ & $N$ & $\begin{array}{l}\text { Per- } \\
\text { cent }\end{array}$ & $N$ & $\begin{array}{l}\text { Per- } \\
\text { cent }\end{array}$ & $N$ & $\begin{array}{l}\text { Per- } \\
\text { cent }\end{array}$ & $N$ & $\begin{array}{l}\text { Per- } \\
\text { cent }\end{array}$ & $N$ & $\begin{array}{l}\text { Per- } \\
\text { cent }\end{array}$ & $N$ & $\begin{array}{l}\text { Percent } \\
\text { of Total }\end{array}$ \\
\hline Copper & 47 & 36.2 & 36 & 27.7 & 19 & 14.6 & 18 & 13.8 & 5 & 3.8 & 5 & 3.8 & 130 & 45.8 \\
\hline Galvanized & 59 & 79.7 & 10 & 13.5 & 3 & 4.1 & 2 & 2,7 & 0 & & 0 & & 74 & 26.1 \\
\hline Copper and galvanized & 29 & 53.7 & 10 & 18.5 & 7 & 13.0 & 4 & 7.4 & 2 & 3.7 & 2 & 3.7 & 54 & 19.0 \\
\hline $\begin{array}{l}\text { Copper or galvanized } \\
\text { and plastic }\end{array}$ & 4 & 36.4 & 0 & & 2 & 18.2 & 2 & 18.2 & $i$ & 9.1 & 2 & 18.2 & 11 & 3.9 \\
\hline Plastic & 0 & & 2 & 50.0 & 1 & 25.0 & 1 & 25.0 & 0 & & 0 & & 4 & 1.4 \\
\hline Not applicable & 7 & 70.0 & 2 & 20.0 & 1 & 10.0 & 0 & & 0 & & 0 & & 10 & 3.5 \\
\hline Nor stated & 1 & 100.0 & 0 & & 0 & & 0 & & 0 & & 0 & . & 1 & 0.4 \\
\hline TOTAL & 147 & 51.8 & 60 & 21.1 & 33 & 11.6 & 27 & 9.5 & 8 & 2.8 & 9 & 3.2 & 284 & 100.0 \\
\hline
\end{tabular}

SOURCE: Schreiber et al. (unpublished data, 1976).

TABLE 4f Distribution of Zinc Content of Drinking Water by Type of Piping

\begin{tabular}{|c|c|c|c|c|c|c|c|c|c|c|c|c|c|c|c|c|}
\hline \multirow[b]{3}{*}{ Pipe Type } & \multicolumn{14}{|c|}{ Zinc Concentration, ppm } & & \\
\hline & \multicolumn{2}{|c|}{$0.000-0.050$} & \multicolumn{2}{|c|}{$0.051-0.075$} & \multicolumn{2}{|c|}{$0.076 \cdot 0.100$} & \multicolumn{2}{|c|}{$0.101-0.500$} & \multicolumn{2}{|c|}{$0.501-1.000$} & \multicolumn{2}{|c|}{$1.001 \cdot 2.000$} & \multicolumn{2}{|c|}{$>2.000$} & \multicolumn{2}{|c|}{ Total } \\
\hline & $N$ & $\begin{array}{l}\text { Per- } \\
\text { cenı }\end{array}$ & $N$ & $\begin{array}{l}\text { Per- } \\
\text { cent }\end{array}$ & $N$ & $\begin{array}{l}\text { Per- } \\
\text { cent }\end{array}$ & $N$ & $\begin{array}{l}\text { Per- } \\
\text { cent }\end{array}$ & $N$ & $\begin{array}{l}\text { Per- } \\
\text { cent }\end{array}$ & $N$ & $\begin{array}{l}\text { Per- } \\
\text { cent }\end{array}$ & $N$ & $\begin{array}{l}\text { Per- } \\
\text { ceni }\end{array}$ & $N$ & $\begin{array}{l}\text { Percent } \\
\text { of Total }\end{array}$ \\
\hline Copper & 79 & 60.8 & 8 & 6.2 & 7 & 5.4 & 22 & 16.9 & 10 & 7.7 & 1 & 0.8 & 3 & 2.3 & 130 & 45.8 \\
\hline Galvanized & 18 & 24.3 & 6 & 8.1 & 6 & 8.1 & 25 & 33.8 & 4 & 5.4 & 10 & 13.5 & 5 & 6.8 & 74 & 26.1 \\
\hline Copper and galvanized & 16 & 29.6 & 2 & 3.7 & 6 & 11.1 & 21 & 38.9 & 7 & 13.0 & 1 & 1.9 & 1 & 1.9 & 54 & 19.0 \\
\hline $\begin{array}{l}\text { Copper or galvanized } \\
\text { and plastic }\end{array}$ & 0 & & 0 & & 2 & 18.2 & 4 & 36.4 & 3 & 27.3 & 1 & 9.1 & 1 & 9.1 & 11 & 3.9 \\
\hline Plastic & 1 & 25.0 & 1 & 25.0 & 0 & & 1 & 25.0 & 1 & 25.0 & 0 & & 0 & & 4 & 1.4 \\
\hline Not applicable & 2 & 20.0 & 1 & 10.0 & 0 & & 4 & 40.0 & 1 & 10.0 & 1 & 10.0 & 1 & 10.0 & 10 & 3.5 \\
\hline Not stated & 0 & & 0 & & 0 & & 1 & 100.0 & 0 & & 0 & & 0 & & 1 & 0.4 \\
\hline TOTAL & 116 & 40.8 & 18 & 6.3 & 21 & 7.4 & 78 & 27.5 & 26 & 9.2 & 14 & 4.9 & 11 & 3.9 & 284 & 100.0 \\
\hline
\end{tabular}

SOURCE: Schreiber et al. (unpublished data, 1976). 
or groundwater composition may be misleading, if we ignore the changes wrought by treatment on the chemistry of a particular water source.

The chemical form of any element in natural water or water entering a treatment plant affects the efficiency of its removal. For example, stable water soluble complexes of metals with either organic or inorganic liquids can pass through a treatment plant unaffected. Sand filters are generally less effective for metal removal than treatments involving coagulation. Chlorination of water following other treatment will often degrade organic complexes of metals and again alter availability.

As water leaves the plant and enters the distribution system, it is again subject to concentration and species variation through interaction with other water constituents and reactions with the distribution system. Calcium and magnesium salts associated with water hardness are excellent coprecipitators of divalent ions such as zinc, cadmium, and lead and often accumulate on the wall of pipes in the distribution system. Later, use of an operational home water softener will remove essentially all divalent elements present in finished water.

The trace element content of surface water, and hence drinking water, is extremely variable on a seasonal basis (Angino et al., 1969). Some of these elements may be removed by various treatment processes. Iron, nickel, cobalt, cadmium, lead, zinc, and copper are most likely to be removed under certain conditions, while lithium, selenium, molybdenum, and arsenic are apt to pass into the delivery system pipes relatively untouched. For the latter components, knowledge of natural concentrations is important. Again a word of caution-it is possible that the trace element chemistry of the water as it emerges from a tap may bear little relation chemically to the water that went into the delivery system.

\section{CONTAMINATION IN WATER SUPPLY SYSTEMS AND TAP WATER}

Few nationwide data exist on the quality of the water as it comes from the tap, except for the Environmental Protection Agency's Interstate Carrier Water Supply data (U.S. Environmental Protection Agency, 1973c). This agency's data base covers a large population, but a small geographical area. Unfortunately, this means that although a water plant analysis is performed well, little is known about the changes in the chemical quality of the water as it moves through the distribution system. Such changes can affect the chemistry of the water appreciably. The metals may either precipitate or be dissolved from the pipes in the system. The latter condition is most apt to be present in areas of soft acidic water (i.e., water with a low $\mathrm{pH}$ ) and dissolved salts (see Table 4).
Reliable data on changes in water quality, as water is pumped through a distribution system, are lacking. The study by Craun and McCabe (1976), discussed in the next section, sheds some light on this problem. For example, heating converts $\mathrm{HCO}_{3}$ to $\mathrm{CO}_{3}$, which combines with calcium, if present in the water, to precipitate $\mathrm{CaCO}_{3}$ in pipes and cooking utensils. Calcium sulfate and silica comprise a portion of many incrustations found in home plumbing.

Many trace elements can occur in drinking water. The maximum permissible chemical concentrations in drinking water of selected toxic substances are given in Table 3. A major source of metal contamination in drinking water is the water supply system itself. This begins with the chemicals used in the water treatment. Copper is often added for algae control in reservoirs; other treatment chemicals contain trace metals that contribute to the trace metals found in the water. Corrosion of the distribution system and household plumbing adds to the metal content of drinking water (see Camp, 1963, pp. 145-204 and accompanying tables).

An industrial health survey was conducted in Chicago in 1968 (McCabe, 1974). Water samples collected as part of this survey provided an opportunity to determine the metal content of a large number of samples from a single system. Composite samples were collected at the treatment plants, and these results were compared with $\mathbf{5 5 0}$ grab samples collected from the distribution system, to give an indication of metal pickup. The metals picked up and percent of samples showing an increase were as follows: cadmium, 15; chromium, 17; cobalt, 10; copper, 28; iron, 39; lead, 20; manganese, 32; nickel, 34; silver, 15; and zinc, 67. Except for lead, the pickup of metals in the Chicago system did not result in samples exceeding the drinking water standards. For lead, 0.7 percent of the samples exceeded the limit. However, when corrosive water is distributed, the problem can be more serious.

TABLE 5 Water Quality Parameters Measured in Treated Water at the Source

\begin{tabular}{lcc}
\hline Parameters & Boston, $\mathrm{MDC}^{*}$ & Seattle \\
\hline $\mathrm{pH}$ & 6.7 & 5.5 \\
Hardness (as $\mathrm{CaCO}_{3}$ ) & $14 \mathrm{ppm}$ & $6 \mathrm{ppm}$ \\
Total dissolved solids (TDS) & $50 \mathrm{ppm}$ & no data \\
Alkalinity (as $\mathrm{CaCO}_{3}$ ) & $8 \mathrm{ppm}$ & $2 \mathrm{ppm}$ \\
Chlorides & $12 \mathrm{ppm}$ & $1.7 \mathrm{ppm}$ \\
Calcium & no data & $2.1 \mathrm{ppm}$ \\
Magnesium & no data & $0.3 \mathrm{ppm}$ \\
Conductivity & no data & $20 \mu \mathrm{mho}$ \\
\hline
\end{tabular}

* MDC is mean daily concentration.

SOURCES: Dangel (1975) and Craun and McCabe (1976). 
Distribution studies conducted in Seattle (Dangel, 1975) and Boston illustrate the effect of corrosive water on tap water quality (Craun and McCabe, 1976). Both Boston and Seattle use impounded surface water and provide chlorination as the only treatment (except that Seattle also fluoridates with fluorosilicic acid $\left(\mathrm{H}_{2} \mathrm{SiF}_{6}\right)$ ). The hardness and alkalinity of these waters are remarkably low, and the $\mathrm{pH}$ is on the acidic side. The dissolved oxygen content of Seattle's water approaches saturation. The distributed waters are excellent solvents and exhibit aggressive corrosion tendencies. Table 5 gives the water quality parameters that were measured in treated water at the source.

In Seattle, that part of the distribution system served by the Tolt River was sampled. Samples were collected from 31 points in the distribution system, primarily from household taps, but some samples were collected from major transmission mains. Two types of samples were collected early in the morning for comparison, a standing and a running sample. Standing samples were the first water to run out of the faucet and represented water with a long residence time in the household plumbing and service line. Running samples were collected afterward, ensuring that the house lines were well flushed and represented water from the mains. This same procedure was followed in Boston, and running and standing samples were collected at 54 households in the Beacon Hill area. Standing samples that had a higher concentration than the running sample collected at the same point (after considering analytical variability) are used as evidence of metal pickup. The percentage of samples with pickup is given in Table 6 .

The pickup of metal in these systems resulted in limits being exceeded, as shown in Table 7 .

The difference in metal pickup between these systems is most likely related to the type of plumbing material and service lines in use. In Boston a high percentage of homes sampled had lead service pipes, whereas in Seattle, copper and galvanized iron were more commonly used. No lead pipes were reported in Seattle, and it is assumed

TABLE 6 Percentage of Samples with Pickup

\begin{tabular}{lll}
\hline & Boston & Seattle \\
\hline Cadmium & 13 & 68 \\
Chromium & 39 & no data \\
Copper & 48 & 55 \\
Iron & 52 & 86 \\
Lead & 50 & 95 \\
Manganese & no data & 86 \\
Zinc & 35 & 95 \\
\hline
\end{tabular}

SOURCES: Dangel (1975) and Craun and McCabe (1976).
TABLE 7 Percentage of Homes with a Sample Exceeding EPA Drinking Water Standards

\begin{tabular}{lcc}
\hline & Boston & Seattle \\
\hline Cadmium & 0 & 7 \\
Chromium & 0 & no data \\
Copper & 19 & 24 \\
Iron & 9 & 76 \\
Lead & 65 & 24 \\
Manganese & no data & 5 \\
Zinc & 0 & 10 \\
\hline
\end{tabular}

SOURCES: Dangel (1975) and Craun and McCabe (1976).

that the source of lead there is from the solder used to join copper piping. The work of Crawford and Clayton (1973) indicates considerable solubility of lead in hard waters as well as soft.

\section{METAL INTAKE}

The Community Water Supply Survey (cwss) collected water samples at the consumers' tap and covered 969 water systems in 9 geographic areas around the country (McCabe et al., 1970). Although this is not a totally representative sample of the United States, its wide coverage should provide an estimate of consumers' metal intake from water supplies (Table 8).

Most investigators feel that the major source of trace metals for man is his food intake. A recent study of trace metals intake from food used the total diets for institutionalized children from 9 to 12 years of age. If a comparison is made between this study and the Cwss, it is found that the largest proportion of trace element intake from water compared with food is for zinc. But. this is only 4.3 percent. Next is cadmium at 3.3 percent, and then manganese at 2.8 percent. The cobalt intake from water was only 0.4 percent; the chromium intake was 0.8 percent. It must be remembered, however, that chromium does not regularly occur in water.

If the average content of metals in water is to have any health effect on man, it must be related to the different forms of the metal (speciation) that occur in water from the speciation of that same metal as it occurs in food. It is possible that the physiological availability may then be different, but this has not been adequately demonstrated.

Apparent correlations of water hardness with certain cardiovascular problems should be viewed with some skepticism. Data presented by Perry et al. (1974) suggest a strong relation between cadmium and hypertension and an inhibition of the cadmium effect by water hardness. The effect of water hardness on cadmium-induced health problems can be logically attributed to the tendency of 
TABLE 8 Estimated Average Intake of Metals by Consumers of Water from Community Water Supplies

\begin{tabular}{lccc}
\hline & $\begin{array}{l}\text { Average } \\
\text { Concentration, } \\
\mu \mathrm{g} / 1\end{array}$ & $\begin{array}{l}\text { Intake at } \\
2 \text { 1/day, } \\
\mu \mathrm{g}\end{array}$ & $\begin{array}{l}\text { Percent of } \\
\text { Samples with } \\
\geqslant 1 \mu \mathrm{g} / 1\end{array}$ \\
\hline Cadmium & 1.3 & 3 & 63 \\
Chromium & 2.3 & 5 & 11 \\
Cobalt & 2.2 & 4 & 62 \\
Copper & 134.5 & 270 & 99 \\
Iron & 166.5 & 330 & 99 \\
Lead & 13.1 & 26 & 74 \\
Manganese & 22.2 & 44 & 78 \\
Nickel & 4.8 & 10 & 78 \\
Silver & 0.8 & 2 & 23 \\
Zinc & 193.8 & 390 & 100 \\
\hline
\end{tabular}

- Intake of $21 /$ day is equivalent to the proverbial 8 glasses of water per day.

SOURCE: McCabe (1974).

carbonates and phosphates, and other anions often associated with water hardness, to precipitate cadmium, thus either effectively removing it or converting it to an unavailable chemical form. For example, calculations by Morel et al. (1973) show that $10^{-6} \mathrm{M}$ (molar) cadmium in $10^{-3} \mathrm{M}$ carbonates $(\mathrm{pH}=7)$ will exhibit a theoretical free cadmium ion concentration of about $5 \times 10^{-11} \mathrm{M}$. Both experimental studies and additional theoretical studies are needed to prove this hypothesis.

\section{EFFECTS OF STORAGE ON TREATED WATER}

Little detailed research has been done on the chemical composition effects of allowing water to stand. However, for the major elements present in drinking water, certain changes are predictable. With a rise in $\mathrm{pH}$ to above 8.5 and a rise in temperature, precipitation of $\mathrm{CaCO}_{3}$ can occur; under certain $\mathrm{pH}$ and temperature conditions, even gypsum and silica precipitate. This action will cause scavenging of selected trace metals (such as iron, manganese, nickel, cadmium, zinc, and lead) from solution and removal of some of the $\mathrm{CO}_{3}$, calcium, and magnesium from the system. Coprecipitation will have little effect on such constituents as arsenic, selenium, molybdenum, lithium, $\mathrm{NO}_{3}, \mathrm{PO}_{4}$, and chloride. Similar precipitation reactions can occur in the distribution system (pipes) itself.

Chemical changes in standing water are clearly affected by whether or not the container is open to the air. If open, an equilibrium will likely be set up between atmospheric $\mathrm{CO}_{2}$ and $\mathrm{O}_{2}$ and $\mathrm{CO}_{2}$ and $\mathrm{O}_{2}$ in the water. These reactions will have no effect on the magnesium, sodium, potassium, and chloride content of the water.
As a whole, chemical changes in standing water are not major. These changes are not likely to be detrimental to the water quality or one's health. The hardness and alkalinity of the water will be changed by

$$
\mathrm{CaCO}_{3}, \mathrm{CaSO}_{4} \cdot 2 \mathrm{H}_{2} \mathrm{O} \text {, and } \mathrm{SiO}_{2}
$$

precipitation. Again, the changes are not likely to be of critical importance to health.

\section{SUMMARY}

Well-defined chemical changes in water composition occur at all stages in the water distribution system, starting with water treatment itself and proceeding to distribution, storage, and delivery at the tap. Major changes in water hardness are commonly generated at the water treatment stage, either to increase it (for pipe protection) or to decrease it to make water less damaging to clothes and more palatable.

\section{MANUALS OF ANALYTICAL METHODS}

- American Public Health Association-American Water Works Association-Water Pollution Control Federation. 1975. Standard Methods for Examination of Water and Wastewater. 14th ed., American Public Health Association, Washington, D.C. 1193 pp.

- American Society for Testing and Materials. 1974. Annual Book of ASTM Standards. Part 31. Water. Philadelphia, Pa. 1130 pp.

- Association of Official Analytical Chemists. 1970. Official Methods of Analysis of AOAC. 11th ed. W. Horwitz, ed. Association of Official Analytical Chemists, Washington, D.C. 1015 pp.

- Brown, E., M. W. Skougstad, and M. J. Fishman. 1970. Methods for collection and analysis of water samples for dissolved minerals and gases, Chap. A1 in Book 5 of Techniques of Water Resources Investigations of the U.S. Geological Survey. U.S. Government Printing Office, Washington, D.C., 160 pp.

- Camp, T. R. 1963. Water and Its Impurities. Reinhold, New York. 355 pp.

- Clark, J. W., W. Viessman, Jr., and M. J. Hammer. 1971. Water Supply and Pollution Control. 2nd ed. International Textbook, Scranton, Pa. 661 pp.

- Rainwater, F. H., and L. L. Thatcher. 1960. Methods for collection and analysis of water samples. U.S. Geol. Surv. Water Supply Pap. 1454, 301 pp.

- U.S. Environmental Protection Agency. 1972. Handbook for Analytical Quality Control in Water and Wastewater Laboratories. Office of Technology Transfer, Washington, D.C. 98 pp. 
- U.S. Environmental Protection Agency. 1974. Methods for Chemical Analysis of Water and Wastes. EPA 625/6-74-003. Office of Technology Transfer, Washington, D.C. 298 pp.

\section{REFERENCES}

American Society for Testing and Materials. 1972. Annual Book of ASTM Standards. Part 23. Water: Atmospheric analysis. Philadelphia, Pa. 1012 pp.

American Society for Testing and Materials. 1974. Annual Book of ASTM Standards. Part 31. Water. Philadelphia, Pa. 1130 pp.

Ángino, E. E., O. K. Galle, and T. C. Waugh. 1969. Fe, Mn, Ni, Co, Sr, $\mathrm{Li}, \mathrm{Zn}$, and $\mathrm{SiO}_{2}$ in streams of the lower Kansas River basin. Water Resour. Res. 5:698-705.

Bevis, H.A. 1960. Significance of radioactivity in water supply and - treatment. J. Am. Water Works Assoc. 52(7):841-846.

Brown, E., M. W. Skougstad, and M. J. Fishman. 1970. Methods for collection and analysis of water samples for dissolved minerals and gases. Chap. Al in Book 5 of Techniques of Water Resources Investigations of the U.S. Geological Survey. U.S. Government Printing Office, Washington, D.C. $160 \mathrm{pp}$.

Camp, T. R. 1963. Water and Its Impurities. Reinhold, New York. Pp. $80-92$.

Clark, J. W., W. Viessman, Jr., and M. J. Hammer. 1971. Water Supply and Pollution Control. 2nd ed. International Textbook, Scranton, Pa. Pp. 383-454.

Craun, G. F., and L. J. McCabe. 1976. Review of the causes of waterborne-disease outbreaks. J. Am. Water Works Assoc. 65:74.

Crawford, M. D., and D. G. Clayton. 1973. Lead in bones and drinking water in towns with hard and soft water. Br. Med. J. 2:21-23.

Dangel, R.A. 1975. Study of Corrosion Products in the Seattle Water Department Tolt Distribution System. EPA 670/2-75-036. U.S. Environmental Protection Agency, National Environmental Research Center, Cincinnati, Oh. 22 pp.

Durfor, C. N., and E. Becker. 1964. Public water supplies of 100 largest cities in the United States, 1962. U.S. Geol. Surv. Water Supply Pap. 1812:45-68.

Geraghty, J. J., D. W. Miller, V.. Van der Leeden, and F. L. Troise. 1973. Water Atlas of the United States. Water Information Center, Inc., Port Washington, New York. 194 pp.

Höll, K. 1972. Water: Examination, Assessment, Conditioning, Chemistry, Bacteriology, Biology. Walter de Gruyter, Berlin.
McCabe; L. J. 1974. Problem of trace metals in water supplies: An overview. In Proceedings, Sixteenth Water Quality Conference: Trace Metals in Water Supplies: Occurrence, Significance, and Control. Bull. 71. University of Illinois, Urbana-Champaign. $139 \mathrm{pp}$.

McCabe, L. J., J. M. Symons, R. D. Lee, and G. G. Robeck. 1970. Survey of community water supply systems. J. Am. Water Works Assoc. 62:670.

Morel, R., R. E. McDuff, and J. J. Morgan. 1973. Interactions and chemostasis in aquatic chemical systems: Role of $\mathrm{pH}, \mathrm{PE}$, solubility, and complexation. In Trace Metals and Metal Organic Interactions in Natural Waters. P. C. Singer, ed. Ann Arbor Science Pub., Inc., Ann Arbor, Mich. Pp. 157-200.

NRC Subcommittee on the Geochemical Environment in Relation to Health and Disease. 1978. Geochemistry and the Environment. Vol. III. Distribution of Trace Elements Related to the Occurrence of Certain Cancers, Cardiovascular Diseases, and Urolithiasis. Captiva Island Workshop, H. C. Hopps, Chairman. National Academy of Sciences, Washington, D.C. $200 \mathrm{pp}$.

Neri, L. C., D. Hewitt, and G. B. Schreiber. 1974. Can epidemiology elucidate the water story? Am. J. Epidemiol. 99:75-88.

Perry, H. M., Jr., E. F. Perry, and M. W. Erlanger. 1974. Reversal of cadmium-induced hypertension by selenium or hard water. In Proceedings of the Eighth Annual Conference on Trace Substances in Environmental Health, June 11-13, 1974. D. D. Hemphill, ed. University of Missouri, Columbia. Pp. 51-57.

Seelig, M. S., and H. A. Heggtveit. 1974. Magnesium interrelationships in ischemic heart disease: A review. Am. J. Clin. Nutr. 27:59-79.

Sharrett, A. R., and M. Feinleib. 1975. Water constituents and trace elements in relation to cardiovascular disease. Prev. Med. 4:20-36.

U.S. Environmental Protection Agency. 1973a. Water Quality Criteria 1972. EPA R3 73 033. U.S. Government Printing Office, Washington, D.C. 594 pp.

U.S. Environmental Protection Agency. 1973b. Manual of Individual Water Supply Systems. Water Supply Division. U.S. Government Printing Office, Washington, D.C. Pp. 73-92:

U.S. Environmental Protection Agency. 1973c. Chemical Analysis of Interstate Carrier Water Supply Systems. 82 pp. (NTIS PB-257 600.)

U.S. Environmental Protection Agency. 1974. Methods for Chemical Analysis of Water and Wastes. EPA 625/6-74-003. Office of Technology Transfer, Washington, D.C. 298 pp. (NTIS PB-211 968.)

U.S. Environmenta! Protection Agency. 1976. National Interim Primary Drinking Water Regulations. Office of Water Supply. EPA 570/9-76-003. P. 5. (NTIS PB-267 630.)

Water Supply Subcommittee MWPS-14. 1968. Private Water Systems. Engineering Extension Department, Kansas State University, Manhattan. Pp. 49-50. 


\title{
Geology and Water Characteristics
}

\author{
ROBERT G. CORBETT
}

The major dissolved ionic species in groundwater and surface water include calcium, magnesium, sodium, potassium, bicarbonate, carbonate, sulfate, and chloride. These eight geochemically significant constituents comprise most of the species in solution. The proportion of these constituents in a natural solution provides the basis for naming the water type. Water characteristics determined in many studies include the major elements mentioned above, plus some minor or trace elements, and certain other chemical, physical, or biological properties (see Table 9).

Hardness, which is defined in the previous chapter, is an important characteristic related mostly to the presence of calcium and magnesium. The Panel was asked to evaluate the alleged relation between water hardness and the incidence of cardiovascular disease.

References to properties and characteristics, other than the major dissolved constituents and hardness, are limited for a variety of reasons. Vitousek (1977) discusses the relation of biologically significant elements in streams to the natural environmental controls.

\section{WATER TYPES}

To provide a basis for comparison of water types and to relate them to geologic environments, a graphic means of presenting data and appropriate terminology may be useful.

The Piper diagram is a multiple-trilinear diagram for graphic representation of the major chemical constituents of water. It effectively portrays analytical data of dissolved constituents for detailed geochemical study (Piper, 1944, p. 914). Similar analytical techniques were developed by Hill (1942) and Langelier and Ludwig (1942). The model used here is a modification by Hem (1970).

The diagram consists of three distinct fields (see Figure 2). The two lower fields are cation and anion triangular composition diagrams, left and right, respectively. Cations and anions are plotted in terms of percentage of milliequivalents per liter. The upper apex of the cation triangular diagram represents 100 percent magnesium, the left apex represents 100 percent calcium, and the right apex represents 100 percent of the sum of sodium and potassium. The upper apex of the anion triangular. diagram represents 100 percent sulfate, the right apex represents 100 percent chloride (shown as $\mathrm{Cl}$ ), and the left apex represents 100 percent of the sum of bicarbonate and carbonate.

The larger diamond-shaped field is also scaled into 100 parts. The point plotted in each triangular field is then projected into the diamond-shaped field. The point where the dashed projection lines intersect denotes the proportions of the major ionic constituents of the natural solution. Total concentration of the eight components (on a milligrams per liter or parts per million basis) is indicated by the size of the circle in the diamond-shaped field (Piper, 1944). Theoretically, cations and anions each make up 50 percent (on a chemical-equivalent basis) of the dissolved constituents, and their summation in the diamond-shaped field adds to 100 percent of the chemical constituents (Hem, 1970, p. 264). In standard practice, 
TABLE 9 Water Quality Parameters

\begin{tabular}{|c|c|}
\hline Water Quality Parameter & $\begin{array}{l}\text { Commonly } \\
\text { Determined by } \\
\text { the USGS }\end{array}$ \\
\hline Silica $\left(\mathrm{SiO}_{2}\right)$ & $\mathbf{X}$ \\
\hline Iron $(\mathrm{Fe})$ & $\mathrm{X}$ \\
\hline Manganese (Mn) & $X$ \\
\hline Calcium (Ca) & $\mathrm{X}$ \\
\hline Magnesium (Mg) & $\mathrm{X}$ \\
\hline Sodium $(\mathrm{Na})$ & $\mathrm{X}$ \\
\hline Potassium (K) & $\mathrm{X}$ \\
\hline Bicarbonate $\left(\mathrm{HCO}_{3}\right)$ & $\mathrm{X}$ \\
\hline Carbonate $\left(\mathrm{CO}_{3}\right)$ & $\mathrm{X}$ \\
\hline Sulfate $\left(\mathrm{SO}_{4}\right)$ & $\mathbf{X}$ \\
\hline Chloride $(\mathrm{Cl})$ & $\mathrm{X}$ \\
\hline Phosphate $\left(\mathrm{PO}_{4}\right)$ & $\mathbf{X}$ \\
\hline Fluoride (F) & $\mathbf{X}$ \\
\hline Nitrogen & \\
\hline Nitrate $\left(\mathrm{NO}_{3}\right)$ & $\mathrm{X}$ \\
\hline Nitrite $\left(\mathrm{NO}_{2}\right)$ & - \\
\hline Ammonia $\left(\mathrm{NH}_{3}\right)$ & - \\
\hline Organic & - \\
\hline Dissolved solids & $\mathrm{x}$ \\
\hline Minor elements* & $\mathbf{X}$ \\
\hline Hardness (calcium, magnesium) & $\mathbf{x}$ \\
\hline Radiochemical $(\alpha, \beta, \mathrm{Ra}, \mathrm{U})$ & - \\
\hline $\mathrm{pH}$ & $\mathbf{X}$ \\
\hline Color & $\mathbf{X}$ \\
\hline Odor & - \\
\hline Turbidity & - \\
\hline Temperature & $\mathrm{X}$ \\
\hline Detergents & $\mathrm{X}$ \\
\hline \multicolumn{2}{|c|}{ Coliform bacteria (most probable number per } \\
\hline $100 \mathrm{ml})$ & - \\
\hline Total plate count (counts per $100 \mathrm{ml}$ ) & - \\
\hline Dissolved oxygen & - \\
\hline Biochemical oxygen demand & - \\
\hline Free carbon dioxide & - \\
\hline
\end{tabular}

* Includes aluminum, barium, beryllium, boron, chromium, cobalt, copper, lead, lithium, molybdenum, nickel, rubidium, silver, strontium, tin, titanium, vanadium, and zinc.

however, only the proportions (instead of the amounts) of cations and anions are shown as points in the triangular diagrams.

\section{CONSTRUCTION OF A SIMPLE PIPER DIAGRAM}

The example chosen also serves as a reference to the weighted mean composition of river water in the world (Livingstone, 1963). A tabulation in parts per million of the concentration of major constituents in such water is as follows:

$\begin{array}{lc}\text { Cations } & \\ \text { Calcium }(\mathrm{Ca}) & 15.0 \\ \text { Magnesium }(\mathrm{Mg}) & 4.1 \\ \text { Sodium }(\mathrm{Na}) & 6.3 \\ \text { Potassium }(\mathrm{K}) & 2.3 \\ \text { Anions } & \\ \text { Chloride }(\mathrm{Cl}) & 7.8 \\ \text { Sulfate }\left(\mathrm{SO}_{4}\right) & 11.2 \\ \text { Carbonate }\left(\mathrm{CO}_{3}\right) & 0 \\ \text { Bicarbonate }\left(\mathrm{HCO}_{3}\right) & 58.4 \\ \text { TOTAL } & 105.1\end{array}$

(Carbonate as a species becomes significant as the $\mathrm{pH}$ approaches 8.3).

The first step is to convert data from a parts per million (or the nearly identical milligrams per liter) value to a milliequivalents per liter basis, which requires taking into account the formula weight and the ionic charge of the species involved. The simplest conversion factors for these species are the reciprocals of the combining weights of the appropriate ions:

$\begin{array}{cc}\text { Cations } & \\ \mathrm{Ca} & 0.04990 \\ \mathrm{Mg} & 0.08226 \\ \mathrm{Na} & 0.04350 \\ \mathrm{~K} & 0.02557 \\ \text { Anions } & \\ \mathrm{Cl} & 0.02821 \\ \mathrm{SO}_{4} & 0.02082 \\ \mathrm{CO}_{3} & 0.03333 \\ \mathrm{HCO}_{3} & 0.01639\end{array}$

In turn, each species concentration is multiplied by the appropriate conversion factor, with the following results in milliequivalents per liter:

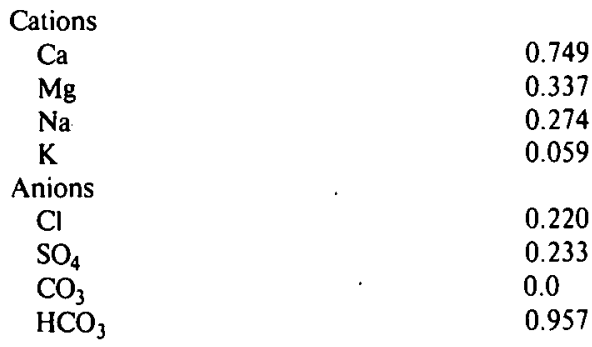

The next step is to combine sodium and potassium in milliequivalents per liter so that they may be treated as a unit, and then combine carbonate and bicarbonate treated as a unit:

$$
\begin{array}{ll}
\mathrm{Na}+\mathrm{K} & 0.333 \\
\mathrm{CO}_{3}+\mathrm{HCO}_{3} & 0.957
\end{array}
$$

Next, the percentage of each of the now three cation units and then the percentage for each of the anion units 
FIGURE 2 Mean composition of river waters of the world (in percent of milliequivalents per liter). SOURCE: Data from Livingstone (1963).

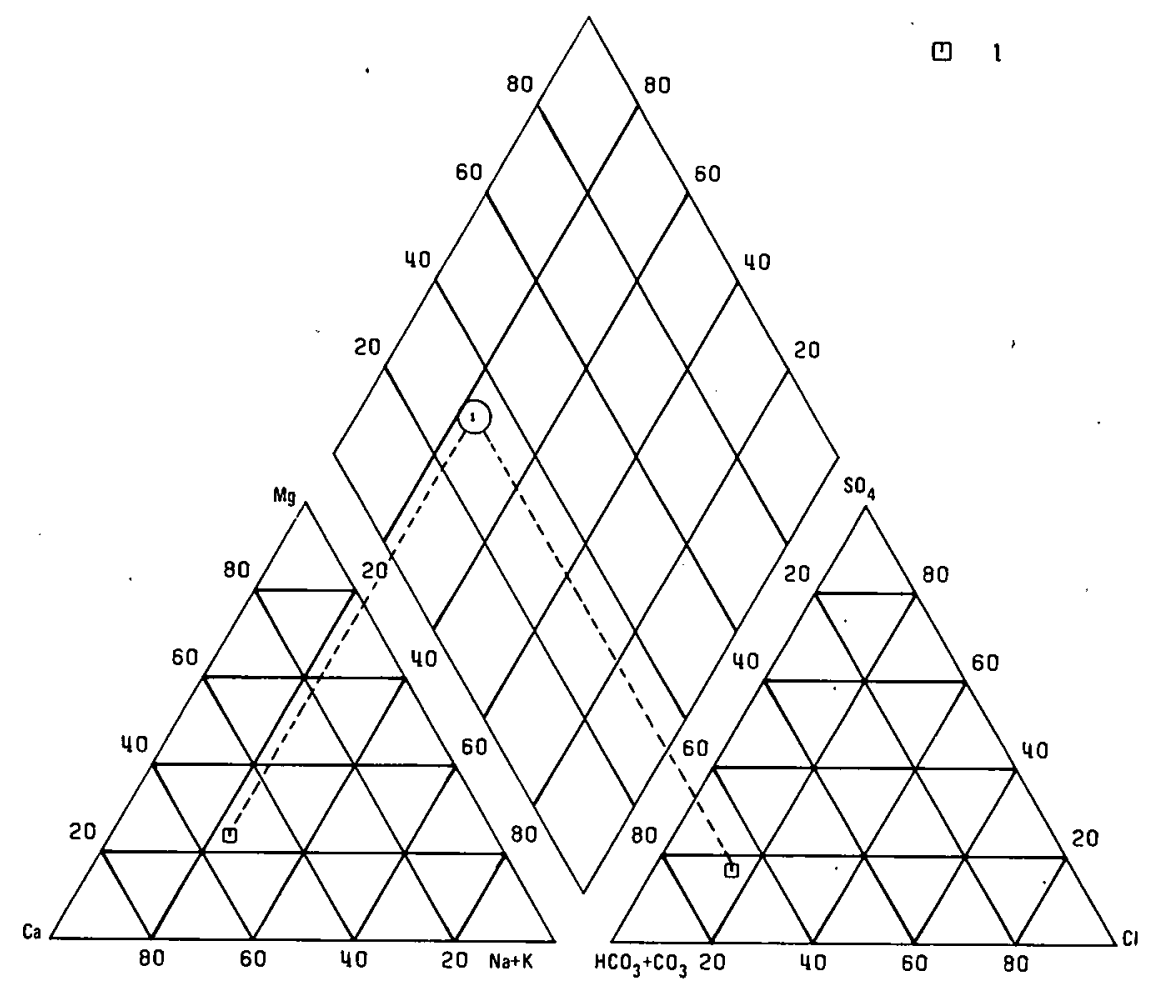

is calculated. This is accomplished, of course, by taking the sum of the milliequivalents per liter for the cations and dividing it into the milliequivalents per liter value for each; multiplying the results by 100 ; and then doing the same for the anions:

$\begin{array}{ll}\text { Cations } & \\ \mathrm{Ca} & (0.749 / 1.419) \times 100=52.8 \\ \mathrm{Mg} & (0.337 / 1.419) \times 100=23.7 \\ \mathrm{Na}+\mathrm{K} & (0.333 / 1.419) \times 100=23.5 \\ \text { Anions } & \\ \mathrm{Cl} & (0.220 / 1.410) \times 100=15.6 \\ \mathrm{SO}_{4} & (0.223 / 1.410) \times 100=16.5 \\ \mathrm{CO}_{3}+\mathrm{HCO}_{3} & (0.957 / 1.410) \times 100=67.9\end{array}$

The point representing the percentage of the three cation units is plotted on a standard three-component diagram, in which calcium is the lower left apex, magnesium is the upper apex, and the sum of sodium and potassium is the lower right apex. A point is plotted on an adjacent threecomponent diagram for the anions, with the sum of carbonate and bicarbonate as the lower left apex, sulfate the upper apex, and chloride the lower right apex (Figure 2).

Next, the cation point is projected into the diamondshaped field along a line parallel to the upper left and lower right sides of the diamond. Similarly, the anion point is projected into the diamond-shaped field along a line parallel to the lower left and upper right sides of the diamond-shaped field. These two projection lines intersect at a point, which on Figure 2 is represented by point 1. A circle, the area of which is proportional to the total parts per million of the eight components, is described about point 1 . This completes the construction of a Piper diagram containing a single point in the diamond-shaped field.

Piper diagrams are used in various ways. The simplest is merely to display data to represent distinctions among individual water samples. One could, for the sake of comparison, portray the average composition of streams of the world, the average composition of ocean water, and the average composition of rainfall on one diagram.

A fairly recent and appealing modification of the Piper diagram involves the use of the three-component cation and anion diagrams to classify a sample as a water type. The water type is named for the dominant cation and dominant anion, defined as constituting more than 50 percent of the cations and 50 percent of the anions on a milliequivalents per liter basis.

This is accomplished graphically by joining the midpoints of each side of each triangular field, thus inscribing an inverted equilateral triangle, which divides each triangular diagram into four smaller triangles. In the instance of the cation triangle, the lower left triangle is the area of calcium dominance; the upper triangle, magnesium dominance; and the lower right triangle, sodium and/or potassium dominance. The centrally 
positioned triangle is the area of no dominant cation, which is explained below (see Figure 3).

A water type is easily named, based on the positioning of the points in the cation and anion triangles. Unless there are no dominant cations or anions, the water type is named for the dominant cation (calcium, magnesium, sodium and/or potassium) followed by a hyphen and a similar term selected from anion-field possibilities (sulfate, chloride, bicarbonate and/or carbonate). For example, in the river water problem described earlier, the water is clearly recognizable as a calcium-bicarbonate type. When a water type plots in the Piper diagram in the no-dominant-cation or no-dominant-anion fields, it indicates that on a percentage milliequivalents per liter basis, no ion is present in an amount greater than 50 percent. In such instances, where one cation and one anion are not dominant, as many as four descriptive names, such as calcium-magnesium-bicarbonate-sulfate, may be used. Here, the percentage milliequivalents per liter of calcium, although less than 50 percent, exceeds that of magnesium (as well as those of sodium and potassium), and bicarbonate, although less than 50 percent, exceeds sulfate (as well as chloride). Thus a water type may be given by 0,1 , or 2 cation names and/or 0,1 , or 2 anion names (see Feth et al., 1965).

Another use of Piper diagrams involves samples arrayed either on a time-based sequence or on the basis of spatial arrangement, such as downdip in an aquifer or downstream in a river. Such an array demonstrates sequential changes in the data, if any, more recognizably than in tabular form.

\section{THE HYDROLOGIC CYCLE AND WATER QUALITY}

The oceans are the great reservoirs of water on earth. Seawater comprises over 98 percent of the mass of the hydrosphere (Mason, 1958, p. 184). Except for desalination plants, which use seawater as a raw water source, man's dependence on the oceans for his drinking water supply is indirect, in that 71 percent of the earth's surface covered by oceans is relied upon to provide, through evaporation, water vapor, which falls on the land. The influence of the oceans on the composition of rainfall can be important. In areas of arid climate and interior drainage, there is a tendency for the rain, commonly a very dilute sodium-chloride water type, to contribute toward the buildup of salts in the soil that results from chemical weathering and evaporation. In humid climates, leaching precludes evaporative buildup of salts in the soil and also removes products of chemical weathering between water and rock and soil. Consequently, the

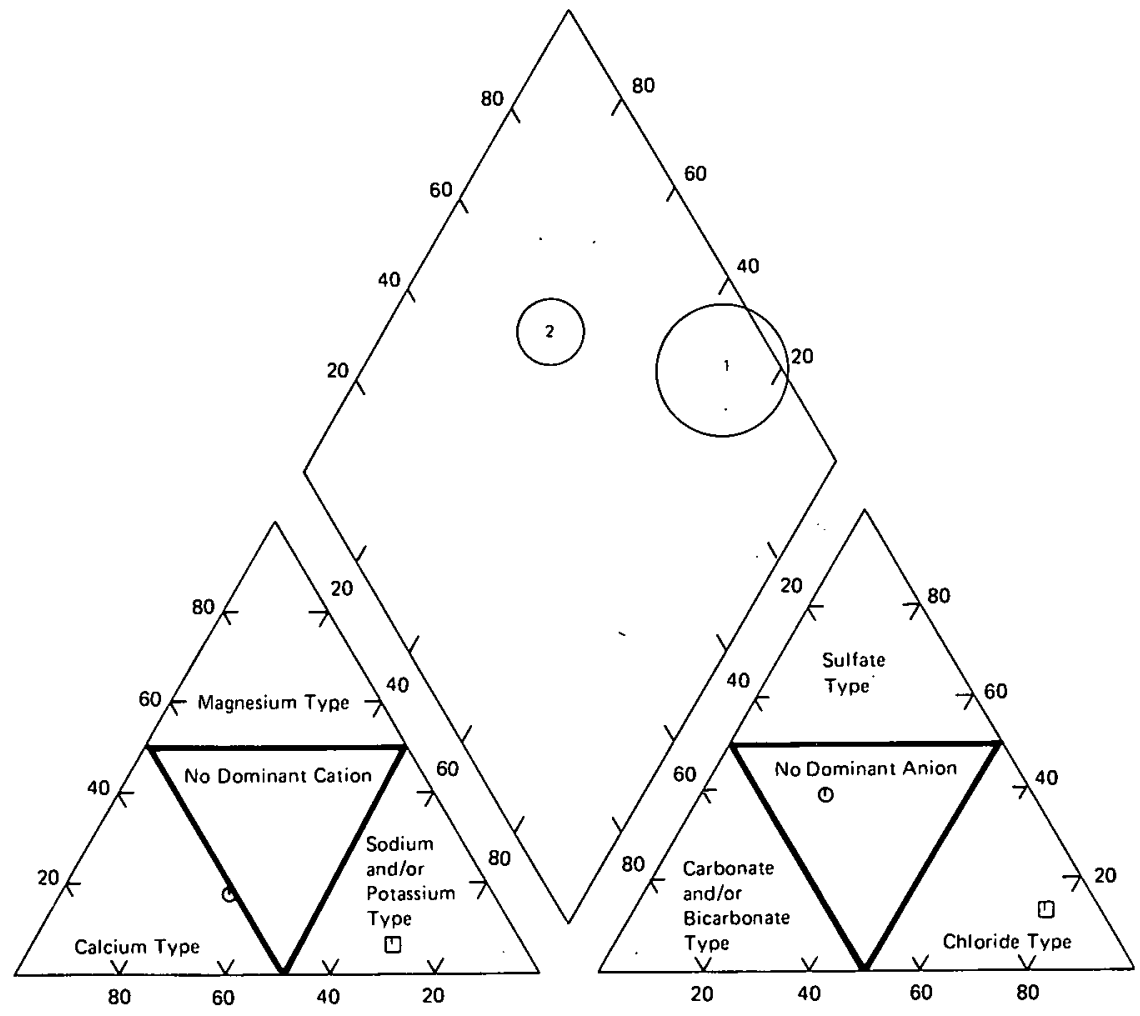

FIGURE 3 Piper diagram showing water types. SOURCE: Corbett and Manner (1975). 


\section{GEOCHEMISTRY OF WATER IN RELATION TO}

composition of the rainfall is subordinate in controlling the composition of water that runs off in streams or infiltrates the soil and rock.

In Table 10 estimates of the quantities, by environment, of the freshwater available in the 48 conterminous United States are given by Mack (1971, pp. 9-10).

Also, groundwater sources have become more important in recent years. Surface water sources are still dominant in total U.S. water use east of the Mississippi River. Georgia, Florida, Mississippi, and Vermont are the only eastern states in which groundwater exceeds 10 percent of the total water used. In contrast, groundwater supplies more than 10 percent of the water used in all but two states west of the Mississippi-Montana and Wyoming. Statistics from 1970 indicate that 50 percent or more of the water used in Arizona, New Mexico, South Dakota, Nebraska, Kansas, Oklahoma, and Arkansas came from groundwater (Murray and Reeves, 1970).

In a survey of the public water supplies of the 100 largest cities serving 34 percent of the U.S. population in 1962, Durfor and Becker (1964) tabulate 67 cities that use only surface water, 20 that use only groundwater, and 14 cities that use a combination of surface water and groundwater.

Per capita use of water in the United States has been increasing, although there are both seasonal and geographic variations.

\section{CHEMICAL NATURE OF PRECIPITATION}

According to Carroll (1962), "Rainfall has a complex composition that varies from place to place, as well as from shower to shower and season to season in the same place." She refers to Hutchinson (1957), who points out that sodium, potassium, magnesium, calcium, chloride, bicarbonate, and sulfate ions are the major constituents in precipitation, together with ammonia, nitrate, nitrite, nitrogen, and other nitrogenous compounds.

She refers to several studies that suggest that the composition of rainfall near the oceans, although very dilute, is dominated by sodium (and chloride), whereas farther inland both calcium, and to a lesser extent,

TABLE 10 Quantities of Freshwater Available in the 48 Conterminous United States

\begin{tabular}{lcc}
\hline Environment & Volume, mile & Volume, $\mathrm{km}^{3}$ \\
\hline Average in stream channels & $<10$ & $<42$ \\
l,562 man-made reservoirs & 106 & 442 \\
Natural lakes (including the Great & & \\
$\quad$ Lakes) & 6,044 & 25,180 \\
Groundwater & 53,400 & 222,000 \\
\hline
\end{tabular}

magnesium, become more important than sodium. She states: "In humid, well-drained regions, water selectively removes cations from weathering rocks and soils, but in areas of limited rainfall and stream activity, the continued addition of water of definite chemical composition changes the composition of the soil water." In this way, sodium chloride or other salts accumulate in the arid regions, but failure to leach rock minerals must also contribute to $\mathrm{NaCl}$ buildup in (semi-)arid regions.

\section{ROCK TYPES AND RELATIVE SOLUBILITY}

Some rocks or minerals within rocks are relatively soluble, whereas others are not. Sometimes this simple concept is overlooked in trying to relate the chemistry of waters in contact with rock to composition of that rock. Among the more common slightly soluble and soluble materials that occur as rocks, or as cementing agents in other rocks, are calcite $\left(\mathrm{CaCO}_{3}\right)$ and dolomite $\left(\mathrm{CaMg}\left(\mathrm{CO}_{3}\right)_{2}\right)$, gypsum $\left(\mathrm{CaSO}_{4} \bullet \mathrm{H}_{2} \mathrm{O}\right)$, anhydrite $\left(\mathrm{CaSO}_{4}\right)$, halite $(\mathrm{NaCl})$, and a variety of less commonly occurring evaporite minerals, as well as sulfide materials contained in other rocks. These materials occur preponderantly in sedimentary terrain, although some occur in metamorphic or, infrequently, in igneous terrain. In contrast, rocks composed of the silicate minerals (such as quartz, feldspar, amphibole, pyroxene, mica, and clay minerals) and oxide minerals (like magnetite and hematite) tend to form distinctive erosional terrains because of their relative insolubility. These minerals occur commonly in igneous and metamorphic terrain and in the clastic sedimentary rocks such as sandstone and shale. In general, the two rock types, sandstone and shale, contain some soluble materials, such as calcite cement, as well as some relatively insoluble materials, such as quartz and clay minerals.

Given enough time, even the relatively insoluble materials exposed to weathering break down, with some components going into solution. However, many natural waters do not remain in contact with the material long enough to take on the anticipated characteristics, and the waters are much more affected by additional rainfall. Groundwater is the best example of natural water which, in general, has had enough time in contact with rock to take on the expected characteristics from such contact.

\section{CONTROLS ON SURFACE WATER CHEMISTRY}

The chemical composition of some rivers appears to be controlled more by the characteristics of precipitation than by the characteristics of rocks in the drainage basin. This seems particularly true in the dilute waters of the tropical rivers of Africa and South America. Here the 
amount of rainfall is high, and the geologic terrain consists of leached areas, such that the rate of supply of dissolved salts to the rivers is very low.

Gibbs (1970) plotted total dissolved salts on a vertical semilogarithmic scale versus a ratio on the horizontal linear scale for major rivers, lakes, and oceans of the world. In Figure 4, the ratio is the weight ratio of sodium to the sum of sodium plus calcium. In Figure 5, the ratio is chloride to the sum of chloride and bicarbonate. Gibbs suggests that natural waters with low total dissolved salts reflect the chemistry of atmospheric precipitation (ratios approaching 1.0 , or solutions with approximately $10 \mathrm{ppm}$ total dissolved salts). Many streams with higher dissolved loads (in the range of $70-300 \mathrm{ppm}$ total dissolved salts) have ratios of 0.5 or less. More highly concentrated

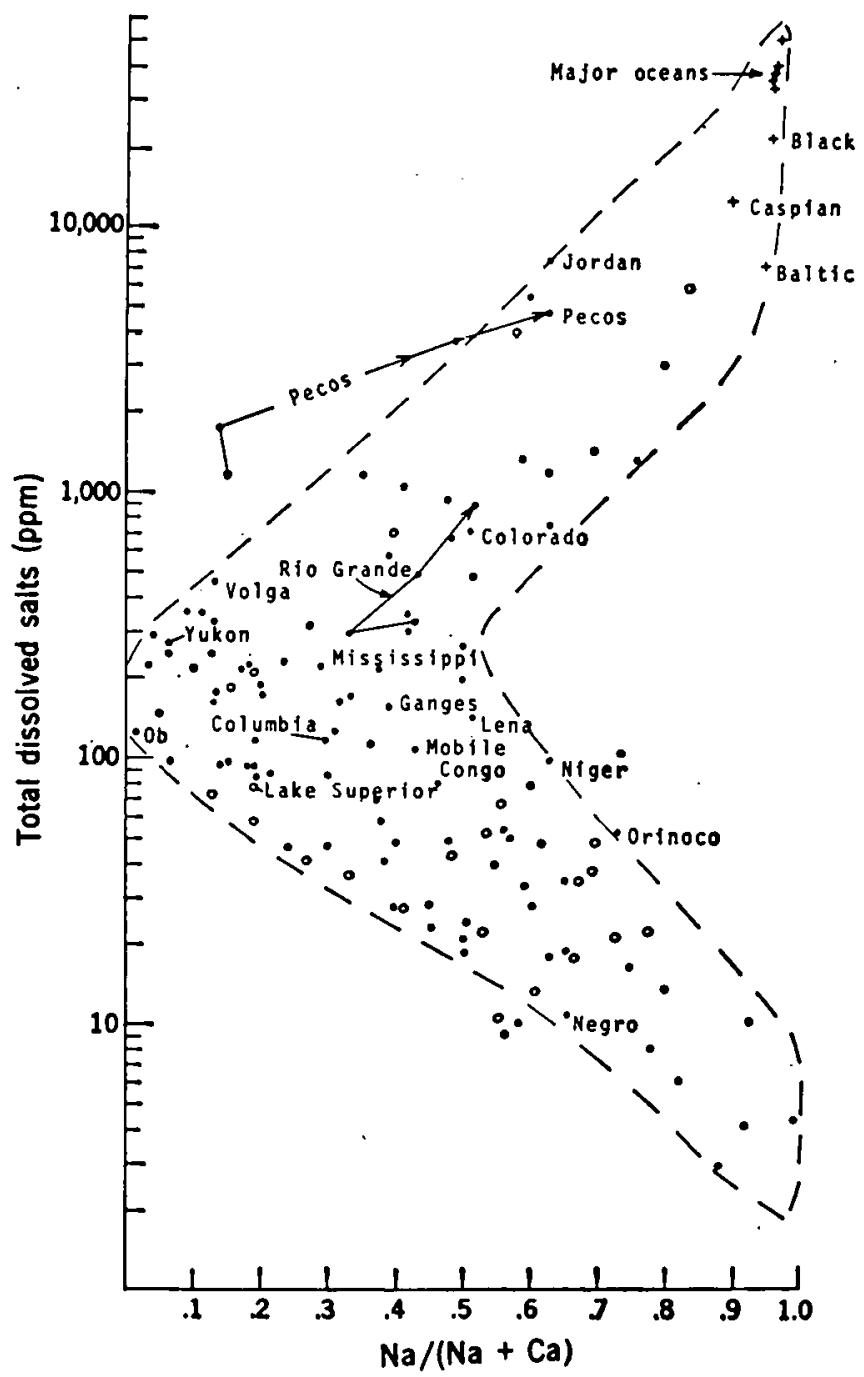

FIGURE 4 Ratio of sodium to sodium plus calcium versus total dissolved salts for major rivers, lakes, and oceans. SOURCE: Gibbs (1970). natural waters, including those streams in arid regions and the major oceans, have higher ratios approaching 1.0. Gibbs reasons that the major streams in the range of 70-300 ppm total dissolved solids show the maximum influence of interaction with rock. Streams with lower concentrations reflect the nature of atmospheric precipitation, and waters with higher concentrations are the result of evaporation, or possibly precipitation of calcium carbonate from solution. Thus relatively high sodium and high chloride reflect atmospheric precipitation or a concentration of river water through evaporation and precipitation, whereas waters with greater proportions of calcium and bicarbonate reflect the influence of reaction with the geologic terrain (Figure 6). Although this approach neglects magnesium and sulfate, it suggests a

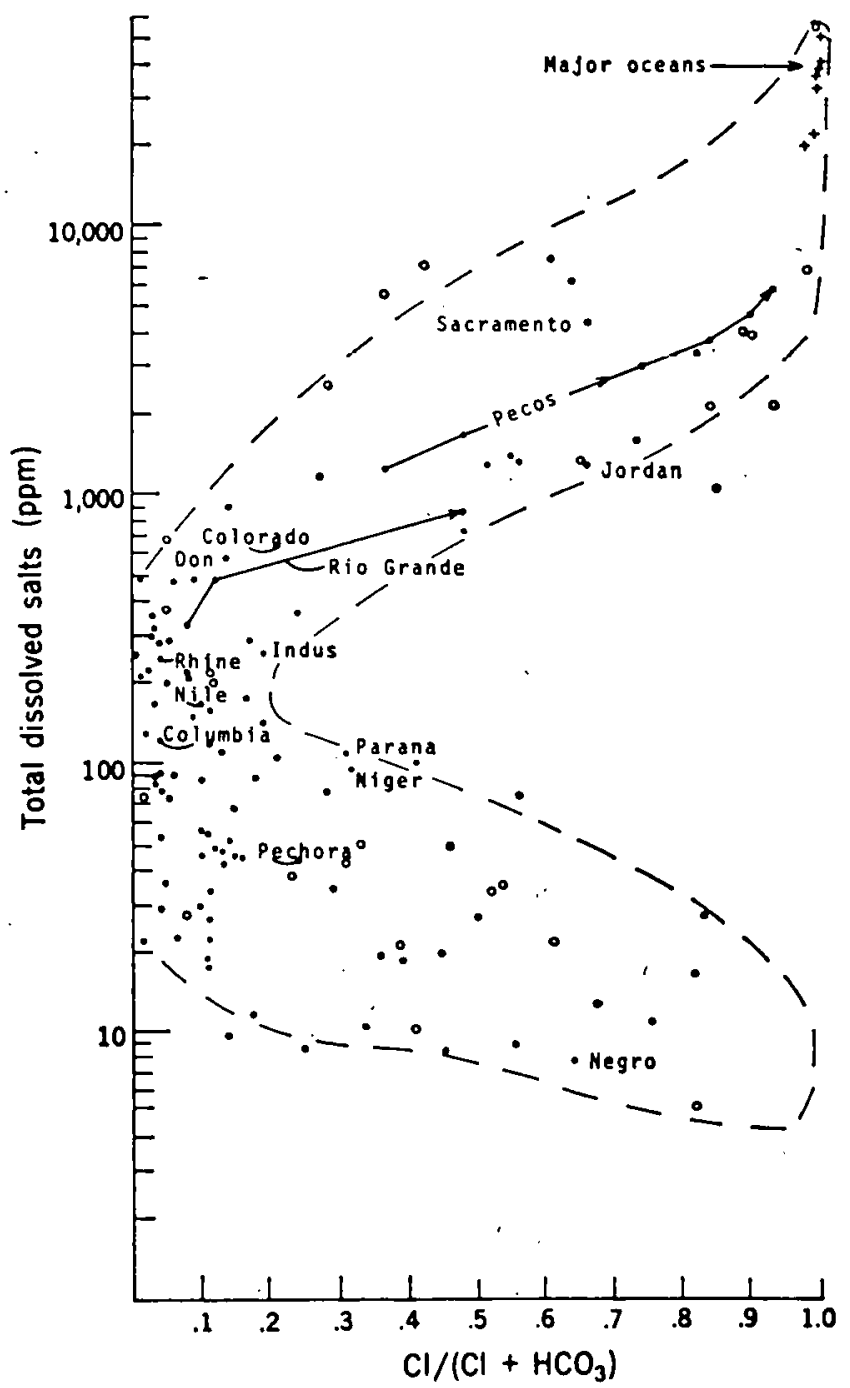

FIGURE 5 Ratio of chloride to chloride plus bicarbonate versus total dissolved salts for major rivers, lakes, and oceans. SOURCE: Gibbs (1970). 


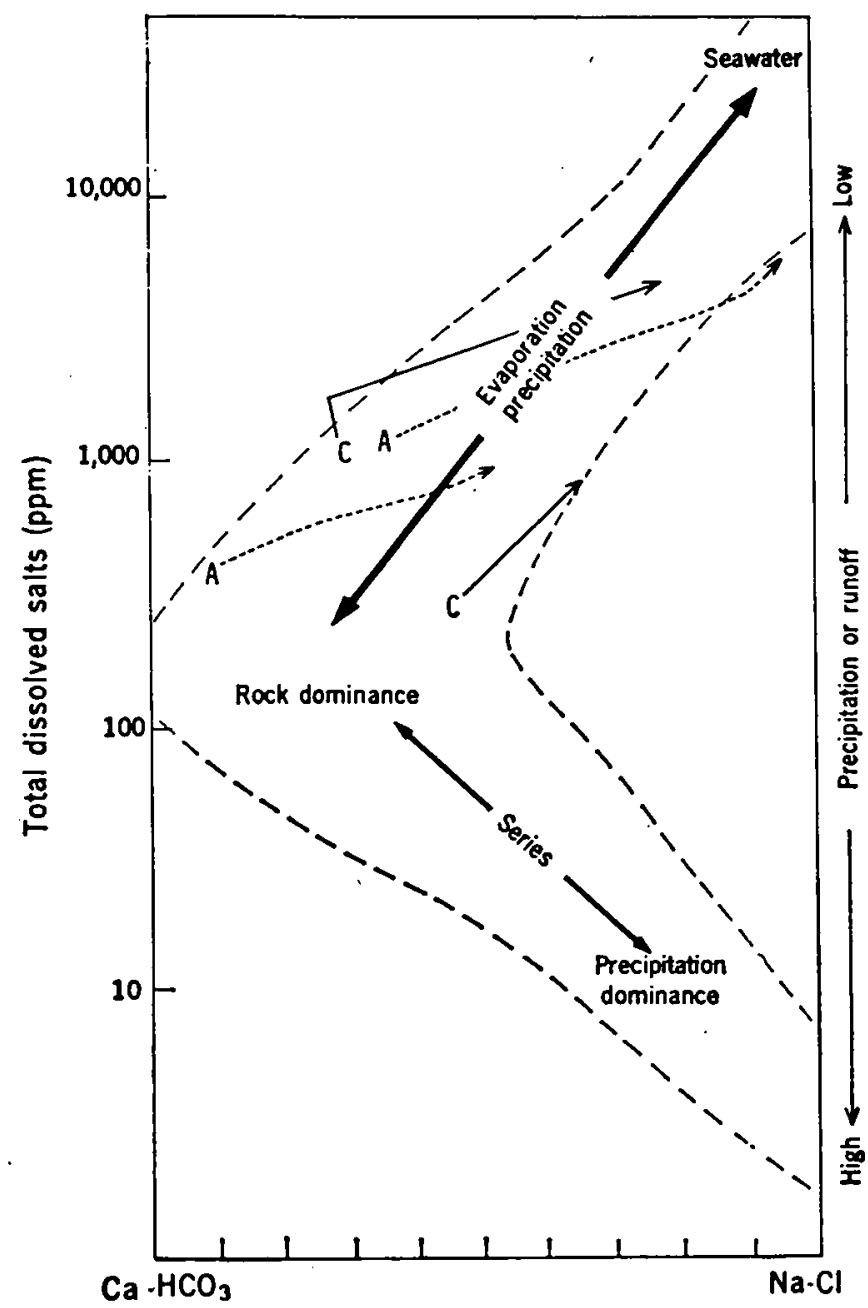

FIGURE 6 Evolution of surface water chemistry, measured by ratio of cations or anions and by total dissolved salts. SOURCE: Gibbs (1970).

highly generalized evolutionary path such as that of a dilute sodium-chloride rainfall in contact with a variety of geologic terrains as it makes its way oceanward and becomes a more concentrated calcium-bicarbonate water. If the river enters an arid region, it may evolve to a concentrated sodium-chloride water through evaporation and precipitation of calcium carbonate, and possibly by contribution of mineralized groundwater, or it may enter the oceans and become highly saline through additional processes of mixing, evaporation, and precipitation.

The composition of a natural water source is thus a function of the nature of its immediate environment. It is related to the solubility of the rock, its degree of access to the atmosphere, the length of time that the water has been in contact with the environment, and the previous composition of the water.

\section{SURFACE WATER CHEMISTRY AND GEOLOGIC TERRAIN}

\section{SIMPLE SITUATIONS}

Miller (1961) investigated the chemical composition of stream waters draining from areas of uniform lithology, a wilderness region in the Sangre de Cristo Range of New Mexico. Terrains consisting principally of granite, of quartzite, and of sandstone containing thin limestone beds were studied.

Miller notes that waters draining a single rock type were essentially uniform, regardless of the extent of the area drained. This suggests that a steady-state relation for various chemical weathering mechanisms affecting the rock-water system is established. Such information lends credence to the presumption that the composition of water derived from several rock types may be a composite of the influences of individual rock types.

Waters draining granite are soft calcium-bicarbonate or calcium-sodium-bicarbonate waters (Figure 7). Waters draining quartzite are soft calcium-bicarbonate waters (Figure 8). Waters draining sandstone are moderately hard calcium-bicarbonate waters (Figure 9). The bicarbonate character of these waters is attributed to atmospheric and pedogenic sources. In addition, dissolution of intergranular carbonate cement and thin limestone beds accounts for the bicarbonate dominance in the moderately hard waters draining sandstone terrain. The overwhelming influence of calcium carbonate on composition of waters draining sandstone is apparent in examining the dominance of calcium in those solutions. The cation content of softer waters draining granite and quartzite reflects the products of chemical weathering of the minerals in those rocks (less soluble than calcium carbonate). A conclusion to be drawn from these data is that water types can be related to lithology if one examines the data closely enough. Table 11 summarizes these relations in Miller's study.

In the unspoiled case the more soluble constituents of the rock have the greatest influences on the chemical character of the water. Under most circumstances, calcite and dolomite are relatively soluble materials. Either as rocks or as cement in other rocks, they may provide a strong influence on the composition of natural waters. Some other rock types are highly soluble, but whether they affect surface waters depends largely upon climate. If available to interact with surface flow, evaporite rocks (like rock salt) strongly influence the character of the runoff by providing sodium, potassium, chloride, and, in some instances, sulfate to the water. The evaporite rock, if exposed, can directly affect the character of runoff in contact with it; if not exposed, it can affect the stream 


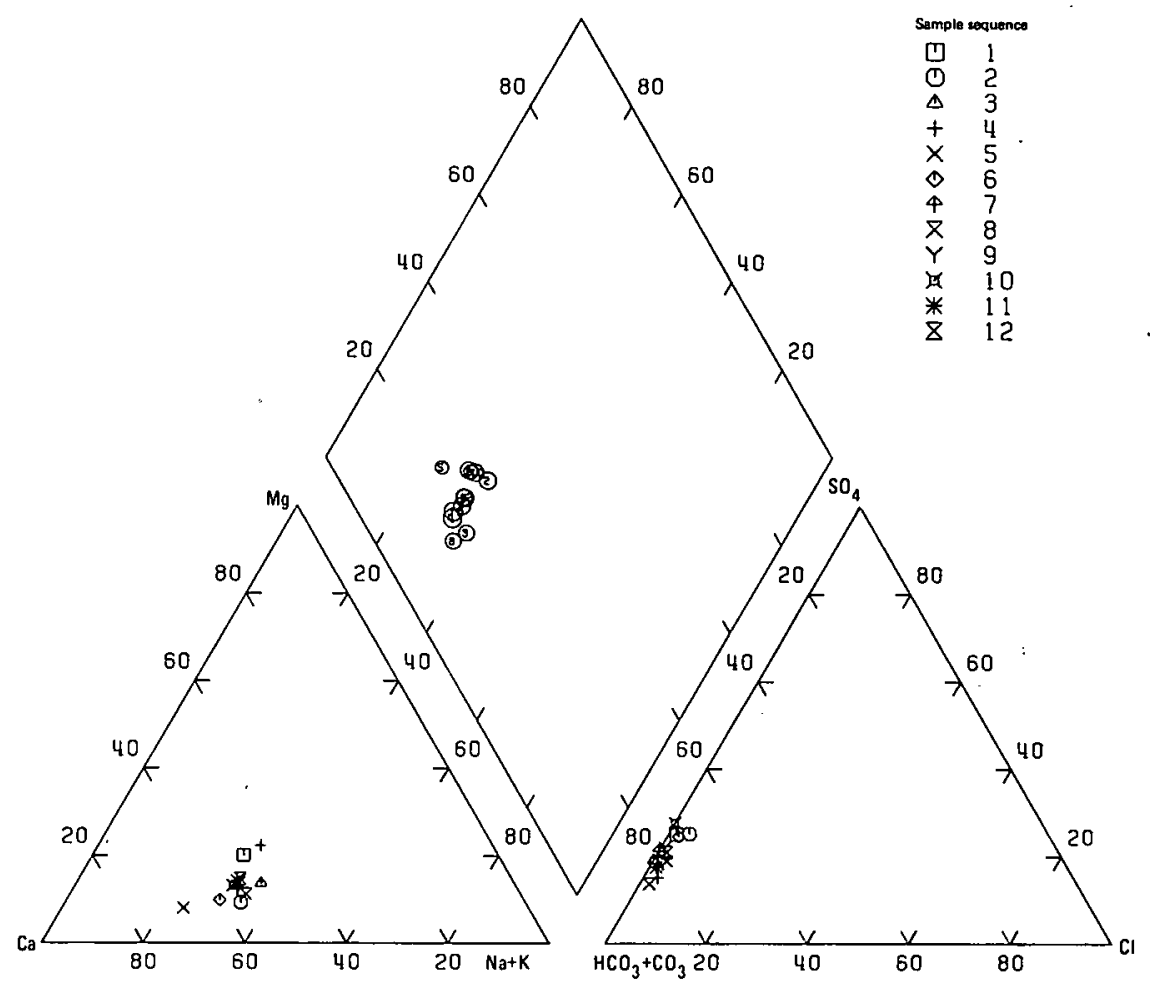

FIGURE 7 Waters draining granite. SOURCE: Data from Miller (1961).

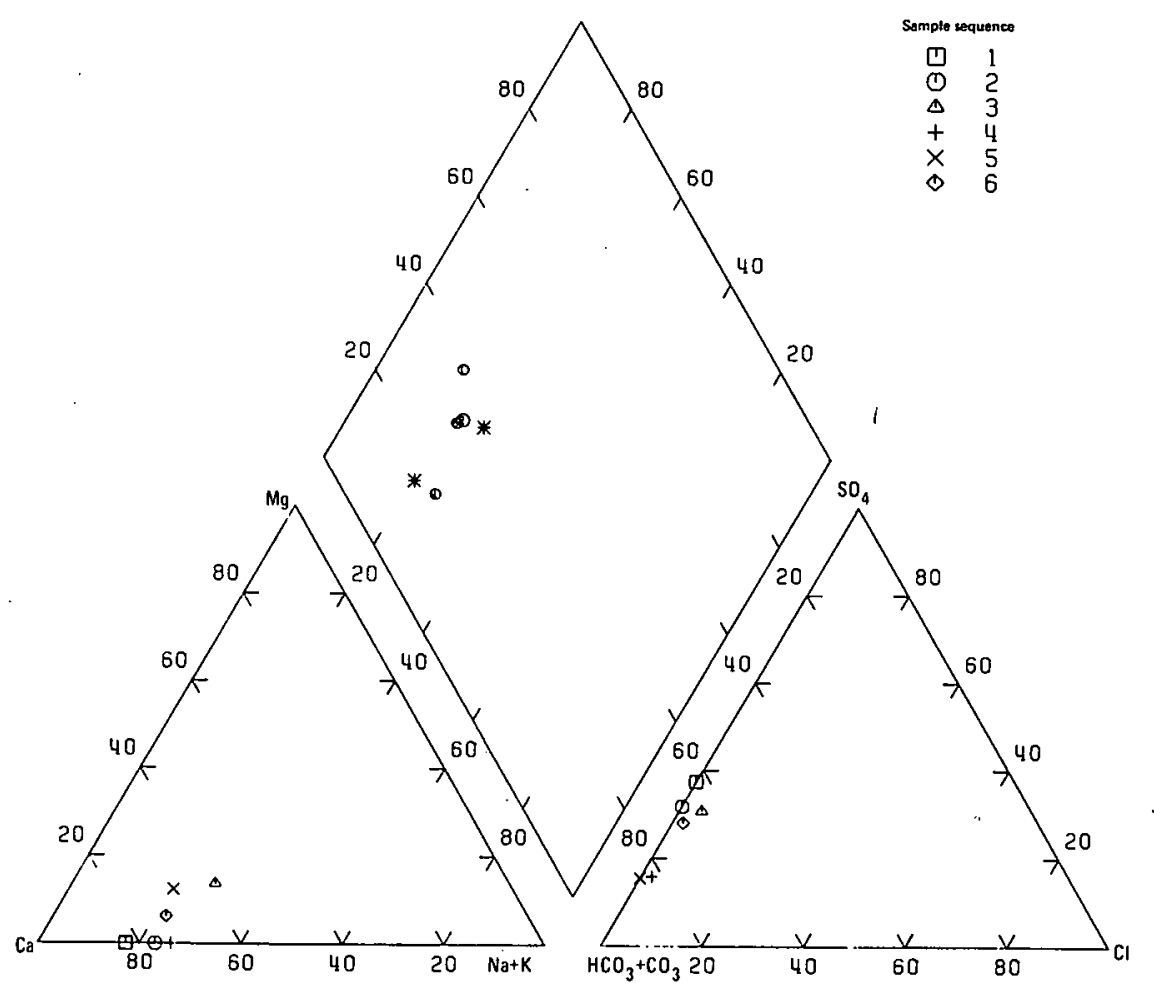

FIGURE 8 Waters draining quartzite. SOURCE: Data from Miller (1961). 


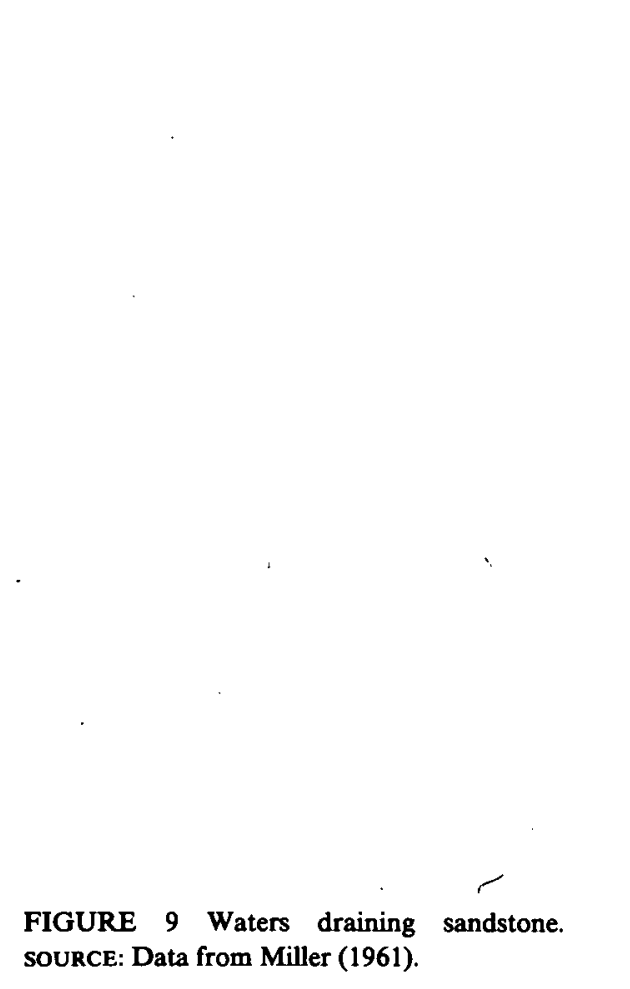

FIGURE 9 Waters draining
SOURCE: Data from Miller (1961).

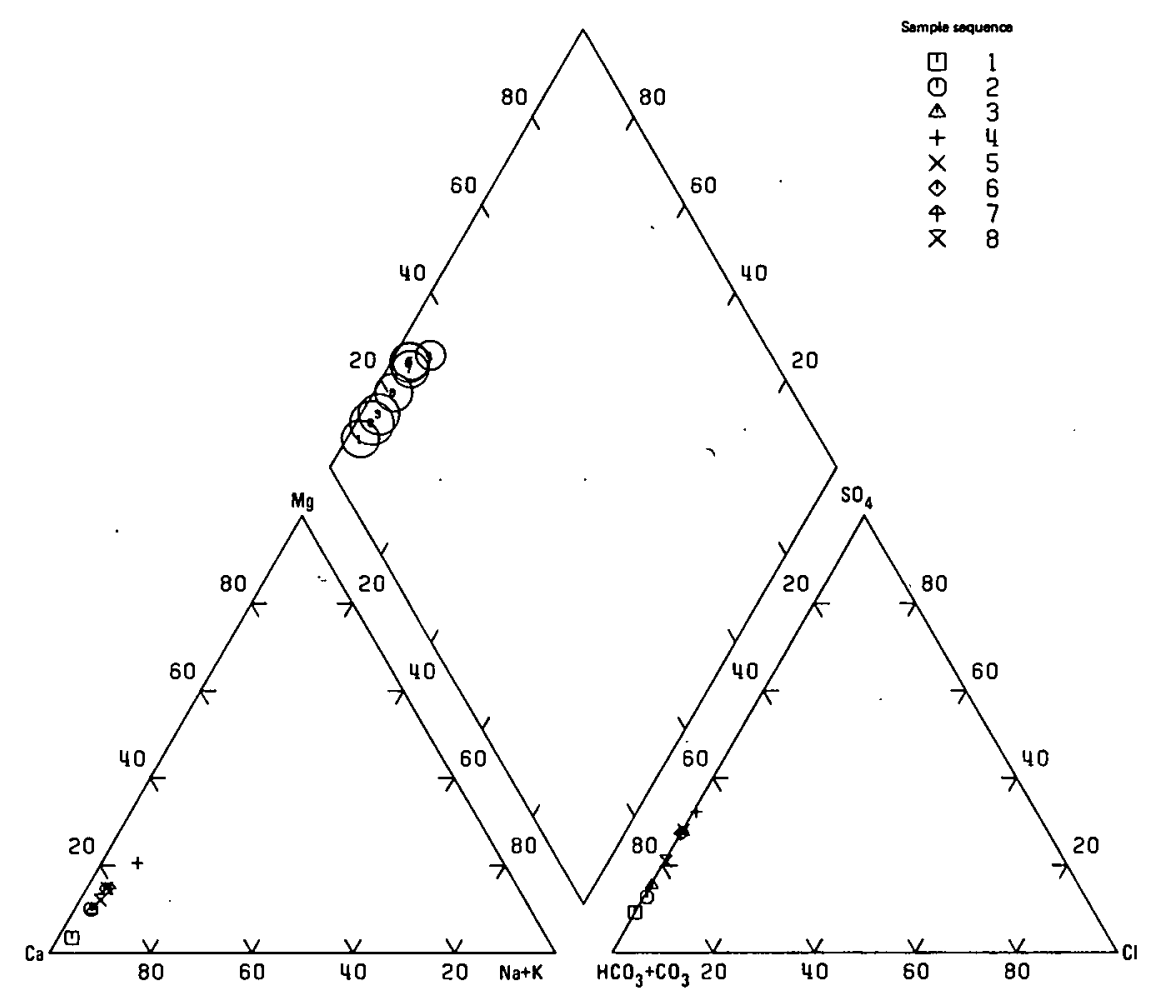

composition through additions of mineralized groundwater.

If none of the readily soluble rock types or minerals is present, as with the granite previously described, chemical weathering of the minerals comprising the rock will still take place, but there is less material to supply to the natural waters. For example, in the chemical weathering of a granite, in which the principal minerals are quartz, microcline, albite, oligoclase, and minor biotite, a soft natural water containing calcium, little sodium and potassium, and even less magnesium, results. The minerals present and the relative mobility of the specific elements that are the products of chemical weathering

TABLE 11 Relation of Water Type to Lithology

\begin{tabular}{|c|c|c|c|}
\hline Lithology & Water Type & Hardness & $\begin{array}{l}\text { Relative } \\
\text { Dominance } \\
\text { of Calcium } \\
\text { Among } \\
\text { Cations }\end{array}$ \\
\hline Granite & Calcium-bicarbonate & Soft & Least \\
\hline Quartzite & Calcium-bicarbonate & Soft & Intermediate \\
\hline Sandstone & Calcium-bicarbonate & $\begin{array}{l}\text { Moderately } \\
\text { hard }\end{array}$ & Greatest \\
\hline
\end{tabular}

determine the water type when readily soluble material is absent.

Most surface waters, particularly downstream segments and large catchments like the Great Lakes, contain a composite of waters draining different terrains.

\section{COMPLEX SITUATIONS}

For data supporting the thesis that the composition of natural waters is related, even in more complex situations, to the rock types drained, a study by Davis (1961, p. B17) is appropriate (see Figure 10). The chemical character of streams at low flow in the southern Coast Ranges of California falls into discrete zones with only minimal overlap on the Piper diagram. The diverse water types represented fall neatly into clusters that may be related to the extent of influence of clastic marine sedimentary rocks of Jurassic and Cretaceous age. The rock type, other than the Franciscan Formation, includes marine and continental deposits of Tertiary age and Quaternary continental deposits. This clustering on the water-type diagram of terrain drained takes place despite similarity of climate and distribution of precipitation of the several drainage basins involved. The difference in the chemical character of the stream waters is clearly the result of the difference in rock type in areas drained.

After reviewing two studies in which chemical data are 
readily relatable to rock type, it is appropriate to provide certain generalizations concerning the relation of rock type to natural water composition. All natural waters contain some dissolved mineral matter. The type of rocks and soils and the length of the period of contact have an important influence on the resulting composition of the water. Streams at low flow generally resemble groundwater in chemical composition, simply because at that time the streams are fed largely by groundwater. Streams during high flow are more dilute as a result of surface runoff. In the primal situation the dissolved solids content of a river is the result of interactions with the atmosphere, soil, and rocks. In the general situation there are additional influences from man's activities ranging from diverse drainages such as from agricultural lands, oil fields, and mines to municipal wastes and industrial effluents. The latter influences are beyond the scope of this review.

\section{SPECIFIC ENVIRONMENTS}

\section{Flowing Streams}

Some streams in arid regions are intermittent and tend to terminate through evaporation and infiltration as they enter low, arid regions from higher source areas. The following generalizations do not apply to these ephemeral streams:

The flow in most streams consists of contributions from groundwater and surface runoff. Unless modified by man through the construction of impoundments, the base flow that takes place during protracted dry periods is fed by groundwater seepage. Consequently, the base-flow water resembles groundwater in chemical characteristics. The water of base flow tends to be hard, contains more total dissolved solids, and is highest in individual constituents in comparison with the (filtered) water of higher-flow periods. Although contributions of runoff during periods of high flow generally dilute the stream, in some highly urbanized regions surface runoff may be of poorer quality for most purposes and higher in total dissolved solids than the groundwater. To determine the characteristics of a stream at any given point, care must be used in designing a sampling plan. Brown et al. (1970, pp. 4-8) describe this procedure, which involves the design of a valid frequency of sampling pattern, as well as a selection of sample collection points. To illustrate the importance of representative samples, some municipal water systems collect grab samples of the raw water at a convenient point near the stream bank, which may not be

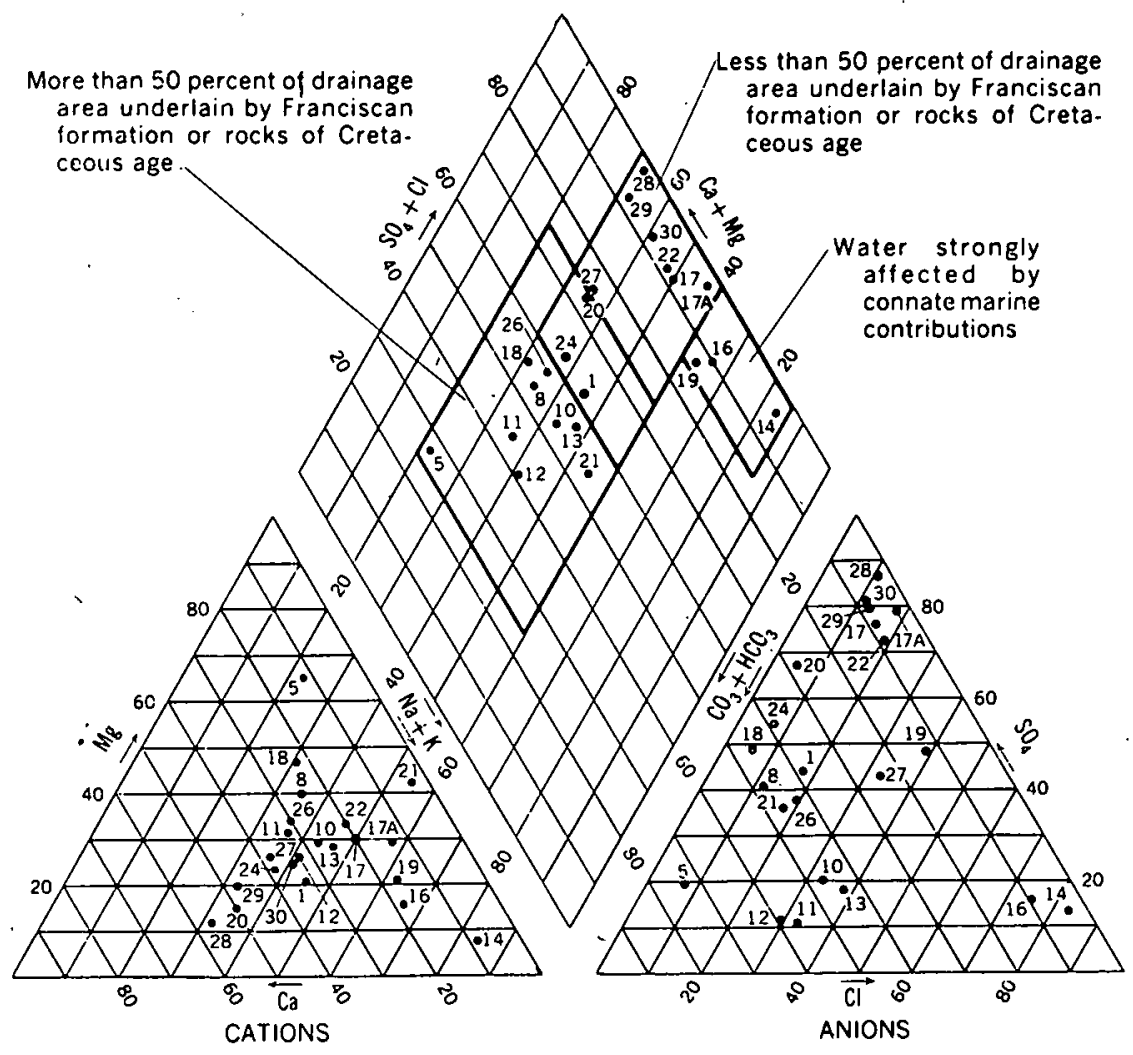

PERCENTAGE OF TOTAL EQUIVALENTS PER MILLION
FIGURE 10 Chemical character of samples from streams at low-flow stage, eastern slope of the southern Coast Ranges. SOURCE: Davis (1961). 


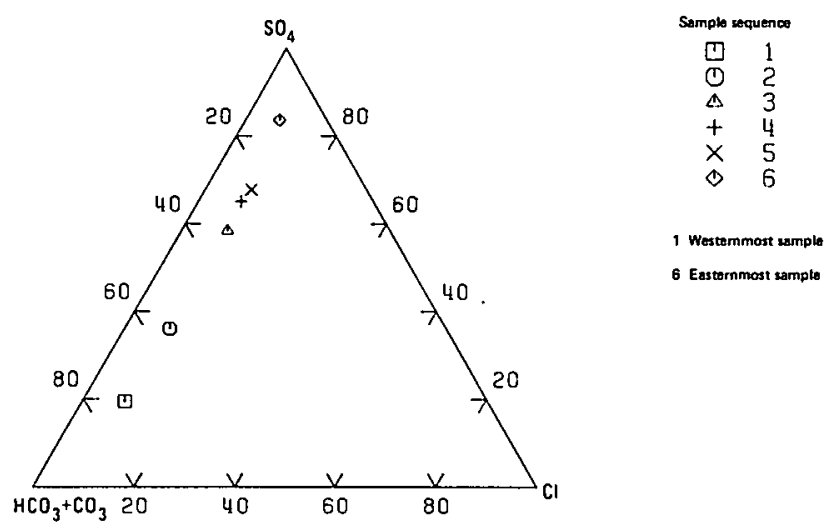

FIGURE 11 Susquehanna River average west to east. SoURCE: Anderson (1963).

representative of the raw water taken into the plant. Although it may be an extreme example, the Susquehanna River at Harrisburg provides an illustration of how incomplete mixing of tributary streams may result in heterogeneous river water. Anion data taken from Anderson (1963) have been placed on a three-component diagram and appear as Figure 11. Samples 1-3 are taken between the west bank and City Island, and samples 4-6 are taken between City Island and the east bank. Similar results appear if one chooses any other set of data presented by Anderson. Under such conditions, a poorly located grab sample may result in misleading information.

The chemical characteristics of the world's major rivers near their mouths are generally considered to be quite similar and uniform. Livingstone (1963) believes that this is the result of the integration of tributaries draining a variety of geologic terrains. Others suggest that this uniformity is the result of buffer action or ionexchange reactions with the suspended load or with the soil.

As one approaches the headwaters of tributaries, the chemical character of the waters takes on greater diversity. For example, Corbett and Manner (1975) report that during a prolonged rainstorm the water type in a small ephemeral drainage basin systematically ranged from sodium-magnesium-chloride through calcium-sulfate, where runoff samples were collected at 20 min intervals (Figures 12 and 13).

The composition of river waters changes markedly as a result of seasonal flow, and dramatic differences may occur within their cross sections. The safest data with which to work are those that are repeated samples over an extended period of time taken to assess the variability of composition. Unfortunately, some published data may represent only a single sample, rather than the larger character of the river.

Although major elements may be generally related to the terrain, trace elements present an enigma. For example, Angino et al. (1969) in a study of the lower
FIGURE 12 Runoff from ephemeral drainage basin, samples 1-12. SOURCE: Corbett and Manner (1975).

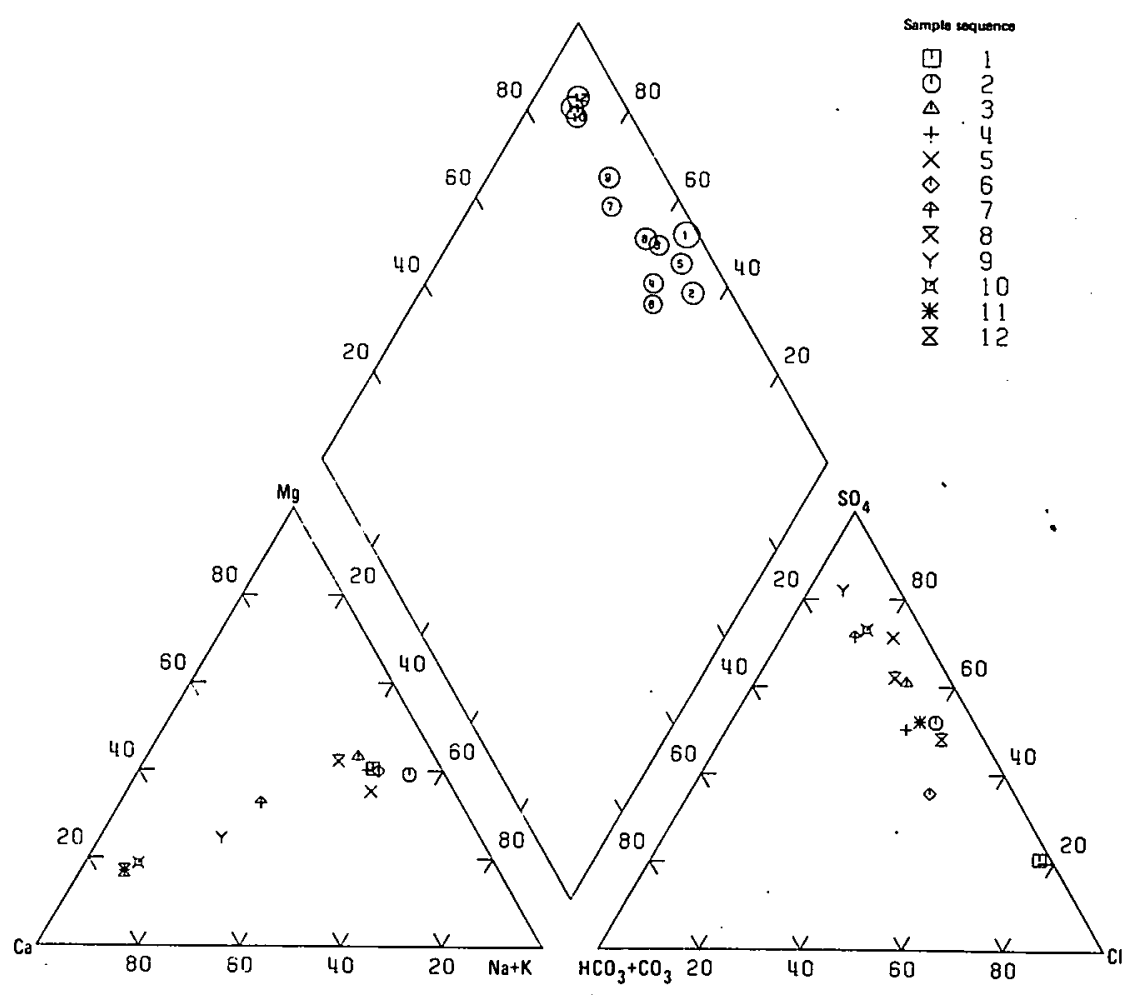




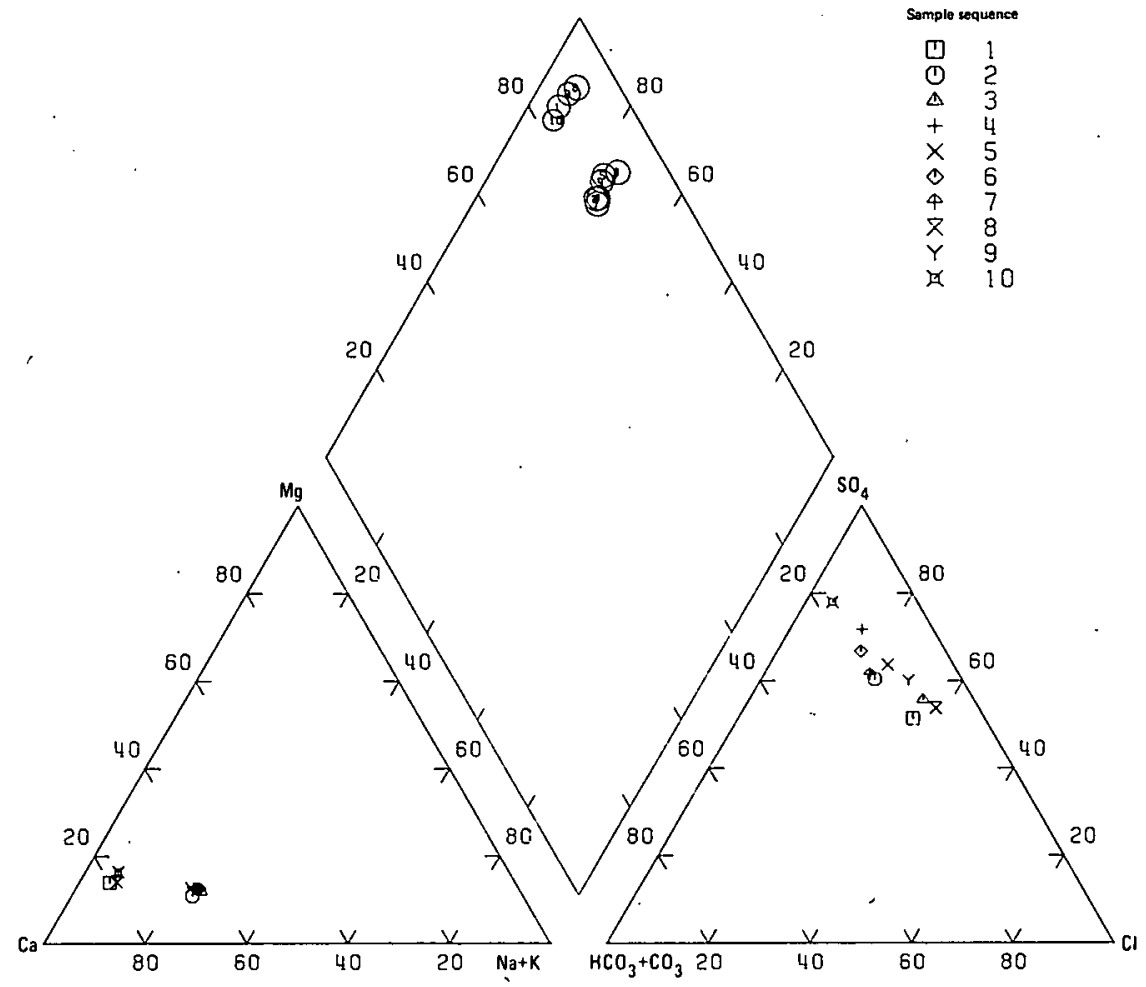

FIGURE 13 Runoff from ephemeral drainage basin, samples 13-22. SOURCE: Corbett and Manner (1975).
Kansas River basin concluded that "No strong relation between trace element concentration and geology/lithology was noted . . . " in the streams, except for strontium. In a later paper, Angino et al. (1974) observed that the trace element concentrations of the streams do not follow any clearly recognized seasonal pattern and there are no significant correlations with discharge. The wide variation in trace element concentration for each stream reported demonstrates the need to examine the concentration of trace elements over extended time periods, before one makes any conclusion about typical ranges of values. These authors note that trace element concentrations based upon one sample from a river “. . . may well give values that can be greater or less by some 200 percent or more than the mean for a given element on a given stream." They also conclude that "the concentrations of iron, manganese, nickel, zinc, and lead in Kansas stream waters (and probably most midcontinent streams) are quite variable and bear little or no relation to the lithology and surface geology of the areas."

Studies involving trace elements in streams are fraught with difficulties of sampling, preservation, and analysis. Despite this, a voluminous literature has emerged. On a national basis, the most extensive studies were begun by the Federal Water Pollution Control Administration in 1957, with the beginning of the Water Quality Surveillance Program. This monitoring effort provides minimum, maximum, and mean values for positive occur- rences as well as data on frequency of detection for many stations in the United States. For example, in the 5-year period from 1962 to 1967 , almost 1,600 samples were analyzed for 19 trace elements (Kopp and Kroner, 1968). Weekly samples composited for 3-month periods were filtered and analyzed by emission spectroscopy. In assessing the occurrences, consideration is given both to natural sources and the probable results of man's activities.

To overcome difficulties in using data from a variety of sources, the National Stream Quality Accounting Network (NASQAN) has been developed. It has four objectives: to account for the quantity and quality of water moving within and from the United States; to depict regional variability; to detect changes in stream quality; and to lay the groundwork for future assessments of changes in stream quality (Ficke and Hawkinson, 1975).

A stated goal of the 525 NASQAN stations, which are mostly operated by the U.S. Geological Survey, is to measure a number of water characteristics by standard methods at stipulated frequencies. This data base is expected to eliminate much of the uncertainty currently existing in the literature about the characteristics to be measured (see Table 12).

\section{Water Reservoirs and Natural Lakes}

Man has constructed reservoirs for a variety of reasons, including flood control, downstream water quality im- 


\section{GEOCHEMISTRY OF WATER IN RELATION TO CARDIOVASCULAR DISEASE}

provement, water supply, recreation, and power generation. In many respects, these man-made bodies of water may resemble lakes. A single sample from either a reservoir or a lake provides, at best, an approximation of water quality, and more often it is likely to be an

\section{TABLE 12 Characteristics Measured at NASQAN} Stations

\begin{tabular}{|c|c|}
\hline & Frequency* \\
\hline \multicolumn{2}{|l|}{ Field determinations } \\
\hline Water temperature & $\mathrm{C}, \mathrm{D}$, or $\mathbf{M}^{\dagger}$ \\
\hline Specific conductance & $\mathrm{C}, \mathrm{D}$, or $\mathrm{M}^{\dagger}$ \\
\hline $\mathrm{pH}$ & $\mathbf{M}$ \\
\hline Discharge & $\mathrm{C}$ \\
\hline Coliform, fecal & $\mathbf{M}$ \\
\hline Streptococci, fecal & $\mathbf{M}$ \\
\hline $\begin{array}{l}\text { Common constituents (dissolved) } \\
\text { (bicarbonate, carbonate, total hardness, } \\
\text { noncarbonate hardness, calcium, magnesium, } \\
\text { fluoride, sodium, potassium, dissolved solids, } \\
\text { silica, turbidity, chloride, and sulfate) }\end{array}$ & $\mathrm{M}$ or $\mathrm{Q}^{\S}$ \\
\hline \multicolumn{2}{|l|}{ Major nutrients } \\
\hline Phosphorus, total $\|$ as $\mathrm{P}$ & $\mathbf{M}$ \\
\hline Nitrite plus nitrate, total as $\mathrm{N}$ & $\mathbf{M}$ \\
\hline Nitrogen; total Kjeldahl as $\mathbf{N}$ & $\mathbf{M}$ \\
\hline $\begin{array}{l}\text { Trace elements (total and dissolved) } \\
\text { (arsenic, cadmium, chromium, cobalt, copper, } \\
\text { iron, lead, manganese, mercury, selenium, and } \\
\text { zinc) }\end{array}$ & $\mathrm{Q}$ \\
\hline \multicolumn{2}{|l|}{ Organics and biological } \\
\hline Organic carbon, total & Q \\
\hline Phytoplankton, total, cells/ml & $\mathbf{M}$ \\
\hline $\begin{array}{l}\text { Phytoplankton, identification of three } \\
\text { codominants }\end{array}$ & $\mathbf{M}$ \\
\hline $\begin{array}{l}\text { Phytoplankton, three codominants, } \\
\text { percent of total }\end{array}$ & $\mathbf{M}$ \\
\hline Periphyton, biomass, dry weight $\mathrm{g} / \mathrm{m}^{\ddagger}$ & 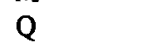 \\
\hline Periphyton, biomass, ash weight $\mathrm{g} / \mathrm{m}^{\ddagger}$ & Q \\
\hline Periphyton, chlorophyll a & $\mathbf{Q}$ \\
\hline Periphyton, chlorophyll b & 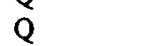 \\
\hline \multicolumn{2}{|l|}{ Suspended sediment } \\
\hline Suspended sediment concentration & $\mathbf{M}$ \\
\hline Percent finer than $0.062-\mathrm{mm}$ sieve diameter & $\mathbf{M}$ \\
\hline
\end{tabular}

- Frequencies: C, continuous; D, daily; M, monthly; Q, quarterly.

${ }^{\dagger}$ Continuous or daily depending upon whether the station is equipped with a monitor or whether daily observations are made. Monthly measurements made at stations where a long-term record is available.

₹ Dissolved constitutents in water are those remaining after filtering samples through $0.45-\mu \mathrm{m}$ membrane filters.

$\S$ Quarterly or monthly, depending upon whether relationships have been established between conductance and concentrations of various common constituents.

II Total concentrations are those determined by analyses of unfiltered samples. They include both dissolved and suspended materials.

SOURCE: Ficke and Hawkinson (1975). inadequate representation of that body of water. That such differences exist has been demonstrated in many studies, based on samples taken at the surface and at various depths at a large number of stations on the body of water. The differences in water quality are both spatial and temporal. Many bodies of water go through an annual cycle of stratification, based on density and temperature distribution. In some instances, for example, bottom waters may become depleted in, or devoid of, dissolved oxygen once or twice during the year. At that time, some elements, such as iron, may increase in concentration as a result of solution from the bottom sediment. Upon oxygenation, the iron may then precipitate back into the sediment.

Some diurnal differences are common as well (Livingstone, 1963 , p. G10). Compounding these variations is the continuing replenishment of water from the sources and loss of water from the outlet.

Reservoirs and some lakes are fragile segments of the environment. They may be subject to pollution and eutrophication, i.e., natural or artificial addition of nutrients, and the effects of added nutrients. A broader treatment of this subject is provided in the NRC Planning Committee for the International Symposium on Eutrophication (1969) symposium proceedings entitled Eutrophication: Causes, Consequences, Correctives.

\section{Great Lakes}

Historic records document that there are longer-term changes in the composition of the open waters, and a myriad of studies indicate shorter-term changes resulting from the pollution associated with harbors, tributaries, and other in-shore areas. Lake Superior contains the softest of the waters in the Great Lakes. This is a direct reflection of the influence of the dominantly Precambrian (igneous and metamorphic) crystalline rock in the drainage area feeding the lake. In contrast, the other Great Lakes containing hard waters are fed by tributaries draining Paleozoic age sedimentary rocks and are influenced to a greater degree by man's activities. A chapter by A. M. Beeton entitled "Changes in the Great Lakes," in Eutrophication: Causes, Consequences, Correctives (NRC Planning Committee for the International Symposium on Eutrophication, 1969), provides an indication of the chemical changes in the waters of these lakes.

In all the lakes, except for Lake Superior, for which no obvious changes are noted, the Great Lakes open waters started to show increased mineral concentrations in 1930, and this trend continues to the present. These changes are generally ascribed to the greater influence of man. 


\section{GROUNDWATER CHEMISTRY AND GEOLOGIC TERRAIN}

Groundwater composition is influenced by factors similar to those affecting surface water: the entraining rock; the residence time in the rock; the previous composition of the groundwater; and, in some instances, the flow path. It is generally presumed that because of the slower movement and longer residence time of groundwater compared to surface water in a given terrain, groundwater maintains a constant composition with time and may vary only slightly from well to well. According to Brown et al. (1970, p. 6): "Commonly differences in mineral composition of rocks within the groundwater reservoir, and variations in rate and chemical composition of recharge from precipitation and stream flow, cause differences in composition of water from place to place in a groundwater reservoir. Differences in samples collected at different times from the same source may also be observed." Two pages later they continue: "Although concentrations of dissolved constituents in groundwater from any one well may vary widely, sometimes severalfold, in general the changes take place much more slowly than those commonly associated with surface water."

The relation between the chemical composition of groundwater and the enclosing rocks has been described by White et al. (1963, pp. F5-F13). They also present approximately 1,200 analyses of "waters of low mineral content associated with common rock types" (White et al., 1963, pp. F14-F29).

Chebotarev (1955) noted that the geochemical type of water changes with an increase in total salinity as well as with increasing depth, such that the shallower waters are bicarbonate waters, which give way to sulfate waters and finally to chloride waters at depth. Feth (1965) drew a parallel conclusion in his examination of shallowest groundwaters containing more than $1,000 \mathrm{ppm}$ dissolved solids. Currently, and for the near future, man can rely on shallow groundwaters as a source of raw water supply, and these studies are therefore of passing interest in this context. However, it is interesting that this sequence of water metamorphism supersedes the influence of the entraining rock for the concentrated brines.

It is widely held that groundwaters are anoxygenic. However, according to Wood $(1976$, p. 22$)$ this is not necessarily true, and in some circumstances, dissolved oxygen may remain even at great depths in aquifers where little or no oxidizable material has been encountered along the path of the water. Wood's Guidelines for Collection and Field Analysis of Groundwater Samples for Selected Unstable Constituents, alerts the uninitiated to the pitfalls associated with the groundwater studies.

\section{COMPILATIONS OF DATA}

\section{INFORMATION AVAILABLE ON A NATIONAL BASIS}

Several researchers from the U.S. Geological Survey have compiled water quality characteristics on a nationwide basis, which have been in part portrayed on maps of the conterminous United States.

The prevalent chemical composition of water in major rivers and well-developed waterways has been presented by Rainwater (1962). Dissolved solids, chemical type, and sediment concentration of rivers appear as plates. As a rough first approximation, areas of high-sediment concentration and high-dissolved-solids concentration of rivers correspond with areas of low (less than $20 \mathrm{in}$.) average annual precipitation. His map showing water by chemical type is Figure 14.

Rainwater (1962) used chemical data during low-flow periods to determine the prevalent chemical type of U.S. rivers. At low-flow periods, it should be recalled, river water more nearly approximates the composition of groundwater feeding the streams than at any other time.

Water in approximately 87 percent of the United States is of the calcium-magnesium type. Within this type, calcium-magnesium-carbonate-bicarbonate water is more common than calcium-magnesium-sulfate-chloride water.

Elaboration of and a slightly different approach to the composition of stream water in the conterminous western states was provided by Feth (1965). Using data based on historic records to 1957, for the states west of the Dakotas, Nebraska, Kansas, Oklahoma, and Texas, he portrays in greater detail the areas in which streams are expected to have maximum concentrations of less than 10 , from 11 to 100 , from 101 to 1,000 , and more than $1,000 \mathrm{ppm}$ calcium, sodium, sulfate, and chloride in stream water. In his text, Feth points to several situations pertinent to this review. With reference to the drainage basins of the Little Colorado River and the Bill Williams River, the former has about twice the mean yearly precipitation of the latter. However, the former is also more highly mineralized. One should not, in every instance, automatically conclude that water of high mineral concentration occurs because the climate is semiarid. The explanation lies in the abundance of readily soluble materials in the sedimentary rocks of the Little Colorado area and their relative absence in the area of the Bill Williams River. A second example by Feth involves the Sevier River in Utah. The river flows northward from volcanic terrain and gains only modest amounts of dissolved materials. As it nears Richfield, Utah, the water begins to reflect the presence of bedded 


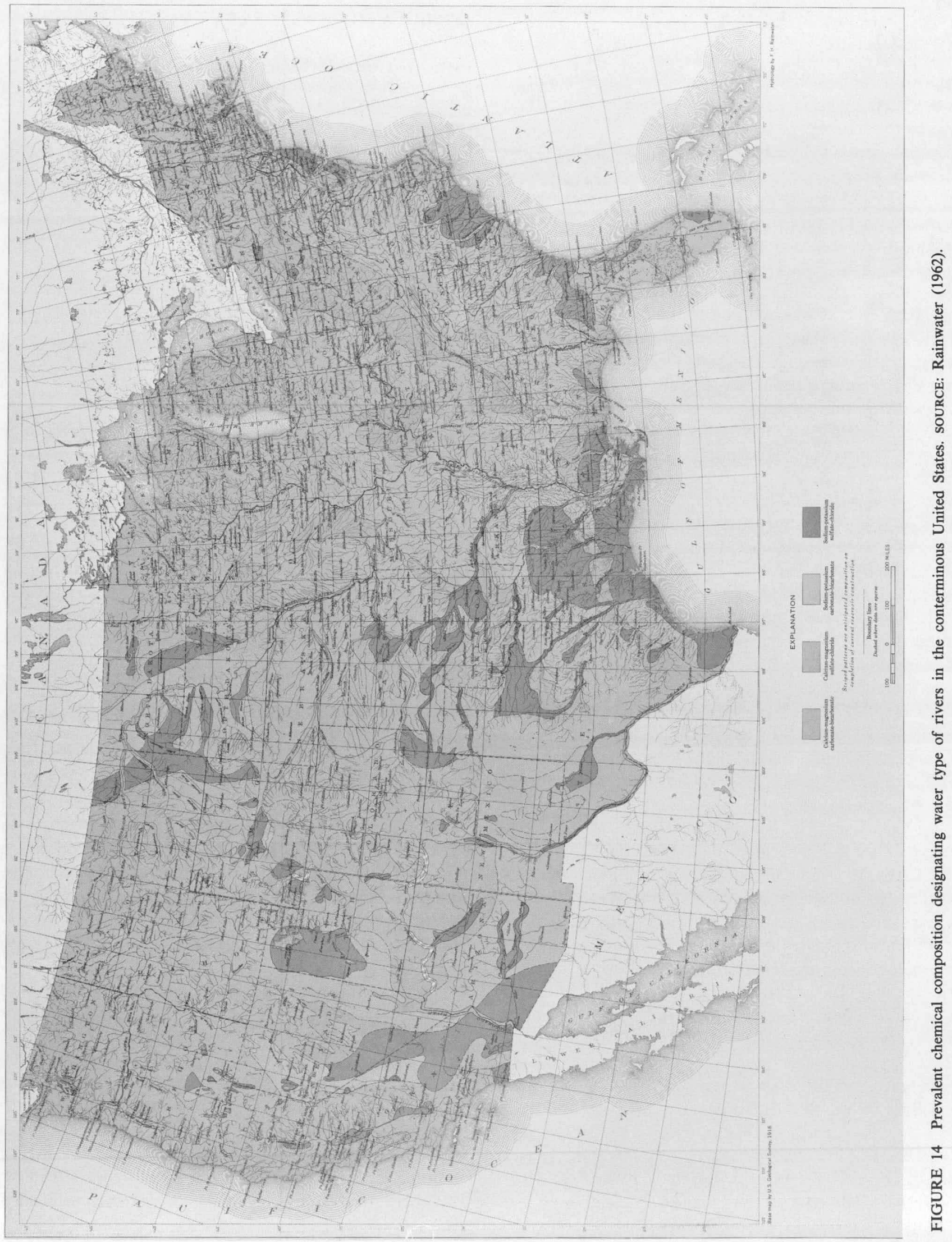


salt and bedded gypsum. There is no abrupt climatic change in this region; rather there is a dramatic change in the nature of the rock.

Hardness data for surface water and for groundwater have been presented by Ackerman and Lof (1959) (Figure 15).

Durfor and Becker (1964) have emphasized the statewide averages (weighted for population) for dissolved solids, hardness, sodium, and fluoride in untreated public water supplies. Their maps were based upon data from 1,596 municipal water systems, as of 1962 . No distinction is made between surface water and groundwater supplies. In general, areas of low dissolved solids correspond to areas of soft water (less than $100 \mathrm{ppm}$ dissolved solids and less than $60 \mathrm{ppm}$ hardness). These include the Pacific Northwest states of Washington and Oregon; the south- eastern states, except for Florida; and the New England states. Areas of low sodium are related to the humid East, and higher sodium is related to areas of lessabundant water supplies. These maps have been used by some authors in attempts to match statewide cardiovascular disease rates to statewide water quality data.

Greater detail concerning the properties of surface waters may be found in publications that focus on a single state. North Carolina, for example, is shown to have soft water, according to Durfor and Becker (1964), and relatively low total dissolved solids, according to Rainwater (1962). With the detail provided by Wilder and Slack (1971a), however, some segments of streams, or entire small streams, are shown to contain hard water. Unpolluted, fresh surface waters of North Carolina are soft, except for a few streams in eastern North Carolina,

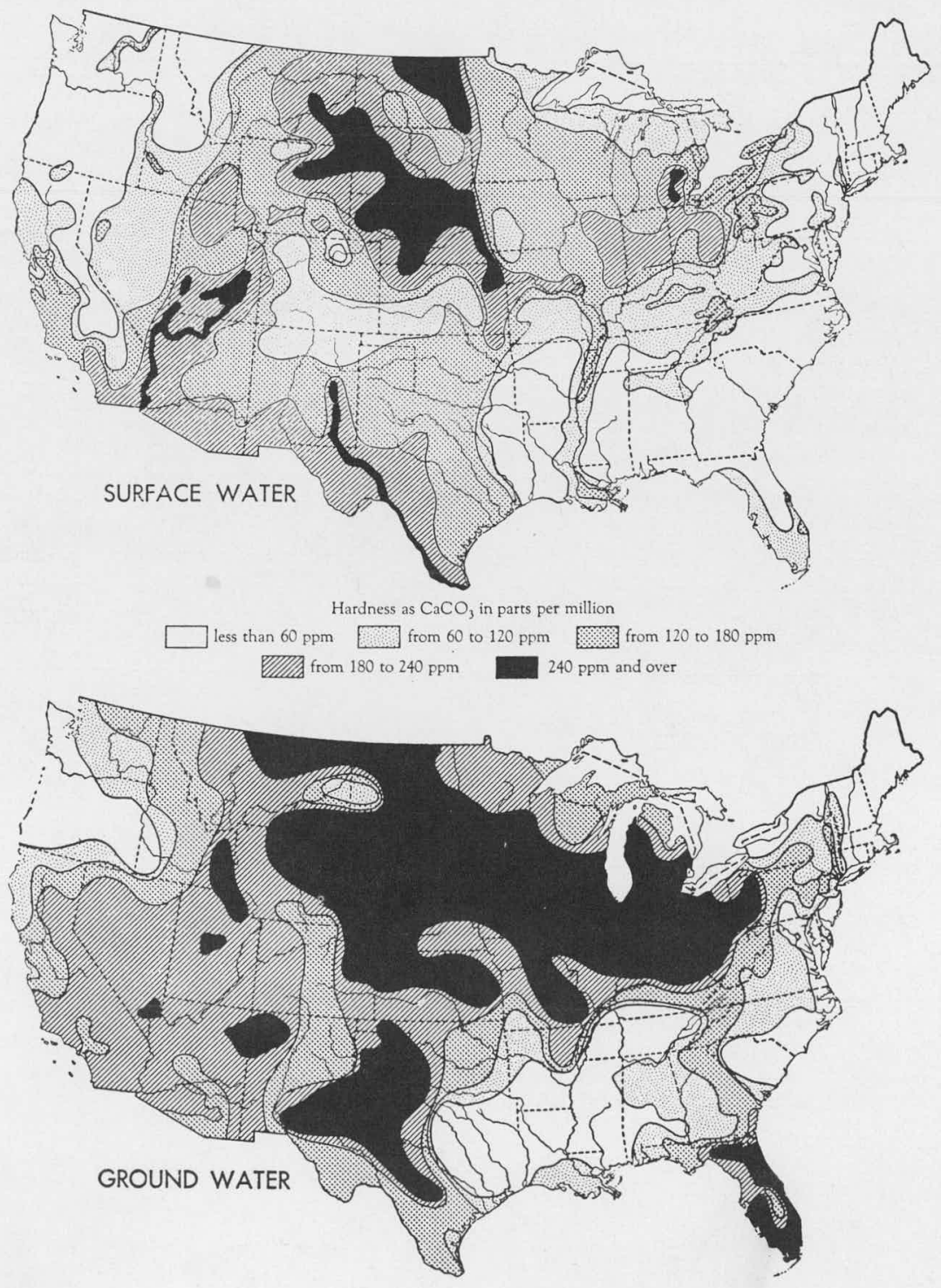

FIGURE 15 Hardness data. SOURCE: Ackerman and Lof (1959). 
FIGURE 16 Reservoir soft water. SOURCE: Data from Durfor and Becker (1964).

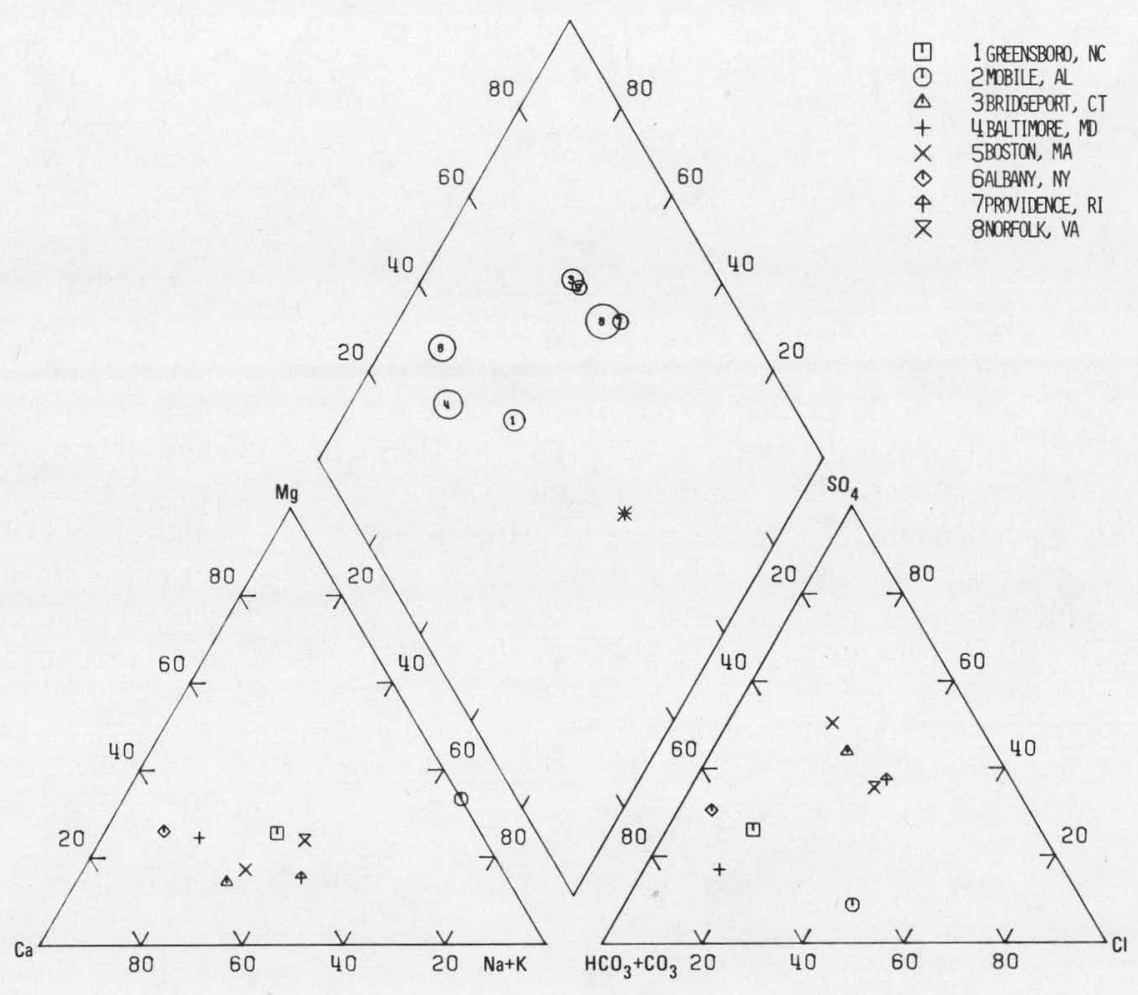

FIGURE 17 Reservoir moderately hard. SOURCE: Data from Durfor and Becker (1964).

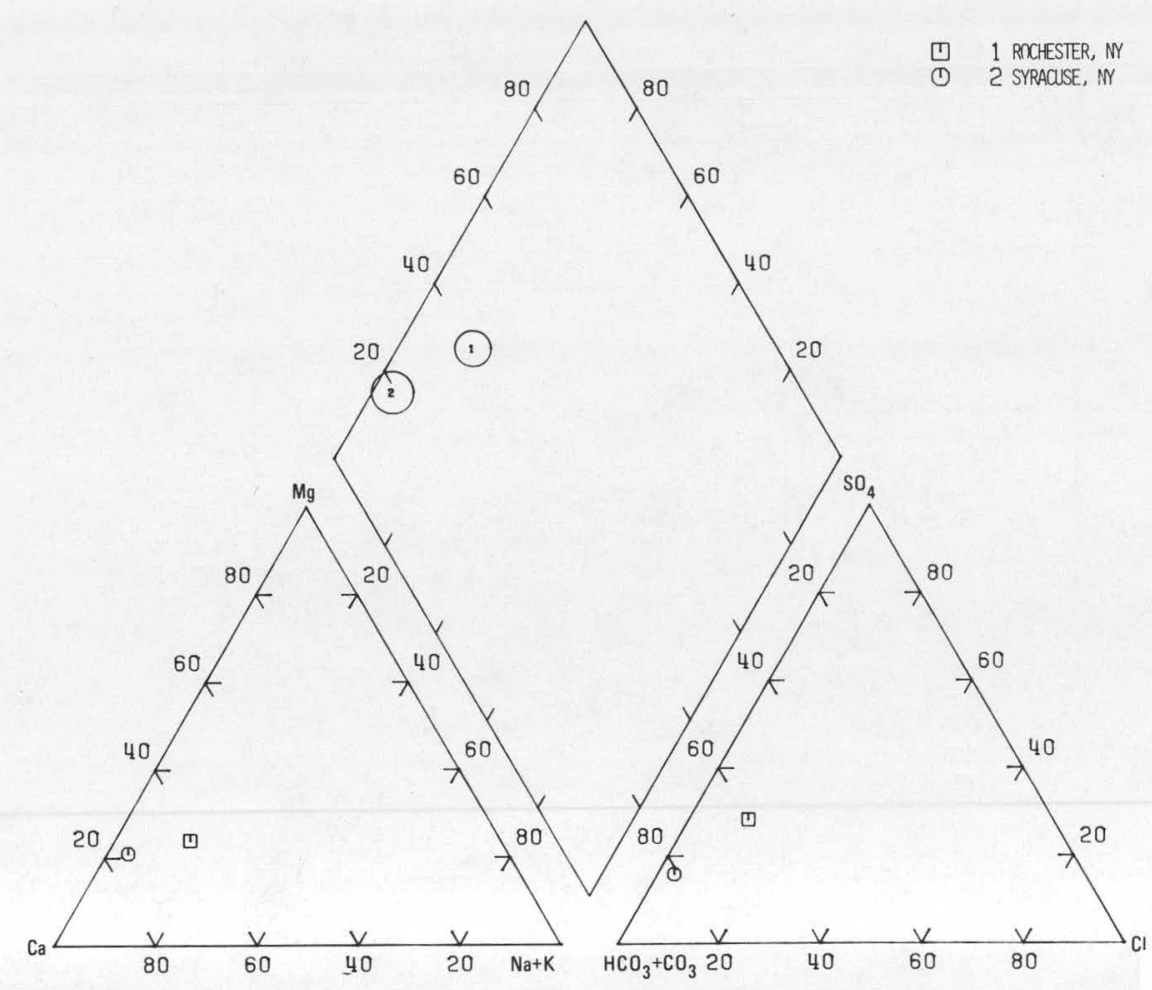


where drainage from limestone beds may make it moderately hard during periods of low flow. In addition, some streams contain hard water as a result of man's activities. The report of Wilder and Slack (1971b) is particularly useful to compare the effects of human activities to the effects of natural conditions on the chemical quality of streams.

\section{MAJOR CITIES}

Durfor and Becker (1964) accumulated data for the drinking water supplies of the 100 largest cities in the United States. In the present chapter, chemical data for raw water as available for either the single or the largest source of water supply for these cities have been plotted on Piper diagrams. These data have been categorized by the nature of the source and the degree of hardness. Considering the four categories of hardness, and the five types of water sources (reservoir, natural streamflow, Great Lakes, groundwater, and inland lakes), a 20possibility matrix exists. However, not all of these 20 categories are represented by the Durfor and Becker data.

Of the 16 cities using reservoir water, 8 have soft water, 2 are moderately hard, 2 are hard, and 4 are very hard (Figures 16, 17, 18, and 19). All waters are a calcium or calcium-sodium type, with some combination of bicarbonate and/or sulfate; none are magnesium or chloride types.

Thirty-one of the cities rely upon natural streamflow. Ten have soft water, nine of which have calcium or calcium-sodium type water with bicarbonate the principal anion (Figure 20). Of the 5 cities with moderately hard water, all have calcium-bicarbonate type water (Figure 21). Of the 7 cities with hard water, 5 of them clearly have calcium-bicarbonate type water, one is a sodium-chloride type, and one is calcium-sulfate-bicarbonate type (Figure 22). Of the 9 cities with very hard water, water types are either calcium, calcium-sodium, or sodium with all anion types represented (Figure 23).

Of the 4 examples of Great Lakes waters, all are hard and of the calcium-bicarbonate type (Figure 24).

Fourteen of the 100 largest U.S. cities use groundwater. Of the 4 that have soft groundwaters, 2 are dominantly of the sodium-bicarbonate type, one is a calcium-magnesium-bicarbonate type, and the other is a sodium-chloride-bicarbonate type (Figure 25). The one example of moderately hard groundwater is of the sodium-calcium-bicarbonate type (Figure 26); and of the 9 with very hard groundwaters, all but 2 have calcium or calcium-magnesium-bicarbonate type water (Figure 27). One is magnesium-calcium-sulfate type, and the other is sodium-calcium-chloride-bicarbonate type.

Two cities have large inland-lake water supplies. One is

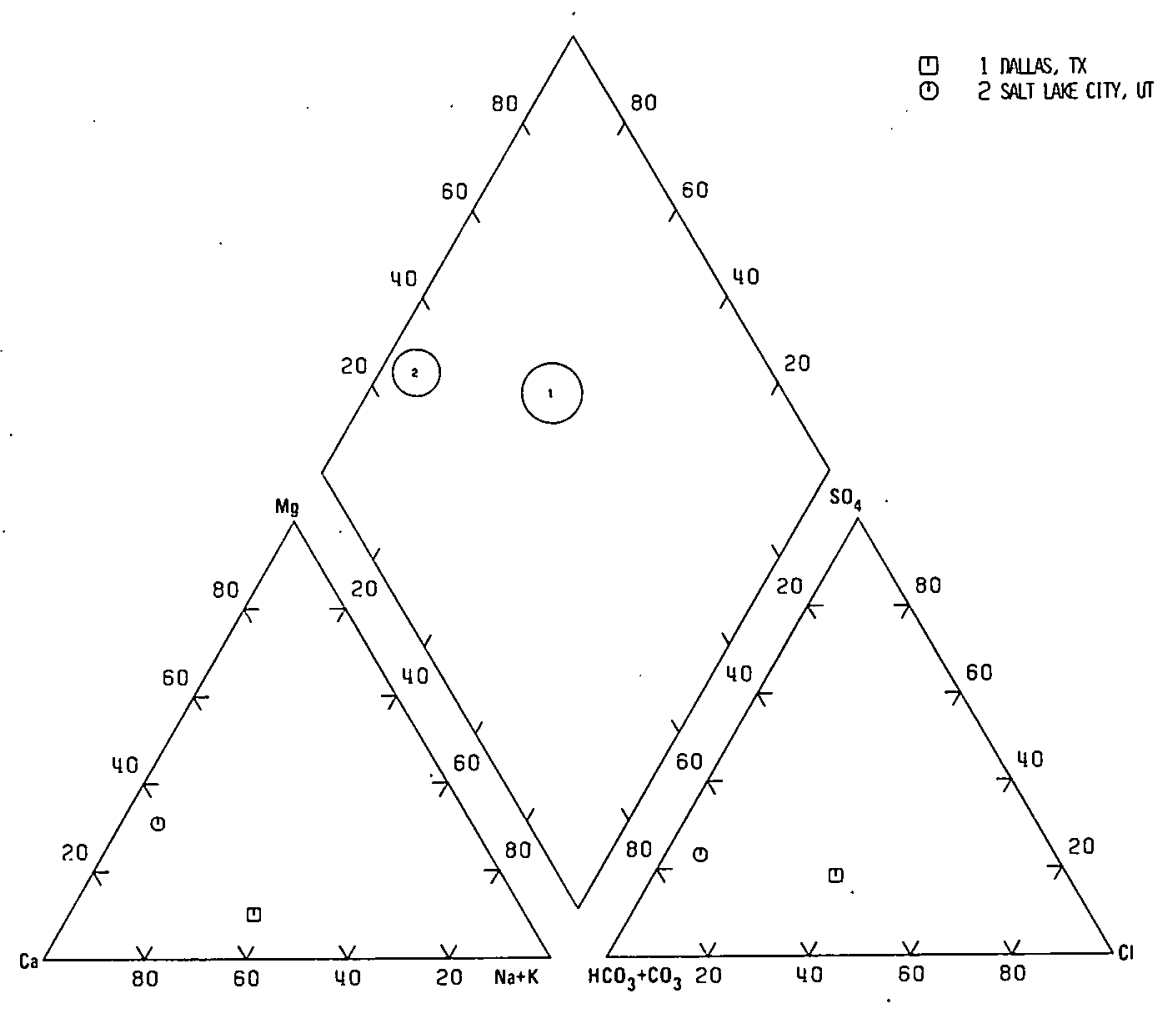

FIGURE 18 Reservoir hard water. SOURCE: Data from Durfor and Becker (1964). 
FIGURE 19 Reservoir very hard water. SOURCE: Data from Durfor and Becker (1964).

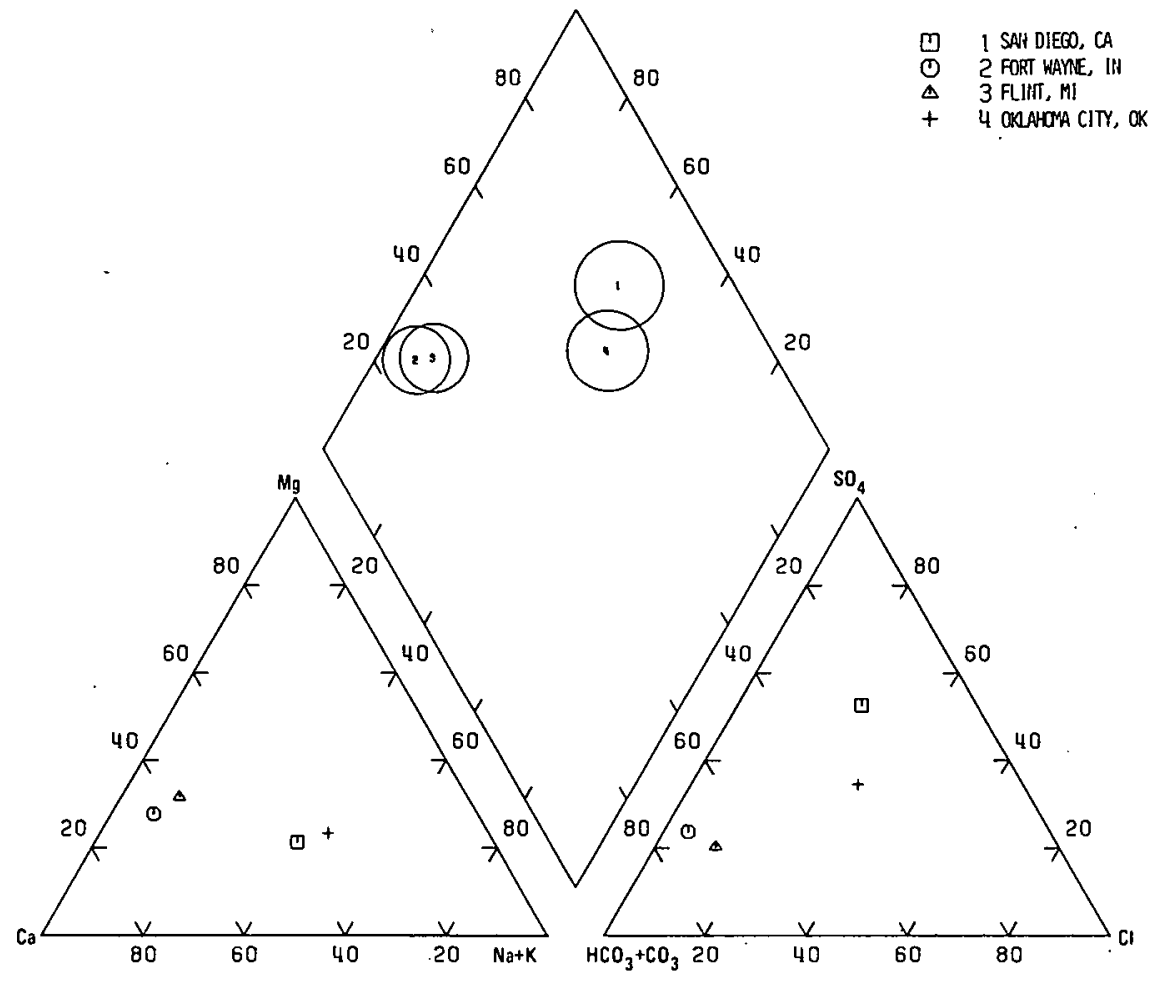

FIGURE 20 Natural streamflow soft water. SOURCE: Data from Durfor and Becker (1964).

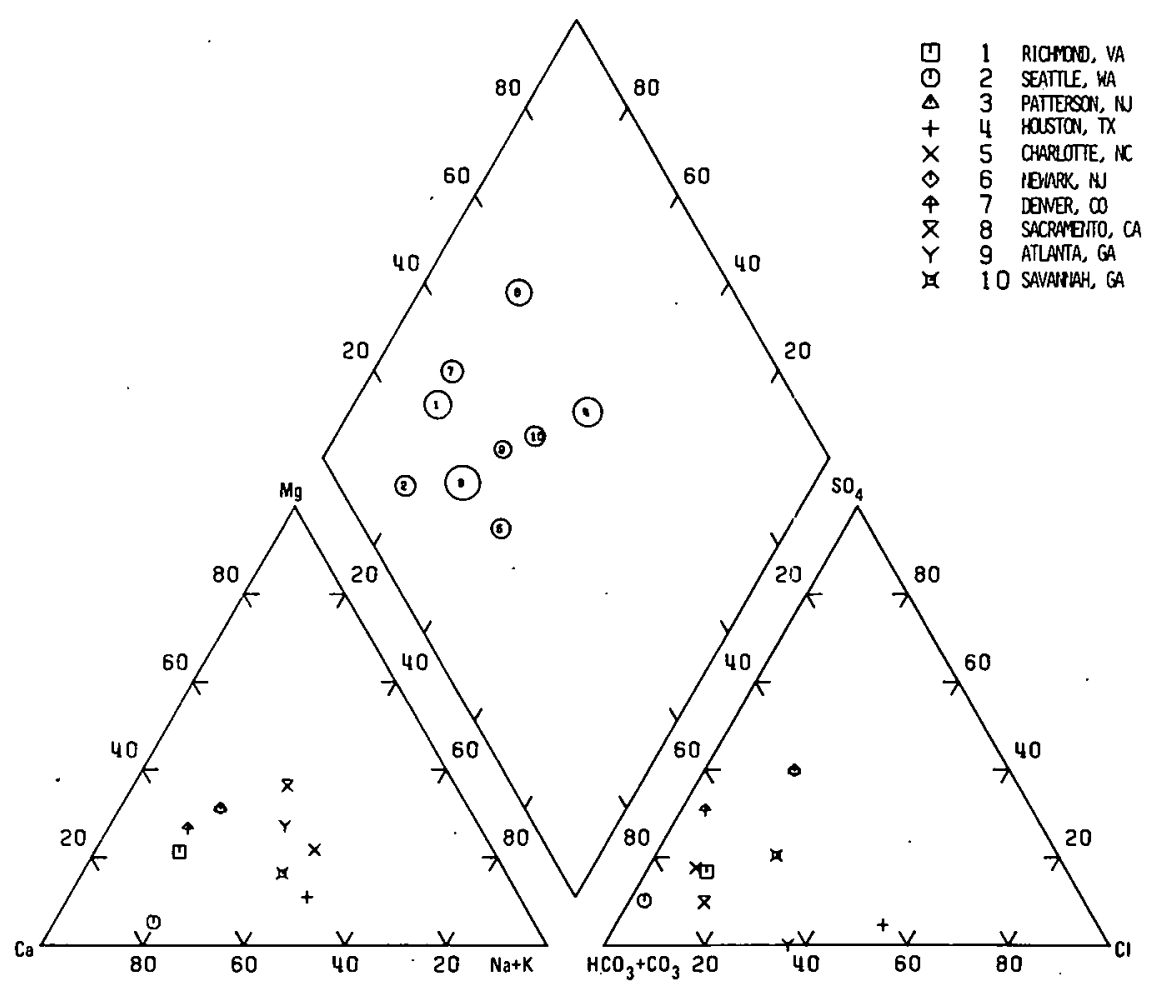




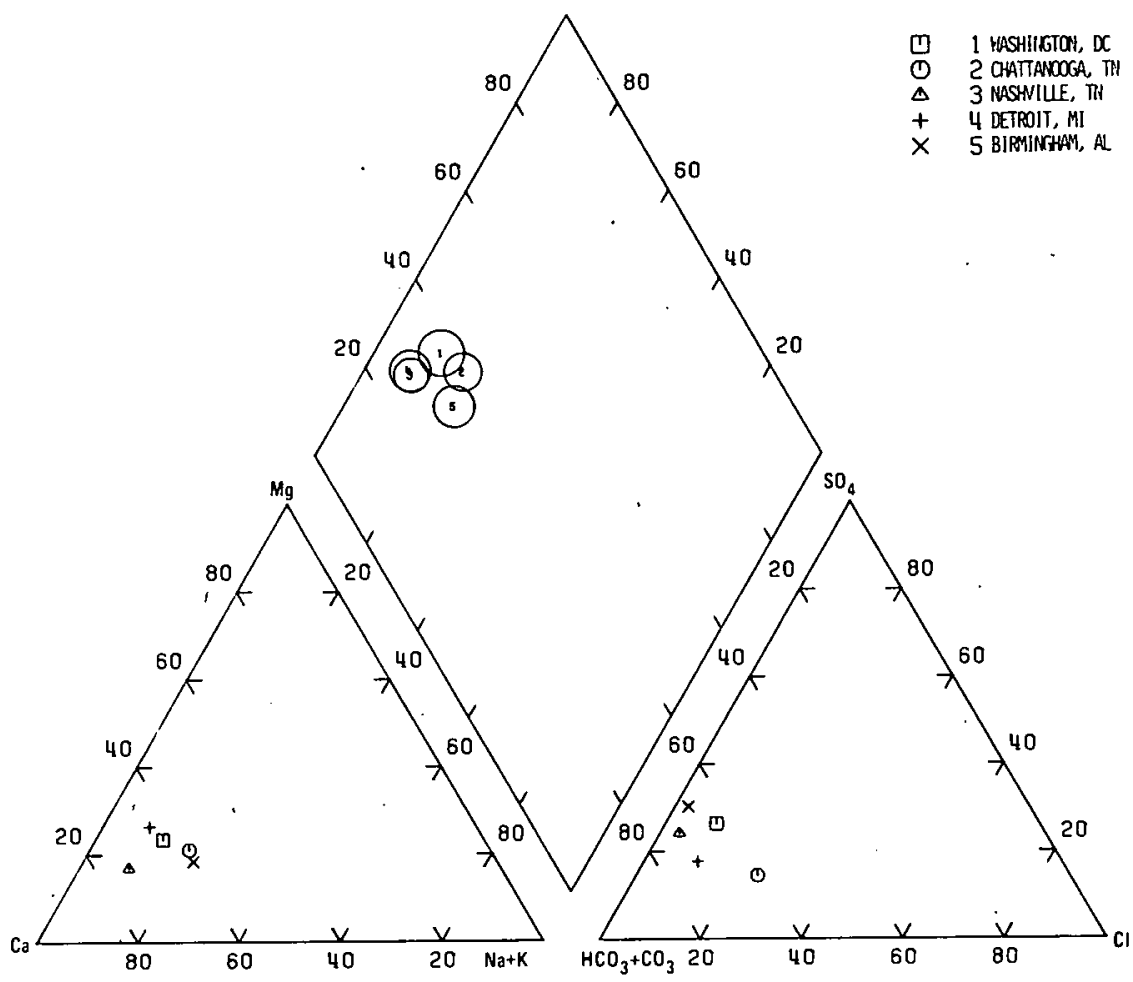

FIGURE 21 Natural streamflow moderately hard water. SOURCE: Data from Durfor and Becker (1964).

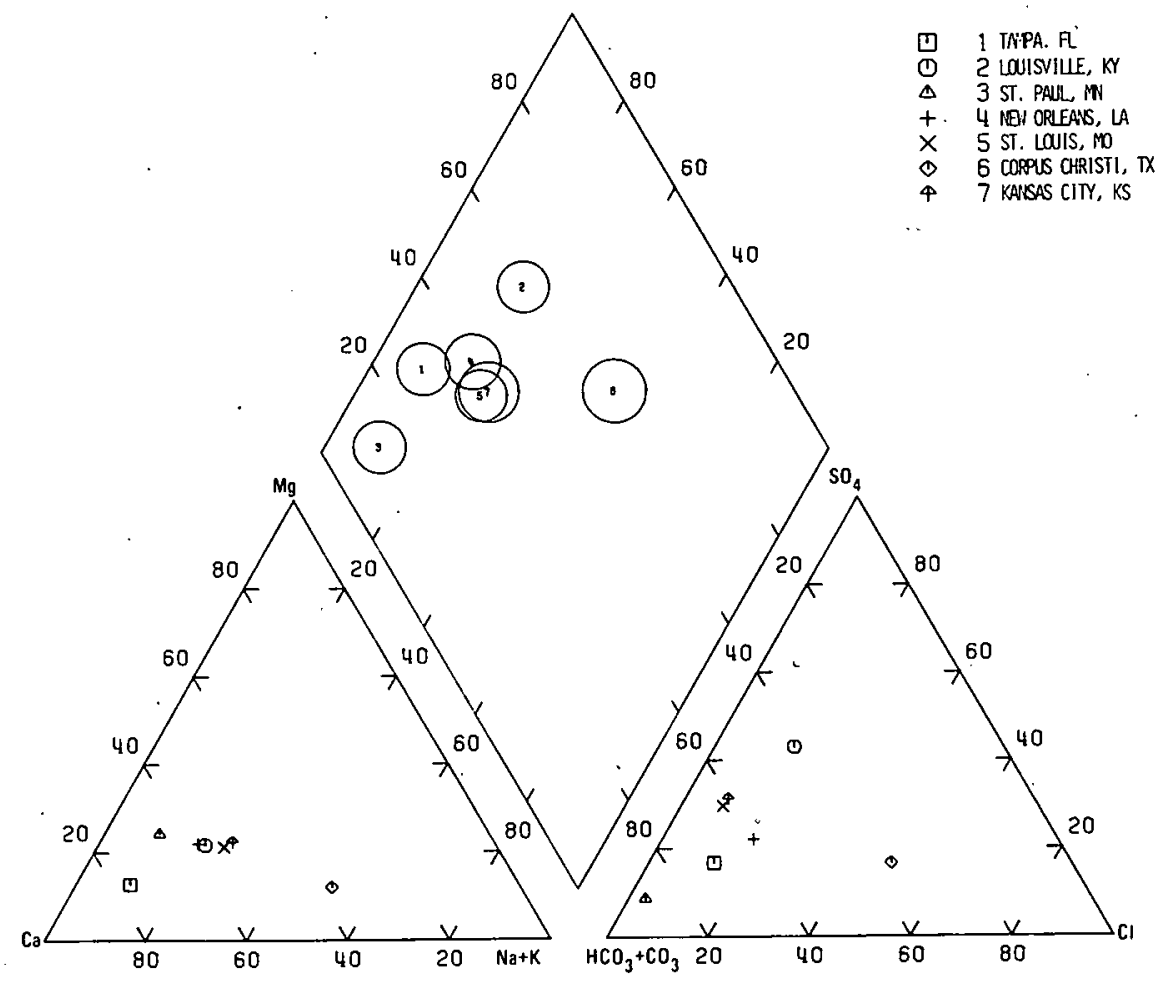

FIGURE 22 Natural streamflow hard water. SOURCE: Data from Durfor and Becker (1964). 
FIGURE 23 Natural streamflow very hard water. SOURCE: Data from Durfor and Becker (1964).

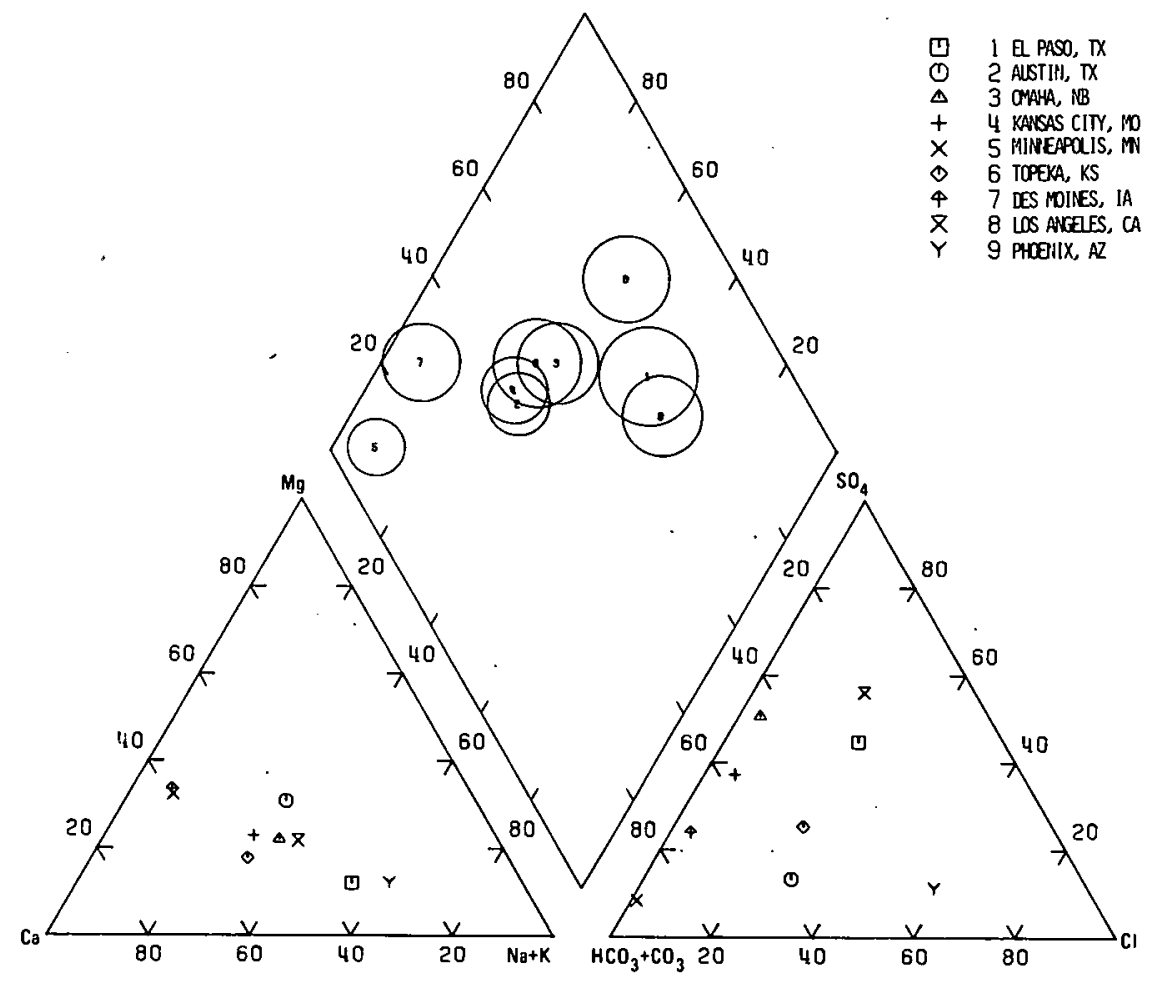

FIGURE 24 Great Lakes hard water. SOURCE: Data from Durfor and Becker (1964).

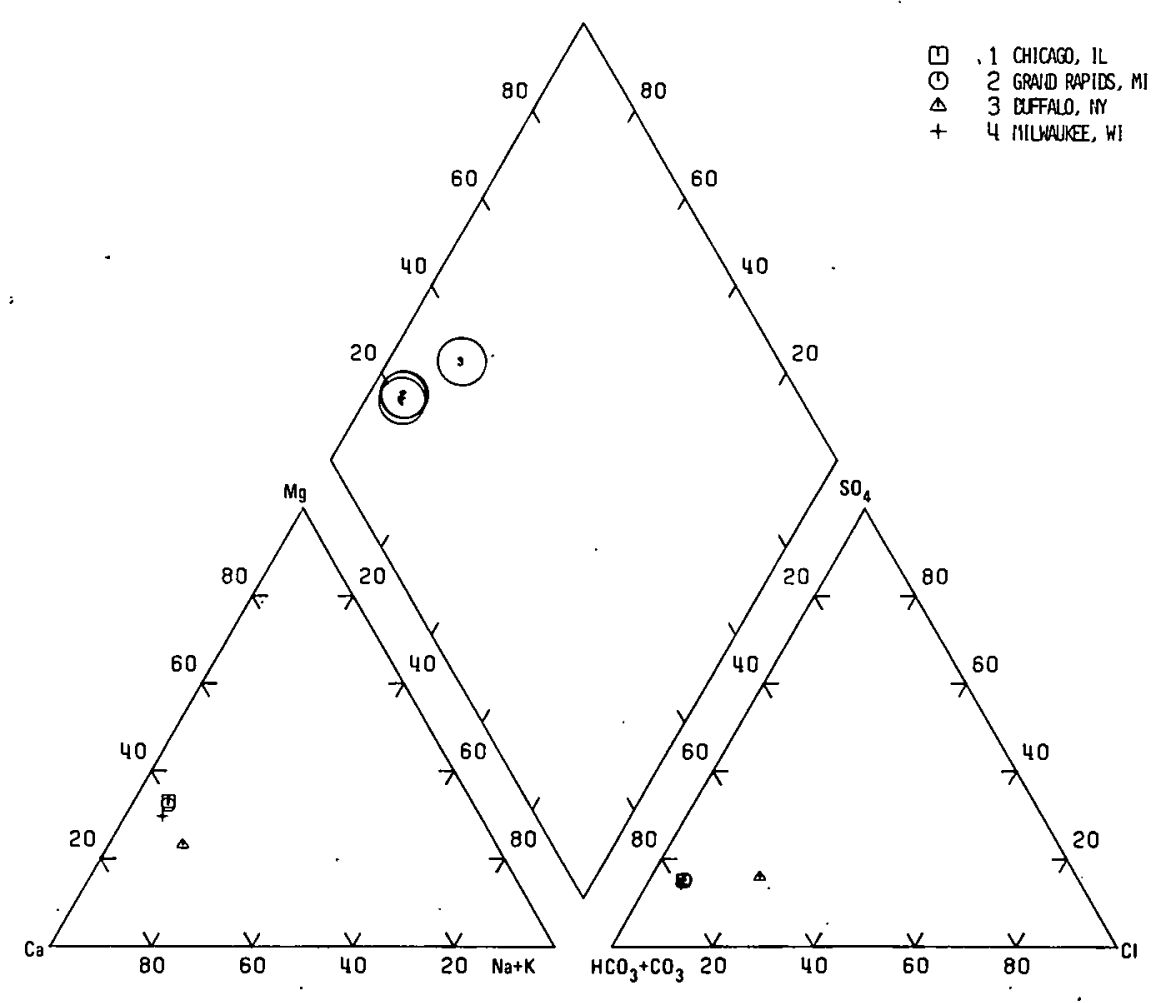




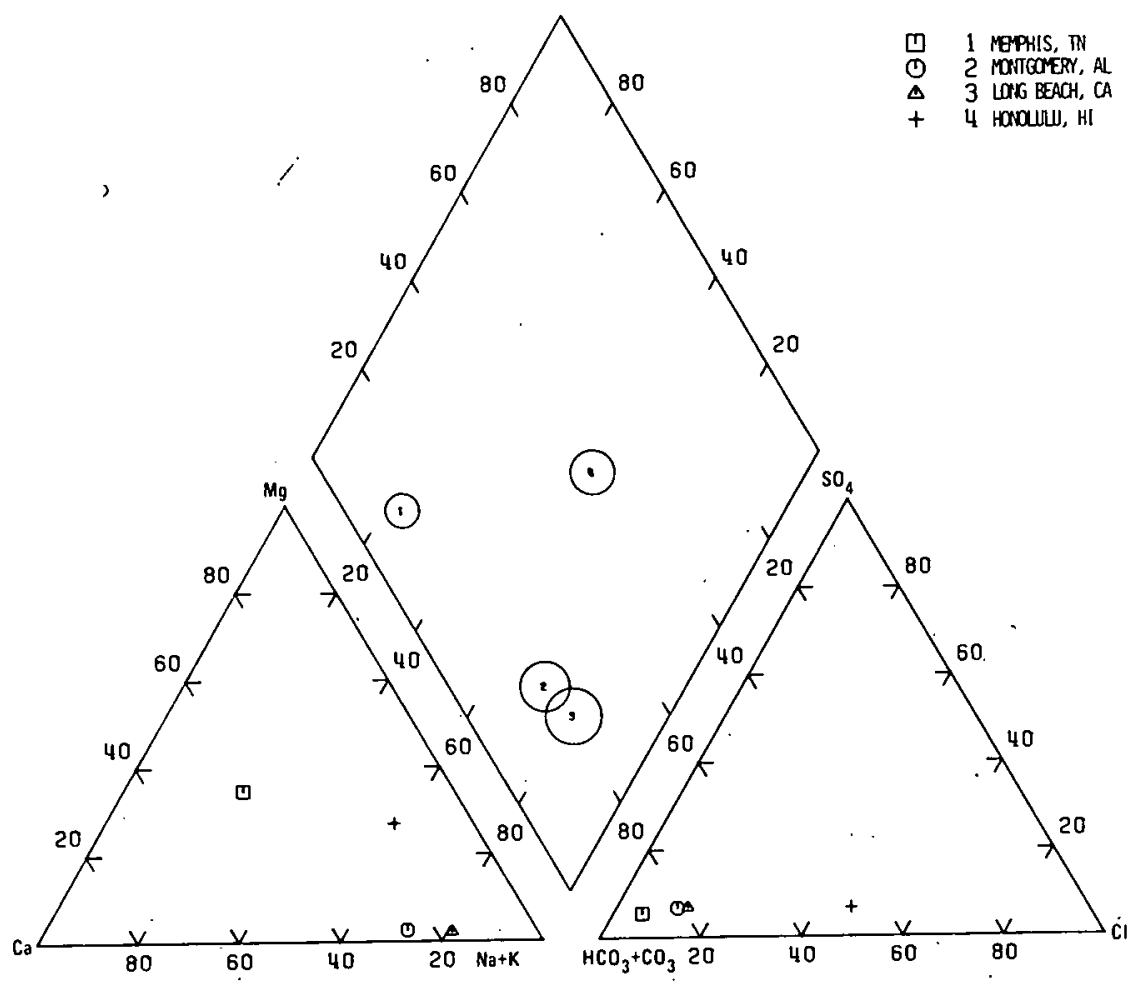

FIGURE 25 Groundwater soft. SOURCE: Data from Durfor and Becker (1964).

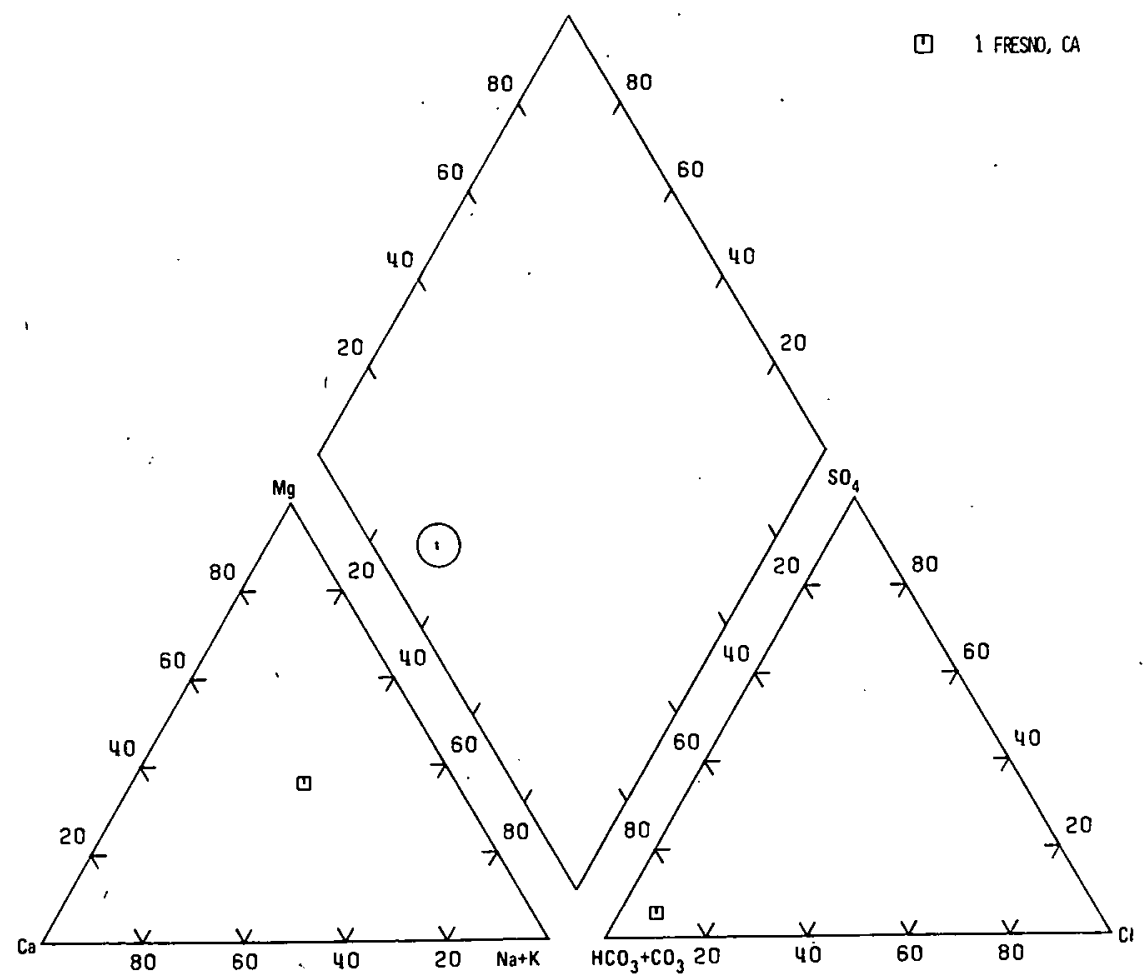

FIGURE 26 Groundwater moderately hard. SOURCE: Data from Durfor and Becker (1964). 
FIGURE 27 Groundwater very hard. SOURCE: Data from Durfor and Becker (1964).

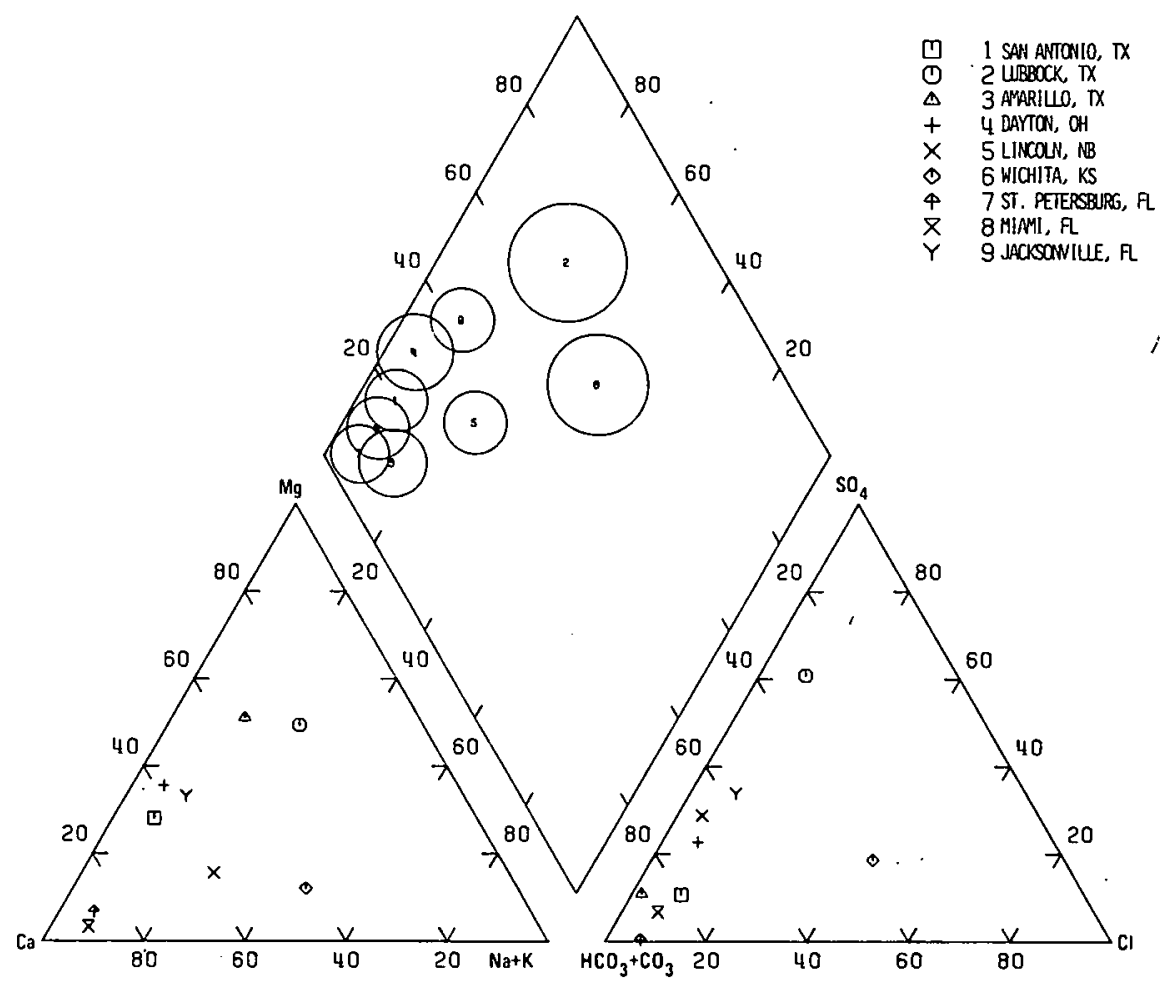

FIGURE 28 Large lake soft water. SOURCE: Data from Durfor and Becker (1964).

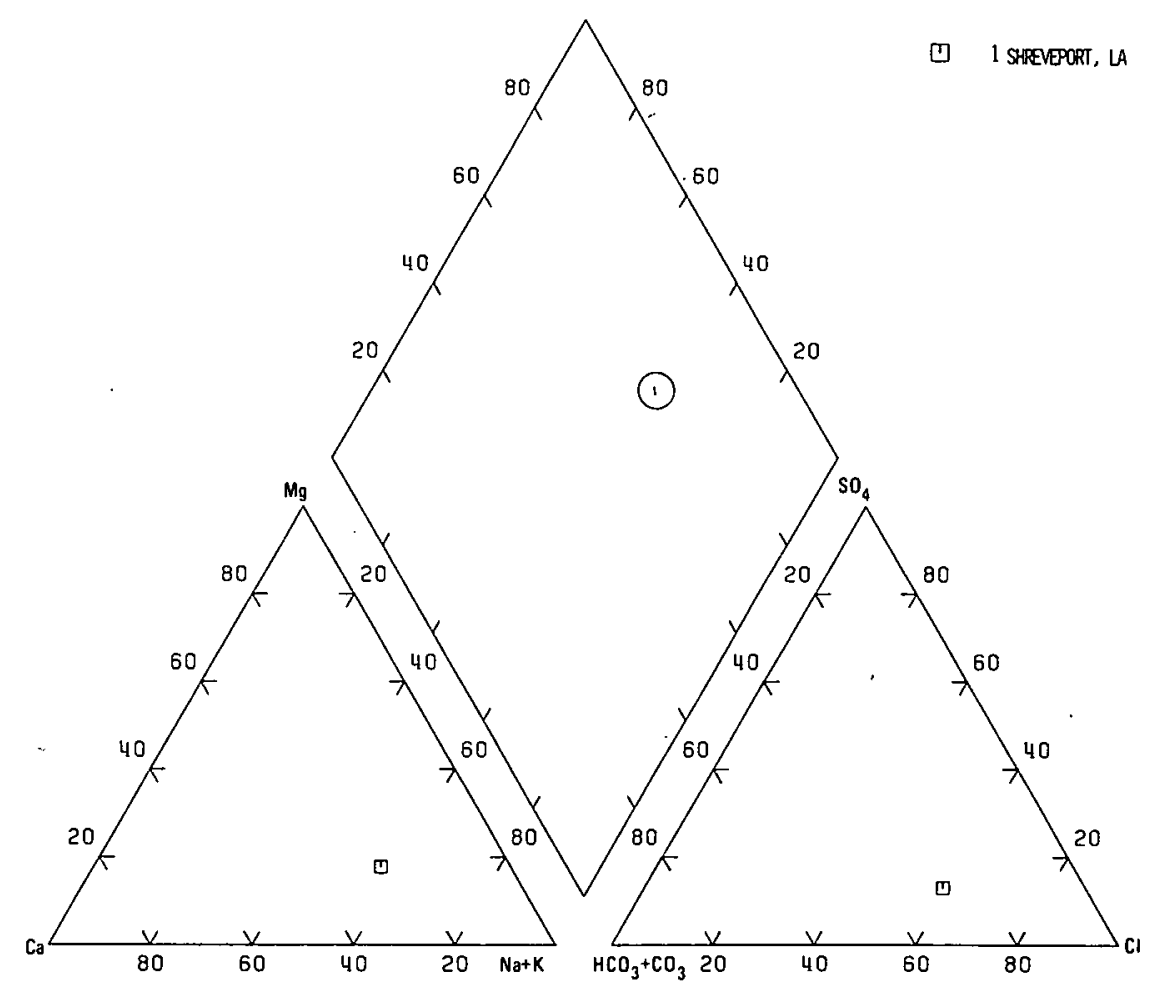




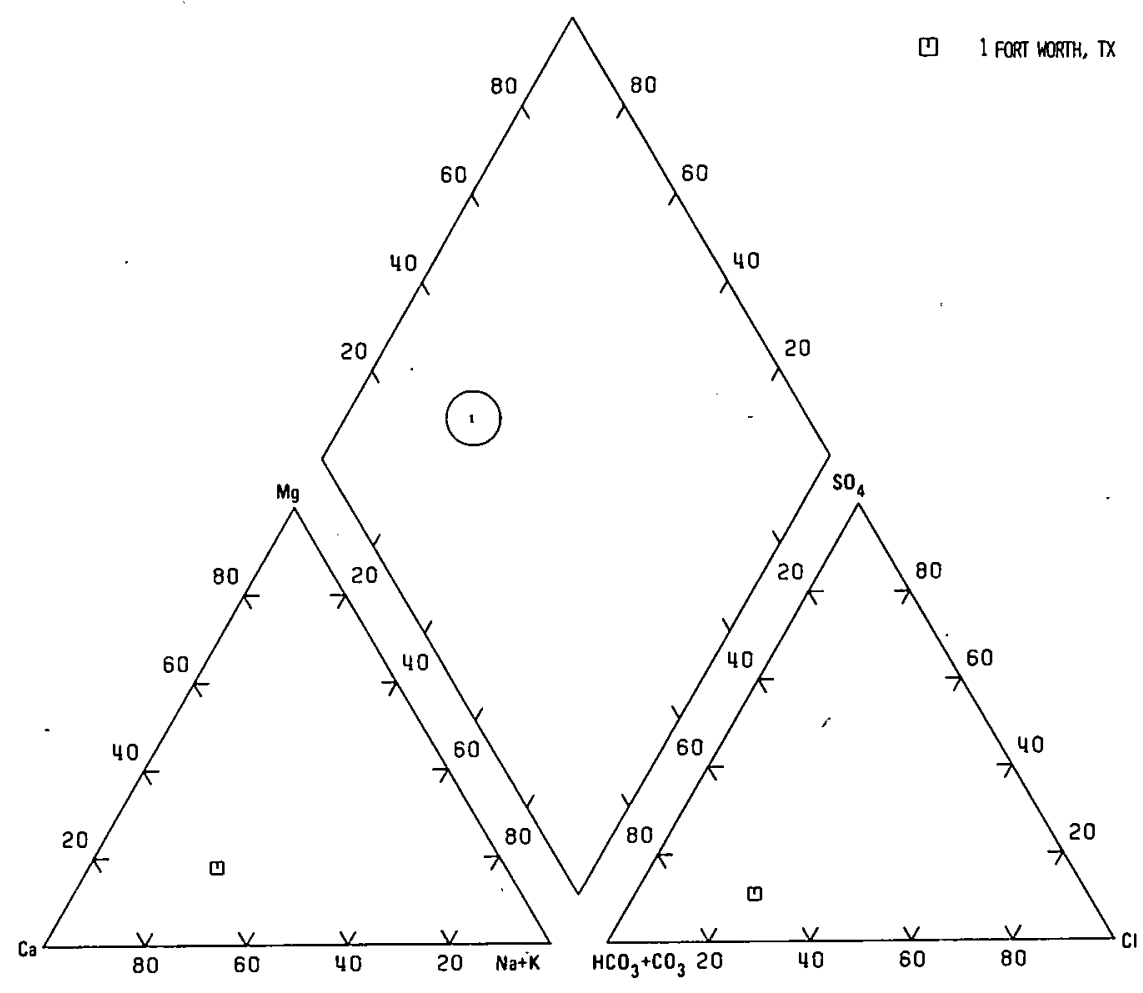

FIGURE 29 Large lake hard water. SOURCE: Data from Durfor and Becker (1964) soft sodium-chloride type (Figure 28), and the other is hard calcium-bicarbonate type (Figure 29).

An analysis of data from Durfor and Becker (1964) shows that a wide range of waters are used, groundwaters are predominantly very hard calcium-bicarbonate types, Great Lakes waters are hard calcium-bicarbonate types, and natural streamflow and reservoir waters range greatly in hardness and water type.

\section{SUMMARY}

Natural waters may be characterized by a measure of the mineral concentration (total dissolved solids or, for certain purposes, hardness) and by a descriptive name based upon the dominance or predominance of specific cations and anions. No clear relation between natural water and terrain has yet been established with regard to trace elements.

Rainfall is dilute, commonly sodium-chloride type water, which through evaporation contributes to buildup of salts in arid regions and is vital to chemical weathering in the humid regions.

Most major U.S. streams are calcium-bicarbonate type waters of moderate hardness. Those with lower mineral concentrations are more influenced by rainfall; those with higher concentrations are the result of mineral precipitation, evaporation, and/or addition of mineralized groundwater. The degree of solubility of the rock terrain and length of time the water is in contact with it play key roles.

Groundwater typically reflects the composition of the enclosing rocks, but the previous composition of the water, residence time, and flow path are significant factors. In general, as the mineral concentration of groundwater increases, the water changes from the bicarbonate through the sulfate to the chloride type.

The oceans are the chief reservoirs of the hydrosphere, containing water of the sodium-chloride type that is high in total dissolved solids.

In the framework of the hydrologic cycle, variations of the composition of natural waters have been explained on the degree of influence of rainfall, chemical weathering of rock, and concentration through mineral precipitation and/or evaporation.

Data on the character of waters in the United States are reviewed, and the widespread occurrence of calciummagnesium-bicarbonate-carbonate type waters is noted.

Maps portraying regional variations in water characteristics, from several points of view, are provided.

Data on the hardness and water type for the water sources of 67 of the 100 largest U.S. cities are recast into Piper diagrams to show the diversity-ranging from soft through very hard waters-with a majority having calcium-bicarbonate type waters. 


\section{CARDIOVASCULAR DISEASE}

\section{REFERENCES}

Ackerman, E. A., and G. O. G. Lof. 1959. Technology in American Water Development. Johns Hopkins Press, Baltimore, Md. Pp. 210 217.

Anderson, P. 1963. Variations in the chemical character of the Susquehanna River at Harrisburg, Pennsylvania. U.S. Geol. Surv. Water Supply Pap. 1779-B. 17 pp.

Angino, E. E., O. K. Galle, and T. C. Waugh. 1969. Fe, Mn, Ni, Co, Sr, $\mathrm{Li}, \mathrm{Zn}$, and $\mathrm{SiO}_{2}$ in streams of the lower Kansas River basin. Water Resour. Res. 5(3):698-705.

Angino, E. E., L. M. Magnuson, and T. C. Waugh. 1974. Mineralogy of suspended sediment and concentration of $\mathrm{Fe}, \mathrm{Mn}, \mathrm{Ni}, \mathrm{Zn}, \mathrm{Cu}$, and $\mathrm{Pb}$ in water and $\mathrm{Fe}, \mathrm{Mn}$, and $\mathrm{Pb}$ in suspended load of selected Kansas streams. Water Resour. Res. 10(6):1187-1191.

Brown, E., M. W. Skougstad, and M. J. Fishman. 1970. Methods for collection and analysis of water samples for dissolved minerals and gases, Chap. Al in Book 5 of Techniques of Water Resources Investigations of the U.S. Geological Survey. U.S. Government Printing Office, Washington, D.C. 160 pp.

Carroll, D. 1962. Rainwater as a chemical agent of geologic processes: A review. Geochemistry of Water. U.S. Geol. Surv. Water Supply Pap. 1535-G. 18 pp.

Chebotarev, I. I. 1955. Metamorphism of natural waters in the crust of weathering. Geochim. Cosmochim. Acta 8:22-48 and 137-170.

Corbett, R. G., and B. M. Manner. 1975. Water Quality and Potential Environmental Impact of Highway Runoff in Ohio. Ohio Department of Transportation and Federal Highway Administration. 157 pp.

Davis, G. H. 1961. Geologic control of mineral composition of stream waters of the eastern slope of the southern coast ranges of California. U.S. Geol. Surv. Water Supply Pap. 1535-B. 30 pp.

Durfor, C. N., and E. Becker. 1964. Chemical quality of public water supplies of the United States and Puerto Rico. U.S. Geol. Surv. Hydrol. Invest. Atlas HA-200.

Feth, J. H. 1965. Calcium, sodium, sulfate, and chloride in stream water of the western conterminous United States to 1957. U.S. Geol. Surv. Hydrol. Invest. Atlas HA-189.

Feth, J. H., et al. 1965. Preliminary map of the conterminous United States showing depth to and quality of shallowest ground water containing more than 1,000 parts per million dissolved solids. U.S. Geol. Surv. Hydrol. Invest. Atlas HA-199.

Ficke, J. F., and R. O. Hawkinson. 1975. The National Stream Quality Accounting Network (NASQAN): Some questions and answers. U.S. Geol. Surv. Circ. 719. 23 pp.

Gibbs, R. G. 1970. Mechanisms controlling world water chemistry. Science 70(3962): 1088-1090.

Hem, J. D. 1970. Study and interpretation of the chemical characteristics of natural water. U.S. Geol. Surv. Water Supply Pap. 1473. 363 pp.
Hill, R. A. 1942. Salts in irrigation water. Trans. Am. Soc. Civil Eng. 107:1478-1493.

Hutchinson, G. E. 1957. A treatise on limnology, Vol. 1 in Geography, Physics and Chemistry. John Wiley, New York. 1015 pp.

Kopp, J. F., and R. C. Kroner. 1968. A Five-Year Summary of Trace Metals in Rivers and Lakes of the United States. U.S. Department of the Interior, Washington, D.C.

Langelier, W. F., and H. F. Ludwig. 1942. Graphical methods for indicating the mineral character of natural waters. J. Am. Water Works Assoc. 34:335-352.

Livingstone, D.A. 1963. Chemical composition of rivers and lakes. Data of Geochemistry. 6th ed. U.S. Geol. Surv. Prof. Pap. 440-G. 64 pp.

Mack, L. E. 1971. Ground water management in development of a national policy on water. Prepared for the National Water Commis sion. NTIS Publ. NWC-EES-71-004. 176 pp.

Mason, B. 1958. Principles of Geochemistry. John Wiley, New York. $310 \mathrm{pp}$.

Miller, J. P. 1961. Solutes in small streams draining single rock types, Sangre de Cristo Range, New Mexico. U.S. Geol. Surv. Water Supply Pap. 1535-F. 23 pp.

Murray, C. R., and E. B. Reeves. 1970. Estimated use of water in the United States in 1970. U.S. Geol. Surv. Circ. 676. $37 \mathrm{pp}$.

NRC.Planning Committee for the International Symposium on Eutrophication. 1969. Eutrophication: Causes, Consequences, Correctives. Proceedings of a symposium. National Academy of Sciences, Washington, D.C. $661 \mathrm{pp}$.

Piper, A. M. 1944. A graphic procedure in the geochemical interpretation of water analyses. Eos Trans. Am. Geophys. Union 914-923.

Rainwater, F. H. 1962. Stream composition of the conterminous United States. U.S. Geol. Surv. Hydrol. Invest. Atlas HA-61.

Vitousek, P. M. 1977. The regulation of element concentrations in mountain streams in the northeastern United States. Ecol. Monogr. 47:65-87.

White, D. E., J. D. Hem, and G. A. Waring. 1963. Chemical composition of subsurface waters. Data of Geochemistry. 6th ed. U.S. Geol. Surv. Prof. Pap. 440-F. 67 pp.

Wilder, H. B., and L. J. Slack. 1971a. Chemical quality of water in streams of North Carolina. U.S. Geol. Surv. Hydrol. Invest. Atlas HA-439.

Wilder, H. B., and L. J. Slack. 1971b. Summary of data on chemical quality of streams in North Carolina 1943-67. Prepared in cooperation with the North Carolina Department of Water and Air Resources. U.S. Geol. Surv. Water Supply Pap. 1895-B. 236 pp.

Wood, W. W. 1976. Guidelines for collection and field analysis of groundwater samples for selected unstable constituents, Chap. D2 in Book 1 of Techniques of Water Resources Investigations of the U.S. Geological Survey. U.S. Government Printing Office, Washington, D.C. 24 pp. 


\title{
Some Interactions Among Elements and Binding Ligands That May Relate to Cardiovascular Disease
}

\author{
HAROLD H. SANDSTEAD
}

This discussion, chiefly involving cadmium, calcium, chromium, copper, manganese, molybdenum, selenium, sodium, and zinc, is, of necessity, speculative. Most of the relevant information comes from experiments conducted on animals. In full recognition that extrapolation from such studies to man is hazardous, incompletely understood observations on animals, which might have implications for human cardiovascular disease, have been included. For purposes of this discussion, the term interactions is used in a broad sense. Some of the known and suspected interactions between elements are shown graphically in Figure 30 . Of these interactions, some that may be of significance for the cardiovascular system will be discussed. Although our understanding of the molecular basis for many of the interactions is incomplete, it is known that chemically and physically similar elements often interact competitively for a specific ligand, i.e., the ion or substance to which they can bind (Hill and Matrone, 1970). Not all interactions between elements are competitive; some are additive or synergistic, and others are indirect. In some instances, the elements act at different steps in a metabolic cycle.

\section{ZINC AND OTHER METALS}

Some interactions within the intestine involving nonabsorbed organic ligands may be important for the cardiovascular system. The formation of an insoluble complex by zinc and phytate is an example of such an interaction. As a result, the intestinal absorption of zinc is decreased (Oberleas, 1973; Klevay, 1977). Calcium appears to facilitate the formation of this insoluble complex. In contrast, phytate does not appear to inhibit the absorption of copper severely (Klevay, 1977). Zinc can apparently form an insoluble complex with dietary fiber (Reinhold, 1975; Ismail-Beigi et al., 1977). Thus consumption of diets very high in dietary fiber and phytate may affect the availability of zinc for intestinal absorption. On the other hand, more modest intakes of dietary fiber, such as may be consumed in the United States, do not appear to adversely affect intestinal absorption of zinc (Sandstead et al., 1978).

High levels of dietary zinc can impair the intestinal absorption of copper (Starcher, 1969), presumably by induction of the synthesis of metallothionein in the intestinal mucosal cells (Cherian, 1977) and the subsequent displacement of the zinc by copper, which has a higher binding affinity for thiolate sulfurs (Hartman and Weser, 1977). It appears that metallothionein regulates the absorption of copper in a manner analogôus to the regulation of iron absorption by intestinal mucosal cell ferritin (Evans and Johnson, 1978). Impairment of copper homeostasis by intakes as low as $150 \mathrm{mg}$ of zinc daily has also been observed in humans treated for sicklecell anemia (Prasad et al., 1978).

The above-cited effects of phytates and dietary fiber on zinc absorption and the inhibitory effects of high levels of zinc on copper metabolism might have implications for the cardiovascular system because an increased intake of zinc relative to copper will increase the serum cholesterol concentrations of rats (Klevay, 1973, 1977) and mice (Jacob et al., 1977), and copper deficiency has been found 


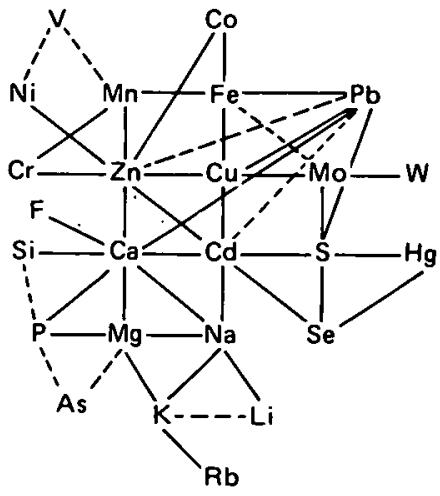

FIGURE 30 Interactions among the elements. Some illustrative interactions are shown. Known interactions are indicated by solid lines, while suspected interactions are indicated by broken lines. Many of the interactions are competitive. Others are either additive or synergistic. Interactions between two elements may be influenced by other elements that are present and that can interact with the two elements in question. Some interactions are indirect in that the elements in question influence different steps in a metabolic pathway. SoURCE: After Sandstead (1976, 1978).

to increase serum cholesterol, impair formation of aortic elastin, and cause myocardial necrosis and rupture (Allen and Klevay, 1978a). Impaired copper nutriture apparently causes increased cholesterol synthesis in the liver and increased clearance of cholesterol into the plasma and bile (Allen and Klevay, 1978b). Abnormalities in elastin (Hill et al., 1967) and collagen (Chou et al., 1969) caused by copper deficiency have been described. The abnormalities in the myocardium are less well understood, though electron microscopic findings have been described (Leigh, 1975).

In cattle, interactions between copper and molybdenum (and sulfur) are important for health (Bremner and Davis, 1973); apparently, they can react with each other to form an insoluble complex within the rumen. In addition, low concentrations of molybdenum in the rumen apparently can lead to the generation of sulfide, which precipitates copper. It therefore seems possible that molybdenum nutriture might play a role in the occurrence of cardiovascular abnormalities related to impaired copper homeostasis.

Zinc and calcium can apparently interact in vivo. Increased dietary calcium will cause a shift of zinc from the liver to the bone (Heth et al., 1966). Such a shift presumably decreases the ratio of zinc to copper in liver. In this regard, it has been shown that supplementation of human diets with calcium decreases the serum concentration of cholesterol (Albanese et al., 1973).

Zinc may interact indirectly with chromium and manganese through its influence on carbohydrate metabolism. Zinc appears necessary for the release of insulin from the beta cells of the pancreas (Huber and Gershoff, 1973) and for normal glucose tolerance (Hendricks and Mahoney, 1972), while manganese is essential for the integrity of the islet tissue. A diabetes-mellitus-like syndrome can be produced in guinea pigs by manganese deficiency (Everson and Shrader, 1968; Shrader and Everson, 1968). Chromium seems to have a role in the utilization of glucose and amino acids by peripheral tissues. It is particularly potent when it is present as part of an organic complex that has been called "glucose tolerance factor" (Mertz et al., 1974). Chromium deficiency in humans has been shown to impair both carbohydrate and amino acid metabolism (Jeejeebhoy et al., 1977). The above observations on the effects of zinc, manganese, and chromium deficiencies on the metabolism of carbohydrates have implications for the cardiovascular system because the findings suggest an interference with the insulin-mediated aspects of carbohydrate metabolism. Such an interference may be analogous to what occurs in diabetes mellitus. The adverse effects of diabetes mellitus on the cardiovascular system are wellknown.

Zinc and chromium also appear to interact within intestinal epithelial cells. Both metals seem to bind to the same low-molecular-weight ligand (Hahn and Evans, 1975), which has been found to facilitate the intestinal absorption of zinc (Evans et al., 1975). The zinc nutriture of rats seems to influence intestinal absorption of chromium. Zinc-deficient rats were found to absorb more chromium (Hahn and Evans, 1975), which is an interesting finding in view of the roles of these two metals in carbohydrate metabolism.

\section{CADMIUM AND OTHER METALS}

Interactions of cadmium with essential elements that might be of significance for the cardiovascular system are those with zinc, copper, calcium, selenium, sulfur, and sodium. Some of these have been reviewed by Fox (1974).

Cadmium-zinc interactions have received the most attention. An increased ratio of cadmium to zinc in the renal cortex has been associated with increased blood pressure (Schroeder, 1967; Lener and Bibr, 1971) and/or increased atherosclerosis (Voors et al., 1973) in humans and increased blood pressure in rats (Schroeder and Vinton, 1962; Perry and Erlanger, 1974). In addition, it has been suggested, but not proved, that increased levels of cadmium in water or foods may contribute to the occurrence of essential hypertension in man (Schroeder and Perry, 1956; Perry, 1973).

Under proper dietary and environmental conditions it is possible to induce increased blood pressure in rats by adding cadmium to their drinking water (Schroeder and 
Vinton, 1962; Perry and Erlanger, 1974, 1976; Perry et al., 1977). The level of cadmium required is relatively low (0.1-10 ppm), and the duration of exposure long (6-12 months). With increased length of exposure (12 months), lower levels of cadmium (0.1-2.5 ppm) cause the blood pressure to continue to increase, whereas the higher levels $(10-50 \mathrm{ppm})$ do not. It seems that the level of zinc in the diet or drinking water must be within a specific range for increased blood pressure to occur. In one study, the feeding of $12.5 \mathrm{ppm}$ zinc in the diet along with $5 \mathrm{ppm}$ cadmium in the drinking water did not result in increased blood pressure after 14 months (Doyle et al., 1975), although sodium retention was increased. In contrast, increased blood pressure occurred in rats fed $12.5 \mathrm{ppm}$ zinc in drinking water with $22.3 \mathrm{ppm}$ zinc in the diet when $2.5 \mathrm{ppm}$ cadmium was added to the drinking water for 12 months (H. M. Perry, cited by Sandstead, 1976). A higher intake of zinc, $50 \mathrm{ppm}$ in drinking water plus 22.3 ppm in the diet, along with $2.5 \mathrm{ppm}$ cadmium in drinking water, caused the blood pressure to increase significantly after 6 months. In contrast, $100 \mathrm{ppm}$ zinc in drinking water, plus the above diet, prevented an increase in blood pressure when either 2.5 or $10 \mathrm{ppm}$ cadmium was given. At a level of $200 \mathrm{ppm}$ zinc in drinking water, plus the above diet, the rats developed increased blood pressure although no cadmium was given. Subsequent work has confirmed the finding that high-zinc intakes without added cadmium caused increased blood pressure (Perry and Erlanger, 1978) and prevented cadmium-induced increased blood pressure when given with cadmium. Thus it appears that the interaction between cadmium and zinc is dependent on the relative amounts of the two elements. At low levels of cadmium, increased blood pressure will not occur unless the amount of zinc is within a specific range, and zinc alone, when given in sufficient amounts, will cause increased blood pressure. It seems possible that induction of metallothionein by cadmium (Winge and Rajagopalan, 1972) and zinc (Bremner and Davis, 1975) and the relative binding of cadmium and zinc to metallothionein may contribute to this phenomenon. It should be noted that the induction of hypertension in humans by cadmium has not been established.

Cadmium, zinc, and copper interact in the arterial wall (Hill et al., 1963). Increased intakes of cadmium cause histologic abnormalities that resemble those of copper deficiency. When increased zinc is given along with the cadmium, the abnormalities are even more severe. The findings suggest that cadmium and/or zinc interfere with the copper-mediated cross-linking of elastin (Hill et al., 1967) and collagen (Chou et al., 1969).

Cadmium, zinc, and copper also interact in the liver. When $1 \mathrm{ppm}$ cadmium and $30 \mathrm{ppm}$ zinc were fed to rats, a 58 percent decrease in serum ceruloplasmin activity was observed along with a decline in the liver and blood copper and a thinning of cortical bone. The effect of cadmium was exacerbated when the amount of either cadmium or zinc was substantially increased (Mills, 1974). The effects of these interactions on hepatic cholesterol metabolism have not been defined. It might be expected that increased zinc or cadmium would increase cholesterol synthesis through interference with copper metabolism. Both cations induce the synthesis of metallothionein (Winge and Rajagopalan, 1972; Bremner and Davis, 1975). Copper will displace both zinc and cadmium from metallothionein (Hartman and Weser, 1977). Copper bound to metallothionein can apparently be taken up by lysosomes (Porter, 1974) from which copper is excreted into the bile (Evans, 1973). The resulting decrease in liver copper might alter hepatic cholesterol metabolism causing increased levels of plasma cholesterol (Allen and Klevay, 1978a, 1978b).

Cadmium and calcium interact in the intestine and elsewhere in the body. A low dietary intake of calcium is associated with an increased intestinal absorption of cadmium in rats (Larsson and Piscator, 1971), whereas increased dietary calcium decreases cadmium absorption. Cadmium can inhibit the absorption of calcium. While direct inhibition seems possible, cadmium has been shown to inhibit the synthesis of the vitamin $D$ derivative, 1-25 (OH) $)_{2}$ cholecalciferol (Suda et al., 1974) by the renal tubule. When cadmium inhibits calcium absorption, a mobilization of calcium and zinc from bone, mediated by Parathormone, presumably occurs (Hurley and Tao, 1972). Mobilization of zinc from the bone would increase the ratio of zinc to copper in the liver and might result in an increased concentration of serum cholesterol (Klevay, 1973; Allen and Klevay, 1978a, 1978b).

Cadmium interacts indirectly with sodium. A low intake of cadmium (5 ppm) will induce sodium retention in rats fed either $12.5 \mathrm{ppm}$ zinc (Doyle et al., 1975) or approximately $75 \mathrm{ppm}$ zinc (Lener and Musil, 1971). Increased dietary sodium has been shown to increase body sodium and to induce hypertension in the rat (Meneely, 1973). It seems likely that the retention of sodium by cadmium-fed rats is at least in part responsible for the increased blood pressure that has been observed when rats were fed cadmium in drinking water for long periods of time (Schroeder and Vinton, 1962; Perry and Erlanger, 1974, 1976).

Cadmium interacts with selenium. Rats given $0.9 \mathrm{ppm}$ selenium in drinking water along with $0.5 \mathrm{ppm}$ in the diet do not develop increased blood pressure when given 2.5 ppm cadmium. This level of selenium given alone will induce increased blood pressure (Perry and Erlanger, 
1974). The mechanism of this cadmium-selenium interaction is not known. Selenium will also protect from another toxic effect of cadmium that might have cardiovascular implications. Cadmium has been shown to injure pancreatic beta cells and impair carbohydrate metabolism (Merali and Singhal, 1975); selenium prevents this injury.

Although we do not know whether most of the interactions observed in animals are of importance for the cardiovascular system of humans, the metabolic similarities between mammalian species suggest that investigation of this possibility is appropriate.

\section{REFERENCES}

Albanese, A. A., A. H. Edelson, M. L. Woodhull, E. J. Lorenze, Jr., E. H. Wein, and L. A. Orta. 1973. Effects of a calcium supplement on serum cholesterol, calcium, phosphorus and bone density of "normal, healthy" elderly females. Nutr. Rep. Int. 8:119.

Allen, K. G. D., and L. M. Klevay. 1978a. Cholesterolemia and cardiovascular abnormalities in rats caused by copper deficiency. Atherosclerosis 29:81-93.

Allen, K. G. D., and L. M. Klevay. 1978b. Copper deficiency in cholesterol metabolism in the rat. Atherosclerosis 31:259-271.

Bremner, I., and N. T. Davis. 1973. Trace metal interactions in animal nutrition. Rep. 29. Rowett Institute, Aberdeen, Scotland. Pp. 126135.

Bremner, I., and N. T. Davis. 1975. The induction of metallothionein in rat liver by zinc injection and restriction of food intake. Biochem. J. 149:733-738.

Cherian, M. G. 1977. Studies on the synthesis and metabolism of zincthionein in rats. J. Nutr. 107:965-972.

Chou, W. S., J. E. Savage, and B. L. O'Dell. 1969. Role of copper in biosynthesis of intramolecular cross-links in chick tendon collagen. J. Biol. Chem. 244:5785-5789.

Doyle, J. J., R. A. Bernhoft, and H. H. Sandstead. 1975. The effects of a low level of dietary cadmium on blood pressure, ${ }^{24} \mathrm{Na},{ }^{42} \mathrm{~K}$ and water retention in growing rats. J. Lab. Clin. Med. 86:57-63.

Evans, G. W. 1973. Biological regulation of copper homeostasis in the rat. World Rev. Nutr. Diet. 17:225-249.

Evans, G. W., and P. E. Johnson. 1978. Copper and zinc binding ligands in the intestinal mucosa. In Trace Element Metabolism in Man and Animals-3. M. Kirchgessner, ed. Arbeitkreis für Tierenahrungsforschung Weihenstethan, Institut für Ernahrungsphysiologie, Freising-Weihenstethan, Germany. Pp. 98-105.

Evans, G. W., C. I. Grace, and H. J. Votava. 1975. A proposed mechanism for zinc absorption in the rat. Am. J. Physiol. 228:501505.

Everson, G. L., and R. E. Shrader. 1968. Abnormal glucose tolerance in manganese-deficient guinea pigs. J. Nutr. 94:89-94.

Fox, M. R. S. 1974. Effect of essential minerals on cadmium toxicity: A review. J. Food Sci. 39:321-324.

Hahn, C. J., and G. W. Evans. 1975. Absorption of trace metals in the zinc deficient rat. Am. J. Physiol. 228: 1020-1023.

Hartman, H. J., and V. Weser. 1977: Copper-thionein from fetal bovine liver. Biochim. Biophys. Acta 491:211-222.

Hendricks, D. G., and A. W. Mahoney. 1972. Glucose tolerance in zinc-deficient rats. J. Nutr. 102:1079-1084.

Heth, D. A., W. Becker, and G. W. Hoekstra. 1966. Effect of calcium, phosphorus and zinc on zinc-65 absorption and turnover in rats fed semipurified diets. J. Nutr. 88:331-337.
Hill, C. H., and G. Matrone. 1970. Chemical parameters in the study of in vivo and in vitro interactions in transition elements. Fed. Proc. 29:1474-1481.

Hill, C. H., G. Matrone, W. L. Payne, and C. W. Barker. 1963. In vivo interaction of cadmium. J. Nutr. 80:227-235.

Hill, C. H., B. Starcher, and C. Kim. 1967. Role of copper in the formation of elastin. Fed. Proc. 26:129-133.

Huber, A. M., and S. N. Gershoff. 1973. Effect of zinc deficiency in rats on insulin release from the pancreas. J. Nutr. 103:1739-1744.

Hurley, L. S., and S. Tao. 1972. Alleviation of teratogenic effects of zinc deficiency by simultaneous lack of calcium. Am. J. Physiol. 222:322325.

Ismail-Beigi, F., J. G. Reinhold, B. Faraji, and P. Abadi. 1977. Effects of cellulose added to diets of low and high fiber content upon the metabolism of calcium, magnesium, zinc and phosphorus by man. J. Nutr. 107:510-518.

Jacob, R. A., L. G. Baesler, L. M. Klevay, D. E. Lee, and P. L. Wherry. 1977. Hypercholesterolemia due to meat anemia. Nutr. Rep. Int. 16:73-79.

Jeejeebhoy, K. N., R. C. Chu, E. B. Marliss, G. R. Greenberg, and A. Bruce-Robertson. 1977. Chromium deficiency, glucose intolerance and a neuropathy reversed by chromium supplementation in a patient receiving long-term total parenteral nutrition. Am. J. Clin. Nutr. 30:531-538.

Klevay, L. M. 1973. Hypercholesterolemia in rats produced by an increased ratio of zinc to copper ingested. Am. J. Clin. Nutr. 26:1060-1068.

Klevay, L. M. 1977. Hypocholesterolemia due to sodium phytate. Nutr. Rep. Int. 15:587-595.

Larsson, S. E., and S. Piscator. 1971. Effect of cadmium on skeletal tissue in normal and calcium-deficient rats. Israel J. Med. Sci. 7:495497.

Leigh, L. C. 1975. Changes in the ultrastructure of cardiac muscle in steers deprived of copper. Res. Vet. Sci. 18:282-287.

Lener, J., and B. Bibr. 1971. Cadmium and hypertension. Lancet 1:970.

Lener, J., and J. Musil. 1971. Cadmium influence on the excretion of sodium by kidneys. Experientia 27:902.

Meneely, G. R. 1973. Toxic effects of dietary sodium chloride and the protective effect of potassium. In Toxicants Occurring Naturally in Foods. 2nd ed. National Academy of Sciences, Washington, D.C. Pp. 26-42.

Merali, Z., and R. L. Singhal. 1975. Protective effect of selenium on certain hepatotoxic and pancreatotoxic manifestations of subacute cadmium administration. J. Pharmacol. Exp. Ther. 195:58-66.

Mertz, W., E. W. Toepfer, E. E. Roginski, and M. M. Polansky. 1974. Present knowledge of the role of chromium. Fed. Proc. 33:22752285.

Mills, C. F. 1974. Trace-element interactions: Effects of dietary composition on the development of imbalance and toxicity. In Trace Element Metabolism in Animals-2. W. G. Hoekstra, J. W. Suttie, H. E. Ganther, and W. Mertz, eds. University Park Press, Baltimore, Md. Pp. 79-90.

Oberleas, D. 1973. Phytates. In Toxicants Occurring Naturally in Foods. National Academy of Sciences, Washington, D.C. Pp. 363371.

Perry, H. M., Jr. 1973. Minerals in cardiovascular disease. J. Am. Diet. Assoc. 62:631-637.

Perry, H. M., Jr., and M. W. Erlanger. 1974. Metal-induced hypertension following chronic feeding of low doses of cadmium and mercury. J. Lab. Clin. Med. 83:541-547.

Perry, H. M., Jr., and M. W. Erlanger. 1976. Cadmium and hypertension. In The Biomedical Role of Trace Elements in Aging. J. M. Hsu, ed. Eckerd College Gerontology Center, St. Petersburg, Fla. Pp. 189-208. 
Perry, H. M., Jr., and M. W. Erlanger: 1978. Effect of a second metal on cadmium-induced hypertension. In Proceedings of the Twelfth Annual Conference on Trace Substances in Environmental Health, June 5-8, 1978. D. D. Hemphill, ed. University of Missouri, Columbia.

Perry, H. M., Jr., M. W. Erlanger, and E. F. Perry. 1977. Elevated systolic pressure following chronic low-level cadmium feeding. Am. J. Physiol. 232:H114-H121.

Porter, H. 1974. The particulate half-cystine copper protein of new born liver. Biochem. Biophys. Res. Commun. 56:661-668.

Prasad, A. S., G. J. Brewer, E. B. Schoomaker, and P. Rabbani. 1978. Hypocupremia induced by large doses of zinc therapy in adults. J. Am. Med. Assoc. 240:2166-2168.

Reinhold, J. G. 1975. Binding of zinc to fiber and other solids of wholemeal bread. In Trace Elements in Human Health and Disease. A. S. Prasad, ed. The Nutrition Foundation, New York. Pp. 163179.

Sandstead, H. H. 1976. Interactions of cadmium and lead with essential minerals. In Effects and Dose Response to Toxic Metals. G. F. Nordberg, ed. Elsevier, Amsterdam. Pp. 511-526.

Sandstead, H. H., L. Klevay, J. Munoz, R. Jacob, G. Logan, Jr., F. Dintzis, G. Inglett, and W. Shuey. 1978. Human zinc requirements: Effects of dietary fiber on zinc metabolism. Fed. Proc. 37:218A.
Schroeder, H. A. 1967. Cadmium, chromium, and cardiovascular disease. Circulation 35:570-582.

Schroeder, H. A., and H. M. Perry, Jr. 1956. Essential and abnormal trace metals in cardiovascular diseases, in Proceedings of the Annual Meeting, Nov. 15-19, 1955, Vol. 4, American Heart Association, Council for High Blood Pressure Research. Pp. 71-105.

Schroeder, H. A., and W. H. Vinton, Jr. 1962. Hypertension induced in rats by small doses of cadmium. Am. J. Physiol. 202:515-519.

Shrader, R. E., and G. J. Everson. 1968. Pancreatic pathology in manganese-deficient guinea pigs. J. Nutr. 94:269-281.

Starcher, B. C. 1969. Studies on the mechanism of copper absorption in the chick. J. Nutr. 97:321-326.

Suda, T., N. Horiuchi, E. Ogata, I. Ezawa, N. Otaki, and M. Kimura. 1974. Prevention by metallothionein of cadmium-induced inhibition of vitamin $D$ activation reaction in kidney. FEBS Lett. 42:23-26.

Voors, A. W., M. S. Shuman, and P. N. Gallagher. 1973. Zinc and cadmium autopsy levels for cardiovascular disease in geographical context. In Proceedings of the Sixth Annual Conférence on Trace Substances in Environmental Health, June 13-15, 1972. D. D. Hemphill, ed. University of Missouri, Columbia. Pp. 215-222.

Winge, D. R., and K. V. Rajagopalan. 1972. Purification and some properties of Cd-binding protein from rat liver. Arch. Biochem. Biophys. 153:755-762. 


\title{
Pathogenesis and Classification of Cardiovascular Diseases in Relation to Minerals in the Drinking Water
}

\author{
JACK P. STRONG and A. WOUTER VOORS
}

The large body of scientific information indicating that certain inorganic or mineral constituents of drinking water are correlated with increased mortality rates for cardiovascular diseases calls for logical approaches to establishing causal relationships, determining the specific types of cardiovascular diseases that are involved, and determining the mechanism (pathogenesis) of the harmful effects and the stages of the disease process that are influenced by the water constituents.

The literature summarized in other reports in this volume suggests that in the United States and other technically developed countries the mortality from certain chronic diseases, particularly cardiovascular disease, hypertension, and stroke, is associated with various water characteristics related to water hardness. These reports, in general, indicate an inverse correlation between the mortality from cardiovascular disease and the amount of water hardness. Hypotheses have been proposed to account for this correlation of water chemistry with morbidity and mortality, and these hypotheses suggest a protective action of some elements found in hard water or harmful effects attributed to certain elements associated with soft water. The hypothetically protective agents include calcium, magnesium, vanadium, lithium, chromium, manganese, selenium, silicon, and perhaps zinc. The hypothetically harmful agents include cadmium, lead, and copper, all of which tend to be found in higher concentration in soft water as a result of its relative corrosiveness. These suggestive findings of significant correlations between water factors and disease, however, are not conclusive, and there is disagreement over the existence of a water factor in the risk of cardiovascular disease and over the magnitude of the problem, if present.

Most of the relationships of drinking water and disease have been derived from studying mortality rates in different geographical locations having different characteristics of drinking water. Autopsy studies have also been performed comparing the content of certain suspect minerals that are increased in soft water between cases with cardiovascular disease and cases without cardiovascular disease. Sufficient significant relation between content of the drinking water and mortality from cardiovascular disease (and supportive studies on the relationship of certain minerals in the drinking water to cardiovascular disease in autopsy studies) is present to provide tantalizing incentives to possible public health intervention. Such intervention would attempt to lower cardiovascular disease mortality, which accounts for approximately half of all deaths that occur each year in the United States, by changing the content of drinking water or of the local foods as indexed by this water. Even though it might be possible to lower cardiovascular death rates without ever knowing the mechanisms by technological manipulation of the water supply in favor of more hypothetically protective constituents and less hypothetically harmful constituents, a superior approach would be to establish as precisely as possible the particular water constituents involved and the mechanisms of the pertinent cardioyascular diseases that are affected.

Before proceeding to the remainder of this report, it is essential to reemphasize what has been amply demonstrated by epidemiologists, biostatisticians, and other 
investigators in the field of cardiovascular research, namely, that mortality rates are notoriously subject to variability and errors because of difficulty in accurate classification of cause of death (Oalmann et al., 1971) and that autopsy studies, while benefiting from more accurate classification of cause of death, have serious liabilities because of inherent bias from the various selection processes that occur in autopsy material (Berkson, 1946; Mainland, 1953; McMahan, 1960, 1963).

The purpose of this report will not be to evaluate the literature concerning possible roles of the various hypothetically harmful or protective elements in the drinking water but to point out how considerations of the pathogenesis and classification of cardiovascular diseases may be valuable in understanding the reported negative association between water hardness and cardiovascular disease mortality.

\section{CARDIOVASCULAR DISEASE}

Some of the literature on drinking water and cardiovascular disease suggests a significant negative association between water hardness and coronary heart disease (atherosclerotic heart disease, 55ICD 420 in the International Classification of Diseases, 1955 Rev. (World Health Organization, 1957)) and/or hypertension with heart disease (Schroeder, 1960, 1966; Morris et al., 1961; Biörck et al., 1965; Biersteker, 1967; Crawford et al., 1968; Schroeder and Kraemer, 1974), while other investigations indicate a relationship between the water softness and the broad category of all cardiovascular disease or all heart disease (Comstock, 1979, this volume). These studies are based on death certificate diagnoses. Knowledge of the imprecision of death certificate diagnoses and understanding of the pathogenesis of cardiovascular disease and areas of possible overlap in diagnoses make it easy to see how ambiguities could arise even if there were a clear-cut effect on either coronary heart disease or all forms of heart disease.

It is important to establish whether the harmful or protective effect of water is clearly implicated in one or more of the major types of cardiovascular disease, such as coronary heart disease (55ICD 420) or hypertensive heart disease (55ICD 440-443) or whether the association is truly with the broader diagnostic categories of cardiovascular disease. In the first instance, one would be concerned with pathogenetic mechanisms for the specific type of cardiovascular disease implicated: for coronary heart disease, the effects of the water factor on the atherosclerotic process or the blood clotting mechanism; for hypertensive disease, the effect of the water factor on blood pressure levels and arteriolar structure and function. On the other hand, if there is no clear-cut association between water factors and any specific form of cardiovascular disease, but a definite association with all forms of cardiovascular disease, one explanation could be that the water factor has a damaging myocardial effect on an already diseased cardiovascular system. Thus individuals suffering from any one of several diseases (for example, coronary heart disease, hypertension, rheumatic heart disease) might have superimposed damage leading to increased morbidity and mortality even though the water factor had nothing to do with the initiation of the primary cardiovascular disease process. A significant association of water factors and the broad classification of all cardiovascular disease has another possible explanation. The water factor might really influence the pathogenesis of only one or two types of cardiovascular disease (say coronary heart disease and hypertensive heart disease), yet problems of misclassification in assigning cause of death would wash out the pure relationship, leaving only a positive significant association with "diseases of the heart" or all cardiovascular disease.

This discussion of pathogenesis and classification of cardiovascular disease must be further complicated by the known interrelationships between two of the most frequent forms of heart disease, namely, coronary heart disease and hypertensive heart disease. Coronary heart disease may occur with or without concomitant hypertension. Yet, hypertension is a well-known and powerful risk factor for the development of coronary heart disease. Therefore the effect of a harmful water factor on hypertension would be reflected, not only in morbidity and mortality rates for hypertensive heart disease, but also in the much larger category of coronary heart disease. As hypertension is a predisposing cause of the two most common forms of stroke, a water effect on hypertension would also influence morbidity and mortality rates for vascular disease of the central nervous system. Special considerations of hypertension and stroke are discussed under the next two headings.

\section{HYPERTENSION}

What are the mechanisms by which water chemistry could be related to hypertension? Two possible pathways are these:

- Some component of the drinking water might produce (or protect against) direct damage to the arterial walls that might result in elevated blood pressure.

- Some water factor might cause (or protect against) increased peripheral resistance and elevated blood pressure by altering the regulatory mechanisms that control arteriolar constriction and dilatation. The regulatory mechanisms might be through some effect on water 
and/or salt retention by the kidneys, renin-angiotensin mechanism, hormonal alterations, or something similar.

The experimental approach using animal models seems best suited to pursue these mechanisms now that certain elements in the water have been postulated as being the protective or harmful agents responsible for cardiovascular disease.

Assuming that some water factor has a direct or indirect causal role in human hypertension, what would be the consequences? The well-known health consequences of hypertension include increased risk of developing coronary heart disease, increased risk of developing cerebral thrombosis resulting from occlusive atherosclerosis (65ICD 433 in the International Classification of Diseases, 1965 Rev. (World Health Organization, 1967)), which is the most common form of stroke, increased risk of developing hypertensive cerebral hemorrhage (65ICD 431 ; the second most common type of stroke), as well as the effects of hypertension on the heart (hypertensive heart disease and cardiac failure; 55ICD 440-443) and kidneys (arteriolar nephrosclerosis; 55ICD 442, 446). In addition, patients with hypertension have an increased susceptibility to various intercurrent diseases. Thus if a true link were to be established between some component of the drinking water and the development of hypertension, the significance in terms of human disease would be very great. The need for and reward from public health intervention by changing water supplies or local foods for the better would obviously also be great.

\section{STROKE}

If a water factor could be documented as being related to some measure of stroke (55ICD 330-334) in human subjects, one would wish to determine the type of stroke with which the water factor is most strongly related. Once established, one would need to consider the possible mechanisms by which the water factor might logically have contributed. Death certificate data on stroke are reasonably reliable for the large category of vascular diseases of the central nervous system. This category, however, includes different forms of stroke with distinctive pathogenetic mechanisms. The major types of stroke in the human, in order of decreasing frequency, are as follows: cerebral infarction caused by atherosclerosis with superimposed thrombosis (occlusive cerebrovascular disease), hypertensive cerebral hemorrhage (intracerebral hemorrhage), and cerebral infarction resulting from embolism (65ICD 434).

Hypertension, as previously noted, may predispose to both cerebral infarction secondary to atherosclerosis and intracerebral hemorrhage, even though by different mechanisms. Hypertension is known to accelerate the development of atherosclerotic lesions in the cerebral arteries as well as in the coronary arteries and aorta. Therefore more extensive atherosclerosis would increase the probability of cerebral thrombosis and occlusive cerebral infarction. This form of stroke may occur, however, in the absence of hypertension provided that atherosclerosis is present in the cerebral arteries. For intracerebral hemorrhage, hypertension has an even stronger relationship. Hypertension is practically a sine qua non and is considered to be the basic underlying cause leading to rupture of small arterioles in the brain with resultant hemorrhage. Cerebral infarction secondary to embolism, however, can be the result of a variety of basic underlying causes including embolism from a plaque in the carotid arteries, dislodgement of a mural thrombus overlying a myocardial infarct, dislodgement of a mural thrombus in the left atrium as a result of atrial fibrillation, and embolism secondary to bacterial endocarditis.

If the evidence relating a water factor to stroke includes subclassification of the type of stroke into these categories, then certain lines of reasoning would come into play. For example, Nefzger et al. (1973) by coding death certificates of U.S. veterans found a difference in mortality caused by intracerebral hemorrhage between cases in Georgia on the one hand and Colorado, Idaho, Montana, Utah, and Wyoming on the other hand, whereas they found no difference in mortality caused by occlusive cerebral vascular disease. If differences in intracerebral hemorrhage, but not in occlusive cerebral vascular disease, occurred in association with water chemistry, this finding would suggest attention to the role of hypertension as a prime suspect because of the very strong relationship between hypertension and intracerebral hemorrhage.

On the other hand, if a water factor were related to cerebral infarction secondary to atherosclerosis and thrombosis (occlusive cerebrovascular disease) and not to cerebral hemorrhage, then the suspected mechanism would be acceleration of the atherosclerotic process in the cerebral arteries (for some reason other than hypertension) or an effect on the clotting mechanism. If a water factor were clearly related to both of these types of cerebrovascular disease, hypertension would again be suspected as a mechanism since it may predispose to both.

Underlying causes of disease processes that might lead to cerebral embolism are so variable that it seems extremely unlikely for a water factor to be detected as solely relating to embolic stroke. Accurate assessment of this type of stroke would not be possible without firm autopsy evidence, and this would not be available in most investigations. 


\section{CONCLUDING REMARKS}

In this brief discussion, we have explored some of the steps in the pathogenesis of hypertension, stroke, and cardiovascular disease that could be affected by suspected water factors. We have also indicated how subclassification of cardiovascular disease is important in understanding the possible relationship of water chemistry and cardiovascular disease.

If water factors do have an effect on hypertension, I stroke, or cardiovascular disease (or any subcategory of cardiovascular disease), we should determine the precise point at which each causative water factor exerts its effect. Such knowledge will be essential if we are to understand the pathogenesis of water-related diseases.

Fortunately for the public, it may not be necessary to understand the complete pathogenetic sequence of waterrelated disease processes for rational public health measures to be taken, assuming that a clearly defined relationship between a water factor and the disease process is confirmed. John Snow's classic intervention in the cholera epidemic in London of 1854 long before the bacteriology of the disease was well understood illustrates this point (Snow, 1936).

\section{REFERENCES}

Berkson, J. 1946. Limitations of the application of fourfold table analysis to hospital data. Biom. Bull. 2:47-53.

Biersteker, K. 1967. Drinkwaterzachtheid en sterfte. Tijdschr. Sociale Geneeskd. 45:658-661.

Biörck, G., H. Bostrom, and A. Widstrom. 1965. On the relationship between water hardness and death rate in cardiovascular diseases. Acta Med. Scand. 178:239-252.

Comstock, G. W. 1979 (this volume). The association of water hardness and cardiovascular diseases: An epidemiological review and critique.

Crawford, M. D., M. J. Gardner, and J. N. Morris. 1968. Mortality and hardness of local water-supplies. Lancet 1:827-831.

Mainland, D. 1953. The risk of fallacious conclusions from autopsy data on the incidence of diseases with application to heart disease. Am. Heart J. 45:644-654.

McMahan, C. A. 1960. Demographic aspects of the population of human autopsied cases as reported in the United States, 1955. Hum. Biol. 32:185-196.

McMahan, C. A. 1963. Selectivity of autopsied cases by assigned cause of death. In International Population Conference, New York, 1961. John Wright and Sons, London. Pp. 713-721.

Morris, J. N., M. D. Crawford, and J. A. Heady. 1961. Hardness of local water-supplies and mortality from cardiovascular disease in the county boroughs of England and Wales. Lancet 1:860-862.

Nefzger, M. D., R. M. Acheson, and A. Heman. 1973. Mortality from stroke among U.S. veterans in Georgia and five western states. I. Study plan and death rates. J. Chronic Dis. 26:393-404.

Oalmann, M. C., H. C. McGill, and J. P. Strong. 1971. Cardiovascular mortality in a community: Results of a survey in New Orleans. Am. J. Epidemiol. 94:546-555.

Schroeder, H. A. 1960. Relations between hardness of water and death rates from certain chronic and degenerative diseases in the United States. J. Chronic Dis. 12:586-591.

Schroeder, H. A. 1966. Municipal drinking water and cardiovascular death rates. J. Am. Med. Assoc. 195:81-85.

Schroeder, H. A., and L. A. Kraemer. 1974. Cardiovascular mortality, municipal water, and corrosion. Arch. Environ. Health (Chicago) 28:303-311.

Snow, J. 1936. On the mode of communication of cholera. In Snow on Cholera. Commonwealth Fund, New York. Pp. 1-175.

World Health Organization. 1957. Classification of Diseases, 1955 Rev. Geneva.

World Health Organization. 1967. International Classification of Diseases, 1965 Rev. Geneva. 


\title{
The Association of Water Hardness and Cardiovascular Diseases: An Epidemiological Review and Critique
}

\author{
GEORGE W. COMSTOCK
}

The investigation of the association of hardness of local drinking water supplies with cardiovascular diseases had its beginning only a little more than two decades ago. As often happens, separate lines of investigation pointed in the same direction, in this case to some characteristic of drinking water as a possible cause of cardiovascular disease. The potential of such a relationship for the control of heart disease and stroke was obvious. Even if something in drinking water had only a small effect, so many people succumb to cardiovascular conditions that alteration of the composition of drinking water could prolong many lives. Furthermore, preventive health measures that are applied at the community level, such as water treatment, have proved to be more effective and less expensive than measures that must be individually applied.

What appears to have been the first paper to call attention to the marked geographic variation in death rates-death rates from heart disease in particularappeared in 1956. Using death rates for the United States in the triennium 1949-1951, Enterline and Stewart (1956) noted that place of residence might well be considered a major risk factor for cardiovascular diseases. Subsequent analyses of these data ruled out as causes of the observed relationship such things as inaccuracies of population or death counts, migration patterns, and availability of medical care (Sauer and Enterline, 1959; Enterline et al., 1960; Sauer, 1962). Although rates were higher in metropolitan than in nonmetropolitan areas, the pattern of high cardiovascular death rates near the East Coast of the United States and along the Gulf Coast and the Great Lakes and low rates in the western plains and middle South persisted when the analysis was limited to metropolitan areas. This was somewhat in contrast to the findings of a study of heart disease in 1940 (Gover and Pennell, 1950). At that time, high arteriosclerotic heart disease death rates (diseases of coronary arteries and diseases of the myocardium combined) were found in the New England and Middle Atlantic regions, and low rates in the South Central regions. These differences became much smaller when the analysis was restricted to cities of over 100,000 population, suggesting that urbanization was a major cause of geographic variation in 1940.

More recent studies of smaller areas in greater detail have confirmed that there are real geographic differences in total death rates; they largely result from differences in cardiovascular death rates, and these differences are large-rates in high-rate areas are approximately twice those in low-rate areas (Chase, 1963; Sauer et al., 1966; Kuller et al., 1969; Sauer and Parke, 1974).

While some characteristic of drinking water was an obvious suspect among the numerous factors that distinguished the high- from low-death-rate areas, the direct approach to the association of water hardness with cardiovascular diseases began on the opposite side of the globe. In 1957 a Japanese agricultural chemist, Jun Kobayashi, published a paper in an obscure journal calling attention to the close association of death rates from apoplexy in various areas of Japan and the acidity of river water (Kobayashi, 1957). He chose the ratio of sulfates to carbonates as his index of water quality. It is 
not clear why this ratio was selected: it is a measure of acidity, and Kobayashi knew that unusually high sulfate levels characterized many Japanese rivers. He also felt that calcium carbonate might in some way help prevent apoplexy. Parenthetically, all river water in Japan is soft.

Kobayashi's work might well have gone unnoticed except for the fact that H. A. Schroeder had been given a grant from the Lasdon Foundation to look into the cardiovascular disease situation in the Orient (Schroeder, 1958). He talked with Kobayashi, was given access to his data on water quality and strokes, and noted that "perhaps an even better correlation is found with the abnormality of river water and death rates from all heart diseases."

On his return to the United States, Schroeder sought to confirm Kobayashi's findings. Because hardness of finished water was the characteristic most widely available, he looked at its relationship to death rates from a variety of causes on a state-by-state basis for the years 1949-1951 (Schroeder, 1960a). He found significant negative correlations with deaths from all causes $(-.36)$, all cardiovascular diseases $(-.56)$, coronary heart disease and other cardiovascular diseases $(-.31$ and -.36 , respectively), and strokes (-.33). More detailed information on water quality was available for 163 metropolitan areas of the United States (Schroeder, 1960b). Among white males 45-64 years of age in these areas, coronary heart disease death rates were negatively correlated with hardness (-.29), with magnesium $(-.30)$, and with calcium (-.27); no association was found with the ratio of sulfates to bicarbonates.

In the years since these pioneering studies, a number of authors and committees reviewed the water hardness association with cardiovascular diseases (Dingle et al., 1964; Anonymous, 1966; Schroeder, 1969; Crawford et al., 1971c; Correa and Strong, 1972; Masironi et al., 1972; Perry, 1972; Masironi, 1973; Punsar, 1973; Neri et al., 1974; Sauer, 1974a; Shaper, 1974; Sharrett and Feinleib, 1975; Gardner, 1976; Heyden, 1976; Hudson and Gilcreas, 1976; Wolman, 1976). Not unexpectedly, they came to different conclusions. Some felt that current knowledge was sufficient to take action with respect to water treatment (Department of Health and Social Security, 1974; Shaper, 1974; Hudson and Gilcreas, 1976); these include two papers, which principally reviewed the evidence favoring their viewpoint (Shaper, 1974; Hudson and Gilcreas, 1976). Others believed that any such action would be unwise at present (Punsar, 1973; Heyden, 1976; Wolman, 1976); one of these authors, after a very thorough review, felt that the association of cardiovascular deaths with soft water might be spurious (Punsar, 1973). Still others suggested that some trace element leached from the distribution system by some waters, but not by others, was the most likely culprit (Schroeder, 1969; Correa and Strong, 1972; Masironi, 1973). None of the reviews indicated that further investigations should be discouraged; indeed, almost all specifically urged further research.

\section{GENERAL STATISTICAL AND EPIDEMIOLOGICAL PROBLEMS}

Before reviewing the currently available evidence on water hardness and cardiovascular disease, it may be appropriate to review some biostatistical and epidemiological problems common to many of these studies. By far, the great majority used correlation coefficients to measure associations rather than the coefficient of regression of a disease index (usually mortality) on hardness. The correlation coefficient is affected much more by chance variation than the regression coefficient, which can be attenuated only by variation in the independent variable (Neri et al., 1972). Furthermore, the correlation coefficient gives no indication of the magnitude of an effect: it is possible to obtain perfect correlation of two variables even when the dependent variable changes little, if at all, with changes in the independent variable. A high degree of correlation is of little importance if there is little change in the cardiovascular death rate with changes in water hardness.

To illustrate this point, consider the hypothetical situations depicted in Figures 31 and 32. In each, dots represent the observations and the line is the calculated regression line, showing the amount of change in disease

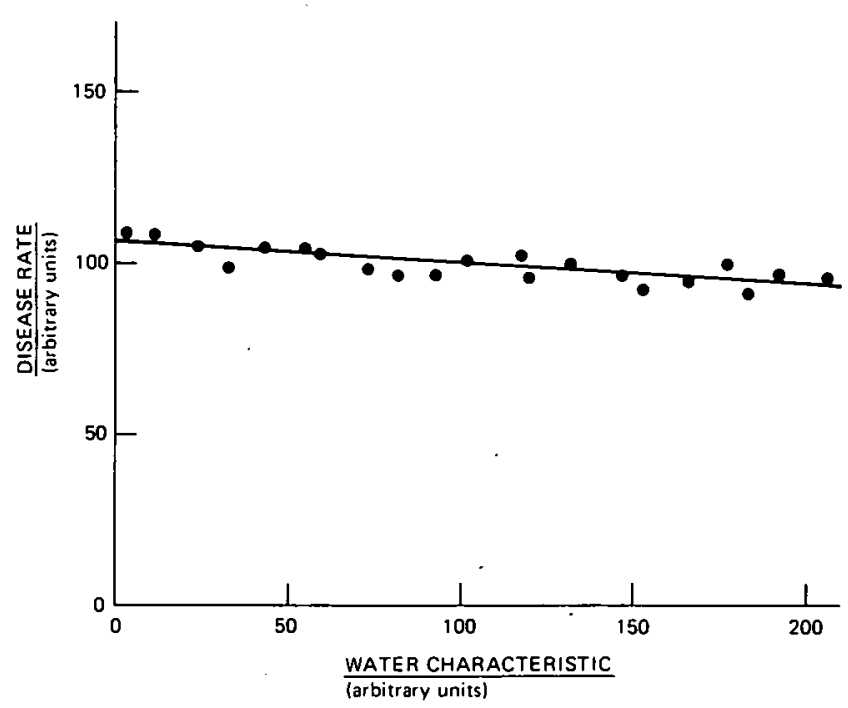

FIGURE 31 Hypothetical example of an association with a large correlation coefficient $\left(r=-.74\right.$ and a small regression coefficient $\left(b_{\mathrm{t}}\right.$ $=-.58)$. 


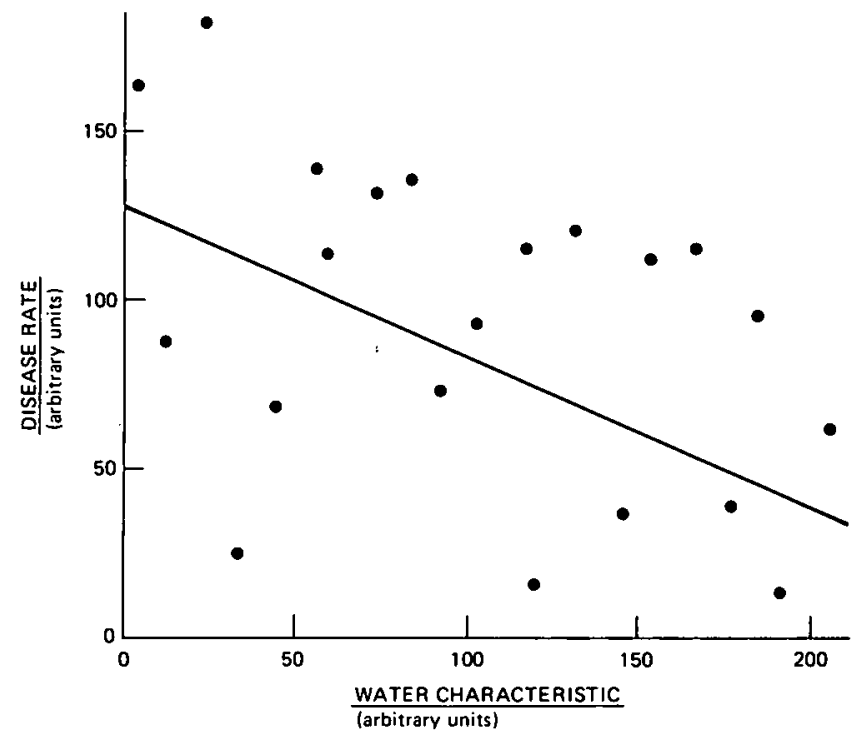

FIGURE 32 Hypothetical example of an association with a correlation coefficient of -.45 and a regression coefficient of -.34 , both of which are only moderately large.

rates (the dependent variable) per unit change in a water characteristic (the independent variable). In Figure 31, all observations fall close to the regression line and the correlation coefficient is high (-.74). The negative sign indicates that the disease rate decreases as the water characteristic increases. In spite of the high correlation coefficient, marked changes in the water characteristic result in only trivial changes in the disease rate.

The situation depicted in Figure 32 is quite different. The observations are not closely clustered around the regression line, and the correlation coefficient $(-.45)$ is much smaller than that for Figure 31. Again its negative sign indicates that disease rates tend to decrease as the water characteristic increases. But the steeper slope of the regression line indicates that on the average modest changes in the water characteristic are associated with important changes in the disease rate, although the wider scatter of observations in Figure 32 makes the exact degree of downward slope much less certain than in Figure 31. Nevertheless, it seems clear that Figure 32 illustrates a situation that is more interesting from an etiological and preventive point of view than Figure 31. Correlation coefficients alone would not have given us this very important bit of information.

Standardized mortality ratios have also been used occasionally instead of adjusted rates. It has been noted that these ratios are dependent, not only on the cause and population subgroups of interest, but also on the frequen- cy of deaths from other causes and among other population subgroups (Crawford et al., 1972a). A distressing number of papers failed to make adjustments of any kind for differences in the compositions of their study populations; even such elementary adjustments as those for age, sex, and race were neglected. Others have used broad age groupings without further adjustment, thereby making the implicit, but possibly unwarranted, assumption that there are no important age differences within the age range under study.

The ecologic fallacy, which is an error caused by attributing a characteristic of a group to all of its component individuals, may also affect some studies on water hardness. Almost all studies have classified areas by the hardness of finished water at the treatment plant. Little regard has been paid to the relative frequency of home water softeners. In hard water areas of the United States the market saturation for water softeners is estimated to be 60-70 percent (Porth, 1970). Water softeners have been estimated to be present in 70 percent of homes in DuPage County, Illinois (Water Quality Association, Wheaton, Illinois, personal communication, 1975) and to be in nearly 10 percent of all U.S. households (Oberhamer, 1975). In homes with deep wells in Washington County, Maryland, water softeners were present in 27 percent and in regular use in 24 percent (Johns Hopkins Training Center for Public Health Research, Hagerstown, Maryland, unpublished data, 1975). They were reported to be present in 30 of 196 homes in Omaha, Nebraska (Bierenbaum et al., 1973). It is not known to what extent the use of water softeners has caused misclassification of persons presumed to be drinking hard water because it is known to be hard at the treatment plant, but it is clear that in the United States considerable misclassification could occur in this way.

The geographic unit of study is also a source of misclassification. The larger the unit, the more broadly representative its population will be, and the more stable its death rates, but the sources of water supply will also be more heterogeneous. Only Winton and McCabe (1970) appear to have addressed themselves specifically to this issue. Sharrett (1979, this volume) addresses the question of small or large regions and strength of correlation, as do Neri et al. (1971 and 1972), but not the heterogeneity of water supplies, explicitly.

An equally important problem of potential misclassification is' the almost complete lack of knowledge about the proportion of daily water intake that comes from the tap, either at home or elsewhere. One study did note that it had been estimated that one sixth of the population in southern California drank bottled water (Allwright et al., 1974), and a small pilot study in a hard water area found 
that half of the subjects drank softened or bottled water at home (Hankin et al., 1970). Schroeder and Kraemer (1974) quote the National Soft Drink Association as estimating the daily per capita consumption of tap water in the United States as $982 \mathrm{ml}$ in 1962 and $929 \mathrm{ml}$ in 1971 and of soft (i.e., nonalcoholic), bottled or canned drinks as $198 \mathrm{ml}$ in 1962 and $360 \mathrm{ml}$ in 1971.

\section{EXPERIMENTAL ANIMAL STUDIES}

Only a few studies of the effects of hardness of water on experimental animals have been reported. Two small experiments on rabbits were reported by Neal and Neal (1962). For both experiments it was reported that rabbits on distilled water developed more atherosclerosis than those on hard water; rabbits given magnesium sulfate developed none at all. Unfortunately, information on experimental methods was sketchy, and results were reported only in general terms.

Three studies on pigs have been reported. The first was an observational study in which aortas were examined from 1,637 swine raised in 12 locations in the United States and Europe (Bijlenga et al., 1967). Atherosclerosis scores at ages 6-7 months and 8-11 months were more than twice as large for animals from soft as from hard water areas, but this difference was not statistically significant. A second study more nearly approximated a controlled trial (Howard et al., 1967). In Great Britain the Pig Industry Development Authority has a number of stations in which pigs are raised on the same diet from a central supply and housed almost identically. The abdominal aortas were examined from animals raised in Sterling, Scotland, with soft water and in Letchworth, England, with hard water. A few more pigs from the soft water region than from the hard water region had evidence of atherosclerosis (69.3 percent versus 61.5 percent), but the areas of involvement in the disease process were smaller in the soft water region. Males from one of the two breeds of pigs had more atherosclerosis in the hard water region. Again, none of the differences was statistically significant. The third study was a controlled experiment in which two groups, of 10 pigs each, were kept from birth under identical conditions, except that one group had normally hard water from Munich's supply in the limestone mountains ( $303 \mathrm{ppm})$ and the other group had water softened to $2 \mathrm{ppm}$ by ion exchange (Puschner et al., 1969). When the pigs were slaughtered at the age of 7 months, no differences in arteriosclerosis or in serum cholesterol were noted.

It is noteworthy that the more rigorous the experimental design, the less the association between water hardness and atherosclerosis.

\section{WATER HARDNESS AND CARDIOVASCULAR DEATHS WITHIN GEOGRAPHIC AREAS}

More than 50 studies have appeared in the past 20 years correlating the hardness of drinking water at treatment plants with mortality data from cardiovascular and other causes. Because of variability in study populations, statistical procedures, measures of water hardness, and indices of mortality, it is nearly impossible to categorize these studies satisfactorily. The reviews by Punsar (1973) and by Neri et al. (1974) contain useful tabulations of the results of many of these studies; both list them in order of publication. For this review, the studies will be considered primarily by size of geographic area (national and international; province and state; county and city) and secondarily by the time period for which mortality data were gathered.

\section{NATIONAL AND INTERNATIONAL}

\section{United States, 1949-1951}

Schroeder (1960a, 1960b) found significantly negative correlations between water hardness and death from cardiovascular causes, including strokes, for states, and between hardness and coronary heart disease for white males, 45-64 years of age, for the 163 largest municipalities.

Dudley et al. (1969) also found a negative correlation between hardness and coronary heart disease in white males aged 45-64, limiting their study to the 116 of the 163 standard metropolitan statistical areas for which they could find complete data for the 35 variables that they used.

Winton and McCabe (1970), using rank order correlation, agreed with the others in that they found a negative correlation of dissolved solids with diseases of the heart, but disagreed with Schroeder in that they observed a positive correlation with strokes. They limited their study to 135 central county areas with well-defined water sources.

\section{United States, 1959-1961}

Schroeder (1966) repeated his earlier study, this time using data from 88 cities. He again found negative correlations between hardness and deaths from arteriosclerotic heart disease, hypertensive heart disease, and strokes. A later paper (Schroeder and Kraemer, 1974) used data from 201 standard metropolitan statistical areas for white and nonwhite males and females, aged 45-64 and 65 and over. He found significantly negative 
correlations between hardness and arteriosclerotic heart disease deaths for all four age-sex groups among whites; the only significantly negative correlation among nonwhites was for nonwhite females 65 and over. Correlations for hypertensive heart disease were significant only for white females $45-64(-.22)$, and for strokes, significant only for cerebral hemorrhage among males 45-64 ( -.28 for whites and -.19 for nonwhites).

Voors (1971) was primarily interested in specific minerals in water and their correlation with age-adjusted arteriosclerotic heart disease deaths in 99 of the 100 largest cities of the United States. Correlations were almost identical for calcium and for magnesium, the major components of water hardness, and were negative for all four race-sex groups, being largest for white males ( -.35 for calcium, -.32 for magnesium) and smallest for nonwhite males ( -.10 for both metals). Sauer studied 92 metropolitan state economic areas (Sauer et al., 1971; Sauer, 1974b). Among whites aged 45-64 and 35-74 (adjusted for age within each group by 10-year subgroups), he found significantly negative correlations for all cardiovascular-renal causes combined and for coronary heart disease.

Hudson and Gilcreas (1976) also reported a negative relation between hardness and cardiovascular death rates among white males. They grouped 96 metropolitan areas into four.categories of water hardness, but did not weight their averages or adjust the death rates for age differences. Their finding is thus of doubtful validity.

\section{United States, after 1961}

Masironi (1970), using hardness and death rates for 42 states, looked at death rates among their total population and among white males $45-64$ for certain causes. He found negative, but nonsignificant, correlations with all cardiovascular diseases and arteriosclerotic heart disease, while correlations were significantly negative with hypertensive heart disease among both study groups.

\section{International Comparisons}

Masironi (1970) summarized data from three Latin American cities with soft water (20-42 ppm) and three with hard water (122-223 ppm). He found hypertensive heart disease death rates to be considerably lower in the hard water cities $(-39$ percent for males, -49 percent for females), arteriosclerotic heart disease death rates to be about the same $(+4$ percent for males, -9 percent for females), and death rates from myocardial degeneration to be strongly disparate for the sexes $(+47$ percent for males, -17 percent for females).

At a meeting of investigators of trace elements as related to cardiovascular diseases, findings from autopsies done in five European cities were reported (World Health Organization, 1973). Three of the cities were in the U.S.S.R., one in Sweden, and one in Czechoslovakia. Water hardness ranged from 178 to $332 \mathrm{ppm}$. Hypertensive heart disease death rates among persons of both sexes aged 20-89 years decreased almost linearly from approximately 60 per 100,000 in the city with the leasthard water to approximately 20 in the city with the hardest water. There was, however, no clear relation of water hardness to the age-adjusted frequency of atherosclerosis in the coronary arteries (Vanacek, 1976).

Strong et al. (1968) studied 23,207 sets of aortas and coronary arteries obtained in autopsies from 14 cities around the world. Among whites in New Orleans, Oslo, São Paulo, and Puerto Rico the correlation between water hardness and the mean percent of the surface involved with raised lesions of atherosclerosis was negative, but among other ethnic groups the correlation was positive.

Among the six Latin American cities reported on by Masironi (1970), the mean proportion of the arterial surface involved with raised lesions was 8.9 percent for the cities with soft water and 9.6 percent for the cities with hard water.

\section{United Kingdom}

Confirmation of Schroeder's findings in the United States came first from the work of Morris et al. (1961), who used data for 83 county boroughs of England and Wales, 1948-1954, for males and females in two age groups, 4564 and 65-74. Correlations of hardness with deaths from all cardiovascular disease, coronary heart disease, myocardial degeneration, hypertensive heart disease, and strokes were all negative, and most were significantly different from zero. Among all four age-sex groups the correlation coefficients of hardness with myocardial degeneration tended to be larger than for other causes, although not quite as large as the coefficients for all cardiovascular causes combined.

Crawford et al. (1968) and Gardner et al. (1969) have further refined the initial study, using data from 19581964 for the 61 county boroughs with more than 80,000 population and the same age-sex grouping. Essentially the same results emerged. The latter study (Gardner et al., 1969) also looked at death rates in the 7-year period around the 1951 census, again with essentially similar results.

Crawford et al. (1977) also studied six towns with soft water (28-40 ppm) and six towns with hard water (253$358 \mathrm{ppm}$ ). The soft water towns had high cardiovascular death rates, the hard water towns had lower rates. 
Sudden deaths made up a greater proportion of male leaths in the soft water towns, but at a low level of ignificance. The differences between the two groups of towns were most clear-cut if comparisons were restricted to deaths apparently occurring within 1 hour of onset of symptoms.

Roberts and Lloyd (1972) examined data on hardness and ischemic heart disease mortality in 50 local authority areas of South Wales and 58 county boroughs of England. They found negative correlation coefficients of -.46 and -.43 , respectively.

Nixon and Carpenter (1974) looked at associations with water hardness as part of a study of natural fluorides in water supplies, using data from 34 towns and agestandardized mortality rates for males and females, 1950-1965. While they too found negative correlations for hardness with cardiovascular death rates after allowing for the effects of social class, air pollution, rainfall, and latitude, the correlations were not statistically significant.

Stocks (1973) analyzed data from 80 county boroughs of England and Wales for 1958-1967, using proportionate mortality ratios with which he claimed "the disturbing effects of different ages are virtually eliminated." $\mathrm{He}$ failed to find significant correlations of water hardness with deaths from arteriosclerotic heart disease or strokes. While there were significant differences in death rates from hypertensive and chronic rheumatic heart diseases with water hardness, the relations were curvilinear, with the highest proportionate mortality ratios among boroughs that had slightly hard to hard water. For hypertensive, chronic rheumatic, and arteriosclerotic heart disease the ratios among boroughs with very hard waters differed considerably according to the type of limestone in the area, being highest with water from magnesian limestones.

\section{Ireland (Irish Republic and Northern Ireland)}

Mulcahy $(1964,1966)$ published two studies of water hardness and cardiovascular mortality. Both suffer from his use of only crude death rates for all ages and for his rather broad age group, 35-64, so that his results are possibly unduly confounded by excessive age differences in his study populations. The first study (Mulcahy, 1964) involved the 15 largest towns in the Irish Republic, presumably for the years 1957-1961. The only sizeable correlations with water hardness were found with death rates for all ages combined; they were negative for arteriosclerotic heart disease, all diseases of the heart, and strokes, but positive for arteriosclerotic heart disease and myocardial degeneration combined. The second raper (Mulcahy, 1966) added information from the 13 largest towns in North Ireland for the years 1957-1961. The correlations for the four preceding cardiovascular categories were all negative, but not significantly so. Virtually all the cases in which there was a relation between hard water and the combined rubrics of arteriosclerotic heart disease and myocardial degeneration were found in the Irish Republic; the regression coefficient for mortality and hardness in North Ireland was only -.0034 .

\section{Canada}

Neri et al. (1972) published one of the few papers that used regression analysis instead of relying solely on correlation. They reported on age-adjusted mortality rates within the age range 25-64 for 1950-1952 and 1960-1962 for 9 provinces and 516 municipalities in Canada. Their index of hardness was carbonate hardness because it yielded better correlations than total hardness. Their findings were "consistent with a tendency for harder water to reduce the risk of death in general, rather than from cardiovascular causes in particular, by a margin of up to 15 percent (using municipalities) or as much as 30 percent (using provinces). . . . "The most marked association of hardness, after that with deaths from all causes, was with strokes. For arteriosclerotic and degenerative heart disease the association was not quite significant at the 5 percent level.

\section{Australia}

Death rates from arteriosclerotic heart disease, age- and sex-specific for the years 1968-1970, in Brisbane were compared with those in Melbourne by Meyers (1975). Melbourne has soft-water (13 ppm on average), while Brisbane has hard water (142 ppm on average), yet death rates from arteriosclerotic heart disease were 14 percent higher for females and 22 percent higher for males in Brisbane than in Melbourne.

\section{Sweden}

Biörck et al. (1965) examined cardiovascular deaths (arteriosclerotic heart disease, myocardial degeneration, and strokes) in 33 Swedish towns with populations of over 25,000 and the Island of Visby for the years 19511960. They analyzed their data by sex and three age groups (25-44, 45-64, and 65-74). Correlations of water hardness with cardiovascular deaths were all negative among these six age-sex groups, except for arteriosclerotic heart disease among persons $25-44$ years of age. For males the most striking correlations were with myocardial degeneration ( -.24 to -.59$)$; among females the most striking were with strokes $(-.27$ to -.43$)$. 


\section{GEOCHEMISTRY OF WATER IN RELATION TO CARDIOVASCULAR DISEASE}

Bostrom and Wester (1967) were primarily interested in correlating death rates with trace elements in the water of the three largest cities in Sweden. If an approximation of hardness is calculated by multiplying the calcium concentration by 2.5 , these three cities had hardness levels of at least 222, 70, and $30 \mathrm{ppm}$. Among females the death rates from arteriosclerotic heart disease and myocardial degeneration showed a gradient, the highest rate being in the city with the softest water. Among males the lowest rate was also in the hard water city, but the highest rate was in the city with water of intermediate hardness.

\section{Netherlands}

Biersteker (1967) used mortality data for 23 cities in the Netherlands for the years 1958-1962 for males and females over 35 , age-adjusted. He found a significant correlation of hardness only with arteriosclerotic heart disease among females, while the correlations with stroke and hypertension among each sex were not significant.

\section{Czechoslovakia}

Svec (1976) found that standardized death rates for all diseases of the circulatory system and arteriosclerotic heart disease in 53 districts of the Czech Socialist Republic in 1965-1969 were higher in Bohemia than in Moravia. Bohemia has softer water than Moravia.

\section{Finland}

Hasanen (1970), primarily interested in the iodine content of drinking water, also looked at correlations of calcium in water with the prevalence of disability resulting from cardiovascular diseases in 21 cities of Finland in 1967. He found significant correlations of -.25 for logarithm of prevalence and -.70 for the untransformed prevalence of disability. (Recalculation of his published data indicates the untransformed correlation coefficient is -.50.) The broad age group of 16-64 was used, and the highest calcium content was only 33.6 ppm, which is equivalent to only $84 \mathrm{mg}$ of calcium carbonate per liter. The only impressive association apparent from his scatter diagrams is that with iodine in the water. In this study, cases are persons with chronic diseases.

\section{Italy}

Scassellati-Sforzolini and Pascasio (1971) looked at data from 68 towns in Italy for the 10-year period 1955-1964, correlating hardness (total, temporary, and permanent) and calcium with seven causes of death-arteriosclerotic and degenerative heart disease; arteriosclerotic and coronary heart disease; myocardial degeneration; vascular lesions of the central nervous system; cerebral hemorrhage; embolic and thrombotic strokes; and other vascular lesions of the central nervous system. Only one statistically significant correlation was found: +.33 between calcium in the water and embolic and thrombotic strokes.

\section{Rumania}

Manescu et al. (1975) reported on mortality rates in 10 localities in Rumania. The hardness of the drinking water varied from 22 to $364 \mathrm{ppm}$, but the results were presented only in terms of two groups, under 100 and over 200 ppm hardness. All cardiovascular death rates were higher in the group with water hardness under 100 . There was apparently no standardization for possible effects of differences in age and sex, even though the remarkable range in total mortality $(199-1,265$ per 10,000) would seem to make such standardization mandatory.

\section{Japan}

Kamiyama et al. (1969) studied two villages in Japan, one a farming and the other a fishing village. Calcium in water, diet, and serum was higher in the fishing village, which had the lower death rate from stroke among persons aged 45-64 in the period 1956-1962.

\section{MAJOR INTRA-NATIONAL DIVISIONS (STATES OR PROVINCES)}

\section{United States}

Lindemann and Assenzo (1964) looked at age-, race-, and sex-adjusted death rates in 1959-1961 for all 77 counties in Oklahoma, where the hardness values ranged from 19 to $942 \mathrm{ppm}$. Essentially no association was found between hardness and cardiovascular disease death rates. Winton and McCabe (1970), however, recalculated the correlations, using only the data from the 38 counties where at least half the population had similar public water supplies. They found that this procedure changed the correlation of hardness with cardiovascular deaths among white males $45-64$ from -.09 to -.32 , neither being significantly different from zero.

In the four major regions of North Carolina, water is softest in the Highlands (23 ppm), intermediate in the Coastal Plain and Piedmont (51-61 ppm), and hardest in the Tidewater region (163 ppm). Tyroler (1970), quoting unpublished data from $R$. C. Brittain, reported that thi 
death rates from arteriosclerotic and degenerative heart disease among white males 55-64 in 1956-1964 were lowest in the soft water Highlands and highest in the intermediate hardness regions. In a later study, Voors (1972) reported a positive association of total arteriosclerotic heart disease deaths with water hardness in the $\mathbf{2 2}$ Tidewater counties of North Carolina, but a negative association in the remaining 26 counties.

Peterson et al. (1970) studied sudden deaths in 19661967 in the State of Washington in two groups of counties, those with water hardness under $100 \mathrm{ppm}$ and those with hardness values between 100 and 200 . Sudden deaths from arteriosclerotic heart disease were more frequent in the soft water counties, while the opposite was true for deaths that were not sudden. The total death rates from arteriosclerotic heart disease were virtually the same in the two groups of counties. Although the hardness ranges in Washington are restricted or narrow, this study did confirm the finding of Anderson et al. (1969) in Ontario with respect to increased frequency of sudden arteriosclerotic heart disease deaths in soft water areas.

Although Morton (1971a, 1971b) did not look at the association of cardiovascular disease and water hardness, he published data from Colorado, which permits correlation and regression coefficients and relative risks to be calculated by using two methods of grouping counties: by altitude and by river basin. By using age-adjusted death rates for two time periods, 1949-1951 and 1959-1961, mortality from arteriosclerotic heart disease; strokes; and general arteriosclerosis and peripheral vascular disease combined all showed negative regression coefficients with hardness. The risk of drinking water of $0 \mathrm{ppm}$ hardness compared to the risk of drinking water of $200 \mathrm{ppm}$ ranged from 1.01 to 1.42 . For hypertension the situation was different; risks of dying from hypertension associated with water of $0 \mathrm{ppm}$ hardness compared with risks associated with water of $200 \mathrm{ppm}$ hardness were only were 0.95 and 0.49 , in 1949-1951 and 1959-1961, respectively, when the counties were grouped by altitude. The same data grouped by river basin produce relative risks of 1.30 and 0.99 . The prevalence of hypertension among Selective Service registrants in 1957-1964 showed a strongly positive association with water hardness with counties grouped by altitude and by river basin, yielding relative risks for $0 \mathrm{ppm}$ hardness and $200 \mathrm{ppm}$ hardness of 0.78 and 0.47 , respectively, an apparent protective effect of soft water.

In a study of arteriosclerotic heart disease deaths in New Mexico, Mortimer et al. (1977) found that there was an inverse association with altitude for males, though there was none for females. In looking for possible causes, they noted that their results were not likely to be related to water hardness because hardness also varies inversely with altitude in New Mexico.

Klusman and Sauer (1975) found in counties in Indiana no significant associations of hardness using ageadjusted cardiovascular-renal death rates for 1959-1961 among males aged 35-74, and even a tendency toward positive correlations. Using stepwise multiple regression, they found the contribution of calcium, magnesium, and hardness to be very small.

The Massachusetts Department of Public Health (1975) also found no significant association of water hardness with local risk of ischemic heart disease in the 23 largest cities in Massachusetts. However, the range of water hardness in these cities was only 6 to $49 \mathrm{ppm}$ (Heidgerd et al., 1972).

\section{United Kingdom}

Hart (1970) says that some of the difference in mortality from coronary heart disease and stroke among males 3564 in two counties of Wales may be attributed to the negative correlation of the death rates from these two causes with water hardness $(-.46$ and significant for arteriosclerotic heart disease; -.26 and nonsignificant for strokes).

Elwood et al. (1974) studied tap water from 15-18 locations in each of 48 local health authorities in South Wales. The correlation of calcium in the tap water with cardiovascular mortality among adults $35-64$ was -.55 . This is one of few papers dealing with tap water, rather than water at the treatment plant.

Connor (1971) noted that in Scotland, Edinburgh, with the hardest water, had a higher arteriosclerotic heart disease death rate among males than Glasgow, with the softest water. However, Crawford et al. (1971c) replied that both towns have soft water, Edinburgh $40 \mathrm{ppm}$ and Glasgow $10 \mathrm{ppm}$. Furthermore, the differences in death rates were slight.

\section{Canada}

Three studies dealt with the relation of water hardness to sudden death in Ontario. Anderson et al. (1969) found the death rates from arteriosclerotic heart disease to be 14 percent lower in areas with hardness values over 200 $\mathrm{ppm}$ than in areas with hardness under $100 \mathrm{ppm}$. The excess in the soft water areas resulted entirely from an excess of coroner's cases of arteriosclerotic heart disease. A second study by Anderson and leRiche (1971) also found negative correlations of sudden death in 34 medium-sized cities and towns in Ontario. Neri et al. (1971) found that the percent of coronary heart disease death certified by a coroner within provinces showed the 
gradient expected from the preceding studies only in Alberta and British Columbia. They raised the possibility that the correlation between hardness and sudden death may result in large part from the fact that both water hardness and the proportion of deaths certified by coroners are correlated with size of community, and hence only indirectly with each other.

Deutscher (1973) reported that there was considerable variation in water hardness in counties in Nova Scotia. Data on water hardness and cardiovascular deaths among males aged 45-64 were given for the 18 counties (10 were paired, and weighted averages of water hardness had to be used for the five pairs). Spearman's (1904) rank order correlation coefficient calculated from Deutscher's data was +.21 for hardness and cardiovascular death rates.

A report from Newfoundland was made by Fodor $e t$ al. (1973). St. John's, with very soft water (3.6 ppm), had a higher death rate from arteriosclerotic heart disease than two other small towns with slightly harder water (weighted average of $38.2 \mathrm{ppm}$ ). The death rates were not adjusted for age within the broad range of 35-69 years. Deaths, other than cardiovascular-renal, also showed a similar excess in St. John's.

\section{Germany}

In 11 towns of lower Saxony, Pflanz and Wolf (1976) looked at deaths from various cardiovascular causes in relation to the water hardness, which ranged from 53 to $603 \mathrm{ppm}$. The death rates were age-standardized and analyzed separately for males and females. Most of the correlations were negative; the only two at the $<0.5$ level of statistical significance were all diseases of the circulatory system among males and acute myocardial infarction among females. All of the relative risks, calculated as the risk of $0 \mathrm{ppm}$ compared to $200 \mathrm{ppm}$ of hardness, were low, ranging from 1.00 to 1.09 , the last being that for acute myocardial infarctions among women.

\section{Czechoslovakia}

As part of a study relating diet to heart disease, Osancova and Hejda (1968) looked at the association of the "incidence of atherosclerosis and some indicators usually accepted to suggest the development of atherosclerosis" in three areas of Bohemia. Arteriosclerosis was least frequent in the lowlands with the softest water (mean calcium $32 \mathrm{ppm}$ ), intermediate in the hills (mean calcium $106 \mathrm{ppm}$ ), and highest in the mountains (mean calcium $179 \mathrm{ppm}$ ), the opposite of what is usually observed.

\section{Italy}

Angelillo and Alamanni (1964), studying five areas in Sardinia, found no correlation of water hardness with deaths from all causes or from all cardiovascular causes. Death rates were not adjusted for age or sex. One district had such marked variations in water hardness that its contribution to the results is uninterpretable.

\section{COUNTIES AND CITIES}

\section{United States}

Muss (1962) compared areas of New York City served by private water companies for 1936-1940 with areas served by the city. Water from the private companies tended to be harder (13-300 ppm) than that from the city (18-53 ppm). The crude cardiovascular death rate in the private company areas was 315 per 100,000 ; that in the areas served by the city was 351 . Muss recognized the many deficiencies of this comparison and claimed only that the direction of the observed difference was compatible with Schroeder's finding.

Although Bierenbaum et al. (1973) were primarily interested in the relationship of water hardness to serum cholesterol, their statement that the cardiovascular mortality of North Carolina was one and one half times the cardiovascular mortality of Nebraska implies that their soft water $(30 \mathrm{ppm})$ city of Winston-Salem had higher cardiovascular death rates than their hard water (154 ppm) city of Omaha. In fact, the opposite seems to be true, both among white males 45-64 (Dudley et al., 1969) and among persons of all ages in 1960, using total cardiovascular deaths for each city or its corresponding county (National Center for Health Statistics, 1963) and populations for the corresponding areas (Hansen, 1963).

Three communities in the Los Angeles area were matched for age, sex; race, income, socioeconomic status, and stability by Allwright et al. (1974). The three communities were Reseda, with water hardness of 82 ppm, Burbank, with 189 ppm, and Downey, with 327 ppm. No correlation could be found between hardness and age- or sex-adjusted mortality in 1969 and 1970 from hypertensive diseases, stroke, arteriosclerotic heart disease, malignant neoplasms, or infant or neonatal mortality. The authors pointed out that their softest water community had water that matched some that had been described as hard in several British studies. Their results suggest that if there is a deleterious effect associated with soft water, it is a threshold effect.

Two studies have been completed in Washington County, Maryland, which is an area with considerable diversity of water supplies. Both compared persons who 
had died from arteriosclerotic heart disease with controls drawn from the same general population and used hardness values determined on samples from the home water taps of both cases and controls. The study by Comstock (1971) involved 412 males 45-64 years of age; that by Schreiber (1977), 284 females in the same age bracket. Comstock's findings indicated the relative risk of water with hardness less than $150 \mathrm{ppm}$ to be 0.75 , not significantly different from 1.0 , but with an upper 95 percent confidence limit slightly less than the 1.2 relative risk postulated by Neri et al. (1974). Schreiber found an increased relative risk with soft water at home, but the 95 percent confidence limits ranged from 0.69 to 3.2.

Bierenbaum et al. (1975) compared workers in Kansas City, Kansas, with water hardness of 189 ppm, with workers from the same industry in Kansas City, Missouri, whose water from the same source was softened to 78 ppm. Cardiovascular-renal mortality, 1969-1971, for persons aged 45-64 was reported to be higher for each race-sex group in Kansas City, Kansas, with its harder water.

Chah et al. (1976) compared water hardness from the homes of 51 persons with coronary heart disease or stroke in Evans County, Georgia, with that of 65 controls matched for race, sex, age, length of residence, and neighborhood. They found no evidence to support an association of soft water with these cardiovascular diseases, but this is not surprising, as controls had to be neighbors of the cases. It is notable that Evans County, although it is located in the high-stroke belt along the Eastern Seaboard, is a hard water area.

\section{Germany}

Keil et al. (1975) looked at the city of Hanover in northern Germany, which has four water sources, two hard and two very hard. The hard water sources have hardness values around $180 \mathrm{ppm}$; the very hard sources around $450 \mathrm{ppm}$. The usually reported findings of lower cardiovascular mortality in areas with harder water were not supported, but the effects of soft water could scarcely be studied in this hard water area.

\section{Hungary}

In six districts of south Budapest, incidence rates of myocardial infarction were determined for 1971 (Gyarfas et al., 1976). Five of the districts obtained drinking water from two wells with an average hardness over the previous 10 years of $232 \mathrm{ppm}$; the sixth district supplemented this supply from another well, causing the hardness to be $367 \mathrm{ppm}$. Registered cases of myocardial infarction among men were significantly less frequent in the sixth district with the harder of the two hard water sources. The rates were adjusted only for sex, and no estimate of the completeness of registration in the six districts is possible.

\section{Italy}

In the 18 communes of Ravenna, Marzot et al. (1968) reported that death rates from myocardial infarction were lower in the 8 communes with water hardness ranging from 360 to $550 \mathrm{ppm}$ than in the 10 with hardness values ranging from 160 to $350 \mathrm{ppm}$. The difference was found only for men; the rates were not adjusted for possible age difference.

Cavallo et al. (1975) divided the districts of Turin into three groups according to their water hardness (approximately 100,220 , and $350 \mathrm{ppm}$ ). Mortality rates were standardized for sex and for broad age groups (30-64, and 65 and over). For total deaths and most cardiovascular causes, the highest rates, averaged for 1972 and 1973, were in areas with intermediate hardness $(220 \mathrm{ppm})$. For all cardiovascular causes combined, the highest rates were in the areas with the hardest water, and the lowest rates in the areas with the softest (but not really soft) water.

\section{EVALUATION OF OBSERVED ASSOCIATIONS}

While associations may be spurious, coincidental, or causal (Susser, 1973; Lilienfield, 1976), there can be little doubt that the negative associations of water hardness with cardiovascular mortality are not spurious. Too many studies have reported statistically significant correlations to make chance or sampling errors a likely explanation. The complete independence of virtually all the observations of water hardness and the measures of cardiovascular disease effectually rules out observer bias as a cause of the relationships.

If the association is not spurious, the question remains whether it is coincidental or causal. By coincidental it is meant that by chance water hardness and cardiovascular disease are each associated with some other variable or variables.

There are several characteristics of observed associations that, if present, increase the probability that the relationship is one of cause and effect. Those that seem pertinent to the present discussion are as follows:

- Consistency. A causal association is likely to be found in different places, at different times, and in different subgroups of the population.

- Strength of association. The greater the relative risk 


\section{CARDIOVASCular Disease}

of disease associated with a characteristic, the more likely it is that the association is causal.

- Dose-response effect. Although some causes have thresholds below (or above) which they do not operate, most causal associations demonstrate a dose-response effect, i.e., a little or low level of a characteristic produces little disease, while increasing levels are associated with a corresponding increasing frequency of disease.

- Specificity. Relatively few factors cause multiple effects, so the more conditions found to be associated with any characteristic, the more suspicious one should be that the association is not causal.

- Experimental changes. If the degree of water hardness is really related to cardiovascular disease, changes in water hardness should be followed by changes in the frequency of cardiovascular disease.

- Coincidental factors. Factors most strongly related to a disease are those most likely to be causal. This may be illustrated by the hypothesized link of soft water to cadmium. If cadmium levels are more closely associated with disease than soft water, the implication is that the true causal factor in soft water is not its softness as such, but its ability to dissolve cadmium, and this ability is found in some, but not all, soft waters.

- Biological plausibility. A biologically plausible explanation for the effect of a characteristic upon the development of a disease increases the likelihood that an association is causal.

\section{CONSISTENCY}

The preceding sections of this review indicate that the negative association of water hardness with cardiovascular mortality was reported in most, but not all, studies. A provocative example is afforded by Canadian data (Neri et al., 1972). If one looks at the country as a whole, there is a negative correlation of cardiovascular mortality within municipalities with hardness of their water supplies. But when data were analyzed by individual provinces, the correlation coefficients remained negative only for Quebec and Ontario, turning to positive for the Maritime Provinces, the Prairie Provinces, and British Columbia.

Another troublesome failure of geographic consistency concerns Birmingham, which with its soft water seems to be an exception among. British towns (Morris et al., 1962). Davies (1962) noted that Birmingham pioneered in effective treatment for acidity, without an appreciable increase in hardness. Like Schroeder and others, he suggested that corrosiveness, rather than softness, might relate to the water factor.

In some other instances the lack of unanimity might be accounted for by inadequate analytic procedures, most commonly the failure to use properly adjusted rates; in still others, by a sharply limited range of water hardness or such small populations that the death rates were subject to large sampling errors. Such deficiencies, however, do not account for all the failures to find the generally observed negative association. Consequently, from the numerous exceptions to the general rule, the association between water hardness and cardiovascular disease can hardly be directly causal. Indirect causality, or direct causality only under certain conditions, are better possibilities.

Most of the studies reviewed dealt with death rates around census years in the early 1950's or 1960's, and generally speaking, similar associations tended to be found at all time periods over the past three decades. Four studies each examined two different time periods, 10 years apart (Schroeder, 1966; Gardner et al., 1969; Morton, 1971a, 1971b; Neri et al., 1972); they also found generally similar associations for each period. Sauer (1974a) noted a rank order correlation of .95 between death rates for 92 metropolitan state economic areas in the United States in 1959-1961 and 1962-1968. Generally speaking, the studies that have reported age-specific correlation coefficients have found them to be roughly similar for various age groups (Schroeder, 1960a, 1960b; Morris et al., 1961; Biörck et al., 1965; Crawford et al., 1968; Hart, 1970). An exception was the finding of several positive coefficients among persons $25-44$ years of age, especially males, in Sweden, although at this age, almost no correlations were significantly different from zero (Biörck et al., 1965). Similarly, the correlations tend to be negative for both sexes, although they often achieve significance for only one sex, notably females in Sweden (Biörck et al., 1965) and for arteriosclerotic heart disease, females in Netherlands (Biersteker, 1967). Few have looked at different ethnic groups. Schroeder and Kraemer (1974) found considerably fewer significant correlations for nonwhites than for whites in the United States, and an international study of pathological changes in aortas and coronary arteries showed a negative association only for whites in New Orleans, Oslo, São Paulo, and Puerto Rico, but positive associations for blacks and for other Latin American populations (Strong et al., 1968).

In most of the studies involving large areas, there is a strong general tendency toward negative correlation coefficients. Most of the discrepancies between them relate only to the statistical significance of the correlations. However, no study has reported really high correlation coefficients, and with the probability that other cardiovascular risk factors vary considerably between populations, the failure to find consistently significant correlations is understandable. The major, and 
most troublesome, inconsistency arises from the numerous failures to find negative associations between hardness and cardiovascular disease in comparisons of companion communities and in studies of variations within small geographic areas.

\section{STRENGTH OF ASSOCIATION}

A major problem in assessing the reality of the causal association of soft water with cardiovascular mortality arises from the fact that all the current evidence points to a weak association at best. Neri et al. (1974) state that a " 20 percent margin of risk . . is the most one is entitled to assume between the extremes of hard and soft water," i.e., a maximum relative risk associated with soft water of 1.20 . Only a few authors published their data in sufficient detail to allow regression analysis. Their results are summarized in Table 13.

In Ontario, Anderson et al. (1969) found the risk of death from arteriosclerotic heart disease, sudden and nonsudden combined, to be 1.13 times as high in areas with water hardness of $0-99 \mathrm{ppm}$ as in areas with hardness of over $200 \mathrm{ppm}$. In Washington County, Maryland, Comstock (1971) found the relative risk for white males 45-64 of arteriosclerotic heart disease associated with drinking water less than $150 \mathrm{ppm}$ of hardness to be 0.75 with 95 percent confidence limits of

TABLE 13 Relative Risks of Dying from Specified Causes Associated with Drinking Soft Water (0 ppm) Compared to Drinking Hard Water (200 ppm) (Calculated from Several Studies)

\begin{tabular}{|c|c|c|}
\hline Cause of Death & Race, Sex, Age & $\begin{array}{l}\text { Relative } \\
\text { Risk* }\end{array}$ \\
\hline \multicolumn{3}{|l|}{ United States (Muss, 1962) } \\
\hline Total cardiovascular disease & WM, 45-64 & 1.25 \\
\hline \multicolumn{3}{|c|}{ England and Wales (Morris et al., 1961) } \\
\hline Total cardiovascular disease & WM, 45-64 & 1.19 \\
\hline \multicolumn{3}{|l|}{ Canada (Neri et al., 1972) } \\
\hline Arteriosclerotic heart disease & $M, 35-64$ & 1.07 \\
\hline Strokes & $M, 35-64$ & 1.15 \\
\hline Other circulatory & $M, 35.64$ & 1.10 \\
\hline \multicolumn{3}{|l|}{ Colorado (Morton, $1971 \mathrm{~b})^{*}$} \\
\hline Arteriosclerotic heart disease & M\&F, age-adjusted & $1.01-1.19$ \\
\hline Strokes & M\&F, age-adjusted & $1.03-1.11$ \\
\hline Hypertensive disease & M\&F, age-adjusted & $0.49-1.30$ \\
\hline Other circulatory & M\&F, age-adjusted & $1.02-1.42$ \\
\hline
\end{tabular}

- Two relative risks are given for Morton's findings, based on two different groupings of the data, by altitude and river basin.
0.49 and 1.14. Schreiber (1977) analyzed the mortality experience for white females of the same age and in the same county and found a relative risk of 1.47 for water with hardness less than $100 \mathrm{ppm}$ compared to water of 150 or more ppm, but again with broad 95 percent confidence limits, 0.69 and 3.2 .

In no study does the association appear to be strong. The weakness of this association must be considered a point against a causal hypothesis.

\section{DOSE-RESPONSE EFFECT}

With low regression and correlation coefficients, it is virtually impossible to tell whether or not there is a threshold effect between water hardness and cardiovascular disease. The general tendency of the correlations to be negative does suggest that there may be a weak doseresponse effect. This is supported by the finding of Crawford et al. (1968) that the trend of cardiovascular mortality on hardness in Great Britain was linear and fairly uniform, and is questioned by the contrary finding in an analysis of proportionate mortality data from England and Wales by Stocks (1973) of a curvilinear effect. With a weak association, perturbations introduced by other risk factors could make the detection of a doseresponse effect very difficult.

\section{SPECIFICITY}

Among the studies that have reported death rates from various causes within the broad group of hypertensivearteriosclerotic cardiovascular-renal diseases, most have found negative correlations for arteriosclerotic and degenerative heart disease, hypertensive disease, and strokes. There is, however, considerable disagreement regarding which of these causes correlates best (i.e., most strongly in a negative direction) with water hardness. Schroeder (1961) called attention to this some time ago, noting that high negative correlations of hardness with hypertensive heart disease were found in the United States but not in the United Kingdom, while the correlations with stroke were more strongly negative in the United Kingdom than in the United States. All of Schroeder's analyses (Schroeder, 1960a, 1960b, 1966; Schroeder and Kraemer, 1974) have shown the highest correlations with arteriosclerotic heart disease, as did Biersteker (1967) in the Netherlands. In England (Morris et al., 1961) and in Sweden (Biörck et al., 1965) the strongest correlations were with myocardial degeneration, while in Colorado (Morton, 1971b) the highest correlations were with deaths from general arteriosclerosis and peripheral vascular disease other than hypertension. Masironi's analysis of 1962 deaths in the United 
States (Masironi, 1970) revealed that the strongest correlations were with hypertensive heart disease, a finding that also held true for six Latin American cities. Another study of mortality in England (Crawford et al., 1968) found the correlations with strokes and other heart disease to be equally strong, and somewhat stronger than those with arteriosclerotic heart disease. In Canada (Neri et al., 1972), the correlation with stroke deaths was much stronger than with arteriosclerotic and degenerative heart disease.

More disturbing than the perturbations within the hypertensive-arteriosclerotic constellation are the numerous other causes of death that have been found to be associated with water hardness, many of them negatively correlated and about as strongly as the cardiovascular causes. This was the situation for water hardness and cancer deaths in the United States (Schroeder, 1960a; Winton and McCabe, 1970; Sauer, 1974b), while in Great Britain the correlation, while still negative, was much less (Morris et al., 1961). Negative correlations have also been reported for cirrhosis (Schroeder, 1960a; Winton and McCabe, 1970) and peptic ulcer (Morris et al., 1961; Winton and McCabe, 1970), while the correlation for gastritis was positive (Winton and McCabe, 1970). In Britain, bronchitis was also negatively associated with hardness (Crawford et al., 1968; Gardner et al., 1969; Hart, 1970), while in the United States, chronic obstructive pulmonary disease is positively associated with total mineralization of water (Sauer, 1974b). Fatal accidents have been found to be positively associated with hardness in the United States (Schroeder, 1960a; Winton and McCabe, 1970; Sauer, 1974a), but to have no association in the United Kingdom (Morris et al., 1961). Noncardiovascular causes as a whole have been found to have a negative correlation in Canada (Neri et al., 1972) and in the United Kingdom (Morris et al., 1961; Crawford et al., 1968), but two other studies, both in the United States (Schroeder, 1960b; Masironi, 1970), failed to find the association to be different from zero. In South Wales (Elwood et al., 1974) the correlation coefficient for total deaths was much more highly negative than that for cardiovascular deaths, a point the authors considered to be against specificity of effect of hardness.

Sudden deaths from causes other than arteriosclerotic heart disease were found to be positively associated with water hardness in Ontario (Anderson et al., 1969) and in Washington State (Peterson et al., 1970), a relationship opposite to that for sudden deaths from arteriosclerotic heart disease.

Infant mortality and congenital malformations have also been found to be associated with water hardness, negatively in the United Kingdom (Hart, 1970; Lowe et al., 1971; Crawford et al., 1972b), but positively in the
United States (Winton and McCabe, 1970). A later study in the United States, adjusting for the effects of socioeconomic status and industrialization, found no evidence for an association of infant mortality with hardness (Spiers $e t$ al., 1974). Adjustment for social factors and latitude did not remove the association with hardness in the United Kingdom (Crawford et al., 1972b).

Deaths from congenital malformations were positively associated with water hardness in two different analyses of the 1949-1951 mortality data in the United States (Schroeder, 1960a; Winton and McCabe, 1970). Although one paper reported a negative association with anencephalus in the United Kingdom (Fedrick, 1970), three others failed to confirm this finding (Field and Smithells, 1971; Lowe et al., 1971; Biggar et al., 1976). Anencephalus was found to be associated with magnesium in drinking water in Canadian cities $(r=-.39)$, but not with calcium or total hardness (Elwood, 1977). In South Wales (Lowe et al., 1971) a remarkably close association was found between hardness and spina bifida, which persisted after adjustment for socioeconomic status.

An intriguing finding was made by an Australian economist (Lyster, 1972) who noted that in areas of high soil mineralization there was an excess of male lambs at birth and in areas that were poorly mineralized, there was a deficiency of male lambs. He also found a deficiency of male births in human births in the Merseyside conurbation (the greater Liverpool area) of England. However, when his data are reanalyzed by periods before, during, and after the hardening of the water from 28 to 62 ppm, they show only slight and inconsistent changes.

In 13 Himalayan villages, endemic goiter varied widely in frequency (Day and Powell-Jackson, 1972). The goiter prevalence was not related to iodine in the water, but rather to the concomitant presence of fluoride, and slightly more closely to hardness (rank correlation coefficient of .77).

Perhaps the lack of specificity of effect was best summed up by Winton and McCabe (1970), who in referring to the considerable number of diseases associated either positively or negatively with water hardness stated: "Dissolved solids may be important to man but one would not expect them to be this important."

\section{EXPERIMENTAL CHANGES}

Theoretically, the ideal way to settle any controversy about the association of water hardness and cardiovascular disease would be to alter the hardness of the water deliberately in half of a number of matched communities. This potentially useful procedure, however, seems unlikely to be accomplished. A few reports of changes ir 
mortality following changes in water hardness for other purposes have appeared in the literature, but none are convincing.

Robertson (1968, 1969) reported on Grimsby and Scunthorpe, two towns in England. Scunthorpe's water was softened, after which its death rate increased by 24 percent. Grimsby's water was not softened, and its death rate fell by 13 percent. The water of Scunthorpe was softened only to $40 \mathrm{ppm}$ of calcium, which is not really soft, and during the same time period the death rates for all of England increased by 19 percent, making it appear that Grimsby, the control town, was really the peculiar one of this pair (Crawford et al., 1971b).

A more recent report on mortality in Scunthorpe (Robertson, 1977) described an immediate rise in mortality following artificial softening of Scunthorpe's water supply in 1958 or 1959 from a hardness of over $400 \mathrm{ppm}$ to $60 \mathrm{ppm}$. Hardness was then successively adjusted to 90, 120, and $225 \mathrm{ppm}$ during the period 1962-1973. From the published graph it is possible to calculate observed and expected deaths from all causes among white males 45-64 years of age from 1959 to 1973. The results of the calculations are not consistent with a harmful effect of soft water. There appears to have been a deficit of deaths during the period when the water hardness was $60 \mathrm{ppm}$, an excess during the periods when the hardness was 90 and $120 \mathrm{ppm}$, and about the expected number of deaths when the hardness was finally adjusted to $225 \mathrm{ppm}$.

Somewhat more convincing was the report by Crawford et al. (1971b) on changes in death rates in 5 British towns whose water became harder, 6 towns whose water became softer, and 72 in which there was no change. In all three groups of towns, cardiovascular mortality increased among males aged 45-64 years, while it decreased among males aged 65-74 and among females of both age groups. Changes in cardiovascular mortality were most favorable; that is, they increased least or decreased most in the towns where the water was hardened, except for females aged 65-74 among whom the decrease in mortality was least marked in towns with hardened water. After standardizing for socioeconomic status, it was found that 9 of the 11 towns with water hardness changes showed death rate changes consistent with the hypothesis that softening was harmful; the two exceptions were the two smallest towns (Crawford et al., 1972a). There was, however, marked variability in the rates, with considerable overlap between the three groups of towns, so that some "hardened" towns had less favorable changes than some "softened" towns. The changes in water hardness were not dramatic, and no town changed from really soft to really hard water, or vice versa.
Lyster (1972) reported that the Merseyside conurbation in England began to draw water from the River Dee, a few miles to the west, in 1958 and that the water hardness increased from $28 \mathrm{ppm}$ to $62 \mathrm{ppm}$ in 1969. Certain parts of the conurbation received the harder water some years earlier than the others. He concluded that the adjusted death rates began to decline 7 years after the change in water supply, the decline being greatest where the consumption of the harder water was greatest. Reanalysis of his data by periods before, during, and after the changes shows that the death rates were highest during the 7-year period in which the water was becoming harder and that they generally remained high after the change to more highly mineralized water.

A report to which considerable uncritical reference has been made is that of changes in mortality in Monroe County, Florida (Groover et al., 1972). In 1941 the principal water source was changed from rainwater $(0.5$ ppm hardness) to deep well water (200 ppm hardness) that during the same year was softened to a hardness of 80-120 ppm. It was reported that the cardiovascularrenal death rate "dropped from the 500 to 700 range to the 200 to 300 level four (4) years after the change." What many authors may not realize is that Monroe County contains the U.S. Naval Base at Key West and that the county experienced marked population changes during and after World War II. The effect of adjustments for age-sex-race changes are shown in Table 14. With allowances for the effect of population changes, it may be seen that the change from 1940 to 1950 in cardiovascular-renal deaths was essentially the same as that for the United States as a whole.

Hudson and Gilcreas (1976) reported on average cardiovascular death rates in 72 metropolitan areas of the United States that did not soften their water (mean hardness $102 \mathrm{ppm}$ ) and 24 that did, using lime softening to decrease the hardness from a mean value of 210 to 93 $\mathrm{ppm}$. The rates were 410 and 380 , respectively, for white males, but were apparently not age-adjusted.

TABLE 14 Cardiovascular-Renal Death Rates per 100,000, Monroe County, Florida, 1940 and 1950

\begin{tabular}{lccc}
\hline Rate & 1940 & 1950 & $\begin{array}{l}\text { Percent } \\
\text { Change }\end{array}$ \\
\hline Crude & 570 & 304 & -47 \\
Age-adjusted* & 702 & 572 & -18 \\
Age-sex-race adjusted* & 684 & 575 & -16 \\
United States, age-adjusted & 508 & 440 & -13 \\
\hline
\end{tabular}

* Adjusted by the indirect method using age-race-sex specific rates for the State of Florida for 1960. 


\section{COINCIDENTAL FACTORS ASSOCIATED WITH CARDIOVASCULAR RISK}

If there is a causal relation between water hardness and cardiovascular disease, a similar relation might also be expected between hardness and some of the known cardiovascular risk factors, such as blood pressure, cholesterol, blood clotting mechanisms, and electrocardiographic abnormalities. This would be particularly true if the effect of water hardness were mediated directly or indirectly through one of these biologic risk factors.

Although it seems unlikely that the calcium content of drinking water could have any effect on serum calcium (Goodhart and Shils, 1973), Langford and Watson (1972) have postulated that a "low calcium intake might accentuate the hypertensinogenic effects of sodium. If this is correct, the higher sodium intake and lower calcium intake of the soft-water areas should additively raise blood pressure, and hypertension is an accepted precursor of cardiovascular deaths. . . ." The hypothesis that cadmium in some soft waters might also lead to hypertension has also been raised (Schroeder, 1969).

Five studies have reported blood pressure levels in hard and soft water areas. In the United Kingdom, one study found that blood pressure was higher in the soft water area and also increased more rapidly with age there (Stitt et al., 1973), while the other found no important differences in blood pressure (Elwood et al., 1971). A comparison of men living in Kansas City, Kansas, and Kansas City, Missouri, showed blood pressure to be higher in the Kansas residents where the water was harder (Bierenbaum et al., 1975). Pflanz et al. (1976) studied a sample of persons, 50 years of age, who lived in Hanover, Germany, a city supplied from four water sources, two "slightly hard" (171-189 ppm) and two "very hard" (400-495 ppm). They looked at blood pressures, body mass (Quetelet's index), ventilatory function, cigarette smoking, and symptoms of angina, dyspnea, and neurosis (Langner's scale). The only significant difference between residents of the very hard water areas and those of the slightly hard water areas was that symptoms of angina were more common among women in the very hard water areas. A very interesting observation, however, was that there were significant differences in blood pressure levels between residents of the two very hard water areas, a difference that the authors attributed to socioeconomic factors.

In natives of New Guinea living in nine villages with water supplies containing between 2 and $8 \mathrm{ppm}$ of calcium (equivalent to 5-20 parts of calcium carbonate), systolic blood pressure showed a decreasing gradient with increasing calcium content (World Health Organization, 1973). It appears, however, that the villages with the softest water are at lower elevations and presumably more closely in touch with western civilization (Masironi, 1977), a factor often found to be associated with high blood pressure.

Cholesterol levels in the serum have also been linked to calcium intake (Bierenbaum et al., 1973). Again the two British studies disagreed, one finding higher cholesterol levels in the soft water area (Stitt et al., 1973), the other no important differences (Elwood et al., 1971). In companion studies between Omaha and Winston-Salem in the United States, and London and Glasgow in the United Kingdom (the first of each pair being a hard water town, the second a soft water town), Bierenbaum $e t$ al. $(1969,1973)$ found mean cholesterol levels to be slightly lower in the soft water cities.

No significant differences in packed cell volume (Elwood et al., 1971) or in thrombin clotting time, kaolin cephalin clotting time, levels of circulating fibrinogen and plasminogen, or levels of fibrin degradation products were found between soft and hard water areas (Elwood $e t$ al., 1972).

Very few studies have considered the possibility that smoking patterns might be different in areas with soft and hard water. Bierenbaum et al. $(1969,1973)$ found this not to be so between two cities in the United States, but showed a marked difference between London and Glasgow, hard and soft water areas, respectively. Even within a single county, middle-aged men with soft water at home were more likely to smoke cigarettes (Comstock, 1971).

A study of risk factors related to strokes has been carried out among approximately 600 persons, 35-54 years of age, in each of three areas (Stolley et al., 1977). Savannah, Georgia, the high-stroke-rate community, has water with a hardness of $120 \mathrm{ppm}$, and Pueblo, Colorado, the low-stroke-rate community, has 279 ppm. Hagerstown, Maryland, the intermediate-stroke-rate area, has water from two sources, one soft and the other slightly hard, giving an average somewhat below $100 \mathrm{ppm}$. Among whites, Hagerstown had the highest and Pueblo the lowest percentage of persons with two or more stroke risk factors (increased levels of cholesterol, blood pressure, cigarette smoking, overweight, and blood glucose). Among blacks, the relations were inconsistent. Black males had the highest percentage in Pueblo and the lowest in Hagerstown, the opposite of the gradient among whites; black females had the highest percentage with two or more risk factors in Savannah and the lowest percentage in Pueblo.

Within Great Britain, mortality rates vary with the ABO blood group distribution (Mitchell, 1977). Although controlling for the percentage of people with blood group $\mathrm{O}$ did not remove the association with water 
hardness, Mitchell underscores the difficulties in sorting out the effects of the numerous and often closely interrelated variables that accompany geography.

Although little work has been done on the association of water hardness with biologic risk factors, other than those of age, sex, and race, the few available results do not favor the hypothesis that some component of water is related both to hardness and to the biologic risk factor. This may be so, for it is still possible that only some soft waters contain this water factor. Further studies along this line should be helpful. One wonders whether findings from the National Health Survey examinations might not make useful contributions.

\section{POSSIBLE CONFOUNDING FACTORS}

A little reflection reveals that many human characteristics, particularly the demographic, socioeconomic, and cultural ones, vary with geography. Because hardness of water also varies with geography, it could well be that in measuring the correlations of hardness with cardiovascular disease, we are really measuring the correlation of some other geographically related characteristic to cardiovascular disease. This was suggested in 1964, when a review panel analyzed Schroeder's data by states according to whether or not they had a seacoast. This procedure markedly reduced the correlation coefficients with cardiovascular mortality; it even changed them to a positive sign for the 23 coastal states (Dingle et al., 1964). Sauer (1962) has also called attention to the fact that the correlation for elevation above sea level is higher than that for water factors with cardiovascular deaths in the metropolitan areas of the United States. A. W. Voors (personal communication, 1977) found the logarithm of water hardness and age-adjusted mortality from arteriosclerotic heart disease for white males in 99 U.S. cities, 1959-1961, to have a correlation coefficient of -.29 , which decreased to -.05 when the death rates were also adjusted for altitude.

Climatic factors are also related to geography. Two studies looked at indices of temperature. In the United Kingdom, temperature was found to be more closely related to cardiovascular deaths than hardness (West $e t$ al., 1973). In the United States the comfort index (based on relative humidity and air temperature) was the most important correlate, with water factors second, after adjustment for age and several indicators of socioeconomic status (Dudley et al., 1969).

In the United Kingdom, rainfall has been a major correlate of cardiovascular mortality. Looking at five indices (social factor score, domestic air pollution, latitude, long-period rainfall, and calcium in water), Gardner et al. (1969) found among eight sex-age-time groups that rainfall was most important in five, latitude in two, and water hardness in only one. Roberts and Lloyd (1972) also found local rainfall to be more closely associated with ischemic heart disease than water hardness. This study has been criticized because its use of standardized mortality ratios rather than adjusted rates introduced an additional element of variation.

In England particularly, latitude has been an important correlate, one that is obviously correlated with sunshine and long-term temperatures. Morris et al. (1962) noted that water hardness and latitude were not correlated. Using these weather variables, including rainfall, they found that latitude and water hardness accounted for about half the variance in cardiovascular death rates. Later, the same group (Crawford et al., 1968) looked at correlations of cardiovascular disease with latitude, temperature, a combined social-factor score, domestic air pollution, and households per car, but not rainfall. All had correlation coefficients somewhat smaller than those with water hardness. Unfortunately, they did not do stepwise regression or partial correlations to obtain a clearer idea of the relative importance of these factors.

Anderson and leRiche (1971) also looked at weather and geographic factors in addition to water hardness, using three different definitions of sudden death-coroner's cases, deaths not in institutions, and certified duration of immediate cause of death. For the first and third definitions, latitude and mean temperature were more important than water hardness; only for the second definition was water hardness of primary importance.

In smaller areas, factors like latitude and weather seem less likely to be important. In Nova Scotia (Deutscher, 1973), two factors accounted for half the variance in coronary heart disease-percent unemployed in the area and distance from Halifax (an index very closely allied with level of education). Urbanization and water hardness had very small effects. In the State of Indiana, Klusman and Sauer (1975) found indices of crowding, especially percent of the population living in multifamily dwellings, to be much more important in explaining cardiovascular mortality than calcium or magnesium in water or water hardness.

In his attempt to discover the cause of the unusually high arteriosclerotic heart disease mortality among young men in the Vale of Glamorgan in South Wales, Hart (1970) found a negative association of hardness with mortality when all localities within two counties were considered. He felt, however, that the comparison between young men in the Vale of Glamorgan and young men in a similar valley would be more appropriate. When this was done, the correlation coefficient between water hardness and mortality became positive. 
Small geographic areas, with considerable variation in water hardness, have a number of advantages for studying its relationship to cardiovascular mortality. Two such studies have been done in Washington County in western Maryland. In one, Schreiber (1977) found that cigarette smoking and frequency of religious attendance each gave a smaller proportion of misclassification of cases and controls than water composition, as determined by discriminant function analysis. In both his study and that by Comstock (1971), a population census permitted very careful matching and adjustment for a variety of socioeconomic factors. Neither study showed a significant association of arteriosclerotic heart disease with water hardness, but a low degree of negative association could not be ruled out.

Finally, a study by Voors (1971) has interesting implications for the possibility that the effects of water hardness are merely reflecting the effects of some other water constituent(s). For 99 of the 100 largest cities of the United States, he looked at the concentration of six metals in the finished water-calcium, chromium, lithium, magnesium, vanadium, and zinc. Holding the effects of the other five constant, he could find no evidence to support a causal association between arteriosclerotic heart disease mortality and calcium or magnesium.

It seems clear that confounding factors cannot be ruled out as a cause of association between water hardness and cardiovascular disease; it is unclear what these factors might be.

\section{BIOLOGICAL PLAUSIBILITY}

It has already been mentioned that water hardness as such can hardly be related to disease and that the most likely effect of a water factor is mediated either through a deficiency of an essential element or an excess of a toxic one (Voors, 1971). Whatever the water factor may be, it can hardly be something present at the source that acts directly as a cause of cardiovascular disease-there are too many studies whose results are inconsistent with this hypothesis. It is much more likely that the water factor operates indirectly.

One possibility is that a characteristic of water sometimes associated with hardness, e.g., corrosiveness, is the water factor, operating through its ability to pick up a trace element from the distribution system. Cadmium dissolved from galvanized pipes by soft waters that are also corrosive exemplifies a biologically plausible mechanism of this type. Cadmium is concentrated in the kidney and is known to be toxic, and by damage to kidney cells it could cause hypertension, a well-recognized risk factor for several cardiovascular diseases.

\section{CARDIOVASCULAR DISEASE}

Schroeder (1969) has been a principal proponent of this particular mechanism.

Another possibility is that water is a source of some essential element that is deficient in the diet in some instances, but not in others. Magnesium is an element often suggested as an example, because it is present in very low levels in soft waters and is often at borderline levels in the diet. However, little is known of the relative availability of magnesium to the body from food or water. It is possible that it is not well absorbed from some foods, and under these circumstances, water could be an important source. Magnesium is also considered to be important for the function of the myocardium (Seelig and Heggtveit, 1974). Anderson et al. (1975) have been among the proponents of magnesium as the water factor.

At present, the only biologically plausible mechanisms for linking water factors to cardiovascular disease are the possibilities that some soft waters may contain a toxic substance (e.g., cadmium) or, more likely, that some hard waters supply a significant amount of some substance (e.g., magnesium) that is beneficial to some people. The possible roles of trace metals and other water components are discussed in other chapters.

\section{CONCLUSION}

An extensive review of the epidemiological literature indicates that there may be a water factor associated with the development of cardiovascular disease, although its existence is far from certain. The factor can hardly be water hardness as such because of its biological implausibility and because of the numerous exceptions to the negative association of water hardness with cardiovascular disease. Its effect, if any, must be very weak in comparison with the effects of known risk factors; an association of even modest strength would surely show up more consistently. Though limited to relatively few studies, the currently available evidence suggests that the water factor is not mediated by blood pressure or serum lipids. A possible mechanism is that enough magnesium is present in some hard waters to prevent borderline magnesium deficiencies in some.persons, thereby reducing their liability to sudden cardiac death.

\section{REFERENCES}

Allwright, S. P. A., A. Coulson, R. Detels, and C. E. Porter. 1974. Mortality and water-hardness in three matched communities in Los Angeles. Lancet 2:860-864.

Anderson, T. W. and W. H. leRiche. 1971. Sudden death from ischemic heart disease in Ontario and its correlation with water hardness and other factors. Can. Med. Assoc. J. 105:1551-1560. 
Anderson, T. W., W. H. leRiche, and J. S. MacKay. 1969. Sudden death and ischemic heart diseases. Correlation with hardness of local water supply. New Eng. J. Med. 280:805-807.

Anderson, T. W., L. C. Neri, G. B. Schreiber, F. D. F. Talbot, and A. Zdrojewski. 1975. Ischemic heart disease, water hardness and myocardial magnesium. Can. Med. Assoc. J. 113:199-203.

Angelillo, B., and U. Alamanni. 1964. Sull'andamento nell provincia di Sassari della mortalita per malattie cardiocircolatorie in rapporto anche ad alcuni fattori alimentari. Ig. Sanita Pubblica. 20:429-435.

Anonymous. 1966. Cardiovascular disease and water supply. Br. Med. J. 1:438.

Bierenbaum, M. L., A. I. Fleischman, J. P. Dunn, H. D. Belk, and B. M. Storter. 1969. Serum lipids in hard and soft water communities. Israel J. Med. Sci. 5:657-660.

Bierenbaum, M. L., A. I. Fleischman, J. P. Dunn, T. Hayton, D. C. Pattison, and P. B. Watson. 1973. Serum parameters in hard and soft water communities. Am. J. Public Health 63:169-173.

Bierenbaum, M. L., A. I. Fleischman, J. P. Dunn, and J. Arnold. 1975. Possible toxic water factor in coronary heart disease. Lancet 1:10081010.

Biersteker, K. 1967. Drinkwaterzachtheid en Sterfte. Tijdschr. Sociale Geneeskd. 45:658-661.

Biggar, R. J., E. A. Mortimer, Jr., and G. E. Haughie. 1976. The relationship of supplemental iodine to neural tube defects in Rochester, New York, 1924-1932. Am. J. Epidemiol. 104:28-33.

Bijlenga, G., E. Dahme, D. K. Detweiler, G. A. Gresham, W. Grunberg, A. N. Howard, A. R. Kagan, M. N. Kaplan, C. J. Van Nie, S. Rubarth, N. A. Sterby, K. H. Stunzi, K. Uemura, and J. C. Whitney. 1967. Comparative studies of atherosclerosis in swine. Bull. WHO 36:457-468.

Biörck, G., H. Bostrom, and A. Widstrom. 1965. On the relationship between water hardness and death rates in cardiovascular diseases. Acta Med. Scand. 178:239-252.

Bostrom, H., and P. O. Wester. 1967. Trace elements in drinking water and death rates in cardiovascular disease. Acta Med. Scand. 181:465-473.

Cavallo, F., G. Gilli, G. Vanini, and E. Vercellotti. 1975. Mortalita cardiovasculare e durezza dell'acqua a Torino negli anni 1972 e 1973 primi risultati di un'indagine epidemiologica. Minerva Med. 66:4307-4310.

Chah, C., S. Heyden, C. Hames, G. Combs, and W. Caster. 1976. Trace elements in the drinking water, Evans County, Ga. study. Cardiovasc. Dis. Epidemiol. Newslett., No. 20, p. 16. (Council on Epidemiology, American Heart Assocation).

Chase, H. C. 1963. Variation in heart disease mortality among counties of New York State. Public Health Rep. 78:525-534.

Comstock, G. W. 1971. Fatal arteriosclerotic heart disease, water hardness at home, and socio-economic characteristics. Am. J. Epidemiol. 94:1-10.

Connor, R. C. R. 1971. The water story (continued). (Letter). Lancet $1: 240$.

Correa, P., and J. P. Strong. 1972. Atherosclerosis and the geochemical environment: A critical review. Ann. N.Y. Acad. Sci. 199:217-227.

Crawford, M. D., M. J. Gardner, and J. N. Morris. 1968. Mortality and hardness of local water supplies. Lancet 1:827-831.

Crawford, M. D., M. J. Gardner, and J. N. Morris. 1971a. Cardiovascular disease and the mineral content of drinking water. Br. Med. Bull. 27:21-24.

Crawford, M. D., M. J. Gardner, and J. N. Morris. 1971b. Changes in water hardness and local death-rates. Lancet 2:327-329.

Crawford, M. D., M. J. Gardner, and J. N. Morris. 1971c. The water story. Lancet 1:916-917.
Crawford, M. D., M. J. Gardner, and J. N. Morris. 1972a. Water hardness, rainfall, and cardiovascular mortality. Lancet 1:13961397.

Crawford, M. D., M. J. Gardner, and P. A. Sedgwick. 1972b. Infant mortality and hardness of local water supplies. Lancet 1:988-992.

Crawford, M. D., D. G. Clayton, F. Stanley, and A. G. Shaper. 1977. An epidemiological study of sudden death in hard and soft water areas. J. Chronic Dis. 30:69-80.

Davies, D. G. 1962. Hardness of local water-supplies and mortality from cardiovascular disease. (Letter to the Editor.) Lancet 2:882883.

Day, T. K., and P. R. Powell-Jackson. 1972. Fluoride, water hardness and endemic goitre. Lancet 1:1135-1138.

Department of Health and Social Security. 1974. Diet and Coronary Heart Disease. Report of the Advisory Panel of the Committee on Medical Aspects of Food Policy (Nutrition) on Diet in Relation to Cardiovascular and Cerebrovascular Disease, Vol. 7. London.

Deutscher, S. 1973. Some factors influencing the distribution of premature death from coronary heart disease in Nova Scotia. Am. J. Public Health 63:150-157.

Dingle, J. H.; O. Paul, W. H. Sebrell, Jr., W. H. Straw, A. Wolman, and J. R. Wilson. 1964. Water composition and cardiovascular health. Ill. Med. J. 125:25-31.

Dudley, E. F., R. A. Beldin, and B. C. Johnson. 1969. Climate water hardness and coronary heart disease. J. Chronic Dis. 22:25-48.

Elwood, J. M. 1977. Anencephalus and drinking water composition. Am. J. Epidemiol. 105:460-467.

Elwood, P. C., D. Bainton, F. Moore, D. F. Davies, E. J. Wakley, M. Langman, and P. Sweetnam. 1971. Cardiovascular surveys in areas with different water supplies. Br. Med. J. 2:362-363.

Elwood, P. C., M. A. Chadd, M. Burr, and I. M. Hayman. 1972: Blood clotting and fibrinolysis in areas with different water supplies. Br. J. Prev. Soc. Med. 26:246-248.

Elwood, P. C., M. Abernethy, and M. Morton. 1974. Mortality in adults and trace elements in water. Lancet 2:1470-1472.

Enterline, P. E., and W. H. Stewart. 1956. Geographic patterns in deaths from coronary heart disease. Public Health Rep. 71:849-855.

Enterline, P. E., A. E. Rikli, H. I. Sauer, and M. Hyman. 1960. Death rates for coronary heart disease in metropolitan and other areas. Public Health Rep. 75:759-766.

Fedrick, J. 1970. Anencephalus and the local water supply. Nature 227:176-177.

Field, D. W., and R. W. Smithells. 1971. Anencephalus and water hardness in south-west Lancashire. Br. J. Prev. Soc. Med. 25:217219.

Fodor, J. G., C. J. Pfeiffer, and V. S. Papezik. 1973. Relationship of drinking water quality (hardness-softness) to cardiovascular mortality in Newfoundland. Can. Med. Assoc. J. 108:1369-1373.

Gardner, M. 1976. Soft water and heart disease? In Environment and Man, Vol. 3. J. Lenihan and W. W. Fletcher, eds. Blackie, Glasgow and London. Pp. 116-135.

Gardner, M. J., M. D. Crawford, and J. N. Morris. 1969. Patterns of mortality in middle and early old age in the county boroughs of England and Wales. Br. J. Prev. Soc. Med. 23:133-140.

Goodhart, R. S., and M. E. Shils. 1973. Modern Nutrition in Health and Disease. Sth ed. Lea and Febiger, Philadelphia, Pa. Pp. 271-272.

Gover, M., and M. Y. Pennell. 1950. Statistical studies of heart disease. VII. Mortality from eight specific forms of heart disease among white persons. Public Health Rep. 65:819-838.

Groover, M. E., Jr., G. E. Antell, J. E. Fulghum, and O. H. Boorde. 1972. Death rates following a sudden change in hardness of drinking water. Cardiovas. Dis. Epidemiol. Newslett. No. 12, p. 17. 
Gyarfas, I., A. Csukas, M. Azabo, A. Tmemsvari, and J. Harsanyi. 1976. Adatok az ivoviz szereperol ischaemias szivbetegsegben. Nepegeszsegugy 57:342-343.

Hankin, J. H., S. Margen, and N. F. Goldsmith. 1970. Contribution of hard water to calcium and magnesium intakes of adults. J. Am. Diet. Assoc. 56:212-223.

Hansen, H., ed. 1963. The World Almanac, 1963. New York WorldTelegram, New York.

Hart, J. T. 1970. The distribution of mortality from coronary heart disease in South Wales. J. Roy. Coll. Gen. Pract. 19:258-268.

Hasanen, E. 1970. Iodine content of drinking water and diseases of the circulatory system. Ann. Med. Exp. Biol. Fenn. 48:117-121.

Heidgerd, R. H., E. H. Jensen, and T. F. Facius. 1972. Condensers. Chap: 16 in ASHRAE Guide and Data Book-Equipment, 1972. C. W. MacPhee, ed. American Society of Heating, Refrigerating and Airconditioning Engineers, New York. P. 154.

Heyden, S. 1976. The hard facts behind the hard-water theory and ischemic heart disease. J. Chronic Dis. 29:149-157.

Howard, A. N., I. N. Jennings, and G. A. Gresham. 1967. Atherosclerosis in pigs obtained from two centres differing in hardness of water supply. Pathol. Microbiol. 30:676-680.

Hudson, H. E., Jr., and F. W. Gilcreas. 1976. Health and economic aspects of water hardness and corrosiveness. J. Am. Water Works Assoc. 68:201-204.

Kamiyama, S., F. Yamada, S. Kobayashi, and E. Takahashi. 1969. Comparative study on physical condition and blood chemistry of inhabitants in farm and fishing villages in relation to their difference in mortality from cerebrovascular disease. Tohoku J. Exp. Med. 97:81-94.

Keil, U., M. Pflanz, and E. Wolf. 1975. Hartes und weiches Trinkwasser und seine Beziehgung zur Mortalitat, besonderes an kardiovaskularen Krankheiten in der Stadt Hannover in den Jahren 1968 und 1969. Forum Umwelt. Hyg. 26:110-117.

Klusman, R. W., and H. I. Sauer. 1975. Some possible relationships of water and soil chemistry to cardiovascular diseases in Indiana. Trace Element Geochemistry in Health and Disease. Geol. Soc. Am. Spec. Pap. 155:27-40.

Kobayashi, J. 1957. On geographical relationship between the chemical nature of river water and death-rate from apoplexy. Ber. Ohara Inst. Landwirtsch. Biol. 11:12-21.

Kuller, L. H., A. Bolker, M. S. Saslaw, B. L. Paegel, C. Sisk, N. Borhani, J. A. Wray, H. Anderson, D. Peterson, W. Winkelstein, Jr., J. Cassel, P. Spiers, A. G. Robinson, H. Curry, A. M. Lilienfeld, and R. Seltser. 1969. Nationwide cerebrovascular disease mortality study. I. Methods and analysis of death certificates. Am. J. Epidemiol. 90:536-544.

Langford, H. G., and R. G. Watson. 1972. Urinary excretion of calcium and sodium in hard and soft water areas. (Letter.) Lancet 1:12931294.

Lilienfeld, A. M. 1976. Foundations of Epidemiology. Oxford University Press, New York. 283 pp.

Lindemann, R. D., and J. R. Assenzo. 1964. Correlations between water hardness and cardiovascular deaths in Oklahoma counties. Am. J. Public Health 54:1071-1077.

Lowe, C. R., C. J. Roberts, and S. Lloyd. 1971. Malformations of central nervous system and softness of local water supplies. Br. Med. J. 2:357-361.

Lyster, W. R. 1972. The sex ratios of human and sheep births in areas of high mineralization. Int. J. Environ. Stud. 2:309-316.

Manescu, S., A. Calciu, and E. Cazaceanu. 1975. Mineralizarea apei potabile si relatia cu mortalitatea prin boli cardiovasculare. Igiena 24:141-146.
Marzot, G., P. Genni, N. Viscomi, and L. D. Poli. 1968. Acqua e mortalita per vasculopatie ischemiche del micardio. Ig. Mod. 61:895-908.

Masironi, R. 1970. Cardiovascular mortality in relation to radioactivity and hardness of local water supplies in the U.S.A. Bull. who 43:687-697.

Masironi, R. 1973. Water quality, trace elements and cardiovascular disease. WHO Chron. 27:534-538.

Masironi, R. 1977. World Health Organization studies in geochemistry and health. In Geochemistry and the Environment. Vol. II. The Relation of Other Selected Trace Elements to Health and Disease. National Academy of Sciences, Washington, D.C. Pp. 132-138.

Masironi, R., A. T. Miesch, M. D. Crawford, and E. I. Hamilton. 1972. Geochemical environments, trace elements, and cardiovascular diseases. Bull. WHO 47:139-150.

Massachusetts Department of Public Health. 1975. A high-risk community. New Eng. J. Med. 293:1044.

Meyers, D. 1975. Ischaemic heart disease and the water factor. A variable relationship. Br. J. Prev. Soc. Med. 29:98-102.

Mitchell, J. R. A. 1977. An association between ABO blood-group distribution and geographical differences in death-rates. Lancet 1:295-297.

Morris, J. N., M. D. Crawford, and J. A. Heady. 1961. Hardness of local water supplies and mortality from cardiovascular disease in the county boroughs of England and Wales. Lancet 1:860-862.

Morris, J. N., M. D. Crawford, and J. A. Heady. 1962. Hardness of local water supplies and mortality from cardiovascular disease. Lancet 2:506-507.

Mortimer, E. A., Jr., R. R. Monson, and B. MacMahon. 1977. Reduction in mortality from coronary heart disease in men residing at high altitude. New Eng. J. Med. 296:581-585.

Morton, W. E. 1971a. Hypertension and drinking water. A pilot statewide ecological study in Colorado. J. Chronic Dis. 23:537-545.

Morton, W. E. 1971b. Hypertension and drinking water constituents in Colorado. Am. J. Public Health 61:1371-1378.

Mulcahy, R. 1964. The influence of water hardness and rainfall on cardiovascular and cerebrovascular mortality. J. Ir. Med. Assoc. 55:17-18.

Mulcahy, R. 1966. The influence of water hardness and rainfall on cardiovascular and cerebrovascular mortality. J. Ir. Med. Assoc. 59:14-15.

Muss, D. L. 1962. Relationship between water quality and deaths from cardiovascular disease. J. Am. Water Works Assoc. 54:1371-1378.

National Center for Health Statistics. 1963. Vital Statistics of the United States, 1960. Vol. II. Mortality. Part B, Table 9.9. U.S. Government Printing Office, Washington, D.C.

Neal, J. B., and M. Neal. 1962. Effect of hard water and MgSO, on rabbit atherosclerosis. Arch. Pathol. 73:400-403.

Neri, L. C., D. Hewitt, and J. S. Mandel. 1971. Risk of sudden death in soft water areas. Am. J. Epidemiol. 94:101-104.

Neri, L. C., J. S. Mandel, and D. Hewitt. 1972. Relation between mortality and water hardness in Canada. Lancet 1:931-934.

Neri, L. C., D. Hewitt, and G. B. Schreiber. 1974. Can epidemiology elucidate the water story? Am. J. Epidemiol. 99:75-88.

Nixon, J. M., and R. G. Carpenter. 1974. Mortality in areas containing natural fluoride in their water supplies, taking account of socioenvironmental factors and water hardness. Lancet 2:1068-1071.

Oberhamer, D. 1975. Memorandum to Water Quality Association Staff: Industry Statistics. Water Quality Association, Lombard, Ill.

Osancova, K., and S. Hejda. 1968. Dietary studies in connection with epidemiology of heart diseases: Results of surveys in Czechoslovakia. In Dietary Studies and Epidemiology of Heart Diseases. C. Den 
Hartog, K. Bezina, F. Fidanza, A. Keys, and P. Roine, eds. Stichtung tot wetenschappelijke Voerlichting op Voedingsgebied, The Hague. Pp. 137-145.

Perry, H. M., Jr. 1972. Hypertension and the geochemical environment. Ann. N.Y. Acad. Sci. 199:202-215.

Peterson, D. R., D. J. Thompson, and J. M. Nam. 1970. Water hardness, arteriosclerotic heart disease and sudden death. Am. J. Epidemiol. 92:90-93.

Pflanz, M., and E. Wolf. 1976. Harte des Trinkwassers und kardiovaskulare Sterblichkeit in den niedersachsischen kreisfreien Stadten. Forum Umwelt. Hyg. 27:246-248.

Pflanz, M., H. D. Basler, J. Collatz, and D. Schwoon. 1976. Einfluss der Harte des Trinkwassers auf den Blutdruck und andere Gesundheitsparameter. Forum Umwelt. Hyg. 27:53-55.

Porth, D. L., ed. 1970. Proceedings of the Fifth International Water Quality Symposium. Water Quality Research Council, Wheaton, Ill. P. 43.

Punsar, S. 1973. Cardiovascular mortality and quality of drinking water. An evaluation of the literature from an epidemiological point of view. Work Environ. Health 10:107-125.

Puschner, H., E. Dahme, N. Zollner, G. Wolfram, and J. Kalich. 1969. Der Einfluss weichen und harten Trickwassers auf die Ausbildung arteriosklerotischer Fruhveranderungen und die Plasmalipoide beim Hauschwein. J. Atheroscler. Res. 9:17-23.

Roberts, C. J., and S. Lloyd. 1972. Association between mortality from ischemic heart disease and rainfall in South Wales and in the county boroughs of England and Wales. Lancet 1:1091-1093.

Robertson, J. S. 1968. Mortality and hardness of water. Lancet 2:348349.

Robertson, J. S. 1969. The water story. Lancet 1:1160.

Robertson, J. S. 1977. The problems of cardiovascular diseases. Minerals and mortality. Community Health 8:226-234.

Sauer, H.I. 1962. Epidemiology of cardiovascular mortality-Geographic and ethnic. Am. J. Public Health 52:94-105.

Sauer, H. I. 1974a. Relationship between trace element content of drinking water and chronic diseases. In Proceedings of the Sixteenth Water Quality Conference: Trace Metals in Water Supplies: Occurrence, Significance, and Control, February 12-13, 1974. J. T. O'Connor and A. R. Sapoznik, eds. Bull. 71. University of Illinois, Urbana-Champaign. Pp. 39-47.

Sauer, H. I. 1974b. Relationship of water to the risk of dying. In Water, Its Effects on Life Quality. Proceedings of the Seventh International Water Quality Symposium. D. X. Manners, ed. David X. Manners Co., Norwalk, Conn. Pp. 76-79.

Sauer, H. I., and P. E. Enterline. 1959. Are geographic variations in death rates for the cardiovascular diseases real? J. Chronic Dis. 10:513-524.

Sauer, H. I., and D. W. Parke. 1974. Counties with extreme death rates and associated factors. Am. J. Epidemiol. 99:258-264.

Sauer, H. I., G. H. Payne, C. R. Council, and J. C. Terrell. 1966. Cardiovascular disease mortality patterns in Georgia and North Carolina. Public Health Rep. 81:455-465.

Sauer, H. I., D. W. Parke, and M. L. Neill. 1971. Associations between drinking water and death rates. In Proceedings of the Fourth Annual Conference on Trace Substances in Environmental Health June 23-25, 1970. D. D. Hemphill, ed. University of Missouri, Columbia. Pp. 318-325.

Scassellati-Sforzolini, G., and F. Pascasio. 1971. Correlazione epidemiologica fra durezza delle acqua potabili e mortalita cardiovascolare. Ann. Sanita Pubblica 32:45-60.

Schreiber, G. B. 1977. Àrteriosclerotic heart disease mortality and water quality. A case against water quality being a cardiovascular disease risk factor. Unpublished doctoral thesis. Johns Hopkins University School of Hygiene of Public Health, Baltimore, Md. 149 pp.

Schroeder, H. A. 1958. Degenerative cardiovascular disease in the Orient. II. Hypertension. J. Chronic Dis. 8:312-333.

Schroeder, H. A. 1960a. Relations between hardness of water and death rates from certain chronic and degenerative diseases in the United States. J. Chronic Dis. 12:586-591.

Schroeder, H. A. 1960b. Relationship between mortality from cardiovascular disease and treated water supplies. Variations in states and 163 largest municipalities of the United States. J. Am. Med. Assoc. 172:1902-1908.

Schroeder, H. A. 1961. Hardness of local water-supplies and mortality from cardiovascular disease. Lancet 1:1171.

Schroeder, H. A. 1966. Municipal drinking water and cardiovascular death rates. J. Am. Med. Assoc. 195:81-85.

Schroeder, H. A. 1969. The water factor. New Eng. J. Med. 280:836838.

Schroeder, H. A., and L. A. Kraemer. 1974. Cardiovascular mortality, municipal water, and corrosion. Arch. Environ. Health 28:303-311.

Seelig, M. S., and H. A. Heggtveit. 1974. Magnesium interrelationships in ischemic heart disease: A review. Am. J. Clin. Nutr. 27:59-79.

Shaper, A. G. 1974. Soft water, heart attacks, and stroke. J. Am. Med. Assoc. 230:130-131.

Sharrett, A. R. 1979 (this volume). The role of chemical constituents of drinking water in cardiovascular disease.

Sharrett, A. R., and M. Feinleib. 1975. Water constituents and trace elements in relation to cardiovascular disease. Prev. Med. 4:20-36.

Spearman, C. 1904. The proof and measurement of association between two things. Am. J. Psychol. 15:72-101.

Spiers, P. S., S. G. Wright, and D. G. Siegel. 1974. Infant mortality and water hardness in the United States. Pediatrics 54:317-319.

Stitt, F.W., D. G. Clayton, M. D. Crawford, and J. W. Morris. 1973. Clinical and biochemical indicators of cardiovascular disease among men living in hard and soft water areas. Lancet 1:122-126.

Stocks, P. 1973. Mortality from cancer and cardiovascular diseases in the county horoughs of England and Wales classified according to the sources and hardness of their water supplies, 1958-1967. J. Hyg. (London) 71:237-252.

Stolley, P. D., L. H. Kuller, M. D. Nefzger, S. Tonascia, A. M. Lilienfeld, G. P. Miller, and E. L. Diamond. 1977. The three-area epidemiological study of geographic differences in stroke mortality. II. Results. Stroke 8(5):551-557.

Strong, J. P., P. Correa, and L. A. Solberg. 1968. Water hardness and atherosclerosis. Lab. Invest. 18:620-622.

Susser, M. 1973. Causal Thinking in the Health Sciences. Concepts and Strategies of Epidemiology. Oxford University Press, New York. 181 pp.

Svec, F. 1976. Vztah nekterych charakteristik pudy k tvrdosti pitne vody a $k$ vybranym ukazatrelum umrtnosti obyvatelstva CSR let 1965-1969. Islka Hyg. 21:74-79.

Tyroler, H. A. 1970. Epidemiologic studies of cardiovascular disease in three communities of the southeastern United States. In The Community as an Epidemiologic Laboratory, I. I. Kessler and M. L. Levin, eds. Johns Hopkins, Baltimore, Md. Pp. 100-121.

Vanecek R. 1976. Atherosclerosis of the coronary arteries in five towns. Chap. 3 of Atherosclerosis of the Aorta and Coronary Arteries in Five Towns. Bull. WHO 53:509-518.

Voors, A. W. 1971. Minerals in the municipal water and atherosclerotic heart death. Am. J. Epidemiol. 93:259-266.

Voors, A. W. 1972. Atherosclerotic heart disease and drinking water trace metals in North Carolina. In Proceedings of the Fifth Annual 
Concerence on Trace Substances in Environmental Health, June 29July 1, 1971. D. D. Hemphill, ed. University of Missouri, Columbia. Pp. 523-534.

West, R. R., S. Lloyd, and C. J. Roberts. 1973. Mortality from ischemic heart disease-Association with weather. Br. J. Prev. Soc. Med. 27:36-40.

Winton, E. F., and L. J. McCabe. 1970. Studies relating to water mineralization and health. J. Am. Water Works Assoc. 62:26-30. Wolman, A. 1976. Notes and Comments. J. Am. Water Works Assoc. 68:216-217.

World Health Organization. 1973. Report of a second meeting of investigators on trace elements in relation to cardiovascular diseases. wHo Int. Doc. CVD/73.4. World Health Organization, Geneva. 


\title{
The Role of Chemical Constituents of Drinking Water in Cardiovascular Diseases
}

\author{
A. RICHEY SHARRETT
}

Associations have been found between hardness of local drinking water supplies and local mortality rates (Comstock, 1979). From the beginning of Schroeder's (1960) early research this finding has raised the question of the possible role of specific constituents of drinking water in the causation of cardiovascular disease. Therefore the first step in the review of data relating to the question of water constituents will be to study their associations with hardness. Constituents closely associated with hardness could provide the explanatory link between hardness and mortality. The section entitled "Associations of Elements in Drinking Water with Hardness" (below) will show that available data are not consistent in providing such a link. It is still possible that specific constituents may have their own direct correlation with death rates. The section entitled "Association of Elements in Drinking Water with Cardiovascular Disease" (which follows) examines the evidence bearing on this possibility. This evidence, too, is inconclusive. Finally, many authors have questioned whether elements in drinking water comprise a substantial enough proportion of human daily ingestion to matter. Evidence is presented in the section entitled "The Association of Elements in Drinking Water with Elements in Human Tissues" to show whether or not drinking water levels of various elements are associated with the concentrations of these elements in human tissues. This evidence indicates the possibility that some elements in drinking water could have an etiologic role in chronic disease. The design of the major studies discussed here is described in greater detail in the previous chapter by Comstock (1979).

\section{ASSOCIATIONS OF ELEMENTS IN DRINKING WATER WITH HARDNESS}

Hardness itself is not a constituent of drinking water but a property, variously defined and variously determined analytically (see Chapter 1). In discussing the possibility that certain elements in water may explain the associations of hardness to mortality, we are concerned with the definition and determination of hardness employed in the studies where this association was examined. The major U.S. studies in this field, those by Dudley, Sauer, Schroeder, and Voors, obtained their water data from a U.S. Geological Survey publication (Durfor and Becker, 1964). This reference defines hardness as "the property of water that is a measure of the amount of soap required to form a lather" and states that it is a property caused primarily by the calcium and magnesium content of the water, and, to a very minor extent, by its content of aluminum, iron, manganese, and other metals. However, the hardness values used in the cardiovascular studies were rarely determined by the soap and lather method. In the data used in Schroeder's (1961) pioneering work (Lohr and Love, 1954), hardness was usually calculated from calcium and magnesium content determined by gravimetric or volumetric methods. The values obtained were stated to be generally higher than those obtained by soap solution. Durfor and Becker (1964) determined hardness by colorimetric titration. This method is reported to have a slightly negative bias (U.S. Environmental Protection Agency, 1971). In practical terms, however, hardness in water used for drinking is determined almost 
entirely by its calcium and magnesium content (see Chapter 2). A clearer definition of water hardness, as it has been studied in relation to cardiovascular disease, is possible probably only by a more detailed description of the performance characteristics of the laboratory methods employed in these particular studies, their accuracy in calcium and magnesium measurement, and the interferences in these methods caused by other elements.

This amount of detail, however, is probably unnecessary. The variation in the relative concentrations of calcium and magnesium in water supplies at any given level of hardness is large in comparison to variability in the laboratory. The biologically important trace metals discussed below have no fixed relationship to hardness and may vary widely. The composition of hard and soft water in terms of biologically important elements is the critical question here. This question will be examined for calcium and magnesium, the essential trace elements chromium, copper, and zinc, and the toxic trace elements cadmium and lead.

\section{CALCIUM. AND MAGNESIUM}

In U.S. studies, hardness of drinking water is just as closely associated with magnesium levels as with calcium levels. Sauer et al. (1970) found that magnesium correlat- ed +.92 and calcium +.94 with hardness among 95 cities. Calcium and magnesium correlated +.79 with each other. In the data used for Schroeder's (1961) original work, this correlation for 163 cities was +.82 . In the towns studied in England and Wales, calcium correlated +.95 with hardness (Crawford et al., 1968) but the correlation for magnesium has not been reported. The generally high correlation of both these elements with hardness and with each other makes it difficult to attribute the associations between hardness and mortality to either calcium or magnesium alone.

\section{TRACE ELEMENTS}

The relation between trace metals and hardness in water is shown in Table 15. The areas shown, North America, England and Wales, and Finland, are areas where trace element data are available and where the negative association between hardness and mortality is usually found.

Before discussion of the results in the table, it is advisable to consider the quality of the data on water composition. Distributional data are given in only two of the reports, McCabe (1970) and Neri et al. (1975). In these reports the concentrations of trace metals are given at several levels of water hardness. Schroeder, Anderson,

TABLE 15 Associations of Biologically Important Trace Metals with Hardness of Drinking Water in Areas of the World Where Hardness Is Associated with Low Cardiovascular Mortality

\begin{tabular}{|c|c|c|c|c|c|c|}
\hline & $\mathrm{Cr}$ & $\mathrm{Cu}$ & $\mathrm{Zn}$ & $\mathrm{Cd}$ & $\mathrm{Pb}$ & Source \\
\hline \multicolumn{7}{|l|}{ North America } \\
\hline Untreated river water & + & + & + & + & + & Masironi, 1970 \\
\hline \multirow[t]{3}{*}{ Finished water at plant } & 0 & - & $?$ & $?$ & 0 & Schroeder, 1966 \\
\hline & + & $?$ & $?$ & $?$ & $?$ & Voors, 1971 \\
\hline & 0 & - & + & 0 & $?$ & Neri et al., 1975 \\
\hline \multirow[t]{4}{*}{ Tap water } & + & - & - & - & - & McCabe, 1970 \\
\hline & + & - & + & 0 & - & Neri et al., 1975 \\
\hline & 0 & - & - & + & + & $\begin{array}{l}\text { Anderson et al., } \\
\quad 1975\end{array}$ \\
\hline & $?$ & 0 & + & 0 & - & Schreiber, 1977 \\
\hline \multicolumn{7}{|l|}{ England and Wales } \\
\hline \multirow[t]{2}{*}{ Tap water } & 0 & + & 0 & 0 & 0 & $\begin{array}{l}\text { Crawford and } \\
\text { Mortis, 1967; } \\
\text { Crawford et al., } \\
1968\end{array}$ \\
\hline & $?$ & $?$ & $?$ & $?$ & 0 & $\begin{array}{l}\text { Crawford and } \\
\text { Clayton, } 1973\end{array}$ \\
\hline n & 0 & + & + & $?$ & - & Elwood et al., 1974 \\
\hline \multicolumn{7}{|l|}{ Finland } \\
\hline \multicolumn{7}{|l|}{ Tap water } \\
\hline Between regions & + & - & 0 & $?$ & 0 & Punsar et al., 1975 \\
\hline Within regions & + & + & 0 & $?$ & $?$ & Punsar et al., 1975 \\
\hline
\end{tabular}

Key: + , higher in hard water; - , lower in hard water; 0 , no relationship; ?, inadequate data. 
Crawford, Punsar, and their associates pool data from hard water and soft water areas and report only a mean race metal value in the soft water area compared with a nean for the hard water area. (Punsar's "hard water area," however, had a calcium concentration of only 23 $\mathrm{mg} / \mathrm{l}$.) All the other reports give only a correlation coefficient to describe the relation between trace elements and hardness. In the cases without distributional data, it is not possible for the reader to evaluate the consistency of the relation, its strength, or its pattern.

In none of the studies is information given to indicate the extent to which trace metal levels at a given sampling point vary over time.

None of the reports discusses the precision or accuracy of their water chemistry. Data for Schroeder's and Voors's reports (which are from Durfor and Becker (1964) and for Masironi's report were the result of analyses in a variety of laboratories cooperating with U.S. water authorities. Data for the remaining studies were presumably generated in central laboratories. The results from the cooperative laboratories, all of the chemistry for which was done in 1962, are probably of low accuracy. Sauer et al. (1970) have shown, for example, that the iron values determined by both the spectrographic and the wet chemical method reported in Durfor and Becker (1964) correlate only +.32 . Zinc was detected in water from only 3 of the 100 cities studied in that report, although it is nearly always detectable in such samples when current technology is used. The analyses in the remaining reports were done more recently by methods that were probably superior.

Several of the reports are representative of a very limited geographic area. McCabe's (1970) paper represents 2600 tap water samples from 969 public water supplies, but the entire study is limited to Vermont and 8 U.S. urban areas. The report by Anderson et al. (1975) is limited to 8 cities in Ontario; Schreiber's (1977) to Washington County, Maryland; that of Elwood et al. (1974) to 48 areas all located in two counties in South Wales; and that of Punsar et al. (1975) to an area in Finland with a total extent the size of a few U.S. counties. In contrast to the limited geographic representativeness of these studies, those by Masironi (1970), Schroeder (1961, 1966), Schroeder and Kraemer (1974), and Voors (1971) relate to drinking water in the entire United States; Masironi-studied river water and Schroeder, Kraemer, and Voors studied city water. The study by Neri et al. (1975) related to 500 towns across Canada.

\section{CHROMIUM}

Chromium was associated with hardness in untreated river water in the United States (Masironi, 1970), and rery study that showed a relationship to hardness,
Role of Chemical Constituents of Drinking Water

showed that relationship to be positive, whether tap water or finished water at the plant was being studied. There is evidence in North American and Finnish data that elevated levels of chromium in drinking water are primarily a geochemical phenomenon. McCabe (1970), for example, found chromium levels in tap water elevated in highly mineralized water, but unrelated to acidity. In the report by Neri et al. (1975) on tap water in 500 Canadian towns, chromium was particularly elevated in areas with the hardest water. In Finland, chromium was noted to be significantly higher in tap waters in the hard water area of the west than in those of the east. Even within these areas, small as they were, chromium showed a positive correlation with calcium and magnesium. Punsar et al. (1975) emphasized the positive association between chromium and hardness as being supportive of the view that chromium protects against heart disease.

The failure to find a relationship in Britain weakens this view, however, because Britain is where hardness appears to show the strongest association to cardiovascular disease. Crawford et al. (1968) do not show their data on chromium, but state simply that chromium levels were similar in hard and soft water towns. In South Wales, Elwood et al. (1974) reported chromium to be unrelated to hardness. In fact, the correlations were negative, though trivial in magnitude, and first morning tap water samples had slightly but significantly higher chromium than evening samples, indicating that in that country, corrosion of plumbing may contribute some chromium to the drinking water. The overall evidence that chromium is the explanatory link in the association of hard water and low mortality, then, is weak.

\section{COPPER}

Copper is positively correlated with hardness in raw river water in Masironi's (1970) report on U.S. states, as are all the other metals, but the coefficient is only +.21 . North American reports on finished water or tap water consistently show higher copper levels in soft water, particularly at low pH, except that Schreiber (1977) found elevated copper levels in acid waters, but not in soft water samples. British data, however, just as consistently show elevated copper in tap water from hard water areas. The data of Punsar et al. (1975) can be interpreted either way: copper was higher in tap water in the soft water of eastern Finland than in the west, but within regions, copper was significantly positively correlated to calcium.

\section{ZINC}

It is evident that zinc in tap water is not consistently related to the hardness of drinking water, not even within a single country. It was strongly related to hardness in 
U.S. river water as shown by Masironi (1970), but in tap water, its sources must be related to both geochemistry and plumbing corrosion. McCabe (1970) shows a consistent relationship of tap water zinc to low $\mathrm{pH}$, but zinc levels are equally high in high- and low-conductance waters. Elwood et al. (1974) also show a positive correlation of zinc to hardness, on one hand, and elevated zinc in morning samples of tap water compared with evening samples, on the other. Schreiber (1977) also showed tap water zinc to be positively correlated both with acidity and with hardness. Zinc is a ubiquitous element, and the relative importance of the geochemical and plumbing contributions to the amount consumed at the tap will vary considerably from place to place.

\section{CADMIUM}

Schroeder and many others have speculated that soft water contributes to cardiovascular mortality by. causing hypertension resulting from cadmium corroded from plumbing materials, particularly galvanized pipe. Table 15, however, does not show evidence of substantial cadmium corrosion by soft water. In untreated river water in the United States (Masironi, 1970), cadmium levels are higher in hard water. There are no data on cadmium in finished water at the plant in the United States, but in Canadian finished water, cadmium was unrelated $(r=-.03)$ to calcium or magnesium (Neri $e t$ al., 1975).

North American data on tap water, where Schroeder's hypothesis can be examined, are unclear. In one county in Maryland (Schreiber 1977), cadmium was related to acidity, but not to water softness. In Canada (Neri et al., 1975), cadmium levels were highest (approximately 1 $\mu \mathrm{g} / \mathrm{l})$ at both of the extremes of the hardness range, indicating perhaps that the geochemical contribution to cadmium levels in drinking water is as significant as the contribution from pipe corrosion. In the U.S. areas studied by McCabe (1970), there were higher levels of cadmium in low-conductance waters. This would indicate the importance of the corrosion factor, but McCabe also found that the highest cadmium levels were in waters of neutral, rather than acid, $\mathrm{pH}$. Anderson found that a pooled sample from Canadian towns with very hard water had a cadmium level of $2 \mu \mathrm{g} / \mathrm{l}$, compared with $1 \mu \mathrm{g} / \mathrm{l}$ for towns with soft water. If both corrosion and geochemistry contribute to cadmium in drinking water in North America, cities in the middle ranges of hardness might have had lower cadmium levels than cities with extreme levels of hardness.

The only information from Europe is the statement by Crawford et al. (1968) that no association was found between cadmium and hardness in their data from Britain.
While corrosion of piping is a known source of cadmium in water, these data indicate that this source may be unimportant in public water supplies. The frequent failure to find an association between cadmium and soft water may be because water samples were collected casually, rather than after water stood overnight in pipes. It may also be because corrosion is not determined primarily by water hardness or because cadmium levels in drinking water are not determined primarily by corrosion.

\section{LEAD}

Soft water in Boston and Seattle (Craun and McCabe, 1975), Glasgow (Beattie et al., 1972), and Belgium (de Graeve et al., 1975) left standing overnight in lead plumbing picks up considerable quantities of lead. The hypothesis that soft water is harmful because of lead corrosion has been the subject of investigation in Britain for years. Much of the home plumbing in Britain is lead, and lead in water could be a factor in cardiovascular disease there. Data on human-tissue lead levels, reported in a later section, make this hypothesis plausible. Surprisingly, however, Crawford and Morris's (1967) and Crawford and Clayton's (1973) work show considerable plumbosolvency in hard waters as well as soft waters. McCabe (1970) also showed highest lead levels in tap water at both extremes of total mineral concentration. The plumbosolvency of soft water is indicated in his data only by the low lead levels of high-pH water. But, lead levels were highest at neutral $\mathrm{pH}$, rather than at low $\mathrm{pH}$. Soft water was somewhat plumbosolvent in Maryland (Schreiber, 1977), but again, the relationship with acidity was stronger than that with softness. Neri et al. (1975) show plumbosolvency only in extremely soft water, with hardness less than $15 \mathrm{mg} / \mathrm{l}$. In the data of Elwood et al. (1974), lead in tap water was significantly negatively correlated with calcium levels. Anderson et al. (1975), however, found lead levels slightly higher in hard water towns. The determinants of lead levels in tap water are apparently complex.

\section{SUMMARY}

Calcium and magnesium are both closely associated with total hardness. There are considerable data on their direct associations with mortality, and these are presented in the following section. None of the trace elements studied, however, appears to be associated with hardness closely enough to explain the hardness-mortality associations, though there are insufficient data to conclude that there is no association. 


\section{ASSOCIATIONS OF ELEMENTS IN DRINKING VATER WITH CARDIOVASCULAR DISEASES}

The evidence bearing on the direct associations of the elements in water considered above to cardiovascular disease rates will be presented in this section. Where correlations with death rates are presented, these are either age-specific or age-adjusted rates, unless otherwise indicated.

\section{CALCIUM AND MAGNESIUM}

The major studies, which correlate both calcium and magnesium with cardiovascular mortality, are shown in Table 16. Calcium and magnesium have equally strong correlations with coronary disease in U.S. data. Other U.S. reports, which studied 1960 coronary death rates in relation to the same water data, used by Voors (Schroeder, 1966; Sauer et al., 1970; Sauer, 1974), showed very similar correlations, except that Schroeder showed a somewhat stronger negative correlation for magnesium $(-.40)$ than for calcium $(-.23)$. Canadian data tended to show somewhat stronger negative correlations for magnesium than for calcium (Neri et al., 1975).
Schroeder was particularly interested in the possibility that the water factor operated by way of an effect on hypertension, which would be manifest in stroke and hypertensive heart disease as causes of death. He showed the correlations only when they were statistically significant, and these are presented in Table 16. The fact that only these few were significant among all the race, sex, age, and cause of death categories studied indicates that neither calcium nor magnesium is consistently related to hypertensive death rates in U.S. cities.

A study of 24 county seats in Texas is interesting, not only because mortality rates were studied in relation to element levels both in drinking water and in urine samples, but also because the study area had an unusually broad range of water-calcium and water-magnesium levels (Dawson, 1978). The results are not shown in Table 16 because mortality rates were inadequately adjusted for age (the broad over-45 age group we used). Mortality rates for coronary heart disease or stroke were not significantly correlated with calcium or magnesium levels either in the drinking water of these cities or in the urine of the residents studied. Also studied were the ratios of sodium to calcium and of sodium to magnesium, both in drinking water and in urine samples. In drinking

TABLE 16 Correlation Coefficients of Calcium and Magnesium in Finished Drinking Water Supplies with Local AgeAdjusted Cardiovascular Mortality Rates

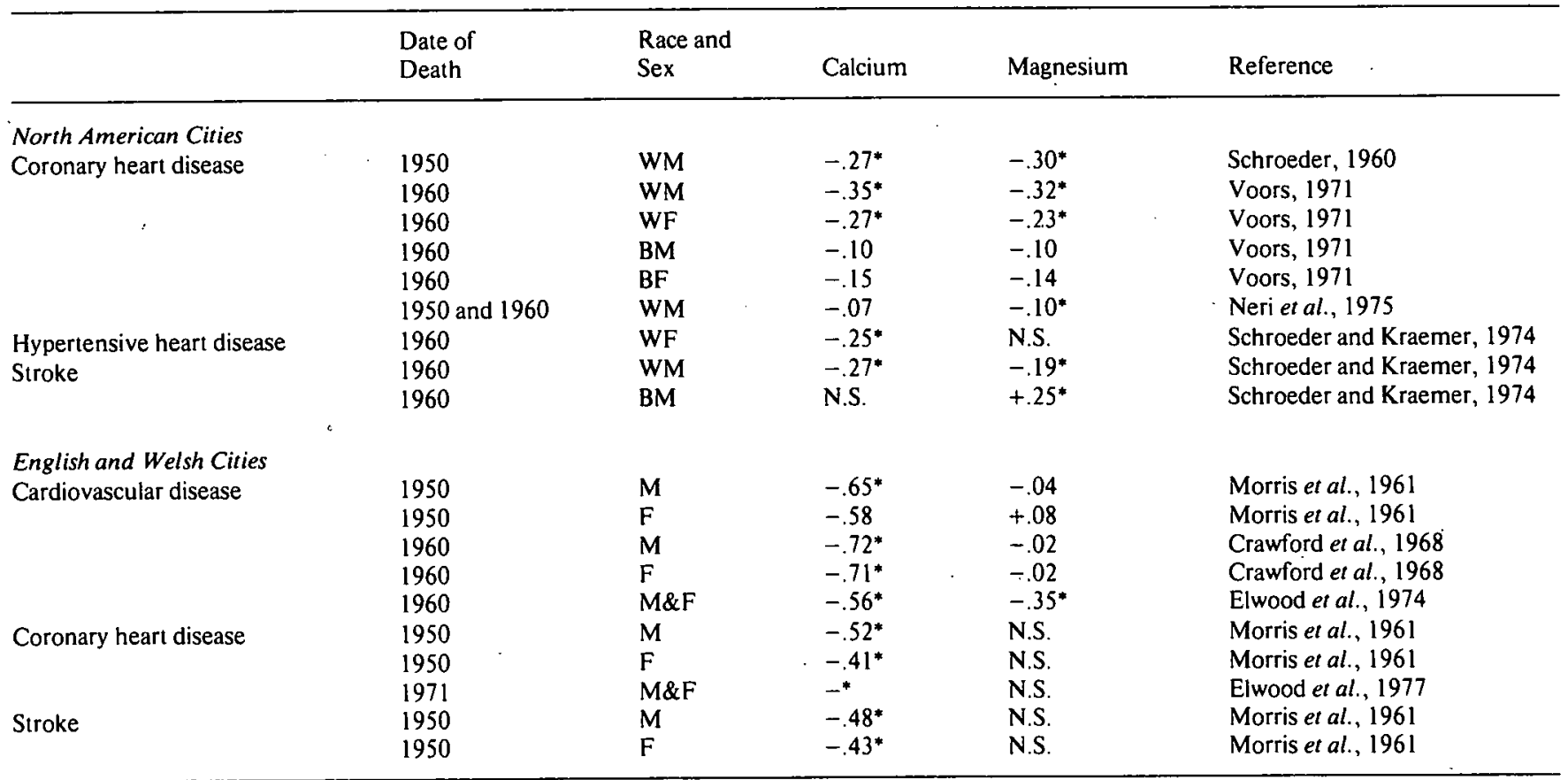

* Significant at $p<.05$. (The coefficient is not shown for Elwood (1977) because a logit transformation was used, and the coefficient was standardized. The association indicated by the asterisk was significant and negative.)

I.S. means not significant and not reported. A coefficient greater than .19 would have been required for significance in Schroeder's study; .27 in Mors's study. 
water, both ratios were significantly positively correlated with death rates for both coronary heart disease and stroke, as would be expected if sodium were harmful, or if calcium and magnesium were protective. The correlations involving calcium and magnesium were of approximately equal strength. With ratios of elements in urine samples, the only significant association found was the positive correlation between stroke and the ratio of sodium to calcium. Mortality rates for hypertensive heart disease, hypertension, and general arteriosclerosis were also analyzed, but these cause-of-death categories were infrequently and irregularly used in these cities, so that the results are probably not meaningful. Unfortunately, it is possible that the associations found in this study were artifacts of the age and ethnic structure of the populations. The drinking water of these Texas cities was harder in the southwest, but the authors did not consider the possibility that their results might be confounded by a younger age structure or larger proportion of the population with a Spanish background in southwest Texas.

Among the English and Welsh county boroughs, very strong negative correlations are found between calcium and cardiovascular mortality. Magnesium appears to be unrelated, except for a modest correlation found for the 48 local authority areas within South Wales studied by Elwood et al. (1974). For coronary disease and stroke categories specifically, calcium again showed significant negative correlations, and magnesium again did not. Stocks (1973) examined mortality separately for English county boroughs with water hardness over $300 \mathrm{mg} / 1$ according to whether the water was drawn from a dolomite aquifer (yielding a high magnesium content) or from other sources. No significant differences were found, but the three towns with a dolomite supply compared with the six towns with other hard water supplies had somewhat lower stroke death rates for males (but not for females) and higher arteriosclerotic heart disease death rates for females (but not for males).

Punsar et al. (1975) found lower levels of both calcium and magnesium in an area of eastern Finland, where incidence and mortality of coronary heart disease are higher than in western Finland. Within the study area of eastern Finland, tap water of coronary decedents had significantly lower levels of magnesium than did tap water of study subjects free of coronary disease. Punsar interpreted this as evidence for a protective effect of magnesium in Finland, but the results were not consistent. Within the region studied, subjects who had died of coronary disease at less than 60 years of age in the western region showed higher magnesium in tap water than did controls.

The suggestion of a protective effect for magnesium in the Finnish data is consistent with the Canadian data. But, British mortality rates have consistently shown litt] or no correlation with magnesium. In the United State, attempts have been made to evaluate the possible independent effects of calcium and magnesium by statistical means. Voors (1971) found that neither element correlated significantly with cardiovascular death rates when the other element was controlled by partial correlations. Sauer (1974) found that magnesium, but not calcium, was significantly associated with death rates for women and that neither element was significantly associated for men, when a variety of water and other environmental factors were entered into a stepwise multiple regression equation.

Because calcium and magnesium levels in public water supplies correlate so closely with each other, estimation of their possible independent effects is difficult by any means, unless study areas can be found where calcium levels are high in relation to those of magnesium or vice versa. Such areas specifically have not been studied, and the geographic correlations published have not produced consistent answers as to the relative importance, if any, of calcium and magnesium in drinking water supplies to local cardiovascular death rates.

\section{CHROMIUM}

In North American and Finnish (but not in British) data, chromium in drinking water appeared to be a possible link in the association between hard water and low cardiovascular death rates, a protective factor because of its consistently positive association with water hardness. The direct associations between chromium in drinking water and local death rates, however, are weak and inconsistent.

Sauer et al. (1970), Voors (1971), and Schroeder and Kraemer (1974) analyzed data from Durfor and Becker (1964) on finished water of the largest U.S. cities. Sauer found that chromium levels correlated +.08 with cardiovascular death rates and -.03 with coronary death rates for whites with both sexes combined, neither coefficient being statistically significant. Voors also found insignificant negative correlations for coronary disease for each color-sex group. The coefficients were reduced to nearly zero when levels of other metals were kept constant by partial correlations. Schroeder found significant correlations, but only for cerebral thrombosis death rates and only for nonwhites. The coefficients were positive, contrary to the hypothesis of chromium as a protective element.

Among 500 Canadian towns, Neri et al. (1975) was able to detect chromium in the tap water of only 39 towns. Among them, chromium levels correlated -.11 
with male coronary death rates (not significant). In this ame set of 39 towns, chromium was also negatively correlated with all-cause mortality, -.09 (not significant), but paradoxically, when the towns without detectable chromium are included in the analysis, the coefficient becomes positive, +.06 (not significant). If coronary death rates, as well, were higher for towns with detectable chromium than for the remaining cities, the Canadian data must be interpreted as not supportive of the hypothesis of a protective role for chromium.

The study of Elwood et al. (1974) in South Wales showed positive correlations between tap water chromium levels and cardiovascular death rates. The coefficients were larger than those in the U.S. data $(+.23$ and +.16 for water samples taken in the morning and in the evening, respectively), but were not statistically significant, as only 48 areas were studied.

The data of Punsar et al. (1975) on two areas within Finland were supportive of the view that chromium is protective. Chromium levels were substantially and significantly lower in the higher-mortality eastern area ( 3 $\mu \mathrm{g} / 1)$ than in the lower-mortality western area $(9 \mu \mathrm{g} / 1)$. Within the eastern area, chromium levels were lower in tap water of subjects with elevated serum cholesterol levels and subjects who died of coronary disease than in tap water of control subjects. These findings were not consistent within the western area, however.

In summary, the correlations between chromium in water and some cardiovascular diseases are weak and inconsistent in North American data, somewhat positive in Welsh data (though still statistically insignificant), and negative in Finnish data.

\section{COPPER}

U.S. studies of copper in finished water supplies and cardiovascular death rates usually show positive correlations. Schroeder (1966) showed a correlation of +.29 for white male coronary death rates. In his 1974 report a positive coefficient for cerebral hemorrhage was significant $(+.21$ for white females), but correlations for coronary death rates were not. Sauer et al. (1970) reported a coefficient for coronary disease for whites of both sexes to be +.16 (not significant). North American tap water studies, however, show no association between copper and cardiovascular disease. Schreiber's (1977) study showed the distribution of copper levels in home drinking water of individuals who had died of coronary disease to be very similar to the distribution among controls living in the same county. Likewise, average tap water copper levels among 500 Canadian towns (Neri $e t$ $a l ., 1975)$ were unrelated to male coronary mortality ttes $(r=+.02)$.
Role of Chemical Constituents of Drinking Water

The Finnish data also suggested a positive association between copper in water and cardiovascular disease (Punsar et al., 1975). Copper levels were significantly higher in the high-death-rate eastern area than in the western area. Within the eastern area, copper levels were significantly higher in tap water of coronary decedents than in tap water of controls. No such association was seen within the western area, however, and there were no associations with cardiovascular risk factors in the study cohort.

In South Wales (Elwood et al., 1974), copper was negatively correlated with local cardiovascular death rates $(-.15$ for morning and -.18 for evening water samples, not significant). Among 61 English and Welsh cities (Elwood, 1977), tap water copper levels were insignificantly related to coronary heart disease rates, and the sign of the coefficient varied with the age group studied.

In summary, statistically significant results suggest a possible adverse effect of copper on cardiovascular disease in some of the U.S. and Finnish studies, but the results in South Wales point (insignificantly) in the opposite direction, and the English data are internally inconsistent.

\section{(ZINC}

Because zinc, as consumed in the home water supply, has no consistent relationship from place to place to the hardness of local drinking water supplies, the associations of hardness and mortality give no clue to the possible association of zinc in water and mortality. Unfortunately, the data on zinc are particularly scanty. None of the U.S. reports based on Durfor and Becker's (1964) data give useful information on zinc, because zinc levels were reported in only three cities.

Masironi (1970) reported negative correlations between zinc in untreated river water and death rates in 42 U.S. states. For hypertensive heart diseases the correlation was -.43 (significant), and for coronary heart disease it was -.11 (not significant). The report of Neri et al. (1975) on tap water from 500 Canadian towns showed low negative correlations between zinc and allcause mortality ( -.05 for Canada and -.12 for Ontario, neither statistically significant), but the only U.S. tap water data on zinc are those from Washington County, Maryland (Schreiber, 1977). The distributions of zinc levels from homes of coronary cases and controls were not significantly different. The study by Anderson et al. (1975) is an exception to the negative correlations, though his results are of limited value because they are based on analyses from only two groups of towns. The hard water low-mortality towns had a somewhat lower 
average tap water zinc concentration than the soft water high-mortality towns, $0.2 \mathrm{mg} / 1$ compared with $0.4 \mathrm{mg} / 1$.

Negative, but not statistically signficant, correlations were the usual finding in the British studies as well. Zinc concentrations in morning tap water samples correlated -.21 (not statistically significant) with cardiovascular mortality in 48 areas of South Wales (Elwood, 1974). Among 61 English and Welsh cities, correlations with coronary heart disease mortality were negative in each of four middle-age age groups, but were trivial in magnitude (Elwood, 1977).

The Finnish study (Punsar et al., 1975) presents a mixed result for zinc. The low-mortality western area had somewhat higher zinc levels in drinking water than the eastern area (not significant), but within the western area, zinc was higher in tap water of coronary decedents than in tap water of subjects free of coronary disease. The study of risk factors was also inconsistent. Zinc appeared to be positively associated with elevated blood pressure and negatively associated with the presence of extra systoles on the electrocardiogram.

Though the available data seem to favor the hypothesis of a protective role for zinc, it must be remembered that the correlations found were usually not significant, they were not always negative, and no nationwide data have yet been published for tap water in the United States.

\section{CADMIUM}

Schroeder and Kraemer (1974) showed that corrosiveness of municipal drinking water was associated with elevated cardiovascular death rates and argued that this supported their view that cadmium corroded from galvanized pipe may be the water factor in cardiovascular disease. As we have seen, the evidence that substantial cadmium corrosion occurs in public water supplies is meager. Also, cadmium levels in tap water have usually been lower than the detection limit for the methods used in the major studies relating water constituents to death rates, so direct evidence bearing on the possible effect of cadmium on death rates is even more scanty.

In Masironi's (1970) U.S. study involving untreated river water, cadmium levels, analyzed before corrosion can change them, were negatively correlated with local death rates from hypertensive heart disease and coronary disease, but the strong association of cadmium with hardness in these raw water samples makes this result not surprising. In the study by Neri et al. (1975) of tap water in 500 towns in Canada, cadmium was detected in only 14 percent of the samples. No significant or substantial correlations with all-cause or coronary mortality were seen. Coronary cases and controls in Washington County, Maryland, did not differ in their tap water cadmium

\section{CARDIOVASCULAR DISEASE}

levels (Schreiber, 1977). Anderson et al. (1975) found average cadmium levels of $2 \mu \mathrm{g} / 1$ in the three hard wate cities with low mortality rates compared with $1 \mu \mathrm{g} / \mathrm{i}$. the five soft water cities with high mortality rates. Bierenbaum et al. (1975), on the other hand, reported higher mortality rates and a higher level of cadmium in tap water samples $(3 \mu \mathrm{g} / 1)$ in Kansas City, Kansas, than in $(1 \mu \mathrm{g} / 1)$ in Kansas City, Missouri. The fact that both cities draw water from the same river makes this an interesting comparison, but in both Anderson's and Bierenbaum's studies the reported levels of cadmium are near the detection limits for the methods used, so these results cannot be considered reliable without knowledge of their accuracy. Distributional data on the levels of tap water cadmium over time or from tap to tap would be particularly helpful. There appears to be no direct evidence concerning the relationship of drinking water cadmium levels to death rates in European studies.

In summary, data on cadmium in tap water are much too fragmentary to permit an evaluation of its possible role in cardiovascular diseases. The infrequency of the detection of cadmium in drinking water samples makes it appear unlikely that cadmium in water plays such a role, or, if it did, that such a role could be discovered in studies of the type described.

\section{LEAD}

As lead also is corrodible from plumbing materials, the most relevant correlations between its level in water and death rates are those involving tap water samples. Neri et al. (1975) analyzed tap water samples from 500 Canadian towns and found detectable lead in 92 percent. Despite this, correlations with death rates were not statistically significant. Coronary cases and controls had similar tap water lead levels in Schreiber's (1977) study.

In the U.S. studies based on analyses of finished water at the plant (Durfor and Becker, 1964), the results are inconsistent. Schroeder (1966) reported that the 25 cities with the highest coronary death rates had levels of lead in water that were similar to those of the 25 cities with the lowest rates, and in Schroeder and Kraemer's (1974) report they found no evidence to implicate excess of this toxic element in coronary disease. Sauer et al. (1970), however, found a significant positive correlation $(+.24)$ between lead and coronary death rates for whites of both sexes. Deaths from hypertensive heart disease were negatively correlated with lead in Schroeder and Kraemer's (1974) work, significantly among three of the four color-sex groups. For cerebral thrombosis, also a sequel of hypertension, negative correlations were found for two color-sex groups, but a significant positive one was found for white females. 
In South Wales (Elwood et al., 1974), lead levels in tap water correlated positively with cardiovascular death rates in the 48 areas studied, with a significant coefficient for water samples collected in the evening $(+.28)$. But when the effect of calcium in water on mortality was included in the analysis, lead made no substantial or significant contribution. In a more recent study conducted by Elwood et al. (1976a) of individual decedents in North Wales, water samples from the homes of cardiovascular decedents did not contain more lead than samples from decedents from other diseases. The individual design of this study adds credibility to these results compared with those of studies of ecological design. Among 61 cities in England and Wales, tap water lead levels were trivially associated with coronary death rates (Elwood, 1977). The coefficients were negative in sign.

Results from the Finnish study (Punsar et al., 1975) are also unclear. Within the western area, tap water of coronary decedents had significantly lower levels of lead than tap water of subjects free of coronary disease. But this was not found in the eastern area, and the two areas did not differ significantly from each other in drinking water lead levels. On the other hand, positive correlations were found between lead and both systolic blood pressure and serum cholesterol in study subjects, though these were significant only in the west for blood pressure and only in the two areas combined for cholesterol.

Recent results from Scotland (Beevers et al., 1976a) are consistent with these findings on blood pressure. Among a screened general population, hypertensives had significantly higher blood lead levels than matched controls. Blood lead levels were related to the lead content of home tap water, according to other work in the same city (Beattie et al., 1972), and this was the case among the normotensives Beevers et al. studied. Among three recent studies involving occupational lead exposure, one showed an association with hypertensive disease (Cooper and Gaffey, 1975) and two did not (Felderman, 1976; Robinson, 1976).

\section{SUMMARY}

No clear pattern has emerged in the mortality studies. In North America, death rates were inconsistently related to levels of lead in finished water at the plant. There were both positive and negative significant correlations. The two studies based on tap water lead showed no significant relationship. In tap water studies in Wales and in England, there was also little if any effect of lead on mortality in either ecological or individual studies. In Finland, however, the interesting result is the possibility of an adverse effect of waterborne lead on blood pressure, and this result is consistent with recent findings in Scotland. If this result is corroborated, part of the reason for the lack of an adverse effect of lead on death rates in most of the above studies may be the infrequency in the populations studied of the combination of lead plumbing and corrosive water. In areas where this combination exists, waterborne lead could conceivably be a factor in cardiovascular disease and deserves specific investigation.

It is not surprising that studies correlating local death rates with drinking water trace element concentrations have failed thus far to produce clear results. In the first place, these are ecological studies. Mortality rates of localities are studied in relation to the average trace element exposures of their populations. But trace element exposure varies considerably among individuals within each locality, so ecological studies will miss much of the total effect of trace element exposure. Secondly, the average trace element exposure in a locality may be very imprecisely measured in the studies cited. This imprecision arises from both laboratory error in trace element measurement and the sampling error resulting from the use of only a few water samples to represent a water supply, which is heterogeneous from tap to tap and from time to time. The effect of these factors is to reduce the chance of detecting real associations and to increase the error in their assessment.

In spite of these factors the studies cited produced a number of statistically significant correlations. The fact that the correlations often contradict each other makes them suspect. In fact, specious correlations should be expected in geographic studies because the assumption of statistical independence is not met. Cities are not independent sampling units. They are clustered into geographic groups with similar water characteristics and mortality rates. Therefore it cannot be assumed that among 100 cities a correlation coefficient of \pm .2 or greater will occur by chance only once in 20 studies, even though a coefficient of this magnitude is significant at the .05 level of confidence. For water hardness, U.S. cities might be said to fit into only a few distinct groups. For 10 groups, a coefficient of \pm .6 would be required for significance, but the correlations presented did not approach that magnitude.

There is no rational way of determining how many independent units 100 U.S. cities represent. One can conclude only that geographic correlations are not nearly as believable as their nominal level of significance would indicate. One must judge them by whether they fit into a consistent pattern. On the basis of this criterion, the findings on waterborne trace elements and mortality should be accorded little credence at this time. 


\section{ASSOCIATION OF ELEMENTS IN DRINKING WATER WITH ELEMENTS IN HUMAN TISSUES}

The failure of the geographic correlational studies to provide consistent evidence for an association between water constituents and cardiovascular mortality does not provide convincing evidence that the constituents of water are unimportant in cardiovascular disease. The ecological method of study is insensitive, and the studies cited have probably characterized the water quality of the localities with some error, at least for the trace elements. Another reason for a failure to find consistent associations may be that drinking water may not be an important contributor to daily human intake for these constituents.

Theoretically, one can estimate the amount of an element contained in the food and water a person consumes to determine whether water is an important contributor. Unfortunately, this is a very inexact procedure. For many of the elements of biological importance, neither the total average human consumption nor the amount consumed through water is known with precision. Where such data exist, they will be mentioned in the discussion to follow, but even then, their value is limited because little is known about the relative availability of the element in water and in food.

Another approach to the question of whether or not drinking water contributes importantly to human intake for certain elements is to determine whether human tissue concentration of these elements varies with the concentration of these elements in local water supplies.

Relevant studies that are available will be summarized below. A more detailed discussion appears in a recent review (Sharrett, 1977).

\section{MAGNESIUM}

Soft water contributes a negligible amount of magnesium to daily human intake, but very hard water may contribute as much as 20 percent of the daily minimum requirement (Hankin et al., 1970; Neri et al., 1975; Marier, 1978). Using the method of calculation of these authors, a concentration of $6 \mathrm{mg} /$ (the median concentration for the largest U.S. cities from Durfor and Becker (1964)) would contribute about 5 percent. Because water is a consistent item in the human diet, this could be etiologically important if normal diets are marginal for this essential nutrient (Seelig, 1964).

Studies of serum magnesium in residents of areas with differing levels of magnesium in the drinking water have not shown a consistent relationship (Anderson, 1972; Bierenbaum et al., 1973, 1974, 1975; Luoma et al., 1973).
In one study, urinary excretion of magnesium did not vary with magnesium in the local water supply (Daunce: and Widdowson, 1972). Among 24 Texas cities with is broad range of drinking water magnesium concentrations, however, the correlation with magnesium excretion was .31, and significant (Dawson, 1978).

The critical tissues to examine for deficiency, however, may be deposition sites. In both bone and coronary arteries, substantially more sudden death victims from soft water Glasgow had low-magnesium levels than from hard water London (Crawford and Crawford, 1967, 1969).

Anderson et al. (1975) reported a set of observations that suggest that the residents of soft water areas have reduced concentrations of magnesium in myocardial muscle tissues compared with residents of hard water areas and that this may be the explanation for the postulated relationship between soft water and elevated cardiovascular mortality rates. The concentration of magnesium in heart muscle from accident victims who resided in towns with an average drinking water magnesium of $3 \mathrm{mg} / \mathrm{\text {was }} 918 \mu \mathrm{g} / \mathrm{g}$ dry weight, compared with $982 \mu \mathrm{g} / \mathrm{g}$ in accident victims who resided in towns with an average drinking water magnesium of $29 \mathrm{mg} /$. The difference was significant and was consistent within age, sex, and cause of death categories. The evidence that low magnesium is etiologically related to cardiovascular death was that decedents from coronary heart disease had significantly lower magnesium levels in heart muscle and in diaphragm muscle than did decedents from accidents. (Low magnesium in heart muscle may, however, have been a consequence of, rather than a cause of, the heart attack, though the portion of heart muscle sampled for analysis was not infarcted.) The hypothesis is consistent with knowledge of the central role played by magnesium in cardiac physiology (Polimeni and Page, 1973).

Anderson's finding of a relationship of tissue levels to drinking water levels of magnesium requires confirmation before the interesting conclusions that can be drawn from it are accepted. The only directly comparable work has recently been reported from England (Chipperfield et al., 1976), where the result contradicts that of Anderson. The fact that each of the elements analyzed-magnesium, potassium, and zinc-was more concentrated on a wet weight basis in hearts of decedent residents of a soft water town than in those of a hard water town led the authors and Anderson et al. (1976) to speculate on whether or not the heart tissues from the two towns had been handled similarly. The magnesium content of the water supplies of the two towns was not given, however.

In summary, the magnesium content of hard water might be sufficient to prevent deficiency if dietarj 
magnesium is marginal, and unconfirmed reports indicate that low levels of magnesium in tissues may occur more often in areas with soft water. That this may relate to the etiology of cardiovascular disease is consistent with physiological considerations.

\section{CHROMIUM}

Average human intake for chromium is estimated to be 50-80 $\mu \mathrm{g} /$ day (NRC Committee on the Biologic Effects of Atmospheric Pollutants, 1974). Kopp (1969) reported that only 15 percent of U.S. finished drinking water supplies contained as much as $1 \mu \mathrm{g} /$ of chromium. Tap water studies have reported average chromium concentrations of 1-9 $\mu \mathrm{g} / \mathrm{l}$, with the higher levels in harder water (McCabe, 1970; Neri et al., 1975; Punsar et al., 1975). Elwood et al. (1974), however, reported average levels of $21 \mu \mathrm{g} / 1$ for South Wales, though they questioned the reliability of their chromium analyses. Because chromium determinations are still difficult, it is probably premature to conclude that water is an unimportant source of human chromium.

The only data on human tissue chromium in relation to drinking water chromium are found in the report by Bierenbaum et al. (1975) of higher serum chromium in subjects from Kansas City, Missouri, than in subjects from Kansas City, Kansas, which corresponded to reported average drinking water levels in the two cities.

\section{COPPER}

In North America, where copper tends to be elevated in tap water in soft water areas, waterborne copper in these areas may constitute a substantial proportion of daily human intake. Neri et al. (1975) estimated that Canadian towns with soft water contributed $1.2 \mathrm{mg}$ toward an average daily copper consumption of $2-4 \mathrm{mg}$. Craun and McCabe (1975), however, estimated that average U.S. tap water contributed only about $270 \mu \mathrm{g}$ of copper per day.

The contribution to human tissue concentrations has not been adequately studied. In Canada there were no significant differences in the average concentrations of copper in muscle tissues of decedents from a group of hard and soft water towns, though they differed appreciably in the copper levels of their water (Anderson et al., 1975; Neri et al., 1975). Among five U.S. towns with available data, copper levels in whole blood (Kubota et al., 1968) were compared with copper levels in finished drinking water (Durfor and Becker, 1964). The correlation was positive and substantial $(+.85)$, but not significant, with data from only five towns. Bierenbaum $e t$ al. (1975) reported that serum copper was higher in Kansas City, Missouri, where the drinking water copper was higher, than in Kansas City, Kansas. An incidental finding in a study of trace element concentration in scalp hair (Harrison et al., 1969) was an outlying elevated copper level in repeated hair samples from a single subject whose drinking water was from a well with higher copper levels.

Schroeder et al. (1966) found higher copper levels in human liver samples in each of seven U.S. cities with soft water than in each of four cities with moderately hard water. But the opposite relation is seen when blood copper (Kubota et al., 1968) is compared with water hardness (Lohr and Love, 1954). For 17 U.S. towns, blood copper was associated with hard water $(r=+.18$, not significant). In these two sets of data, however, copper levels in water are not available, so their relevance to the present discussion depends on whether the generally observed association of copper with soft water in the United States holds true for these particular 17 towns. Thus the data on tissue copper suggest that waterborne copper may contribute to human tissue levels, but it is too fragmentary to permit definite conclusions to be drawn.

\section{ZINC}

Daily zinc intake is estimated at $10-15 \mathrm{mg}$ with average American diets (Sandstead et al., 1970; Halstead et al., 1974). Of this, the average U.S. tap water concentration of zinc of $200 \mu \mathrm{g} / 1$ (Craun and McCabe; 1975) would ordinarily contribute very little, except perhaps in the cases of dietary deficiency, the prevalence of which is unknown.

Little is known about contributions of water to tissue concentrations of zinc. Bierenbaum et al.'s (1975) finding of markedly elevated serum zinc in residents of Kansas City, Missouri, in comparison with residents of Kansas City, Kansas, where zinc levels in drinking water are lower, awaits resolution of the question of acute toxicity in his subjects (see the discussion in the following section). Anderson et al. (1975), however, found significantly higher zinc concentrations in diaphragm muscle in decedents of the Canadian towns with lower average zinc concentrations in the drinking water. The scanty data available, then, are inconsistent.

\section{CADMIUM}

Despite the interest in cadmium as a possible intermediary in the relationship between water hardness and mortality, there is little solid evidence to cite. One reason, perhaps, is that the intake of cadmium from water appears to be small in relation to that from food and 
other sources, probably less than 5 percent (Fleischer et al., 1974; Craun and McCabe, 1975; Fassett, 1975).

The evidence relating to human tissue levels is contradictory. Bierenbaum et al. (1975) reported serum cadmium levels of $16.4 \mu \mathrm{g} / \mathrm{I}$ in normal subjects from Kansas City, Kansas, compared with $1.2 \mu \mathrm{g} / \mathrm{l}$ in subjects from Kansas City, Missouri, where the tap water levels were reported as $3 \mu \mathrm{g} / \mathrm{l}$ and $1 \mu \mathrm{g} / \mathrm{l}$, respectively. The authors found their serum zinc and cobalt values to be as troublesome as those for cadmium, and they considered that acute toxicity might be the explanation (Bierenbaum, 1975). This, however, is surprising because it would require that their Missouri subjects were exposed to toxic levels of cobalt and zinc and their Kansas subjects were exposed to toxic levels of cadmium.

Beevers et al. (1976b) found no correlation between blood cadmium and tap water cadmium levels among 117 screenees from a hypertension survey in a city in Scotland; their tap water levels averaged $1.3 \mu \mathrm{g} / \mathrm{l}$, with a maximum of $5.9 \mu \mathrm{g} / \mathrm{l}$. In a Canadian study of accident victims in areas with similar tap water cadmium levels, concentrations of cadmium in three types of muscle tissue were unrelated to concentrations in drinking water (Anderson et al., 1975; Neri et al., 1975).

\section{LEAD}

The relation of tap water lead levels to soft water has not been shown consistently enough to make lead appear to be a promising explanatory link in the relationship of soft water and cardiovascular disease, and it has not shown consistent correlations with mortality rates, but evidence that human tissue levels are affected by waterborne lead is accumulating.

Modest elevations in blood lead in residents of soft water towns with lead plumbing in their homes have been seen recently in Glasgow (Beattie et al., 1972; Addis, 1974; Beevers, 1976a), Edinburgh (Covell, 1975), Wales (Elwood et al., 1976b), Belgium (de Graeve et al., 1975), and Boston (Craun and McCabe, 1975). Crawford and Crawford (1969) and Crawford and Clayton (1973) found larger and significantly higher levels of lead in bones of decedents from soft water towns than in decedents of hard water towns.

These findings, together with the results suggesting a possible role of waterborne lead in hypertension (Punsar et al., 1975; Beevers et al., 1976a) should provoke further research in potentially affected areas.

\section{SUMMARY}

There is little evidence bearing on the question of a substantial contribution of drinking water to human tissue levels of cadmium, chromium, or zinc. Copper and magnesium levels of tissues may be related to drinking water, however, and confirmatory evidence should be sought. Lead levels in blood, and possibly other tissues, are almost certainly affected by lead levels in drinking water in areas where these levels are particularly elevated, and the possible implications of low-dose chronic exposure should be of great interest.

\section{REFERENCES}

Addis, G. 1974. Lead levels in the water of suburban Glasgow. Nature 252:120.

Anderson, T. W. 1972. Serum electrolytes and skeletal mineralization in hard-and soft-water areas. J. Can. Med. Assoc. 107:34-37.

Anderson, T. W., L. C. Neri, G. B. Schreiber, F. D. F. Talbot, and A. Zdrojewsky. 1975. Ischemic heart disease, water hardness and myocardial magnesium. J. Can. Med. Assoc. 113:199-203.

Anderson, T. W., L. C. Neri, D. Hewitt, G. Schreiber, and J. R. Marier. 1976. Magnesium in heart muscle. Lancet 1:644.

Beattie, A. D., M. R. Moore, W. T. Devenay, A. R. Miller, and A. Goldberg. 1972. Environmental lead pollution in an urban soft-water area. Br. Med. J. 1:491-493.

Beevers, D. G., E. Erskine, M. Robertson, A. D. Beattie, B. C Campbell, A. Goldberg, and M. R. Moore. 1976a. Blood-lead and hypertension. Lancet 2:1-3.

Beevers, D. G., B. C. Campbell, A. Goldberg, M. R. Moore, and V. M. Hawthorne. 1976b. Blood-cadmium in hypertensives and normotensives. Lancet 2:1222-1224.

Bierenbaum, M. L. 1975. Letter to editor. Lancet 2:76.

Bierenbaum, M. L., A. I. Fleischman, J. D. Dunn, T. Hayton, D. C. Pattison, and P. B. Watson. 1973. Serum parameters in hard and soft water communities. Am. J. Public Health 63(2):169-173.

Bierenbaum, M. L., A. I. Fleischman, R. Stein, and T. Hayton. 1974. Effect of fluoridated water upon serum lipids, ions, and cardiovascular disease mortality rates. J. Med. Soc. N.J. 71:(9)663-666.

Bierenbaum, M. L., A. I. Fleischman, J. Dunn, and J. Arnold. 1975. Possible toxic water factor in coronary heart disease. Lancet 1:10081010.

Chipperfield, B., J. R. Chipperfield, G. Behr, and P. Burton. 1976. Magnesium and potassium content of normal heart muscle in areas of hard and soft water. Lancet 1:121-122.

Comstock, G. W. 1979 (this volume). The association of water hardness and cardiovascular diseases: An epidemiological review and critique.

Cooper, W. C., and W. R. Gaffey. 1975. Mortality of lead workers. J. Occup. Med. 17(2):100-107.

Covell, B. 1975. Lead content in household water in Edinburgh. Health Bull. Edinburgh 33(3):114-116.

Craun, G. F., and L. J. McCabe. 1975. Problems associated with metals in drinking water. J. Am. Water Works Assoc. 67:593-599.

Crawford, M. D., and D. G. Clayton. 1973. Lead in bones and drinking water in towns with hard and soft water. Br. Med. J. 2:21-23.

Crawford, M. D., and T. Crawford. 1969. Lead content of bones in a soft and a hard water area. Lancet 1:699-701.

Crawford, M. D., and J. N. Morris. 1967. Lead in drinking water. Lancet 2:1087-1088.

Crawford, M. D., M. J. Gardner, and J. N. Morris. 1968. Mortality and hardness of local water supplies. Lancet 1:827-831.

Crawford, T., and M. D. Crawford. 1967. Prevalence and pathological changes of ischemic heart disease in a hard-water and in a soft-water area. Lancet 1:229-232. 
Dauncey, M. J., and E. M. Widdowson. 1972. Urinary excretion of calcium, magnesium, sodium, and potassium in hard and soft water areas. Lancet 1:711-714.

Dawson, E. B., M. J. Frey, T. D. Moore, and W. J. McGarrity. 1978. Relationship of metal metabolism to vascular disease mortality rates in Texas. Am. J. Clin. Nutr. 31:1188-1197.

de Graeve, J., P. Jamin, and D. Rondia. 1975. Plombemie d'une population adulte de l'Est de la Belgique. Rev. Epidemiol. Med. Soc. Sante Publique. 23(2):131-152.

Durfor, C. N., and E. Becker. 1964. Public water supplies of the 100 largest cities in the United States, 1962. U.S. Geol. Surv. Water Supply Pap. 1812.

Elwood, P. C., M. Abernethy, and M. Morton. 1974. Mortality in adults and trace elements in water. Lancet 2:1470-1472.

Elwood, P. C., A. S. St. Leger, F. Moore, and M. Morton. 1976a. Lead in water and mortality. Lancet 1:748.

Elwood, P. C., A. S. St. Leger, and M. Morton. 1976b. Dependence of blood-lead on domestic water lead. Lancet 1:1295.

Elwood, P. C., A. S. St. Leger, and M. Morton. 1977. Mortality and the concentration of elements in tap water in the country boroughs in England and Wales. Br. J. Prev. Soc. Med. 31:178-182.

Fassett, D. W. 1975. Cadmium: Biological effects and occurrence in the environment. Ann. Rev. Pharmacol. 15:425-435.

Felderman, E. J. 1976. Blood-lead and hypertension. Lancet 2:1135.

Fleischer, M., A. F. Sarofim, D. W. Fassett, P. Hammond, H. T. Shacklette, I. C. T. Nisbet, and S. Epstein. 1974. Environmental impact of cadmium: A review by the panel on hazardous trace substances. Environ. Health Perspect. 7:253-323.

Halstead, J. A., J. C.. Smith, Jr., and M. 1. Irwin. 1974. A conspectus of research on zinc requirements of man. J. Nutr. 104(3):345-378.

Hankin, J. H., S. Margen, and N. F. Goldsmith. 1970. Contribution of hard water to calcium and magnesium intakes of adults. J. Am. Diet. Assoc. 56:212-224.

Harrison, W. W., J. P. Yurachek, and C. A. Benson. 1969. The determination of trace elements in human hair by atomic absorption spectroscopy. Clin. Chim. Acta 23:83-91.

Kopp, J. F. 1969. The occurrence of trace elements in water. In Proceedings of the Third Annual Conference on Trace Substances in Environmental Health, June 24-26, 1969, D. D. Hemphill, ed. University of Missouri, Columbia. Pp. 59-73.

Kubota, J., V. A. Lazar, and F. Losee. 1968. Copper, zinc, cadmium, and lead in human blood from 19 locations in the United States. Arch. Environ. Health 16:788-793.

Lohr, E. W., and S. K. Love. 1954. The industrial utility of public water supplies in the United States, 1952. U.S. Geol. Surv. Water Supply Pap. 1299 and 1300.

Luoma, H., S. K. J. Helminen, H. Ranta, I. Rytomaa, and J. H. Meurman. 1973. Relationships between the fluoride and magnesium concentrations in drinking water and some components in serum related to cardiovascular diseases in men from four rural districts in Finland. Scand. J. Clin. Lab. Invest. 32:217-224.

Marier, J. R. 1978. Cardio-protective contribution of hard waters to magnesium intake. Rev. Can. Biol. 37:115-125.

Masironi, R. 1970. Cardiovascular mortality in relation to radioactivity and hardness of local water supplies in the U.S.A. Bull. WHO 43:687-697.

McCabe, L. J. 1970. Metal levels found in distribution samples. In Seminar on Corrosion by Soft Water. American Water Works Association, Washington, D.C. June 21, 1970.
Role of Chemical Constituents of Drinking Water

Morris, J. N., M. D. Crawford, and J. A. Heady. 1961. Hardness of local water supplies and mortality from cardiovascular disease. Lancet 1:860-862.

NRC Committee on Biologic Effects of Atmospheric Pollutants. 1974. Chromium. National Academy of Sciences, Washington, D.C. 155 pp.

Neri, L. C., D. Hewitt, G. B. Schreiber, T. W. Anderson, J. S. Mandel, and A. Zdrojewsky. 1975. Health aspects of hard and soft waters. J. Am. Water Works Assoc. 67(8):403-409.

Polimeni, P. 1., and E. Page. 1973. Magnesium in heart muscle. Circ. Res. 33(4):367-374.

Punsar, S., O. Erametsa, M. J. Karnoven, A. Ryhanen, P. Hilska, and H. Vornamo. 1975. Coronary heart disease and drinking water. J. Chronic Dis. 28:259-287.

Robinson, T. R. 1976. The health of long service tetraethyl leads workers. J. Occup. Med. 18(1):31-40.

Sandstead, H. H., R. F. Burk, G. H. Booth, and W. J. Darby. 1970. Current concepts on trace minerals-Clinical considerations. Med. Clin. North Am. 54(6): 1509-1531.

Sauer, H. I. 1974. Relationship between trace element content of the drinking water and chronic diseases. In Proceedings 16th Water Quality Conference. University of Illinois, Urbana. Feb. 12, 1974.

Sauer, H. I., D. W. Parke, and M. L. Neill. 1970. Associations between drinking water and death rates. In Proceedings of the Fourth Annual Conference on Trace Substances in Environmental Health, June 23-25, 1970. D. D. Hemphill, ed. University of Missouri, Columbia. Pp. 318-325.

Schreiber, G. B. 1977. Arteriosclerotic heart disease mortality and water quality: A case against water quality being a cardiovascular disease risk factor. Unpublished doctoral thesis. Johns Hopkins University School of Hygiene and Public Health, Baltimore, Md. 149 pp.

Schroeder, H. A. 1960. Relation between mortality from cardiovascular disease and treated water supplies. J. Am. Med. Assoc. 172(17):1902-1908.

Schroeder, H. A. 1961. Hardness of local water-supplies and mortality from cardiovascular disease. Lancet 1:1171.

Schroeder, H. A. 1966. Municipal drinking water and cardiovascular death rates. J. Am. Med. Assoc. 195(2):81-85.

Schroeder, H. A., and L. A. Kraemer. 1974. Cardiovascular mortality, municipal water, and corrosion. Arch. Environ. Health 28:303-311.

Schroeder, H. A., A. P. Nason, I. H. Tipton, and J. J. Balassa. 1966. Essential trace metals in man: Copper. J. Chronic Dis. 19:10071034.

Seelig, M. S. 1964. The requirement of magnesium by the normal adult. Am. J. Clin. Nutr. 14(6):342-390.

Sharrett, A. R. 1977. Water hardness and cardiovascular diseaseElements in water and human tissues. Sci. Total Environ. 7:217-226.

Stocks, P. 1973. Mortality from cancer and cardiovascular diseases in the county boroughs of England and Wales classified according the the sources and hardness of their water supplies, 1958-1967. J. Hyg. (London) 71:237-252.

U.S. Environmental Protection Agency. 1971. Methods for Chemical Analysis of Water and Wastes, 1971. Stock no. 5501-0067. U.S. Government Printing Office, Washington, D.C.

Voors, A. W. 1971. Minerals in the municipal water and atherosclerotic

heart death. Am. J. Epidemiol. 93(4):259-266. 


\title{
8
}

\section{The Association of Trace Elements and Cardiovascular Diseases: A Selected Review of Positive Findings in the Literature}

\author{
A. WOUTER VOORS
}

The possibility that a negative correlation exists between drinking water hardness and cardiovascular disease mortality has stimulated the search for other correlates of cardiovascular disease that both explain its relationship to water hardness and provide a theory coherent with current knowledge of cardiovascular disease pathogenesis.

As early as 1962, Schroeder and Vinton (1962) had suggested that low-dose cadmium may be a cause of cardiovascular disease mortality, Perry and Erlanger (1974) did much to corroborate that thesis, and Carroll (1966) provided some independent epidemiological support for it.

Current knowledge of trace elements in this regard has been reviewed by Masironi (1969) and, more recently, by Sharrett and Feinleib (1975). Cadmium's role was reviewed by Fulkerson and Goeller (1973) and by Friberg et al. (1974).

\section{GENERAL STATISTICAL, EPIDEMIOLOGICAL, AND ANALYTICAL PROBLEMS}

Any search for association between a given disease and a choice of variables can fall into the snares of editorial bias, type I error, and type II error. Editorial bias occurs when positive results are published, but, for lack of reading appeal, negative results are rejected. Except for a sound skepticism, the reader has no defense against such bias.

Type I error-concluding that a statistical association exists when in fact it does not-occurs when an investiga- tor looks at a number of associations, say 20 , and draws a positive conclusion . when only one of them is statistically significant at the 5 percent level. In all probability, however, 1 of 20 truly nonsignificant correlations should turn up in this category by chance alone, by virtue of the definition of the significance level. The remedy is to adjust the critical level of significance accordingly to a lower percentage.

Type II error-concluding that no significant statistical association exists, when indeed it does-is encountered, not only by chance in an estimable proportion of cases, but also when the observations are beset by a large measurement error (Crawford et al., 1972; Neri et al., 1972). The best means to avoid such error is painstaking precision of observation.

Special complications are encountered in the epidemiological analysis of autopsy data (Mainland, 1953) and in the use of accident victims as a comparison group (Carroll and Haddon, 1965).

Determining low concentrations of trace elements in biological tissues and urine has many pitfalls (Gorsuch, 1970; John and 'VanLaerhoven, 1976). Cadmium adsorption to glass and cadmium sublimation during dry ashing are well-known obstacles. However, the method of standard addition of the element to the untreated specimen ("spiking") can help to avoid a number of analytical errors. A compilation from the literature of population values of cadmium concentrations in urine, as determined by many authors using a variety of methods, may serve as an accessory orientation to the state of trace element assessment in biological tissues or media (see 
Table 17). It is obvious that the large variation of these listed data indicates that the current state of laboratory practice warrants extreme caution in data interpretation.

\section{METHOD}

\section{CHOICE OF TRACE ELEMENTS}

By definition for this review, the choice of trace elements for study was limited to those having a conceptual or demonstrated relation to the hardness of municipal water supplies. The relation would involve cadmium and lead as associated with soft water; calcium, magnesium, selenium, and silicon as associated with hard water; and zinc, apparently not associated with water hardness. Of these, calcium and magnesium are not "trace" elements, because they occur in the vertebrate body in rather large quantities, and therefore they will not be included in this review.

\section{SELECTION OF LITERATURE}

Because of space restrictions, it was not possible to include all animal experiments and all epidemiological observations obtainable from the literature. Rather, current biological models that are helpful and relevant to the problem are outlined, and a few animal experiments that illustrate the models are mentioned. Only epidemiological studies deemed relevant are listed. Because the potential explanations of negative findings are more

TABLE 17 Reported Quantities of Cadmium in Human Urinary Excretion-Population-Based Cadmium Excretion

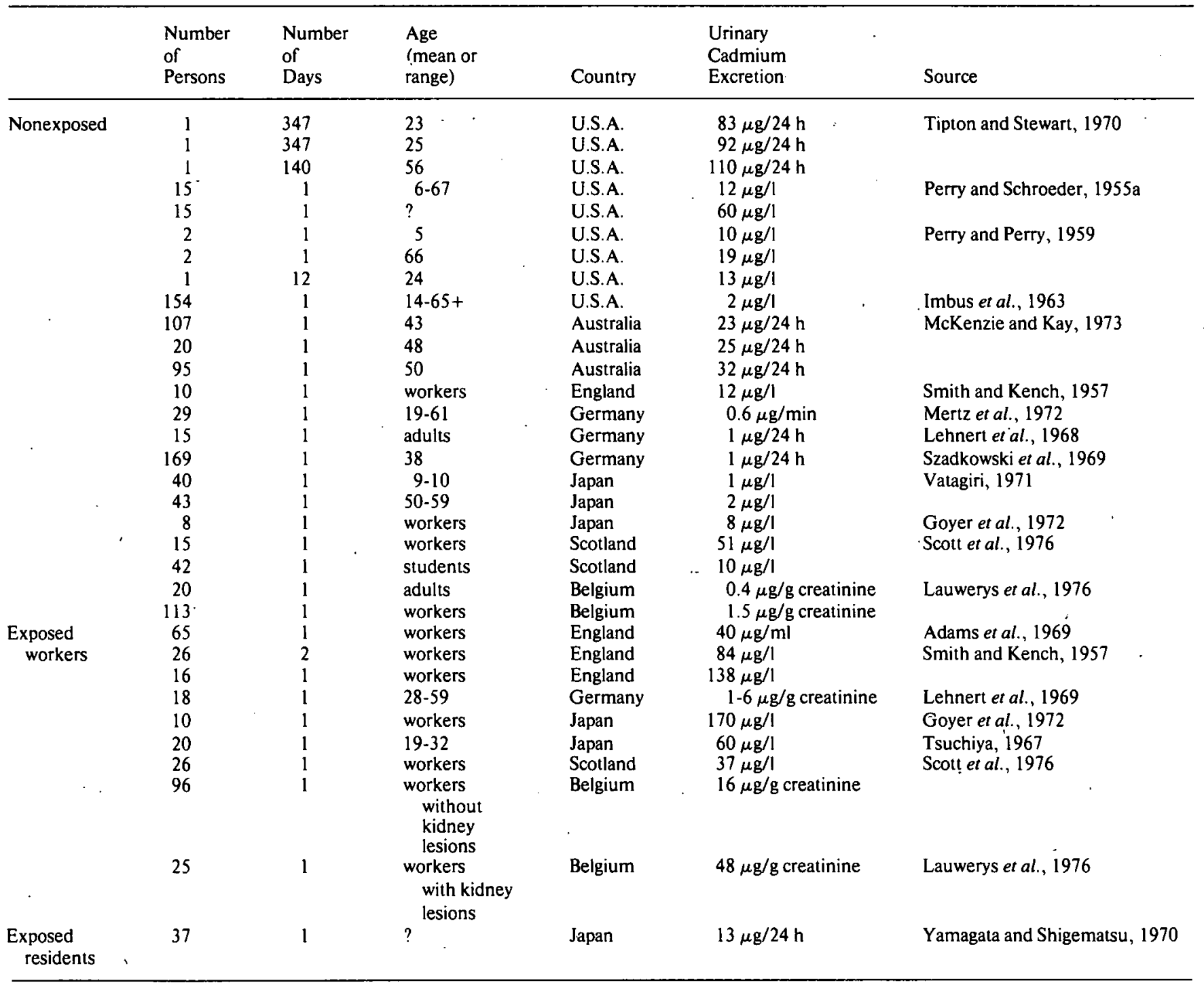




\section{4}

GEOCHEMISTRY OF WATER IN RELATION TO

complex than those of positive findings, negative findings are listed only when they offer strong evidence for a reasonable alternative. For further simplification, positive findings that were later proved not to lead to affirmative conclusions generally have been omitted from the present review.

The end result has become an impressionistic picture, provocative for further study, rather than an encyclopedia of what has been done in this field.

\section{METAL TOXICITY AND HOST DEFENSE}

Metal toxicity in relation to water softness and mortality resulting from cardiovascular disease may involve at least four groups of mechanisms:

- A primitive system of acquired resistance against some heavy metals exists by which the host cell, within hours, produces a soluble protein (metallothionein) that binds the toxic metal atom. This primitive defense reaction lasts for days (Webb and Verschuyle, 1976). The existence of this defense system renders the interpretation of epidemiological cross-section population data difficult. Challenge-response relationships may not be estimable, and metallothionein may under special circumstances even be toxic (Cherian et al., 1976).

Other host defense systems presumably include the presence of some active form of the element competing with the toxic atom for a place in the functioning enzyme molecule. Zinc protection against cadmium may be in this category (Hill and Matrone, 1970).

Finally, vitaminlike and other substances have been observed to protect the host metabolism against heavy metal toxicity under certain conditions, involving largely unknown molecular action. Among the latter substances, selenium can be assessed in the tissue at autopsy.

- The kidney regulation of water excretion during long-term sodium surfeit is influenced by trace elements.

- A relationship with the cardiac conduction tissue may be inferred, as confirmed by Kopp et al. (1978). The excess of ischemic and atherosclerotic heart disease mortality attributable to softness of the water supply may reflect only sudden deaths. This finding is reported from studies in Canada (Anderson et al., 1969; Neri et al., 1971; Fodor et al., 1973), in the State of Washington (Peterson et al., 1970), in eastern North Carolina (Voors, 1972), and in England and Wales (Crawford et al., 1977). If this inference is correct, it may point to molecular action on the heart conduction tissue, as exemplified by magnesium (Anderson, 1977).

- In the case of cadmium, renal storage poses an additional complication. The biological half-life of cadmi- um in the human kidney is 16-50 years .Friberg et al., 1974; Elinder et al., 1976), which is comparable to the half-life of the host. Because in every host, kidney function deteriorates with time (Rowe et al., 1976), and, in fact, may be itself a determinant of the length of the host's life, the loss of cadmium-storing cells in the kidney (which loss is presumably caused by this storage) may result in a decrease of host life expectancy. This possibility makes the epidemiological interpretation of data on renal tissue metal levels at autopsy a complex issue.

\section{EXPERIMENTAL ANIMAL STUDIES}

\section{HOST DEFENSE SYSTEM INVOLVING CADMIUM}

Terhaar et al. (1965) administered cadmium and found that against a second dose given 2 days later, host resistance had increased considerably. Apparently, the cadmium ion induces the host cell to produce metallothionein (Bryan and Hidalgo, 1976; Hidalgo et al., 1976). Webb and Verschuyle (1976) found that this protection is maximal from 1 to 3 days after pretreatment and then decreases and that during the protection the capacity for cadmium-thionein synthesis increases, resulting in the retention in the liver of the pretreated animal of a greater percentage of a later cadmium dose, but that uptake of the cation into other organs (heart, kidney, pancreas, spleen) is unaffected by the pretreatment. Hence those findings suggest that preinduced metallothioneins do not have a significant role in the protection against the acute toxicity of cadmium. Leber and Miya (1976) showed that zinc as well as cadmium can elicit this response and that both metals are bound by this protein.

\section{KIDNEY REGULATION OF WATER EXCRETION ON A LONG-TERM BASIS}

With regard to cadmium, the following findings are reported.

Perry and Erlanger (1974) were able to produce hypertension in rats by giving drinking water with 1000 $\mu \mathrm{g} / \mathrm{l}$ cadmium for 1 year. Preliminary findings indicate that a concentration of $100 \mu \mathrm{g} / 1$ in the drinking water produces the same results (Perry et al., 1976).

Perry et al. (1971) injected $1 \mathrm{mg}$ cadmium per kilogram of body weight in rats once a week for 24 weeks and produced an antinatriuretic effect. Doyle et al. (1974) put $5,000 \mu \mathrm{g} / 1$ cadmium in the drinking water of rats for 161 days and found retention of injected radioactive sodium. 
Thind et al. (1973) produced arterial hypertension and sinus bradycardia by injecting $2 \mathrm{mg}$ cadmium acetate per kilogram of body weight in dogs after 24 weekly or triweekly injections.

With regard to mercury and lead, Perry and Erlanger (1974) found a pressor effect from 5,000 and $10,000 \mu \mathrm{g} /$ mercury in drinking water of rats, administered for 1 year. They also observed an additive effect of lead and cadmium, in concentrations of 5,000 and $100 \mu \mathrm{g} /$, respectively, in the drinking water for 3 months, on the blood pressure of rats (Perry and Erlanger, 1977, 1978).

All the cadmium dosages quoted here are large in comparison to the average human cadmium consumption through drinking water $(<10 \mu \mathrm{g} /$ ), although the lowest quoted dosage $(100 \mu \mathrm{g} / \mathrm{l})$ may begin to approach human cadmium intake from total food consumption.

\section{CARDIAC CONDUCTION TISSUE WITH EMPHASIS ON CADMIUM}

Marsh (1976) perfused beating isolated chicken hearts with cadmium solution and found that it caused a decrease in the amplitude of the heart contraction at 5 and 10-nanomolar (nM) solutions $(0.6-1.1 \mu \mathrm{g} / 1)$. Similarly, Hawley and Kopp (1975) found that in the electrocardiogram of beating isolated rat hearts the PR time (the duration of transmission of the neural impulse at the atrioventricular node) was prolonged if the infusion fluid contained cadmium at a concentration of $300 \mathrm{nM}(33.7 \mu \mathrm{g} / \mathrm{l})$, and they also found that at higher concentrations the heart rate was reduced and atrioventricular block occurred at a concentration of 3,000 nmol/1 (337 $\mu \mathrm{g} / 1)$ (Kopp and Hawley, 1976). These relationships have been confirmed recently by chronic in vivo studies (Kopp et al., 1978).

Tissue distribution studies in mammals after administration of known cadmium dosage have been conducted by Thind and Fischer (1975) and Amacher and Ewing (1975) on dogs and by Berlin and Ullberg (1963) on mice. Apparently, cadmium concentration in the heart is relatively high during the first hour after administration but decreases during the rest of the day in mice. In dogs, cadmium concentration in the heart and blood vessels remains high during the first week after administration.

A large dosage of lead also can induce atrioventricular conduction defects (Myerson and Eisenhauer, 1963). The possible interaction between lead and cadmium in such induction has not been studied, although these two metals have been found to have an additive effect with respect to other toxic actions (Murthy et al., 1975; Der et al., 1976; Perry and Erlanger, 1977).

\section{LEAD AND CARDIOMYOPATHY}

Asokan et al. (1971) gave 1 percent lead acetate as drinking fluid to 8-week-old Sprague-Dawley rats. At the age of 16 weeks their myocardia showed diffuse degenerative changes. Moore et al. (1975) put $1 \mathrm{ppm}$ lead as lead acetate $(4.83 \mu \mathrm{mol} / \mathrm{l})$ in the drinking water of rats for 1 year. They found high lead levels in the heart muscle (16-29 $\mu \mathrm{mol} / \mathrm{kg}$ weight, corresponding to about $500 \mathrm{ppm}$ ash weight) and loss in mitochondrial structure (Moore, 1975).

\section{SELENIUM AND PROTECTION AGAINST CADMIUM} AND OTHER TOXICITIES

The volume of literature on this subject is large. Parizek et al. (1971) and Perry et al. (1974) gave principal references. The toxic or harmful action of cadmium may be counteracted by the presence of selenium through largely unknown mechanisms.

\section{ZINC AND PROTECTION AGAINST CADMIUM TOXICITY}

It has been conjectured that replacement of cadmium by zinc in enzyme molecules may protect against the toxic action of cadmium (Schroeder and Buckman, 1967; Schroeder et al., 1968; Webb, 1972). The mechanism appears to be elemental competition as influenced by the tissue concentration of both metals.

\section{SILICON AND THE CARDIOVASCULAR SYSTEM}

Loeper et al. (1966) have shown that healthy aortas are richer in silicon than atheromatous aortas and that relatively high levels of silicon are present in the mucopolysaccharides connecting collagen with the elastic fibers. Schwarz, after having demonstrated that silicon is essential for normal growth in rats (Schwarz and Milne, 1972), has proposed that silicon functions as a crosslinking agent of the connective tissue's ground matrix (Schwarz, 1973) and that silicon also could be an active component of dietary fiber in its hypothesized role of protecting against atheromata (Schwarz, 1977).

\section{TRACE ELEMENTS AND CARDIOVASCULAR DEATHS: EPIDEMIOLOGICAL STUDIES}

This review will consider the effects of cadmium, lead, selenium, zinc, and silicon. In each instance, three aspects are discussed: geographical correlations between regional mortality and an index of element intake, human 
blood or urine levels and an index of morbidity, and autopsied tissue analysis and cause of disease or death.

\section{CADMIUM}

From animal study findings, one can conclude that, where possible, a distinction should be made between hypertension and cardiac arrest. That distinction will be maintained in the subsections that follow.

\section{Geographical Correlations}

The level of cadmium in renal tissue relative to that of zinc was positively related to hypertension or cardiovascular mortality in a comparison of 119 subjects from several countries (Perry et al., 1961). The amount of cadmium in the ambient air was compared with mortality because of hypertensive and atherosclerotic heart disease in 28 large U.S. cities. The Pearson correlation coefficient was 0.76 (Carroll; 1966). Hickey et al. (1967), using related data, showed that "all diseases of the heart" correlated more highly with cadmium content in polluted air than did hypertensive heart disease mortality. Schroeder and Kraemer (1974) developed the idea of a correlation with the corrosiveness of piped water, and, using a modification of Langelier's index of corrosiveness, they obtained a high negative correlation with "arteriosclerotic heart disease" as a cause of mortality, considering data from 94 major U.S. cities.

\section{Human Blood or Urine Levels and Morbidity}

Glauser et al. (1976) and Bierenbaum et al. (1975) found a positive association between cadmium levels in the blood and the presence of hypertension for two different populations. Thind and Fischer (1976) likewise found a significant elevation of plasma cadmium levels in hypertensive patients. However, Beevers et al. (1976a) were unable to confirm this finding, using a different population, although here an interaction between cadmium and lead cannot be excluded (Beevers et al., 1976b; Werth, 1976; Perry and Erlanger, 1977).

Perry and Schroeder (1955a, 1955b) found higher urinary excretion of cadmium in untreated hypertensive patients than in treated or normotensive persons. McKenzie and Kay (1973) found that the 24-h urinary cadmium excretion was higher in hypertensive women under treatment than in normotensive women, thus partly confirming Perry and Schroeder's finding.

No comparisons have been reported between persons with certain electrocardiographic abnormalities and controls with regard to cadmium levels in blood or urine.

Populations with other environmental evidence of heavy cadmium exposure are discussed by Hammer et al. (1972) and Tsuchiya (1976). In neither study was cadmium exposure found to be related to increased blood pressure in any consistent way.

\section{Tissue Analysis at Autopsy and Cause of Disease or Death}

Indraprasit et al. (1974) found that hypertensive patients had a higher cadmium level in the spleen than did normotensive patients. They speculated that the spleen may scavenge cadmium compounds released from other organs. Lener and Bibr (1971) found that renal cadmium levels were higher for hypertensive men than for controls of about the same age. Schroeder (1965). found the cadmium:zinc ratio in the kidney to be higher in hypertensives than in controls. Voors et al. (1975) confirmed that finding in a different autopsy population.

With regard to heart disease mortality, Syversen et al. (1976) found that patients dying of ischemic heart disease and those dying from cerebrovascular accidents had higher hepatic cadmium levels than patients dying of other causes. Voors and Shuman (1977) found higher hepatic cadmium levels in patients dying of heart disease than in those dying of other causes, but data from Morgan (1969) and Tipton (1960) were not in agreement with this finding.

\section{LEAD}

\section{Geographical Considerations}

Sauer (1974) found a positive correlation between lead in the drinking water and death rates from cardiovascularrenal disease for 92 metropolitan state economic areas in the United States. The data reported by Crawford and Clayton (1973) hint at a similar correlation. However, because the sources of lead and cadmium are sometimes associated, the correlation may merely reflect cadmium toxicity (Challop, 1971).

\section{Human Blood and Urine Levels and Morbidity}

Beevers et al. (1976b), in a matched control study performed in western Scotland, found an association between the lead level in blood and the presence of hypertension. Werth (1976) commented that perhaps the association of that study may be explained by concomitantly dissolved and ingested cadmium. Indeed, Lewis et al. (1976) did find a Pearson correlation coefficient of 0.42 between 24-h urinary lead and cadmium levels in 788 inpatients of Indiana hospitals. Dietary lead and cadmium may have sources in common (Stenstrom and 
Vahter, 1975). These elements may enhance each other's toxic action on host cells (Murthy et al., 1975; Der et al., 1976; Perry and Erlanger, 1977). Beevers did subsequently test 70 hypertensives and 70 controls for cadmium blood levels and did not find significant differences (Beevers et al., 1976a).

Tissue Analysis at Autopsy and Cause of Disease or Death

A positive association between lead level in the aortic wall and death caused by heart disease in an autopsy study has been reported (Voors et al., 1973).

\section{SELENIUM}

\section{Geographical Correlations}

Shamberger et al. (1975) found a negative correlation between selenium content of the soil, as evidenced by levels in sampled fodder, and hypertensive death rates in a comparison among several states in the United States. Frost (1972) compared selenium maps and heart disease mortality maps and noted a suggestive inverse relationship between heart disease mortality and an estimate of the amount of selenium available in the soil for plants.

\section{Human Blood or Urine Levels and Morbidity}

No studies have been located.

\section{Tissue Analysis at Autopsy and Cause of Disease or Death}

Voors et al. (1978) found a low negative correlation between heart weight and level of selenium in renal cortex, controlling for cadmium level, in 48 noncancer subjects below the age of 60 years in an autopsy study.

ZINC

\section{Geographical Correlations}

No studies have been located.

\section{Human Blood or Urine Levels and Morbidity}

Low zinc levels in the plasma of persons with atherosclerosis have been reported (Volkov, 1963). In myocardial infarction, low zinc levels in plasma are well known, but these are usually explained as a consequence rather than as a cause of the cardiac event (Wacker et al., 1956; Halsted and Smith, 1970).

\section{Tissue Analysis at Autopsy and Cause of Disease or Death}

Netsky et al. (1969) found increased zinc levels in the kidneys of hypertensives. Those authors did not determine the cadmium levels. (For findings on cadmium:zinc ratios, see the section "Cadmium.")

\section{SILICON}

\section{Geographical Correlations}

In the United States, $\mathrm{SiO}_{2}$ detected in the analysis of drinking water' had the highest negative correlation with age-adjusted mortality rates resulting from cardiovascular diseases, when compared with all other element factors considered, according to the data of Schroeder and Kraemer (1974). However, the text of this paper cautioned that there is poor absorption of $\mathrm{SiO}_{2}$. On the other hand, in Sweden (Biörck et al., 1965), water hardness correlated more negatively with cardiovascular disease mortality than did $\mathrm{SiO}_{2}$.

\section{Human Blood or Urine Levels and Morbidity}

No studies have been located.

\section{Tissue Analysis at Autopsy and Cause of Disease or} Death

No studies have been located.

\section{EVALUATION OF OBSERVED ASSOCIATIONS}

Because of the strength of various general environmental and behavioral influences on cardiovascular mortality (e.g., excessive intake of calories, saturated fat, cholesterol, sodium, and sucrose; smoking; lack of exercise; social class factors; altitude), trace metals probably do not play a major role in the United States today. However, the data reviewed here do not exclude the possibility of a moderately strong influence of cadmium on cardiovascular disease mortality. In view of the relative ease by which protective action in this field can be implemented, it is possible-but as yet unproved-that cadmium control measures may result in an important public health advance.

Because several heavy metals are dissolved simultaneously through the corrosive action of water in a piping system, the interaction of these metals in their effect on the host cell should be further studied, especially with 
regard to cardiac conduction impairment and possible pressor effect in conjunction with sodium.

The delivery system of environmental trace elements to the human organism is not limited to drinking water for human consumption, but also includes irrigation of foodand fodder-producing land and drinking water for livestock and fish, all entering the local food chain. It is here that the combination of acidic soil (in the southeastern and northeastern United States) and sludge containing heavy metals deserves attention.

\section{SUMMARY}

The conceptual and observed relations between the elements associated with softness of the water supply and cardiovascular disease are reviewed. The toxic elements examined are cadmium and lead, and the protective elements are selenium, zinc, and silicon.

Animal experiments show that chronic low-level cadmium intake may have toxic effects that are not necessarily seen in chronic high-level cadmium intake, because of a cadmium-zinc specific system of host defense. These toxic effects are sodium retention and cardiac arrest. There is little evidence that relatively low levels of lead are toxic to the cardiovascular system, except for causing cardiomyopathy. Even such levels are high, when compared with human lead intake from drinking water sources, but the synergistic effect with cadmium is known. The protective action of selenium and zinc applies mainly to cadmium toxicity. The mode of the protective action of silicon, if any, is unclear at present.

Epidemiological associations between the cadmium level in blood or urine and hypertension have been recorded repeatedly, although the literature is by no means unanimous in this respect. Likewise, epidemiological associations between the cadmium level or cadmium:zinc ratio in liver, kidney, or spleen and cardiovascular disease have been reported for several autopsy studies, but other studies contradict these findings. The positive results are in agreement with certain animal experiments. Some epidemiological support exists for the notion of a protective effect by selenium. For zinc, however, epidemiological studies yielded equivocal results. For silicon, epidemiological data are scarce and contradictory.

In conclusion, the harmful action of dissolved elements from sludge, and from pipes, appliances, kitchen utensils, or earthenware containing stagnant, warm, corrosive water is a possibility not discounted by current knowledge. Further research into a possible protective action of silicon also seems worthwhile.

\section{REFERENCES}

Adams, R. G., J. F. Harrison, and P. Scott. 1969. The development of cadmium-induced proteinuria, impaired renal function, and osteomalacia in alkaline battery workers. Quart. J. Med. 38:425-443.

Amacher, D. E., and K. L. Ewing. 1975. Cadmium deposition in canine heart and major arteries following intravascular administration of cadmium chloride. Bull. Environ. Contam. Toxicol. 14:457-464.

Anderson, T. W. 1977. Water hardness, magnesium and ischemic heart disease. N.S. Med. Bull. 56(2):58-61.

Anderson, T. W., W. H. leRiche, and J. S. MacKay. 1969. Sudden death and ischemic heart disease. New. Eng. J. Med. 280:805-807.

Asokan, S. K., C. A. Malpass, and F. T. Ulmer. 1971. Experimental lead cardiomyopathy. Circulation 46, Suppl. 2, p. 104.

Beevers, D. G., B. C. Campbell, A. Goldberg, M. R. Moore, and V. M. Hawthorne. 1976a. Blood-cadmium in hypertensives and normotensives. Lancet 2:1222-1224.

Beevers, D. G., E. Ersking, M. Robertson, A. D. Beattie, B. C. Campbell, A. Goldberg, M. R. Moore, and V. M. Hawthorne. 1976b. Blood-lead and hypertension. Lancet 2:1-3.

Berlin, M., and S. Ullberg. 1963. The fate of $\mathrm{Cd}^{109}$ in the mouse: An autoradiographic study after a single intravenous infection of $\mathrm{Cd}^{109} \mathrm{Cl}_{2}$. Arch. Environ. Health 7:686-693.

Bierenbaum, M. L., A. I. Fleischman, J. Dunn, and J. Amold. 1975. Possible toxic water factor in coronary heart-disease. Lancet 1:10081010.

Biörck, G., H. Bostrom, and A. Widstrom. 1965. On the relationship between water hardness and death rate in cardiovascular diseases. Acta Med. Scand. 178:239-252.

Bryan, S. E., and H. A. Hidalgo. 1976. Nuclear cadmium: Uptake and disappearance correlated with cadmium-binding protein synthesis. Biochem. Biophys. Res. Commun. 68:858-866.

Carroll, R. E. 1966. The relationship of cadmium in the air to cardiovascular disease death rates. J. Am. Med. Assoc. 198:267-269.

Carroll, R. E., and W. Haddon. 1965. Pitfalls in the use of "accident victims" as comparison groups. J. Chronic Dis. 18:601-603.

Challop, R. S. 1971. Role for cadmium in lead poisoning. New Eng. J. Med. 285:970-971.

Cherian, M. G., R. A. Goyer, and L. Delaquerrier-Richardson. 1976. Cadmium-metallothionein-induced nephropathy. Toxicol. Appl. Pharmacol. 38:399-408.

Crawford, M. D., and D. G. Clayton. 1973. Lead in bones and drinking water in towns with hard and soft water. Br. Med. J. 2:21-23.

Crawford, M. D., M. J. Gardner, and J. N. Morris. 1972. Water hardness, rainfall, and cardiovascular mortality. Lancet 1:13961397.

Crawford, M. D., D. G. Clayton, F. Stanley, and A. G. Shaper. 1977. An epidemiological study of sudden death in hard and soft water areas. J. Chronic Dis. 30:69-80.

Der, R., Z. Fahim, and M. Yousef. 1976. Environmental interaction of lead and cadmium on reproduction and metabolism of male rats. In Proceedings of the Tenth Annual Conference on Trace Substances in Environmental Health, June 8-10, 1976. D. D. Hemphill, ed. University of Missouri, Columbia. Pp. 505-517.

Doyle, J. J., R. A. Bernhoft, and H. H. Sandstead. 1974. The effects of a low level of dietary cadmium on some biochemical and physiological parameters in rats. In Proceedings of the Eighth Annual Conference on Trace Substances in Environmental Health, June 11-13, 1974. D. D. Hemphill, ed. University of Missouri, Columbia. Pp. 403-409.

Elinder, C. G., T. Kjellstrom, L. Friberg, B. Lind, and L. Linnman. 1976. Cadmium in kidney cortex, liver, and pancreas from Swedish autopsies: Estimation of biological half time in kidney cortex, considering calorie intake and smoking habits. Arch. Environ. Health 31:292-302. 
Fodor, J. G., C. J. Pfeiffer, and V. S. Papezik. 1973. Relationship of drinking water quality (hardness-softness) to cardiovascular mortality in Newfoundland. Can. Med. Assoc. J. 108:1369-1371.

Friberg, L., M. Piscator, G. Nordberg, and T. Kjellstrom. 1974. Cadmium in the Environment. 2nd ed. CRC Press, Cleveland, Ohio.

Frost, D. V. 1972. The two faces of selenium-Can selenophobia be cured? CRC Crit. Rev. Toxicol. 1:467-514.

Fulkerson, W., and H. E. Goeller, eds. 1973. Cadmium the Dissipated Element. Oak Ridge National Laboratory, Oak Ridge, Tenn. 473 pp.

Glauser, S. C., C. T. Bello, and E. M. Glauser. 1976. Blood-cadmium levels in normotensive and untreated hypertensive humans. Lancet 1:717-718.

Gorsuch, T. T. 1970. The Destruction of Organic Matter. Pergamon Press, Oxford, England.

Goyer, R. A., K: Tsuchiya, D. L. Leonard, and H. Kahyo. 1972. Aminoaciduria in Japanese workers in the lead and cadmium industries. Am. J. Pathol. 57:635-642.

Halsted, J. A., and J. C. Smith. 1970. Plasma-zinc in health and disease. Lancet 1:322-324.

Hammer, D. I., J. F. Finklea, J. P. Creason, S. H. Sandifer, J. E. Keil, L. E. Priester, and J. F. Stara. 1972. Cadmium exposure and human health effects. In Proceedings of the Fifth Annual Conference on Trace Substances in Environmental Health, June 29-July 1, 1971. D. D. Hemphill, ed. University of Missouri, Columbia. Pp. 269-283.

Hawley, P. L., and S. J. Kopp. 1975. Extension of PR interval in isolated rat heart by cadmium. Proc. Soc. Exp. Biol. Med. 150:669-671.

Hickey, R. J., E. P. Schoff, and R. C. Clelland. 1967. Relationship between air pollution and certain chronic disease death rates. Arch. Environ. Health 15:728-738.

Hidalgo, H. A., V. Koppa, and S. E. Brian. 1976. Effect of cadmium on RNA-polymerase and protein synthesis in rat liver. FEBS Lett. 64:159-162.

Hill, C. H., and G. Matrone. 1970. Chemical parameters in the study of in vivo and in vitro interactions of transition elements. Fed. Proc. 29:1475-1481.

Imbus, H. R., J. Cholak, L. H. Miller, and -T. Sterling. 1963. Boron, cadmium, chromium, and nickel in blood and urine: A survey of American working men. Arch. Environ. Health 6:286-295.

Indraprasit, S., G. V. Alexander, and H. C. Gonick. 1974. Tissue composition of major and trace elements in uremia and hypertension. J. Chronic Dis. 27:135-161.

John, M. K., and C. J. VanLaerhoven. 1976. Error in cadmium determinations due to adsorption by filter papers. Bull. Environ. Contam. Toxicol. 15:211-213.

Kopp, S. J., and P. L. Hawley. 1976. Factors influencing cadmium toxicity in A.V conduction system of isolated perfused rat heart. Toxicol. Appl. Pharmacol. 37:531-544.

Kopp, S. J., H. M. Perry, V. Fisher, M. Erlanger, and E. F. Perry. 1978. Altered myocardial excitability, morphology and metabolism induced by long term, low level cadmium feeding. In Proceedings of the Twelfth Annual Conference on Trace Substances in Environmental Health, June 5-8, 1978. D. D. Hemphill, ed. University of Missouri, Columbia.

Lauwerys, R. R., J. P. Buchet, and H. Roels. 1976. The relationship between cadmium exposure or body burden and the concentration of cadmium in blood and urine in man. Int. Arch. Occup. Environ. Health 36:275-285.

Leber, P., and T. S. Miya. 1976. A mechanism for cadmium- and zincinduced tolerance to cadmium toxicity: Involvement of metallothionein. Toxicol. Appl. Pharmacol. 37:403-414.

Lehnert, G., K. H. Schaller, and T. Haas. 1968. Atomabsorptionsspektrometrische Cadmiumbestimmung in Serum und Harn. Z. Klin. Chem. Klin. Biochem. 6:174-176.

Lehnert, G., G. Klavis, K. H. Schaller, and T. Haas. 1969. Cadmium determination in urine by atomic absorption spectrometry as a screening test in industrial medicine. Br. J. Ind. Med. 26:156-158.

Lener, J., and B. Bibr. 1971. Cadmium and hypertension. Lancet 1:970.

Lewis, S. C., A. B. Forney, and R. B. Forney. 1976. Correlation of lead and cadmium in human urine. J. Forensic Sci. 21:150-153.

Loeper, J., J. Koeper, and A. Lemaire. 1966. Etude du silicium en biologie animale et au cours de l'atherome. Presse Med. 74:865-868.

Mainland, D. 1953. The risk of fallacious conclusions from autopsy data of the incidence of diseases with applications to heart disease. Am. Heart J. 45:644-654.

Marsh, N. A. 1976. The effect of divalent cations on the isolated chicken heart. J. Physiol. 256:17p-18p.

Masironi, R. 1969. Trace elements and cardiovascular diseases. Bull. wHO 40:305-312.

McKenzie, J. M., and D. L. Kay. 1973. Urinary excretion of cadmium, zinc and copper in normotensive and hypertensive women. N.Z. Med. J. 78:68-70.

Mertz, D. P., R. Koschnick, and G. Wilk. 1972. Renale Ausscheidungsbedingungen von Cadmium beim normotensiven und hypertensiven Menschen. Z. Klin. Chem. Klin. Biochem. 10:21-24.

Moore, M. R. 1975. Lead and the mitochondrion. Postgrad. Med. J. 51:760-764.

Moore, M. R., P. A. Meredith, A. Goldberg, K. E. Carr, P. G. Toner, and T. D. V. Lawrie. 1975. Cardiac effects of lead in drinking water of rats. Clin. Sci. Mol. Med. 49:337-341.

Morgan, J. M. 1969. Tissue cadmium concentration in man. Arch. Int. Med. 123:405-408.

Murthy, L., S. Highhouse, L. Levin, E. E. Menden, and H. G. Petering. 1975. A study of the combined toxic effects of oral cadmium and lead in rats. In Proceedings of the Ninth Annual Conference on Trace Substances in Environmental Health, June 10-12, 1975. D. D. Hemphill, ed. University of Missouri, Columbia. Pp. 395-401.

Myerson, R. M., and J. H. Eisenhauer. 1963. Atrioventricular conduction defects in lead poisoning. Am. J. Cardiol. 11:409-412.

Neri, L. C., D. Hewitt, and J. S. Mandel. 1971. Risk of sudden death in soft water areas. J. Epidemiol. 94:101-104.

Neri, L. C., J. S. Mandel, and D. Hewitt. 1972. Relation between mortality and water hardness in Canada. Lancet 1:931-934.

Netsky, M., W. W. Harrison, M. Brown, and C. Benson. 1969. Tissue zinc and human disease: Relation of zinc content of kidney, liver, and lung to atherosclerosis and hypertension. Am. J. Clin. Pathol. 51:358-365.

Parizek, J., I. Ostaladova, J. Kalonskova, A. Babicky, and J. Benes. 1971. The detoxifying effects of selenium: Interrelations between selenium and certain metals. In Newer Trace Elements in Nutrition, W. Mertz and W. E. Cornatzer, eds. Marcel Dekker, New York. Pp. 85-122.

Perry, H. M., and M. W. Erlanger. 1974. Metal-induced hypertension following chronic feeding of low doses of cadmium and mercury. $J$. Lab. Clin. Med. 83:541-547.

Perry, H. M., and M: W. Erlanger. 1977. Effect of a second metal on cadmium-induced hypertension. In Proceedings of the Eleventh Annual Conference on Trace Substances in Environmental Health, June 6-9, 1977. D. D. Hemphill, ed. University of Missouri, Columbia. Pp. 280-288.

Perry, H. M., and M. W. Erlanger. 1978. Hypertensive effect of chronically feeding very low concentrations of lead and cadmium together. In Proceedings of the Twelfth Annual Conference on Trace Substances in Environmental Health, June 5-8, 1978. D. D. Hemphill, ed. University of Missouri, Columbia.

Perry, H. M., and E. F. Perry. 1959. Normal concentrations of some trace metals in human urine: Changes produced by ethylenediaminetetraacetate. J. Clin. Invest. 33:1452-1463.

Perry, H. M., and H. A. Schroeder. 1955a. Concentration of trace 
metals in urine of treated and untreated hypertensive patients compared with normal subjects. J. Lab. Clin. Med. 46:936.

Perry, H. M., and H. A. Schroeder. 1955b. Comparison of the concentration of several trace metals in the urine of treated and untreated malignant hypertensive patients as compared with normal individuals. Circulation 12:758-759.

Perry, H. M., I. S. Tipton, H. A. Schroeder, R. L. Steiner, and M. J. Cook. 1961. Variation in the concentration of cadmium in human kidney as a function of age and geographic origin. J. Chronic Dis. 14:259-271.

Perry, H. M., E. F. Perry, and J. E. Purifoy. 1971. Antinatriuretic effect of intramuscular cadmium in rats. Proc. Soc. Exp. Biol. Med. 136:1240-1244

Perry, H. M., E. F. Perry, and M. W. Erlanger. 1974. Reversal of cadmium-induced hypertension by selenium or hard water. In Proceedings of the Eighth Annual Conference on Trace Substances in Environmental Health, June 11-13, 1974. D. D. Hemphill, ed. University of Missouri, Columbia. Pp. 51-57.

Perry, H. M., M. W. Erlanger, and E. F. Perry. 1976. Limiting conditions for the induction of hypertension in rats by cadmium. In Proceedings of the Tenth Annual Conference on Trace Substances in Environmental Health, June 8-10, 1976. D. D. Hemphill, ed. University of Missouri, Columbia. Pp. 459-467.

Peterson, D. R., D. J. Thompson, and J. M. Nam. 1970. Water hardness, arteriosclerotic heart disease and sudden death. Am. J. Epidemiol. 92:90-93.

Rowe, J. W., R. Andres, J. D. Tobin, A. H. Norris, and N. W. Shock. 1976. The effect of age on creatinine clearance in men: $A$ crosssectional and longitudinal study. J. Gerontol. 31:155-163.

Sauer, H. I. 1974. Relationship between trace element content of the drinking water and chronic diseases, observed effects of trace metals in drinking water on human health. Paper presented at 16th Water Quality Conference, University of Illinois, Urbana.

Schroeder, H. A. 1965. Cadmium as a factor in hypertension. J. Chronic Dis. 18:647-656.

Schroeder, H. A., and J. Buckman. 1967. Cadmium hypertension: Its reversal in rats by a zinc chelate. Arch. Environ. Health 14:693-697.

Schroeder, H. A., and L. A. Kraemer. 1974. Cardiovascular mortality, municipal water, and corrosion. Arch. Environ. Health 28:303-311.

Schroeder, H. A., and W. H. Vinton. 1962. Hypertension induced in rats by small doses of cadmium. Am. J. Physiol. 202:515-518.

Schroeder, H. A., A. P. Nason, and M. Mitchener. 1968. Action of a chelate of zinc on trace metals in hypertensive rats. Am. J. Physiol. 214:796-800.

Schwarz, K. 1973. A bound form of silicon in glycosaminoglycans and polyuronides. Proc. Natl. Acad. Sci. U.S.A. 70:1608-1612.

Schwarz, K. 1977. Silicon, fibre, and atherosclerosis. Lancet 1:454-457.

Schwarz, K., and D. B. Milne. 1972. Growth-promoting effects of silicon in rats. Nature 239:333-334.

Scott, R., P. J. Paterson, E. A. Mills, A. McKirdy, G. S. Fell, J. M. Ottoway, F. E. R. Husain, O. P. Fitzgerald-Finch, A. J. Yates, and A. Lamont. 1976. Clinical and biochemical abnormalities in coppersmiths exposed to cadmium. Lancet 2:396-398.

Shamberger, R. J., S. A. Tytko, and C. E. Willis. 1975. Selenium and heart disease. In Proceedings of the Ninth Annual Conference on Trace Substances in Environmental Health, June 10-12, 1975. D. D. Hemphill, ed. University of Missouri, Columbia. Pp. 15-22.

Sharrett, A. R., and M. Feinleib. 1975. Water constituents and trace elements in relation to cardiovascular diseases. Prev. Med. 4:20-36.

Smith, J. C., and J. E. Kench. 1957. Observations on urinary cadmium and protein excretion in men exposed to cadmium oxide dust and fume. Br. J. Ind. Med. 14:240-245.

Stenstrom, T., and M. Vahter. 1975. Cadmium and lead in brewed coffee. Var Foeda (Stockholm) 27:150-156.
Syversen, T. L. M., T. K. Stray, G. B. Syversen, and J. Ofstad. 1976. Cadmium and zinc in human liver and kidney. Scand. J. Clin. Lab. Invest. 36:254-256.

Szadkowski, D., K.-H. Schaller, and G. Lehnert. 1969. Renale Cadmiumausscheidung, Lebensalter und arterieller Blutdruck. $Z$. Klin. Chem. Klin. Biochem. 7(5):551-552.

Terhaar, C. J., E. Vis, R. L. Roudabush, and D. W. Fassett. 1965. Protective effects of low doses of cadmium chloride against subsequent high oral doses in the rat. Toxicol. Appl. Pharmacol. 7:500.

Thind, G. S., and G. M. Fischer. 1975. Cadmium and zinc distribution in cardiovascular and other tissues of normal and cadmium-treated dogs. Exp. Mol. Pathol: 22:326-334.

Thind, G. S., and G. M. Fischer. 1976. Plasma cadmium and zinc in human hypertension. Clin. Sci. Mol. Med. 51:483-486.

Thind, G. S., D. N. Biery, and K. G. Bovee. 1973. Production of arterial hypertension by cadmium in the dog. J. Lab. Clin. Med. 81:549-556.

Tipton, I. H. 1960. The distribution of trace metals in the human body. In Metal Binding in Medicine. M. J. Seven and L. A. Johnson, eds. Lippincott, Philadelphia, Pa. Pp. 27-42.

Tipton, I. H., and P. L. Stewart. 1970. Long term studies of elemental intake and excretion of three adult male subjects. Devel. Appl. Spectrosc. 8:40-50.

Tsuchiya, K. 1967. Proteinuria of workers exposed to cadmium fume: The relationship to concentration in the working environment. Arch. Environ. Health 14:875-880.

Tsuchiya, K. 1976. Epidemiological studies on cadmium in the environment in Japan: Etiology of itai-itai disease. Fed. Proc. 35:2412-2418.

Vatagiri, Y. 1971. Excretion of cadmium in the urine of various age groups. Med. Biol. (Tokyo) 82:239-243.

Volkov, N. F. 1963. Cobalt, manganese and zinc content in the blood of atherosclerosis patients. Fed. Proc. 22, Transl. Suppl., pp. T897T899.

Voors, A. W. 1972. Atherosclerotic heart disease and drinking water trace metals in North Carolina. In Proceedings of the Fifth Annual Conference on Trace Substances in Environmental Health, June 29July 1, 1971. D. D. Hemphill, ed. University of Missouri, Columbia. Pp. 523-534.

Voors, A. W., and M. S. Shuman. 1977. Liver cadmium levels in North Carolina residents who died of heart disease. Bull. Environ. Contam. Toxicol. 17:692-696.

Voors, A. W., M. S. Shuman, G. P. Woodward, and P. N. Gallagher. 1973. Arterial lead and cardiac death: A hypothesis. Environ. Health Perspect., Exp. Iss. 4, p. 97.

Voors, A. W., M. S. Shuman, and P. N. Gallagher. 1975. Atherosclerosis and hypertension in relation to some trace elements in tissues. World Rev. Nutr. Diet. 20:299-326.

Voors, A. W., M. S. Shuman, A. J. Blotcky, and W. D. Johnson. 1978. Adjusted cadmium levels in the renal cortex and heart weight at autopsy. In Proceedings of the Twelfth Annual Conference on Trace Substances in Environmental Health, June 5-8, 1978. D. D. Hemphill, ed. University of Missouri, Columbia.

Wacker, W. E. C., D. D. Ulmer, and B. L. Vallee. 1956. Metalloenzymes and myocardial infarction. New. Eng. J. Med. 255:449-456.

Webb, M. 1972. Protection by zinc against cadmium toxicity. Biochem. Pharmacol. 21:2767-2771.

Webb, M., and R. D. Verschuyle. 1976. An investigation of the role of metallothioneins in protection against the acute toxicity of the cadmium ion. Biochem. Pharmacol. 25:673-679.

Werth, J. 1976. Blood-lead and hypertension. Lancet 2:263.

Yamagata, N., and I. Shigematsu. 1970. Cadmium pollution in perspective. Bull. Inst. Public Health (Tokyo) 19:1-27. 


\section{Index}

The boldface numbers indicate the start of an extensive discussion of the topic.

air pollution, cardiovascular mortality, 63 albite, weathering, 22

algae, copper, 10

aluminum, water hardness, 4, 69

aluminum sulfate, coagulant, 6

American Public Health Association, 4

American Society for Testing and Materials (ASTM), 4

American Water Works Association, 4

amino acids, chromium, 40

ammonium, in precipitation; 18

amphiboles, solubility, 18

analysis, water, methods, 3

anencephalus, water hardness, 60

angina, water hardness, 62

Angino, Ernest E., iii, 2

anhydrite, solubility, 18

Annual Book of ASTM Standards, Part 31,

"Water" (book), 4, 12

aorta, atherosclerotic lesions, 46

lead, 87

silicon, 85

water hardness, 58

aortic elastin, copper deficiency, 40

apoplexy, water chemistry, 48

arsenic, drinking water, 5,10

stored water, 12

arterial hypertension, cadmium, 85

arteries, atherosclerotic lesions, 46

cadmium, 41

copper, 41

magnesium, 78

water hardness, 58

zinc, 41

arteriolar nephrosclerosis, 46

arteriosclerosis, drinking water, 3

sodium/calcium, 74 sodium/magnesium, 74

water hardness, $55,56,59$

arteriosclerotic heart disease, calcium, 52

calcium/magnesium, 64

dolomite water, 74

elevation, 63

geographic variation, 48

magnesium, 52

relative mortality risk (table), 59

United States, mortality, 51, 52

water hardness, 52-60, 63, 64

Asilomar Workshop, vii

Assembly of Life Sciences, Committee on Safe Drinking Water, Subcommittee on Epidemiology, ix

Association of Official Analytical Chemists (AOAC), 4

atherosclerosis, 46,52

cadmium/zinc relations, 40

pigs, 51

rabbits, 51

water hardness, 52

zinc, 87

atherosclerotic heart disease, 45

cadmium, 86

water hardness, 84

atherosclerotic lesions, 46

atrial fibrillation, 46

atrioventricular conduction defects, lead, 85

automobiles, cardiovascular mortality, 63

autopsies, bias, 44

bacterial endocarditis, 46

Baker, Earl W., v

barium, drinking water, 5

water hardness, 4

Berner, Robert A., v bicarbonate, groundwater, 14

lakes, relation to chlorine (illus.), 19

lime-soda water softening, 6

oceans, relation to chlorine (illus.), 19

precipitation, 18

rivers, relation to chlorine (illus.), 19

water treatment, 5, 7

bile, copper, 41

copper nutritive, 40

Bill Williams River, water chemistry, 27

biological risk factors, cardiovascular disease, 63

biotite, weathering, 22

Biscayne, Florida, water system, 5

Block, Fred, iii

blood, cadmium, 80,86

copper, 41,79

lead, $77,80,86$

zinc, 87

blood clots, atherosclerotic proneness, 45

blood clotting mechanisms, cardiovascular risk, 62

blood glucose, water hardness, 62

blood group distribution, water hardness, 62

blood pressure, arteriolar structure and function, 45

cadmium, 85,86

cadmium/zinc relations, 40

calcium, 62

cardiovascular risk, 62

lead, 77,85

mercury, 85

selenium/cadmium relations, 41

sodium, $41^{\circ}$

water hardness, 62,64

zinc, 41,76

blood vessels, cadmium, 85 
bone, cadmium, 41

magnesium, 78

zinc, 41

Boston, Beacon Hill, drinking water, 11

analysis (table), 11

metal pickup (table), 11

plumbing, 11

survey, 11

water quality (table), 10

Brittain, R. C., 54

bronchitis, water hardness, 60

cadmium, analytical problems, 82

arterial hypertension, 85

arteries, 41

atherosclerotic heart disease, 86

biological resistance, 84

blood, 80,86

blood pressure, 85,86

blood vessels, 85

bone, 41

calcium in water, 10

carbohydrate metabolism, 42

cardiac arrest, 86

cardiac conduction tissue, 85

cardiovascular disease, 39

problems, 82

cardiovascular mortality, 76, 82, 85, 86, 87

collagen, 41

copper metabolism, 41

coronary heart disease, 76

drinking water, $5,10,44,64,76$

food, 11

pipes (table), 8

sodium, 84

elastin, 41

electrocardiac abnormalities, 86

heart, 84, 85

hepatic cholesterol metabolism, 41

hypertension, 11, 40, 41, 62, 72, 84, 86

hypertensive heart disease, 76,86

interaction with metals, 40

intestine, relation to calcium, 41

ischemic heart disease, 86

kidney, $64,84,86$

zinc, 86

kidney tissue, 86

liver, 41,84

magnesium in water, 10

metallothionein, 41,84

muscle tissue, 80

pancreas, 84

pancreatic beta cells, 42

Parathormone, calcium relations, 41

pipes, $7,64,76$

protection by selenium, 85

protection by zinc, 85

relation to selenium, 41

relation to sodium, 41

renal storage, 84

serum, 80

serum ceruloplasmin, 41

sinus bradycardia, 85

spleen, 84,86 stored water, 12

tissue, 79

urine, 82, 86; (table), 83

water hardness, 72

zinc interaction, 40

calcite, solubility, 18, 22

calcium, arteriosclerosis, sodium, 74

arteriosclerotic heart disease, 52, 64

blood pressure, 62

cadmium in water, 10

cadmium interaction, 40

cardiovascular disease, 39

cardiovascular mortality, 73, 74; (table),

lead, 77 .

sodium, 73

coronary heart disease, $49,52,73,74$

drinking water, 44,70

groundwater, 14

hypertensiogenic sodium, 62

hypertension, 73

sodium, 74

hypertensive heart disease, 73

sodium, 74

in precipitation, 18

interaction with zinc, 40

intestine, cadmium relations, 41

lakes, relation to sodium (illus.), 19

lead, in water, $\cdot 10$

lime-soda water softening, 6

oceans, relation to sodium (illus.), 19

Parathormone, cadmium relations, 41

phytate, 39

rivers, relation to sodium (illus.), 19

serum calcium, 62

serum cholesterol, 40, 62

stored water, 12

stroke, 73,74

urine, 73

water hardness, $4,5,69,70$

water treatment, 5

zinc in water, 10

calcium carbonate, hardness, calculations, 4

precipitation in pipes, 10

river water, 19

calcium oxide, $\mathrm{pH}$ adjustment, 6

calcium sulfate incrustations, 10

California, Coast Range streams, analyses (illus.), 23

cancer, water hardness, 60

Capon Springs Workshop, vii

Captiva Island Workshop, vii

carbohydrate metabolism, cadmium, 42 zinc/chromium/manganese interactions, 40

carbon dioxide, $\mathrm{pH}$ effects, 6

water treatment, 6

carbonate, groundwater, 14

stored water, 12

water treatment, 5

carbonate hardness, 4,5

cardiac arrest, cadmium, 85

cardiac conductive tissue, cadmium, 85 water hardness, 84 cardiac failure, 46

cardiac physiology, magnesium, 78

cardiomyopathy, lead, 85

cardiovascular disease, binding ligands, 39

biological plausibility, 64

biological risk factors, 63

cadmium, 39

problems, 82

calcium, 39

chromium, 39, 74

copper, 39,75

drinking water, 4, 44, 45

element interactions, 39

lead, $72,77,86$

manganese, 39

metallothionein, 84

molybdenum, 39

relative mortality risk (table), 59

selenium, 39

sodium, 39

sodium/magnesium, 73

trace elements, 82

summary, 88

water chemistry, $49,69,73$

water effects, 45

water hardness, $11,45,48,52,57$

conclusions, 64

epidemiology problems, 49

statistical problems, 49

zinc interactions, 39

cardiovascular mortality, air pollution, 63

automobiles, 63

cadmium, 76, 82, 85, 86, 87

calcium, 73, 74

calcium/lead interaction, 77

calcium/magnesium interactions (table), 73

chromium, 75

climate, 63

comfort index, 63

copper, 75

crowding, 63

elevation, 63

latitude, 63

lead, 77

magnesium, 73, 74

rainfall, 63

religion, 64

seacoasts, 63

silicon, 87

smoking, 64

sodium/calcium relations, 73

sodium/magnesium relations, 73

temperature, 63

trace elements, 85

United States, 51

water hardness, 51, 58, 63; (table), 70

weather, 63

zinc, 76,86

cardiovascular-renal mortality, Florida (table), 61

cardiovascular risk, factors, 62

cardiovascular system, silicon, 85

carotid artery, plaque, 46 
Castaño, John R., v

Cathles, Lawrence M., III, v cation exchange, water softeners, 7

cattle, copper/molybdenum interactions, 40 copper/sulfur interactions, 40

cerebral embolism, 46

cerebral hemorrhage, 46

copper, 75

United States, mortality, 52

water hardness, 54

cerebral infarction, 46

cerebral thrombosis, 46

chromium, 74

lead, 76

chemistry, precipitation, 18

surface water, 18

Chicago, drinking water survey, 10

chloride, groundwater, 14

precipitation, 18

river water, 19

stored water, 12

surface water, 22

chlorination, effects, 6 water treatment, $5,10,11$

chlorine, lakes, relation to $\mathrm{HCO}_{3}$ (illus.), 19 oceans, relation to $\mathrm{HCO}_{3}$ (illus.), 19 rivers, relation to $\mathrm{HCO}_{3}$ (illus.), 19 water treatment, 5,7

1-25(OH $)_{2}$ cholecalciferol, cadmium/calcium relation, 41

cholera, 47

cholesterol, cadmium, 41

cardiovascular risk, 62

serum, zinc/copper relations, 39

water hardness, 62

zinc, 41

chromium, amino acids, 40

carbohydrate metabolism, 40

relation to zinc, 40

cardiovascular disease, 39,74

cardiovascular mortality, 75

cerebral thrombosis, 74

coronary heart disease, 74

drinking water, $5,10,44,74$

epithelial cells, zinc interaction, 40

food, 11

glucose, 40

glucose tolerance factor, 40

ligands, 40

serum cholesterol. 75

tissue, 79

water hardness, 71

zinc nutriture, 41

cirthosis, water hardness, 60

cities, water chemistry, 31

clay minerals, solubility, 18

climate, cardiovascular mortality, 63

coagulation, turbidity, 6

water treatment, 10

cobalt, blood, 80

drinking water, 10,11

food, 11

collagen, cadmium, 41

copper, 41 copper deficiency, 40

silicon, 85

zinc, 41

comfort index, cardiovascular mortality, 63

Community Water Supply Service (cWss), 11

Comstock, George W., iii, ix, 8

conclusions, cardiovascular disease and water hardness, 64

congenital malformations, water hardness, 60

connective tissue, silicon, 85

contamination, water, 10

copper, algae control, 10

arteries, 41

bile, 41

blood, 41, 79

cadmium interactions, 40

cardiovascular disease, 39,75

cardiovascular mortality, 75

cattle, molybdenum interaction, 40

sulfur interactions, $\mathbf{4 0}$

cerebral hemorrhage, 75

collagen, 41

coronary heart disease, 75

drinking water, $5,10,44,75,79$

pipes (table), 9

elastin, 41

hair, 79

hepatic cholesterol, 41

interaction with zinc, 39,40

liver, 41,79

zinc ratio, 40

lysosomes, 41

metabolism, cadmium interaction, 41

zinc interaction, 41

metallothionein, 39

muscle, 79

phytate, 39

pipes, 7

plasma cholesterol, 41

serum cholesterol, 41

zinc relations, 39

1 tissue, 79

water hardness, 71

copper deficiency, aortic elastin, 40

collagen, 40

elastin, 40

myocardial necrosis, 40

myocardium, 40

serum cholesterol, 39

copper homeostasis, cattle, molybdenum nutriture, 40

zinc, 39

copper nutriture, bile, 40

liver cholesterol, 40

plasma cholesterol, 40

Corbett, Robert G., iii

coronary arteriosclerosis, magnesium, 78

coronary heart disease, 45,46

cadmium, 76

calcium, 49, 52, 73, 74

chromium, 74

copper, 75 drinking water; 45

education, 63

lead, 76

magnesium, 49, 52, 73, 74

sodium/calcium interaction, 73

sodium/magnesium interaction, 73

sulfite/bicarbonate interaction, 49

unemployment, 63

United States, mortality, 51

water chemistry, 49

water hardness, $49,52,54,55,57$

zinc, 75,76

correlation coefficient compared with regression coefficient (illus.), 49, 50

Cretaceous rocks, surface water, 22

crowding, cardiovascular mortality, 63

cyanide, drinking water, 5

degenerative heart disease, water hardness, $54,55,59,60$

diabetes mellitus, manganese deficiency, 40

diaphragm muscle, magnesium, 78

zinc, 79

dietary fiber, phytate, 39

disease statistics, editorial bias, 82

Dlugosz, Lena, ix

dolomite, solubility, 18, 22

water hardness, 74

dolomite water, arteriosclerotic heart disease, 74

stroke, 74

drinking water, arsenic, 5, 10

barium, 5

Boston survey, 11

analysis (table), 11

cadmium, 5, 10, 44, 64, 76

calcium, 44,70

carbon dioxide/oxygen equilibrium, 12

carbonate hardness, 5

cardiovascular disease, 3, 44, 45

chemistry, 69

change from water softening (illus.), 6

summary, 12

Chicago survey, 10

chlorination, 11

chromium, 5, 10, 44, 74

cobalt, 10

contamination, 10

copper, $5,10,44,75,79$

coronary heart disease, 45

cyanide, 5

geochemistry, distribution and treatment, 3

hardness, cardiovascular disease, 11

hypertension, 44

iron, 5,10

kidneys, 46

lead, $5,10,44,76$

$\mathrm{pH}, 72$

lithium, 10, 44

magnesium, 44, 64, 70

manganese, $5,10,44$

metal intake, 11; (table), 12

metal pickup, Boston (table), 11 


\section{Index}

Seattle (table), 11

molybdenum, 10

nickel, 10

phenols, 5

renin-angiotensin mechanism, 46

Seattle, survey, 11

analyses (table), 11

selenium, $5,10,44$

serum magnesium, 78

silicon, $\mathbf{4 4}$

silver, 5,10

sodium/cadmium relations, 84

soft and hard, mortality risk (table), 59

storage effects, 12

stroke, 44,46

trace elements, 10; (table), 70

relation to disease, 3

summary, 80

vanadium, 44

zinc, $5,10,44,71,75$

$\mathrm{pH}, 72$

editorial bias, disease statistics, 82

education, coronary heart disease, 63

elastin, cadmium, 41

copper, 41

copper deficiency, 40

zinc, 41

electrocardiogram, cadmium, 86

zinc, 76

electrocardiographic abnormalities, cardiovascular risk, 62

element interactions (illus.), 40

elevation, arteriosclerotic heart disease, 63

cardiovascular mortality, 63

embolic stroke, 46

embolism, 46

water hardness, 54

ephemeral stream, analyses (illus.), 24, 25

epithelial cells, zinc/chromium interaction, 40

excrement, magnesium, 78

Federal Water Pollution Control Administration, 25

feldspar, solubility, 18

ferritin; iron, 39

- fibrin degradation, water hardness, 62

fibrinogen, water hardness, 62

Florida, hard water, aquifers, 5

Floridian water systems, 5

flowing water, chemical analyses, 23

hard, Piper diagram (illus.), 33

sampling techniques, 23

seasonal variations, 24

soft, Piper diagram (illus.), 32

very hard, Piper diagram (illus.), 34

fluorine, goiter, 60

water hardness, 5,53

fluorosilicic acid, drinking water, 11

Franciscan Formation, Cretaceous, 22

fresh water, United States, availability (table), 18
Galke, June R., iii

gastritis, water hardness, 60

geochemistry, drinking water, distribution and treatment, 3

geology, groundwater, 27

surface water, 20

water characteristics, 14

water hardness, 4

Giletti, Bruno J., v

glucose tolerance factor, chromium and zinc, 40

Gluskoter, Harold J., iv, v

goiter, fluorine, 60

granite, surface water, 20

Piper diagram (illus.), 21

Great Lakes, hard water, Piper diagram (illus.), 34

water chemistry, 26

groundwater, dissolved ions, 14

geology, 27

moderately hard, Piper diagram (illus.), 35

soft, Piper diagram (illus.), 35

sources, United States, 18

very hard, Piper diagram (illus.), 36

gypsum, precipitation, stored water, 12 solubility, 18

hair, trace elements, 79

halite, solubility, 18

surface water, 22

Handbook for Analytical Quality Control in Water and Wastewater Laboratories (book), 12

Hartung, Rolf, iv

Hartwick, Stephen S., ix

heart, cadmium, 84,85

lead, 85

magnesium, 78

potassium, 78

selenium, 87

zinc, 78

heart conduction tissue, magnesium, 84

heart disease, relation to hypertension, 45

water hardness, 48

heart muscle, magnesium, 78

Helsing, K. J., 8

hematite, solubility, 18

hemorrhage, intracerebral, 46

hepatic cholesterol metabolism, cadmium, copper, and zinc, 41

Hopps, Howard C., ix

Horvath, Donald J., iv

Hurley, Lucille S., iv

hydrochloric acid, effect on $\mathrm{pH}, 6$

hydrological cycle, water quality, 17

hypertension, 45, 46, 47

cadmium, $11,40,41,62,72,84,85,86$

calcium/magnesium ratio, 73

drinking water, 3,44

hypertensive heart disease, 45

kidneys, 64

lead, 76, 77, 80, 86

relative mortality risk (table), 59

selenium, 87 sodium, 41

sodium/calcium ratio, 74

stroke, 45

water hardness, 54, 55, 56, 59

hypertensive cerebral hemorrhage, 46

hypertensive heart disease, 45,46

cadmium, 76, 86

calcium/magnesium interaction, 73

lead, 76

sodium/calcium interaction, 74

sodium/magnesium interaction, 74

United States, mortality, 51, 52

water hardness, 52, 53, 60

zinc, 75

igneous rocks, composition, 18

infant mortality, water hardness, 60

insulin, zinc, 40

Interstate Carrier Water Supply, data, 10

intestine, calcium/cadmium relations, 41

intracerebral hemorrhage, 46

ion-exchange reaction (illus.), ?

iron, drinking water, 5,10

ferritin, 39

stored water, 12

water hardness, 4,69

scale (table), 4

water softening, 5,7

iron sulfate, coagulant, 6

ischemic heart disease, cadmium, 86

rainfall, 63

water hardness, $53,55,84$

islet tissue, manganese, 40

Japan, river water, sulfate/carbonate ratio, 48

Jenne, Everett A., iv

Jurassic rocks, surface water, 22

Kansas River basin, water analysis, 25

kaolin, cephalin clotting, water hardness, 62

kidney, cadmium, 64, 84, 86

cadmium/zinc ratio, 86

drinking water, 46

hypertension, 64

sodium, 84

trace elements, 84

zinc, 86,87

Klumb, G., 7

Kobayashi, Jun, 48

Kurland, Leonard T., iv

lakes, diumal chemical changes, 26

chloride/bicarbonate ratio (illus.), 19

sodium/calcium ratio (illus.), 19

water chemistry, 26

Piper diagrams (illus.), 36, 37

lambs, mineralized soil, 60

Lasdon Foundation, 49

latitude, cardiovascular mortality, 63

lead, aorta, 87

atrioventricular conduction defects, 85

blood, 77, 80, 86

blood pressure, 77,85

calcium in water, 10 
cardiomyopathy, 85

cardiovascular disease, 72,$77 ; 86$

cardiovascular mortality, 77

cerebral thrombosis, 76

coronary heart disease, 76

drinking water, $5,10,44,76$

$\mathrm{pH}, 72$

pipes, 7 ; (table), 9

heart, 85

hypertension, $76,77,80,86$

hypertensive heart disease, 76

magnesium in water, 10

mitochondrial structure, 85

serum cholesterol, 77

stored water, 12

tissue, 80

urine, 86

water hardness, 72

ligands, binding, cardiovascular disease, 39

zinc and chromium, 40

lime-soda, water softening, 6

limestone, surface water, 20

lithium, drinking water, 10, 44

pipes (table), 8

stored water, 12

water softening, 7

Little Colorado River, water chemistry, 27

liver, cadmium, 41, 84

copper, 41,79

zinc, 41

zinc/copper ratio, 40

liver cholesterol, copper nutriture, 40

lysosomes, copper, 41

magnesium, arteriosclerosis, sodium, 74 arteriosclerotic heart disease, 52, 64

bone, 78

cadmium in water, 10

cardiac physiology, 78

cardiovascular mortality, 73, 74; (table), 73

sodium, 73

coronary heart disease, 49, 42,.73, 74

sodium, 73

diaphragm muscle, 78

drinking water, $44,64,70$

excrement, 78

groundwater, 14

hardness calculations, 4

heart, 78

heart conduction tissue, 84

heart muscle, 78

human tissue, 78

hypertension, 73

sodium, 74

hypertensive heart disease, 73

sodium, 74

lead in water, 10

lime-soda water softening, 6

myocardial muscle, 78

myocardium, 64

precipitation, 18

stored water, 12

stroke, 73,74 sodium, 73

urine, 73,78

water hardness, $4,69,70$

water treatment, 5

zinc in water, 10

magnesium deficiency disease, water hardness, 64

magnetite, solubility, 18

manganese, carbohydrate metabolism, 40

cardiovascular disease, 39

drinking water, 5, 10, 44

food, 11

islet tissue, 40

stored water, 12

water hardness, 4, 69

water softening, 5,7

manganese deficiency, diabetes mellitus, 40

map, United States, water hardness, 29

rivers, water quality, 28

Marier, John, ix

McMillan, Gardner C., iii

mercury, blood pressure, 85

metal intake, drinking water, 11; (table), 12

metal pickup, drinking water (table), 11

metal toxicity, 84

metallothionein, cadmium, 41, 84

cardiovascular disease, 84

copper, 39

zinc, $39,41,84$

metamorphic rocks, composition, 18

Methods for Chemical Analysis of Water and Wastes (book), 4, 13

Methods for Collection and Analysis of Water Samples (book), 12

Miami Oolite, 5

mica solubility, 18

microcline, weathering, 22

mitochondrial structure, lead, 85

molybdenum, cardiovascular disease, 39

cattle, copper interaction, 40

drinking water, 10

stored water, 12

molybdenum nutriture, copper homeostasis, cattle, 40

mortality, geographic variation, 48

standardized ratios, 50

mortality rates, water hardness, 61

mucopolysaccharides, silicon, 85

mural thrombus, 46

muscle, copper, 79

muscle tissue, cadmium, 80

myocardial degeneration, water hardness, $52,53,54,59$

myocardial infarction, water hardness, 56 , 57

zinc, 87

myocardial muscle, magnesium, 78

myocardial necrosis, copper deficiency, 40

myocardium, copper deficiency, 40

magnesium, 64

NASQAN stations, characteristics measured (table), 26

National Cancer Institute, ix
National Health Survey, 63

National Research Council, Planning Committee for the International Symposium on Eutrophication, 26

National Science Foundation, ix

National Soft Drink Association, 51

National Stream Quality Accounting Network (NASQAN), 25

neoplasms, water hardness, 56

New Mexico, Sangre de Cristo Range, water chemistry, 20

New York reservoir, hard water, Piper diagram (illus.), 30

nickel, drinking water, 10

stored water, 12

nitrate, in precipitation, 18

stored water, 12

water softening, 7

nitrogen, in precipitation, 18

nitrogen dioxide, in precipitation, 18

noncarbonate hardness, 4

obstructive pulmonary disease, water hardness, 60

occlusive atherosclerosis, 46

occlusive cerebrovascular disease, 46

occlusive cerebrovascular infarction, 46

oceans, calcium/sodium ratio (illus.), 19

chlorine/bicarbonate ratio (illus.), 19

Official Methods of Analysis of AOAC, 11 th edition (book), 12

oligoclase, weathering, 22

Olivieri, Vincent P., ix

overweight, water hardness, 62

packed cell volume, water hardness, 62

Page, Albert L., iv

Paleozoic rocks, water chemistry, 26

pancreas, cadmium, 84

zinc, 40

pancreas beta cells, cadmium, 42

Panel on Aging and the Geochemical Environment (PAGE), vii

Panel on the Geochemical Environment and Urolithiasis (POGU), vii

Panel on Geochemistry of Water in Relation to Cardiovascular Disease (PoWC), vii, ix, 3

members, iii

Panel on the Trace Element Geochemistry of Coal Resource Development Related to Health (PECH), vii

Papike, James J., v

Parathormone, cadmium/calcium ratio, 41

peptic ulcer, water hardness, 60

peripheral vascular diseases, water hardness, 55,59

Petering, Harold G., iv

Petrie, William L., iii

$\mathrm{pH}$, drinking water, adjustment, 5, 6

lead, 72

pipes (table), 8

zinc, 71

effects of carbon dioxide, 7 
effects of chlorine, 6

phenols, drinking water, 5

phosphate, stored water, 12

phosphoric acid, pH adjustment, 6

phytate, calcium, 39

copper, 39

dietary fiber, 39

zinc, 39

Pig Industry Development Authority, 51

pigs, atherosclerosis, 51

serum cholesterol, 51

water hardness, 51

Pipér diagrams, water analyses, 14

water types (illus.), 17

pipes, drinking water, Boston, 11

cadmium, 64, 76; (table), 8

copper (table), 9

lead (table), 9

lithium content (table), 8

pH effects (table), 8

Seattle, 11

zinc (table), 9

plaque, carotid artery, 46

plasma, cadmium, 86

zinc, 87

plasmacholesterol, copper, 41

copper nutriture, 40

plasminogen, water hardness, 62

potassium, groundwater, 14

heart, 78

in precipitation, 18

stored water, 12

surface water, 22

water treatment, 5

Precambrian rocks, water chemistry, 26

precipitation, chemical nature, 18

public water supplies, surface water standards (table), 6

pyroxene, solubility, 18

quartz, solubility, 18

weathering, 22

quartzite, surface water, 20

Piper diagram (illus.), 21

Quaternary rocks, surface water, 22

rabbits, atherosclerosis, 51

water hardness, 51

radioactive minerals, water softening, 7

rainfall, cardiovascular mortality, 63

ischemic heart disease, 63

recommendations, water and cardiovascular disease, 2

religion, cardiovascular mortality, 64

renal cortex, cadmium/zinc relations, 40

renal cortex, selenium, 87

renal mortality, Florida (table), 61

renal tubule, cadmium/calcium relations, 41

renin-angiotensin mechanism, drinking water, 46

reservoirs, hard water, Piper diagram (illus.), 30,31

soft water, Piper diagram (illus.), 30

very hard water, Piper diagram (illus.), 32 resin, water softeners, 7

rheumatic heart disease, 45

water hardness, 53

river water, chlorine/bicarbonate ratio (illus.), 19

composition (illus.), 16

sodium/calcium ratio (illus.), 19

United States, water chemistry (map), 28

Roberson, C. E., ix

rocks, relative solubility, 18

relation, water type to lithology (table), 22

Rose, Arthur W., v

sand filters, water treatment, 10

Sandstead, Harold H., iii

sandstone, composition, 18

surface water, 20

Piper diagram (illus.), 22

Schreiber, George B., iv, 8, 9

Schroeder, H. A., 49

seacoasts, cardiovascular mortality, 63

Seattle, drinking water, analysis (table), 11 metal pickup (table), 11

plumbing, 11

survey, 11 .

Tolt River, water source, 11

water quality (table), 10

sedimentary rocks, composition, 18

selenium, cadmium interaction, 40, 41

cardiovascular disease, 39

drinking water, $5,10,44$

height, weight influence, 87

hypertension, 87

protection against cadmium, 85

renal cortex, 87

soil, 87

stored water, 12

tissue, 84

serum, cadmium, 80

calcium, 62

chromium, 79

cobalt, 80

copper, 79

zinc, 79,80

serum ceruloplasmin, cadmium/zinc, 41

serum cholesterol, calcium, 40, 62

chromium, 75

copper, 41

copper deficiency, 39

lead, 77

pigs, 51

water hardness, 56

serum lipids, water hardness, 64

serum magnesium, drinking water, 78

Sevier River, water chemistry, 27

shale, composition, 18

Sharrett, A. Richey, iii

sickle-cell anemia, 39

silica, incrustations, 10

precipitation, stored water, 12

silicate minerals, solubility, 18

silicon, aortas, 85

cardiovascular mortality, 87

cardiovascular systems, 85 connective tissue, 85

drinking water, 44

mucopolysaccharides, 85

silver, drinking water, 5,10

sinus bradycardia, cadmium, 85

sludge, trace elements, 88

Smith, Ivan C., iv

smoking, cardiovascular mortality, 64

water hardness, 62

Snow, John, 47

soda ash, pH adjustment, 6

water softening, 6

sodium, arteriosclerosis, 74

blood pressure, 41

cadmium interaction, 40

cardiovascular disease, 39

collagen, 85

coronary heart disease, calcium/magnesium, 73

drinking water, cadmium, 84

groundwater, 14

hypertensinogenic effects, 62

hypertension, 41, 74

hypertensive heart disease, 74

kidneys, 84

lakes, relation to calcium (illus.), 19

oceans, relation to calcium (illus.), 19

precipitation, 18

relation to cadmium, 41

river water, 19

relation to calcium (illus.), 19

stored water, 12

stroke, 73

surface water, 22

urine, 73

water softening, 6

water treatment, 5

soil, selenium, 87

trace elements, 88

spina bifida, water hardness, 60

spleen, cadmium, 84, 86

Standard Methods for Examination of Water and Wastewater (book), 12

stored water, trace elements, 12

stroke, 46, 47

calcium, 74

calcium/magnesium, 73, 74

dolomite water, 74

drinking water, 44,46

hypertension, 45

magnesium, 74

relative mortality risk (table), 59

sodium/calcium, 73

sodium/magnesium, 73

United States, mortality, 51

water hardness, $48,49,52,53,54,55,56$, $57,59,60,62$

Strong, Jack P., iii

strontium, water hardness, 4

water softening, 5

sulfate, coronary heart disease, bicarbonate ratio, 49

lime-soda water softening, 6

surface water, 22 
water softening, 7

ulfides, solubility, 18

ulfite, groundwater, 14

in precipitation, 18

water treatment, 5

sulfur, cadmium interaction, 40

cattle, copper interactions, 40

sulfuric acid, pH adjustment, 6

summary, geology and water chemistry, 37

surface water, granite, Piper diagram (il-

$$
\text { lus.), } 21
$$

quartzite, Piper diagram (illus.), 21, 22

Surface Water Standards, Public Water Supplies (table), 6

Susquehanna River, analytical techniques, 24

chemical analyses (illus.), 24

Techniques of Water Resources Investigations of the U.S. Geological Survey (book), 12

temperature, cardiovascular mortality, 63

Tertiary rocks, surface water, 22

thrombin clotting, water hardness, 62

thrombosis, 46

water hardness, 54

tissue, cadmium, 79

chromium, 79

copper, 79

lead, 80

magnesium, 78

selenium, 84

trace element analysis. 82

water chemistry, 77

zinc, 79

total hardness, definition, 4

trace elements, cardiovascular disease, 82 summary, 88

cardiovascular mortality, 85

chemical methods, 83

drinking water, 10: (table), 70

relation to disease. 3

summary, 80

experimental animal studies, 84

flowing water, 25

hair, 79

kidneys, 84

sludge, 88

soils, 88

tissue analyses, 82

urine, 82

water hardness, 70

Trumpower, Kathleen E., ix

unemployment, coronary heart disease, 63

United States, arteriosclerotic heart disease mortality, 51, 52

available fresh water (table), 18

cardiovascular mortality, 51

cerebral hemorrhage, mortality, 52

coronary heart disease, mortality, 51

groundwater sources, 18

hypertensive heart disease, mortality, 51 . 52 rivers, water chemistry (map), 28

stroke, mortality, 51

water hardness (map), 29

U.S. Atomic Energy Commission, ix

U.S. Bureau of Mines, ix

U.S. Department of Energy, ix

U.S. Energy Research and Development. Administration, ix

U.S. Environmental Protection Agency, ix

U.S. Geological Survey, ix, 25

water quality parameters (table), 15

U.S. National Committee for Geochemistry, members, $v$

Subcommittee on the Geochemical Environment in Relation to Health and Disease, vii, 3

members, iv

urine, cadmium, 82, 86; (table), 83

calcium, 73

lead, 86

magnesium, 73,78

sodium, 73

trace elements, 82

zinc, 87

Vale of Glamorgan, Wales, 63

vanadium, drinking water, 44

vascular lesions, water hardness, 54

Vidale, Rosemary J., $v$

Voors, A. Wouter, iii, 63

water, geochemistry and cardiovascular disease, recommendations, 1 summary, 1

water, hard, flowing, Piper diagram (illus.), 33

manual of analytical techniques, 12 soft, flowing, Piper diagram (illus.), 32 soft, reservoir, Piper diagram (illus.), 30 surface, chemistry, 18

very hard, flowing, Piper diagram (illus.),

very hard, reservoir, Piper diagram (illus.), 32

Water and Its Impurities (book), 12

water characteristics, geology, 14

water chemistry, apoplexy, 48

arteriosclerotic heart disease, 64

California streams. Piper diagram (illus.), 23

cardiovascular disease, 69,73

evolution (illus.), 20

geology, 20

summary, 37

Great Lakes, 26

human tissue, 78

methods, 3

Piper diagrams. 14

reservoirs and natural lakes, 26

Sangre de Cristo Range. New Mexico. 20

water distribution, chemical changes, 7

water hardness, 4, 69

aluminum, 69

anencephalus, 60 angina, 62

animal studies, 51

aortas, 58

arteries, 58

arteriosclerosis, 55, 56, 59

arteriosclerotic heart disease, 52, 53, 54, $55,56,57,58,59,60,63,64$

atherosclerosis, 52

atherosclerotic heart disease, 84

blood glucose, 62

blood group distribution, 62

blood pressure, 62,64

bronchitis, 60

cadmium, 72

calcium, 69,70

cancer, 60

cardiac conduction tissue, 84

cardiovascular disease, 45, 48, 52, 57

conclusions, 64

cardiovascular mortality, 51, 58, 63; (table), 70

cerebral hemorrhage, 54

chemistry, 69

cholesterol, 62

chromium, 71

cirrhosis, 60

colorimetric titration, 69

congenital malformations, 60

copper, 71

coronary heart disease, $49,52,54,55,57$

definitions, 4, 69

degenerative heart disease, $54,55,59,60$

dolomite, 74

embolic stroke, 54

fibrin degradation, 62

fibrinogen, 62

flowing water, Piper diagram (illus.), 33

fluorine, 53

gastritis, 60

geology, 4

Great Lakes, Piper diagram (illus.), 34

hypertension, 54, 55, 56, 59

hypertensive heart disease, $52,53,60$

infant mortality, 60

iron, 69

ischemic heart disease, $53,55,84$

kaolin cephalin clotting, 62

lead, 72

magnesium, 69, 70

magnesium deficiency disease, 64

malignant neoplasms, 56

manganese, 69

mortality, 61

myocardial degeneration, $52,53,54,59$

myocardial infarction, 56,57

obstructive pulmonary disease, 60

overweight, 62

packed cell volume, 62

peptic ulcer, 60

peripheral vascular disease, 55,59

pigs, 51

plasminogen, 62

rabbits, 51

reservoir. Piper diagram (illus.), 31 


\section{Index}

rheumatic heart disease, 53

scales (table), 4

serum cholesterol, 56

serum lipids, 64

smoking, 62

source, 4

spina bifida, 60

stroke, 48, 52, 53, 54, 55, 56, 57, 59, 60, 62

tap water, 5

thrombin clotting, 62

thrombotic stroke, 54

trace elements, 70

United States (map), 29

vascular lesions, 54

zinc, 71

water quality, Boston (table), 10

data compilations, 27

hydrologic cycle, 17

major cities, 31

parameters (table), 15

rivers, United States (map), 28

Seattle (table), 10

surveillance program, 25

water softeners (home treatment), 7

water softening, bicarbonate, 7

cation exchange, 7

chloride, 7

effects on chemical composition (illus.), 6

effects on statistics, 50

iron, 5,7

lithium, 7

manganese, 5,7

nitrate, 7

radioactive minerals, 7

resins, 7

soda ash, 6

sodium, 6

strontium, 5

sulfate, 7

treatment, 5 water solubility, rock types, 18

Water Supply and Pollution Control, 2nd edition (book), 12

water systems, contamination, 10

water treatment, 5

bicarbonate, 5

calcium, 5

carbonate, 5

chlorination, 5,10

coagulation, 10

fluorine, 5

magnesium, 5

pH adjustment, 5

potassium, 5

sand filters, 10

sodium, 5

softening, 5

sulfate, 5

water treatment (homes), 7

water types, 14, 17

Piper diagram (illus.), 17

weather, cardiovascular mortality, 63

weathering, water composition, 18

Wetherill, George W., v

Zen, E-an, $v$

zinc, arteries, 41

atherosclerosis, 87

blood, 87

blood pressure, 41,76

bone, 41

cadmium interaction, 40

calcium interaction, 10, 40

carbohydrate metabolism, chromium and manganese, 40

cardiovascular disease, 39

cardiovascular mortality, 76, 86

collagen, 41

copper homeostasis, 39

copper interaction, 39 copper metabolisḿ, 41

coronary heart disease, 75,76

diaphragm muscle, 79

drinking water, $5,10,11,44,71,75$

$\mathrm{pH}, 72$

pipes (table), 9

elastin, 41

electrocardiograms, 76

epithelial cells, chromium interaction, $\mathbf{4 0}$

food, 11

glucose tolerance, 40

heart, 78

hepatic cholesterol metabolism, 41

hypertensive heart disease, 75

insulin, 40

intestinal absorption, 39

kidney, 86,87

cadmium, 86

ligands, 40

liver, 41

chromium ratio, 40

magnesium in water, 10

metallothionein, $39,41,84$

myocardial infarction, 87

pancreas, 40

phytate, 39

pipes, 7

plasma, 87

protection against cadmium, 85

serum ceruloplasmin, 41

serum cholesterol, copper relation, 39

stored water, 12

tissue, 79

urine, 87

water hardness, 71

zinc. nutriture, chromium relations, 40 